University of Rhode Island

DigitalCommons@URI

Open Access Dissertations

1998

\title{
Violence Desistance Among Battering Men: Existing Interventions and the Application of the Transtheoretical Model of Change
}

Deborah A. Levesque

University of Rhode Island

Follow this and additional works at: https://digitalcommons.uri.edu/oa_diss

\section{Recommended Citation}

Levesque, Deborah A., "Violence Desistance Among Battering Men: Existing Interventions and the Application of the Transtheoretical Model of Change" (1998). Open Access Dissertations. Paper 936. https://digitalcommons.uri.edu/oa_diss/936

This Dissertation is brought to you for free and open access by DigitalCommons@URI. It has been accepted for inclusion in Open Access Dissertations by an authorized administrator of DigitalCommons@URI. For more information, please contact digitalcommons-group@uri.edu. 


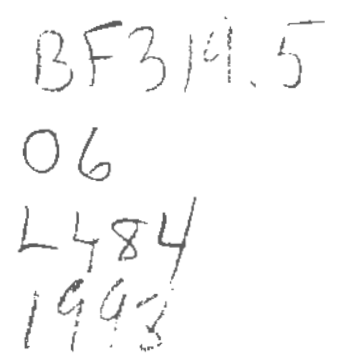

VIOLENCE DESISTANCE AMONG BATTERING MEN:

EXISTING INTERVENTIONS AND THE APPLICATION OF THE

TRANSTHEORETICAL MODEL OF CHANGE

BY

DEBORAH A. LEVESQUE

A DISSERTATION SUBMITTED IN PARTIAL FULFILLMENT OF THE

REQUIREMENTS FOR THE DEGREE OF

DOCTOR OF PHILOSOPHY

IN

PSYCHOLOGY

$$
4137616
$$

UNIVERSITY OF RHODE ISLAND

1998 


\begin{abstract}
This research examines the efficacy of existing interventions for battering men and assesses the applicability of the Transtheoretical Model of Change to the problem of violence desistance. In Chapter I, separate meta-analyses of batterer treatment outcome studies relying on partner reports of recidivism $(\underline{N}=7)$ and official records $(\underline{N}=11)$ are conducted to assess treatment efficacy. A third analysis examines the overall rate of recidivism across studies that follow treatment completers $(\underline{N}=38)$. Results show that the effect of treatment is small at best and moderated largely by program, study, and publication variables. The overall rate of post-treatment recidivism is $21.6 \%$. Chapter 2 traces the evolution of the battered women's movement and two interventions for assaultive men: arrest and treatment. It argues that these potentially powerful interventions are of limited efficacy for three reasons: 1) they are based on a sociopolitical understanding of violence and change rather than empirically validated theories of individual behavior change; 2) they tend to be standardized and "one size fits all," neglecting individual differences in readiness to change; 3) they tend to be confrontational and coercive. The Transtheoretical Model is presented as a new way of conceptualizing change in violent men and increasing treatment efficacy. In Chapters 3 and 4, measures of the core constructs of the Transtheoretical Model—stage of change, decisional balance, and self-efficacy-are developed, and tests of the applicability of the model to violence desistance are conducted. Batterers in treatment at two Rhode Island agencies $(\underline{N}=258)$ completed a questionnaire that included the new measures and measures of partner blame, violence in the last year, violence cessation strategies,
\end{abstract}


demographics, treatment history, and social desirability. A 4-dimensional continuous measure and several algorithms were developed to assess change readiness. Cluster analysis yielded six change profiles using the continuous measure. Results provide strong evidence of the applicability of the model and external validity of the staging measures. For example, participants with early stage profiles minimized the pros and valued the cons of changing, and blamed their partners significantly more than later-stage participants. The need for longitudinal research and the benefit of stage-matched interventions for battering men are discussed. 


\section{ACKNOWLEDGEMENTS}

Three people have had a profound impact on my work and on my development as a researcher. Jim Prochaska provided the WHAT, an innovative vision of behavior change. Wayne Velicer provided the HOW, excellent training in methodology and statistics. And Richard Gelles, my major professor, provided the WHY, knowledge about the problem of family violence and the urgent need for solutions. I am especially indebted to Richard Gelles for encouraging me to think BIG. He has been a tremendous advocate for me.

I'd like to give special thanks to members of my dissertation committeeLeonard Gerber, Wayne Velicer, Joseph Rossi, Alexa Albert, and Lawrence Grebsteinfor their thought-provoking feedback on earlier drafts of the dissertation.

It is important to recognize the role of two Rhode Island agencies in the instrument development work. Kevin Murphy and his staff at DAPAC and Christine Harkins' staff at Kent House helped with focus groups, item writing, and data collection. They shared their experiences, expertise, and enthusiasm, demonstrating that practitioners and researchers can work together in this very politicized field. The multi-disciplinary Family Violence Research Team here at URI has been a great cheering section, while keeping me on my toes with its diverse theoretical perspectives.

I would like to thank my friends who have been there to support, prod, and humor me at various stages in this process: Michael Stevens, Paula Janicki, Richard Bennett, Janet Dryfoos, and Karl Hanson. Finally, I am most indebted to my family who believed in me throughout. 


\section{PREFACE}

The program of research presented here is organized using a manuscript format. Although later chapters build loosely on earlier ones, each chapter is designed to stand alone. Consequently, the reader will find some redundancy in the theoretical and empirical material presented. This research aims to answer four questions: 1) Do existing interventions for battering men work? 2) Why aren't interventions more effective? 3) How can the Transtheoretical Model of Change help us to understand violence desistance and change among battering men? and 4) Does the Transtheoretical Model apply to violence desistance?

Chapter 1, an empirical study, aims to answer the first question: Does treatment work? The project began as a qualitative review of the batterer treatment outcome literature. It soon became clear, however, that a thorough synthesis of the data would be impossible, given the large number of studies that had been conducted and the extent to which they differed on methodological, measurement, program, and other characteristics that might influence outcome. Gradually, the review evolved into a formal meta-analysis using multivariate statistical techniques to deal with complexity in the data. To my knowledge, this is the first meta-analysis of batterer treatment outcome studies.

Chapter 2, a literature review and commentary, examines social and political context to understand the development of our principal interventions for battering men, arrest and batterer treatment, and why they aren't more effective. These interventions arose out of the battered women's movement and are based on a socio-political understanding of violence and change. While potentially powerful vehicles for social change, they tend to neglect individual-level change strategies and principles, to be 
codified in state law and thus insensitive to individual differences, and to be confrontational and coercive. The Transtheoretical Model of Change is introduced as an alternative conceptual framework for understanding and facilitating change at the individual level.

Chapter 3, an empirical study, lays the groundwork for the application of the Transtheoretical Model of Change to violence desistance with the development and initial validation of measures of the model's core construct, Stage of Change. Chapter 4 continues this work with the development of measures of two additional model constructs, Decisional Balance and Self-Efficacy. Seven tests of the model are then conducted to assess whether relationships between Stage of Change and behavior, Decisional Balance and Self-Efficacy found in research on other types of behavior change hold for violence desistance as well.

Chapter 5 summarizes the research findings and their practical implications, and outlines recommendations for future research.

The timeliness of this work cannot be underestimated. In an effort to establish a level of quality assurance and accountability in programs offering services to men who batter, about half of the US states have begun to specify the length, content, and even the theoretical approach to treatment. It is critical that we pause to consider the effectiveness of the programs we are mandating, and to assess the applicability and utility of a robust model of change. The costs of partner violence are too great to risk settling on--and institutionalizing--interventions that may not work or may be less effective than other possible interventions. Once the core constructs of the Transtheoretical Model and their hypothesized relationships have been applied to the problem of partner violence, the 
model and measurement tools can help guide intervention efforts to increase their impact on the serious problem of male-to-female partner violence. 


\section{TABLE OF CONTENTS}

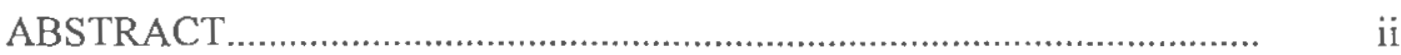

ACKNOWLEDGEMENTS .................................................................. iv

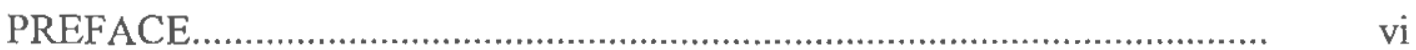

TABLE OF CONTENTS...................................................................... ix

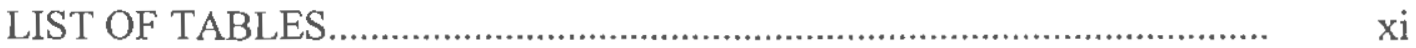

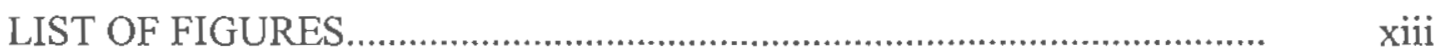

CHAPTER 1

Meta-Analytic Evaluation of Treatment Outcome Research on Men

Who Batter: Some Preliminary Findings............................................... 1

Introduction.......................................................................... 2

Method................................................................................. 12

Sample....................................................................... 12

Coding........................................................................ 12

Meta-Analytic Procedures.................................................. 14

Results................................................................................ 18

Study Characteristics....................................................... 18

Overall Effect Sizes, Recidivism Rates, and Tests

of Homogeneity............................................................... 20

Tests of Multivariate Models............................................... 21

Discussion.................................................................................... 28

Where Do We Go From Here?............................................ 35

References............................................................................... 35

Tables ........................................................ 48

\section{CHAPTER 2}

The Neglect of Individual Change Principles and Strategies in Social Change Efforts: A Case for the Application of the Transtheoretical Model of Change to the Problem of Male-to-Female Partner Violence.......

Introduction............................................................................. $\quad 55$

The Evolution of Interventions for Battering Men................... 60

The Success of Social and Individual Change Interventions.............. 67

A Statue with Feet of Clay ............................................ 71

The Transtheoretical Model of Change............................... 76

Conclusions and Directions for Future Research................... 82

References.................................................... 85

Tables............................................................................ 102 


\section{CHAPTER 3}

Development and Initial Validation of Stages of Change

Measures for Battering Men in Treatment

Introduction

Method

Item Generation.................................................................. 118

Participants........................................................................ 119

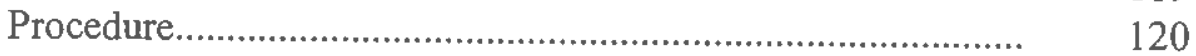

Results...................................................... 125

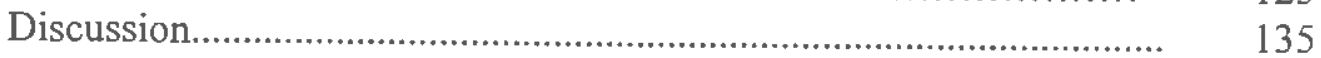

Notes.......................................................... 141

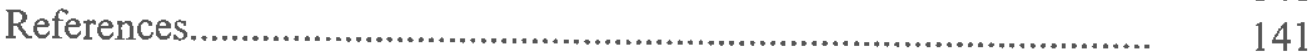

Tables and Figures...........................................................................

\section{CHAPTER 4}

Tests of the Applicability of the Transtheoretical Model of Change

to Violence Desistance among Battering Men

Introduction

Study 1

Method

Results

Study 2

Method

Results.

Discussion.

References....

Tables and Figures

CHAPTER 5

Summary and Recommendations.

APPENDIX A A..................................................... 228

APPENDIX B ..................................................... 233

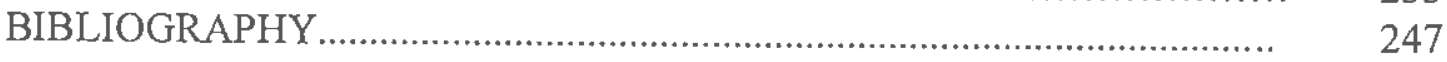




\section{LIST OF TABLES}

Table 1.1. Study Characteristics

Table 1.2. Weighted Least Squares Multiple Regressions of Study

Characteristics on Treatment Effect Size in Between Groups

Studies Relying on Partner Reports of Recidivism.

Table 1.3. Weighted Least Squares Multiple Regressions of Study Characteristics on Treatment Effect Size in Between Groups

Studies Relying on Official Reports of Recidivism

Table 1.4. Weighted Least Squares Multiple Regressions of Study Characteristics on Recidivism Rates.

Table 2.1. Processes of Change in the Desistance of Male-to-Female Partner Violence.

Table 2.2 Integration of Stages and Processes of Change.

Table 3.1. Frequency Distribution of Stage of Change for Ending the Violence as Measured by Three Staging Algorithms.

Table 3.2. Inter-Scale Correlations, Correlations with Social Desirability, Coefficient Alphas, Means, and Standard Deviations for Four URICA-B 1 Scales.

Table 3.3. Algorithm Stage Distributions for the Six URICA-B1 Profiles..

Table 3.4. Results of Statistical Tests Examining Differences Across Stages Based on Four Classification Schemes.

Table 3.5. Significant Differences Across Six Stage Clusters.

Table 3.6. Violence Cessation Strategies for Six Stage Clusters.

Table 3.7. Significant Difference Across Stage for Three Staging Algorithms

Table 4.1. Gondolf's Developmental Model for Integrated Interventions. 209

Table 4.2. Processes of Change in Partner Violence Desistance. 210

Table 4.3. Integration of Stages and Processes of Change 
Table 4.4. Items by Scale and Varimax Pattern for the Decisional Balance Measure for Battering Men....

Table 4.5. Items and Component Loadings for Tempting Situations

Scale.

Table 4.6. Descriptive Statistics, Coefficient Alphas, Correlations with Social Desirability and Scale Intercorrelations for Three Decisional Balance Scales and Tempting Situations Scale.

Table 4.7. Algorithm Stage Distribution for the Six URICA-B1 Profiles....

Table 4.8. Violence Cessation Strategies, Partner Violence, Partner Blame, Decisional Balance, and Temptation for Four Stages of Change.. 216

Table 4.9. Violence Cessation Strategies, Partner Violence, Partner Blame Decisional Balance, and Temptation for Six Stage Clusters.

Table 4.10. Descriptive Statistics, Coefficient Alphas, Correlations with Social Desirability and Scale Intercorrelations for Relationship Violence and Partner Blame Variables.. 


\section{LIST OF FIGURES}

Figure 3.1. Four Correlated Factors Model for the URICA-BI .......... 160

Figure 3.2. Mean Scale Scores for Resistant Cluster.................... 161

Figure 3.3. Mean Scale Scores for Immotive Cluster..................... 162

Figure 3.4. Mean Scale Scores for Non-Reflective Cluster............... 163

Figure 3.5. Mean Scale Scores for Ambivalent Cluster.................. 164

Figure 3.6. Mean Scale Scores for Decision-Making Cluster............ 165

Figure 3.7. Mean Scale Scores for Participation Cluster.................. 166

Figure 4.1. Six URICA-B1 Cluster Profiles............................................ 219

Figure 4.2. Mean Standardized Decisional Balance Scores for Four Algorithm Stages of Change................................................. 220

Figure 4.3. Mean Standardized Decisional Balance Scores for Six URICA B-1 Clusters....................................................... 221 
CHAPTER 1

Meta-Analytic Evaluation

of Treatment Outcome Research on Men Who Batter:

Some Preliminary Findings 


\section{Introduction}

In 1984, the US Attorney General's Task Force on Family Violence wrote that arrest followed by court-ordered psychotherapeutic treatment offers "great hope and potential for breaking the destructive cycle of violence" in intimate relationships (US Department of Justice, 1984, p. 48). Court-ordered treatment has since emerged as one of society's interventions of choice for men who assault their wives and partners. Eight states now have laws mandating treatment for men convicted of domestic assault, or as a condition of deferred sentencing (Zamora, 1995). In an effort to establish a level of quality assurance and accountability in the ever-increasing number of programs offering services to men who batter (Hart, 1992), states have begun to specify the length, content, and even the theoretical approach to treatment. A recent study found that 12 states have adopted standards for program certification or funding, 2 states have recommended standards, and 12 have standards under development (Zamora, 1995).

Ideally, the primary goal of batterer treatment is violence desistance. The extent to which programs achieve this goal is most often represented in measures of its counterpart, recidivism. To date, more that three dozen outcome studies have examined recidivism among men who complete batterer treatment, and several narrative reviews of the research have synthesized results across studies. While one review concludes that batterer treatment does reduce recidivism (Saunders \& Azar, 1989) and one reports "cautious optimism" (Feldman \& Ridley, 1995), the others withhold judgment, citing small treatment effects (Rosenfeld, 1992; Tolman \& Bennett, 1990), methodological flaws in research designs (Eisikovits \& Edleson, 1989; Hamberger \& Hastings, 1993), unexplained discrepancies in results (Tolman \& Edleson, 1995), the likelihood that 
violence desistance and recidivism are multiply-determined (Rosenfeld, 1992; Tolman \& Bennett, 1990; Tolman \& Edleson, 1995), and differences across studies in treatment modalities, research methods, and definitions of success that make synthesis "impossible" (Hamberger \& Hastings, 1993, p. 220; also see Eisikovits \& Edleson, 1989; Rosenfeld, 1992).

Rosenfeld (1992) summarized the results of the outcome research quantitatively, providing descriptive statistics (mean recidivism rates weighted by sample size) for various subgroups of studies in an effort to control for possible confounds. However, the analysis includes only a small number of variables that might influence recidivism rates, considers only one variable at a time, and does not provide enough data to allow readers to gauge the reliability of the pooled findings.

Now, 14 years since the report of the US Attomey General's Task Force on Family Violence, we still cannot say with any certainty whether batterer treatment is actually effective in helping men end their violence (National Research Council \& Institute of Medicine, 1998). As this social response to the problem of partner violence becomes fixed in state statute and program standards for certification, it is critical that we assess treatment efficacy using more rigorous research designs and research synthesis techniques. The costs of partner violence to victims, their children, and society at large are too great to risk settling on--and institutionalizing--an intervention that may not work or may be less effective than other possible interventions.

The present study is the first to use formal meta-analytic procedures and a multivariate statistical approach to guide the synthesis and interpretation of treatment outcome research on men who batter. First, the present study examines the overall 
effectiveness of batterer treatment in reducing recidivism and the influence of six classes of study characteristics--program, intervention, client, study design, measurement, and publication characteristics--on effectiveness in studies comparing the recidivisim rates of treatment and comparison groups. Second, it examines the overall rate of recidivism and the methodological factors influencing recidivism rates in all studies--including singlegroup studies--that follow treatment completers over time. Sugarman and Hotaling (1989) used a similar approach to understand differences in reported rates of dating violence across studies.

Before moving on, it is important to mention that recidivism has been criticized as an outcome measure in evaluations of batterer treatment (Feldman \& Ridley, 1995) and other offender programs (Glaser, 1973). 1t is a dichotomous variable that classifies all men as treatment successes or failures, and is insensitive to other changes that may be clinically significant, such as reductions in the frequency or severity of violence. Most outcome studies relying on pre- and post-treatment assessments do indeed find significant reductions in violence (e.g., Dutton, 1986; Waldo, 1986; Hamberger \& Hastings, 1988; Petrick, Gildersleeve-High, McEllistrem, \& Subotnik, 1994; studies 1 and 2 in Faulkner, Stoltenberg, Cogen, Nolder, \& Shooter, 1992; cf Harrell, 1991). However, the field is bound to the goal of complete desistance because any violence, no matter how infrequent or minor, places women at risk for injury and maintains an environment of fear (Rosenbaum, 1988). As a result, outcome studies relying only on continuous measures to assess reductions in violence will receive no further consideration here. 
The moderator variables selected for the meta-analyses tap critical issues in the study and implementation of batterer treatment. A summary of these issues is presented below.

Program and intervention characteristics. A national survey of batterer treatment programs (Roberts, 1982) identified three types of programs that provide interventions to batterers: 1) programs offered by established social service agencies that treat a range of mental health problems (e.g., community mental health clinics); 2) programs offered by battered women's shelters and crisis centers; and 3) independent programs developed specifically to treat battering men. National surveys have found that a majority of programs rely most on group counseling for men (Eddy \& Myers, 1984; Pirog-Good \& Stets-Kealey, 1985) or a combination of group, individual, and couple's therapy (Roberts, 1982). Feminists and battered women's advocates disapprove of the couples' approach because it implies that both partners perpetuate destructive relationship patterns and are thus responsible for the violence (Avis, 1992; Bograd, 1992).

Furthermore, it ignores the real power differential between males and females in the family and in society at large (Pence, 1985; Bograd, 1992; Goldner, Penn, Sheinberg, \& Walker, 1990), and places women at risk for further violence if they speak openly (Kaufman, 1992). However, two studies comparing all-men's groups to couples' groups (Brannen, 1994; Klein, 1991), and another comparing all-men's groups to alternative treatments such as AA, marital, and individual therapy (Newell, 1994) found no significant differences in post-treatment recidivism rates. A fourth study that compared couple's counseling to couples' groups (Harris, Savage, Jones, \& Brooke, 1988) also found no effect for treatment modality. 
Feazell, Mayers, and Deschner (1984) identified a set of intervention techniques commonly used in US programs: 1) sex role resocialization; 2) cognitive-behavioral anger management; 3) relaxation training; and 4) assertiveness training. In sex role resocialization, which developed primarily out of the battered women's movement's profeminist model, men are confronted about their sex role expectations and the acceptability of violence (Pence, 1983; Pence \& Paymar, 1993). While some early programs chose an unstructured group format to foster development of interpersonal skills and ease isolation (e.g., Adams \& McCormick, 1982), programs since the 1980's have become more structured and psychoeducational in nature (e.g., Ganley, 1981; Edleson, 1984; Pence, 1983; Saunders, 1984). Most are time-limited, ranging from 6 to 32 weeks in duration (Eisikovits \& Edleson, 1989; Tolman \& Bennett, 1990).

Treatment comparison studies have found no effects for treatment length, format, and service comprehensiveness (Edleson \& Syers, 1990, 1991; Flournoy, 1992; Gondolf, 1997), suggesting that the "Dodo bird conjecture" that bona fide psychotherapies are equally effective (Wampold, Mondin, Moody, Stich, Benson, \& Ahn, 1997) deserves consideration here. However, a recent study suggests that we should revise our question from "what works best" to "what works best for whom." In a comparison of feminist cognitive-behavioral and psychodynamic group treatment for batterers, Saunders (1996) found no main effect for therapeutic approach, but an interaction between client characteristics and approach. Clients with dependent personality traits were less likely to recidivate following psychodynamic group treatment, and those with antisocial traits responded better to feminist cognitive-behavioral treatment. 
In the absence of a body of data showing what works best, what works best for whom, or whether batterer treatment even works at all, a number of states have developed standards for program certification or funding that emphasize a pro-feminist approach (Maiuro, 1997). For example, the Massachusetts Guidelines state that while psychodynamic, cognitive-behavioral, and other approaches and interventions "may, from time to time, be incorporated into a treatment model that focuses on power and control in relationships, they are inadequate and inappropriate if they stand alone as the focus of treatment" (Massachusetts Guidelines and Standards for the Certification of Batterers' Treatment Programs, Section 4.6, 1994). Such guidelines often specify the length of treatment and discourage couples counseling. If, however, the "Dodo bird conjecture" is false, programs standards at this early stage in the development of batterer treatment do a disservice to the field--and, in the end, to victims of violence--by insisting on interventions and therapeutic approaches that may be sub-optimal, limiting opportunities for client-treatment matching, and inhibiting experimentation and innovation.

Client characteristics. Research has begun to examine sociodemographic and personality variables that might discriminate recidivists from non-recidivists among treatment completers. To date, there is preliminary evidence that men who engage in further violence are more likely to have drug and alcohol problems (DeMaris \& Jackson, 1987; Hamberger \& Hastings, 1990; Harrell, 1991; Shepard, 1992; cf Edleson \& Syers, 1990), and more likely to be narcissistic (Hamberger \& Hastings, 1990). Age, education level, marital status, past criminal and violent behavior, and other variables that predict violence recidivism in other criminal populations (e.g., Rice \& Harris, 1995) are for the 
most part unrelated to recidivism in batterers (DeMaris \& Jackson, 1987; Edleson \& Syers, 1990; Hamberger \& Hastings, 1990; Harrell, 1991; Shepard, 1992; Rosenbaum, 1997). Two studies have found that self-referred clients are more likely than courtmandated clients to reoffend following treatment (Edleson \& Syers, 1991; Rosenbaum, 1997); two studies found no differences (DeMaris \& Jackson, 1987; Hamberger \& Hastings, 1990).

Methodological problems. Violence is an inconstant phenomenon. For instance, follow-up interviews of participants in the 1985 Second National Family Violence Survey found that $42 \%$ percent of the men who severely assaulted their female partners at least once during the year prior to the 1985 survey committed no severe assaults the following year (Feld \& Straus, 1990). "Spontaneous desistance" of violence (Fagan, 1989) may represent a temporary lull in the cycle of violence (Walker, 1979) or more permanent change in the absence of formal intervention. In either case, it highlights the need for adequate follow-up periods and, more important, the need for no-treatment control groups to take into account the natural course of violence in studies of treatment efficacy. The field has justifiably placed ethical concerns above scientific rigor, however. Afraid that withholding batterer treatment may place female partners at increased risk for injury, even death (Saunders, 1988), few researchers have been willing to employ classical experimental designs with random assignment to no-treatment control groups.

Hamberger and Hastings (1993) have questioned this working principle, arguing that it may be unethical to offer treatment of unproved efficacy. Treatment is time-consuming and expensive for men, and may encourage unwarranted optimism and a sense of safety 
in victims. One of the best predictors of whether or not a woman will return to her partner after a shelter stay is whether or not her partner is in treatment (Gondolf, 1988).

A majority of the outcome studies include no comparison group whatsoever. Many of those that do include a comparison to compare treatment completers to noncompleters use a quasi-experimental design. The non-completers in most of these studies are men who dropped out of treatment, refused treatment, or were deemed inappropriate for treatment for some reason. Because any number of subject characteristics associated with non-completion (e.g., resistance, low motivation) might also influence outcome, results may be confounded. Other studies compare convicted offenders who were and were not mandated to treatment by the criminal justice system. Possible biases in judges' decision-making may once again confound results.

Problems assessing outcome. Many researchers continue to question the reliability and validity of the best recidivism measures that exist today. It is well accepted that the primary sources of such data--criminal records, batterers' self-reports, and partners' reports--provide underestimates of violence, though the degree of underestimation and how it varies from case to case remains unknown (Straus, 1990; Straus, Gelles, \& Steinmetz, 1980). For instance, the 1985 Second National Family Violence Survey found that only $6.7 \%$ of female victims of partner violence report their assaults to police (Straus \& Gelles, 1990). Given the low rate of reporting, criminal records may better represent partners' attitudes and expectations regarding the legal system than recidivism, per se (see Harrell, 1991).

The Conflict Tactics Scales (Straus, 1979) and modified versions such as the Abusive Behavior Inventory (Shepard \& Campbell, 1992) are the most widely used self- 
report measures of violence. They can be administered to offenders to assess the frequency with which they used various rational, verbally aggressive, and physically aggressive conflict tactics in the relationship, or to victims to assess their abuse experiences. Partners' reports on the CTS and similar scales are often considered the "criterion" measure of violence because they yield the highest estimates of the frequency and severity of aggression (Szinovacz, 1983; Edleson \& Brygger, 1986; Jouriles \& O’Leary, 1985; Edleson \& Grusznski, 1989). However, researchers have identified problems with this measure as well. For example, although victim's reports appear unrelated to social desirability and impression management (Arias \& Beach, 1987; Dutton \& Hemphill, 1992), other factors such as shame, denial, fear of retribution, or desire to protect the male partner from legal sanctions may lead victims to minimize their abuse experiences (Dutton, 1986; Edleson \& Brygger, 1986; Harrell, 1991; Rosenbaum, 1988). Another problem with partner data is that they simply are not available for men who are no longer in ongoing relationships (Rosenbaum, 1988). To help compensate for biases in criminal records, batterers' self-reports, and partner reports, researchers have recommended combining data from all available sources, with any positive finding representing violence (e.g., Hamberger \& Hastings, 1988; Harrell, 1991; Saunders, 1989).

Differences in measurement approaches and data sources impede the comparison of results across studies. Another problem is that researchers have made little attempt to develop and adhere to a standard definition of recidivism. CTS-type measures vary in the number and range of behaviors included as indicators of recidivism. While some studies omit tactics from the standard CTS (Straus, 1979) physical aggression scale, others add 
tactics such as choking (DeMaris \& Jackson, 1987), and reckless driving (Saunders, 1996). Measures drawing from criminal records vary on the standard of proof (e.g., calls to police vs. conviction) required to determine that further violence has occurred. A few studies neglect to define violence altogether.

Publication characteristics. Publication bias is the tendency of researchers, reviewers, and editors to submit and publish studies with positive findings and to withhold and reject studies with negative findings; such a bias can impede the dissemination of knowledge and lead to overly optimistic evaluations of treatment effiicacy (Dickersin, 1990). To date, there have been no formal examinations of publication bias in the batterer treatment outcome research.

The meta-analytic approach. In the present study, two meta-analyses of treatment outcome studies evaluated the effectiveness of batterer treatment in reducing violence recidivism and whether effect sizes were homogeneous or varied more than expected on the basis of sampling error alone. The first examined between-groups studies relying on partner reports of recidivism, and the second examined between-groups studies relying on official records. When the hypothesis of homogeneity was rejected, potential moderator variables (program, intervention, study design, measurement, and publication characteristics) were examined in an attempt to account for unexplained variance. A third meta-analysis assessed the overall rate of recidivism in all studies that followed treatment participants over time, and identified study design, measurement, and publication characteristics that moderate measures of recidivism. 


\section{Method}

\section{$\underline{\text { Sample }}$}

The sample consisted of 38 outcome studies examining partner violence recidivism for men who participated in court-mandated batterer treatment. Published studies and unpublished doctoral dissertations, master's theses, conference presentations, and formal research reports completed between 1980 and August, 1997 were identified using computer searches of PsychLit, Medline, and Dissertation Abstracts International, and manual searches of published review articles and the conference programs of the American Psychological Association and the International Family Violence Research

Conference. Whereas the sample of published studies can be considered reasonably exhaustive, the sample of unpublished studies is limited to those that could be obtained relatively easily (with three or fewer phone calls). Studies were included if they used either a single-group $(n=23)$ or between-groups $(n=15)$ design, had a sample size of five or greater, and provided a post-treatment measure of recidivism for male treatment participants.

\section{Coding}

A coding system was developed to code study design, measurement, publication, program, and intervention characteristics. Operational definitions for each variable are provided in the Coding Manual in Appendix A. All of the coding was conducted by the author.

The program characteristics coded included agency type (social service agency, shelter-run and independent batterer program), treatment modality (men's group, other), treatment format (psychoeducational, other), number of sessions, and program attrition 
rate. The following intervention techniques were coded as present if they were mentioned in the program description, and absent if they were not: sex role resocialization, cognitive-behavioral anger management, time-out, communication skills training, relaxation training, and assertiveness training. Client characteristics included age, years of education, percent married, percent living with partner, percent employed, percent minority status, and percent court-involved.

The following study design variables were also coded: overall study design (outcome only, between-groups), method of group assignment for between-groups studies (random assignment, assignment based on decision by therapist or client via drop-out, assignment based on decision by judge or probation officer, combined input from both clinic and court), and follow-up period in months. Measurement characteristics included study participation rate, data source (client, victim, official records, combined), and level of measure inclusiveness. For CTS-type measures administered to clients and partners, measure inclusiveness was scored on a 3-point scale with $1=$ less inclusive than standard CTS (Straus, 1979), 2=standard, and $3=$ more inclusive. For criminal record measures, $l=$ conviction or prosecution, $2=$ arrest or criminal charges filed, and $3=$ police contacts for partner assault or threats.

The two publication characteristics examined were document source (journal article, book chapter, conference presentation, unpublished research report, thesis or dissertation) and year of publication, presentation, or completion.

In studies with multiple comparison groups, all comparison groups were collapsed into a single composite group. Because there are no statistically significant differences between comparison groups on post-treatment measures of recidivism (see Edleson \& 
Syers, 1990, 1991; Flournoy, 1992; Gondolf, 1997, mentioned above), this procedure should have no effect on the results of the study. If a study's comparison groups differed on moderator variables of interest, variables were coded as missing.

\section{Meta-Analytic Procedures}

The basic steps in a meta-analysis are to synthesize results across studies to determine the overall effect of one variable (e.g., batterer treatment) on another (e.g., recidivism), to test whether the overall effect is significantly different from zero, and to test whether the studies effect sizes are homogeneous or vary more than we might expect based of sampling error alone. When the hypothesis of homogeneity is rejected, potential moderator variables might be examined in an attempt to account for unexplained variance.

Computing and summarizing effect sizes. Summary statistics from each study must be converted into standardized effect sizes before they can be combined, summarized, and further analyzed. For between-groups studies in the present metaanalysis, effect size was defined as Cohen's $h$ (Cohen, 1988), the difference between the recidivism rate for the comparison group and the recidivism rate for the treatment group after they were transformed to radians (Rosenthal, 1994). Cohen's $h$ was calculated as follows:

$$
h=2 \arcsin \sqrt{p_{\mathrm{ic}}}-2 \arcsin \sqrt{p_{\mathrm{it}}} .
$$

The arcsin transformation normalizes the distribution and stabilizes the variance of proportions (Eisenhart, 1947; Cohen, 1988; Rosenthal, 1994; Rossi, 1985). Because the variance of proportions is greatest at .50 and smallest at .00 and 1.00 , comparisons of 
raw proportions have less statistical power near the middle of the scale (e.g., .45 and .55) than near the ends (e.g., .00 and .10). Arcsin-transformed proportions offer an advantage over raw proportions because they have variances that are independent of the radian measure, and thus permit the synthesis of comparisons across studies (Rosenthal, 1994). The arcsin transformation of the difference between .45 and .55 yields an $h$ of .20 , whereas the transformation of the difference between .00 and .10 yields and $h$ of .64 . Cohen (1988) considered an effect $h$ of .20 to be a small effect, .50 medium, and .80 large.

Next, an estimate of the overall effect of treatment, $h$, was calculated for between-groups studies by averaging the study effect sizes weighted by the inverse of their variance. Weighting minimizes the variance of $h$. by giving less weight to study effect sizes with larger variances (i.e., those that are measured less reliably). Variance is inversely related to sample size. The variance of Cohen's $h$ is the sum of the reciprocals of the treatment group and comparison group n's (Rosenthal, 1994). The null hypothesis that the population effect is zero was tested by computing a $Z$ statistic, $h$. divided by a measure of the standard error of $h$. The null hypothesis can be rejected if $Z$ exceeds 1.96, the critical value of $Z$ for a 2 -tailed test at $\alpha=.05$. These procedures are described in more detail by Shadish and Haddock (1994).

In the synthesis of results across the 23 single-group and 15 between-groups studies examining rates of recidivism in treatment completers, recidivism rates were weighted by sample size before averaging. 
Several studies reported multiple measures of recidivism (i.e., measures from different sources, levels of inclusiveness, or timepoints). While it is possible that aggregating multiple measures of effect size or recidivism within a given study might provide more reliable parameter estimates, it seemed more important at this stage to preserve measure distinctiveness for two reasons: 1) it is unclear that different indices of recidivism do indeed represent the same underlying constructs; and 2) it permits an examination of the relationship between measure characteristics and treatment effects or recidivism rates. Between-groups studies relying on partner reports and official records were analyzed separately. When a study reported multiple measures from a single source, the effect size associated with the largest $n$ was selected. Presumably, $n$ 's differed across measures because of subject attrition, which can pose a major threat to external validity (Campbell \& Stanley, 1963). Selecting measures with the largest $n$ 's reduced this threat to validity. When $n^{\text {'s }}$ were equal, the effect size associated with the highest recidivism rate was selected. All studies examining recidivism in treatment completers were analyzed together, regardless of data source, using the measure selection criteria outlined above (largest $n$, highest recidivism rate); data source was used as a moderator variable.

Homogeneity of effect sizes and recidivism scores. Homogeneity of effect sizes and recidivism scores was indexed by the $Q$ statistic,

$$
Q=\sum_{i=1}^{k} w_{i} h^{2}-\frac{\left(\sum_{i=1}^{k} w_{i} h_{i}\right)^{2}}{\sum_{i=1}^{k} w_{i}},
$$

distributed approximately as chi-square with $k-1$ degrees of freedom. The null hypothesis of homogeneity was rejected if $Q$ exceeded the upper-tail critical value of chi-square with 
$k-1$ degrees of freedom. Each study's contribution to $Q, Q_{i}$, was also examined to identify outliers.

Tests of multivariate models. To examine how well six classes of moderator variables could account for unexplained variance in effect sizes in between-groups studies, regression models were run using SPSS for Windows Version 6.1.4 and tested using DSTAT meta-analysis software (Johnson, 1989) and procedures described by Hedges (1994, pp. 295-298). For the two sets of between-groups studies, weighted least squares regressions were conducted in which effect size $(h)$ was the dependent variable, moderator variables within a given class (e.g., study design characteristics) were the independent variables, and the reciprocal of the sampling variances was the weight. For the larger set of studies, the recidivism rate was the dependent variable, and sample size was the weight. Standard errors and significance tests for the unstandardized regression coefficients generated by SPSS, incorrect for meta-analysis, were re-calculated using DSTAT. The null hypothesis of model fit was retained if the weighted residual sums of squares (also generated by SPSS), $Q_{E}$, was less than the critical value of chi-square with $k-m-1$ degrees of freedom, where $m$ is the number of moderator variables included in the regression. $Q_{E}$ is a new homogeneity statistic, $Q$, minus the variance accounted for by the moderator variables.

With the goal of model building, a stepwise regression procedure described by Hedges (1994, pp. 295-298) was used to identify classes of variables that accounted for enough unique variance to warrant their inclusion in a larger, optimal regression model. A class of variables was included in the stepwise procedure if its multiple $R$ was significantly different from zero in the first set of regression analyses outlined above; 
individual moderator variables were included in their class if their regression coefficients were significantly different from zero $(p<.05)$. A class of variables was retained in the model if it accounted for a significant amount of additional variance (i.e., if the difference in $\mathrm{Q} E$ 's for the smaller and larger models exceeded the difference in chi square values with $k-m_{1}-1$ and $k-m_{1}-m_{2}-1$ degrees of freedom, where $m_{1}$ and $m_{2}$ are the number of moderator variables in the smaller model and the class under consideration, respectively).

\section{Results}

\section{Study Characteristics}

Study characteristics for all 38 batterer treatment outcome studies and two subsets of between-groups studies--those relying on partner reports of recidivism and those relying on official records--are summarized in Table 1.1. Three between-groups studies report both partner reports and official records, and thus are included in both subsets. The three sets of studies are similar with respect to program, intervention, outcome measure, participant, and publication variables, with some important exceptions. Treatment group sample sizes range from 8 to 655 (total $N=3611$ ) for all 38 studies. Combined treatment and comparison group $N$ 's range from 57 to 188 (total $N=767$ ) for the subset of seven between-groups studies relying on partner reports, and from 35 to 446 (total $N=2193$ ) for the subset of 11 studies relying on official records.

The modal program assessed is offered by a social service agency that treats a variety of mental health problems, rather than by an agency established specifically to treat perpetrators or victims of partner violence, or by another type of sponsoring institution identified during the coding (i.e., the criminal justice system, universities). The modal program provides batterers' group counseling that is psycho-educational and 
time-limited in nature; only 2 of 31 studies reporting on program length described their groups as open-ended. Time-limited programs run 6 to 32 sessions (mean= 17 sessions, median=16 sessions, mode $=12$ sessions for all studies). A majority of the programs provide training in anger management and sex role resocialization, but not in assertiveness. Programs are about as likely as not to help clients build communication and relaxation/stress management skills, and to teach men how to use timeout to interrupt the escalation of conflict. The mean program attrition rates for the three sets of studies are similar to the rate of $40 \%$ found in a nation-wide survey of batterer treatment programs (e.g., Pirog-Good \& Stets, 1986). What is notable about participant sample characteristics such as age and education is that they are reported in only one- to twothirds of studies, with the exception of court-involvement, which is reported in over $70 \%$ of studies.

In about half of between-groups studies, comparison groups are composed at least in part of treatment drop-outs or men deemed inappropriate for treatment by program staff. The frequency distributions for study follow-up periods are positively skewed. Follow-ups range from 0 to 62 months (mean $=14$ months, median $=12$ months, mode $=6$ months for all studies). Seven studies use measures of recidivism from multiple sources. Measurement characteristics reported in Table 1 are for measures selected for analyses using criteria outlined above. Nearly one quarter of all studies did not provide a precise operational definition of recidivism.

Between-groups studies are about twice as likely as single-group studies to begin follow-up before the end of treatment (e.g., at the time of sentencing). Between-groups studies relying on partner reports tend to have shorter follow-up periods, lower 
participation rates, and samples with lower percentages of court-mandated subjects than between-groups studies relying on official records. Also, the programs they assess tend to be longer and are more likely to include sex role resocialization.

The findings of approximately two-thirds of studies included in the present metaanalyses were published in journals or as book chapters. The first single-group study was published in 1981, and the first between-groups study was published five years later, in 1986.

\section{Overall Effect Sizes, Recidivism Rates, and Tests of Homogeneity}

Between-groups studies relying on partner reports. For between-groups studies relying on partner reports, the overall effect size was not significantly different from zero ( $h=.06, n=7, Z=0.85, \mathrm{~ns}$ ). When radians were converted back to proportions, the overall mean weighted recidivism rates for the treatment and comparison groups were $34.2 \%$ and $31.9 \%$, respectively. The homogeneity statistic was statistically significant $(Q=38.7$, $d f=6, p<.01$ ), indicating that effects varied across studies more than expected based on chance alone and that an examination of moderating factors is warranted. However, one outlier, Harrell (1991), the only study to find a negative effect for treatment $(h=-.72)$, contributed more than half of this variance $\left(Q_{i}=23.6\right)$. When Harrell is excluded from the study sample, the mean weighted effect size for treatment is statistically significant from zero $(h=.27, n=6, Z=3.25, p<.01)$, and the hypothesis of homogeneity of effect sizes is retained $(Q=8.9, d f=5, \mathrm{~ns})$,

Between-groups studies relying on official records. For between-groups studies relying on criminal records, the overall effect size was small but statistically significant ( $h=.19, n=11, Z=4.41, p<.01$ ). The mean weighted recidivism rates for the treatment and 
comparison groups were $14.3 \%$ and $21.8 \%$, respectively. The homogeneity statistic was statistically significant $(Q=46.1, d f=10, p<.01)$, with three outliers (Dutton, 1986; Harrell, 1991; Waldo, 1988) accounting for nearly $90 \%$ of the variance in effect sizes. When the three outliers are excluded from the study sample, the mean weighted effect size drops slightly to $.17(n=8, Z=3.66, p<.01)$ and homogeneity statistic drops to 4.1 $\left(d f=7\right.$, ns). Once again, Harrell (1991) was the most extreme outlier $\left(Q_{i}=16.0\right)$ and the only study to find a negative effect for treatment $(h=-.41)$.

All outcome studies reporting post-treatment rates of recidivism. Among all 38 batterer treatment outcome studies, the mean weighted rate of recidivism for treatment completers was $21.6 \%$. The assumption of homogeneity of recidivism scores was rejected $(Q=66.9, d f=37, p<.01)$.

\section{Tests of Multivariate Models}

Outliers such as Harrell (1991) were included in tests of multivariate models since the major goal of the analyses was to identify sets of study characteristics that moderate treatment effects and might account for aberrations. However, in an attempt to maximize the robustness of the findings, excluded froin the model tests were study characteristics that appeared unstable in the presence of outliers. Specifically, study characteristics were omitted if their correlations with between-groups effect sizes changed valence in the presence and absence of Harrell (1991).

Because of missing data, treatment attrition rate and all participant characteristics except percentage court-involved were also omitted from analyses. Percentage of courtinvolved subjects was examined as a program characteristic. Cases were deleted from a given analysis if a majority of the remaining variables were missing. Otherwise, missing 
values for continuous variables were replaced with weighted sample means; missing values for dichotomous variables were replaced with a value of 0.5 . Measure inclusiveness was assigned a value of 1 on a 3-point scale for studies in which recidivism was not operationally defined. (Studies with undefined measures tended to yield the lowest rates of post-treatment recidivism). A square root transformation was used on the follow-up period variable in order to reduce the skewness of the distribution.

The following four categorical variables were dichotomized for the multiple regressions: agency type (established social service agency, other), method of group assignment (clinic or clinic plus court, other), data source (partner reports alone or in combination with other sources, other), and document type (published, unpublished).

Between-groups studies relying on partner reports. All program characteristics (agency type, number of sessions, percentage court-involved) and measurement characteristics (data source, measure inclusiveness, study participation rate), two intervention characteristics (communication and relaxation training), and one publication characteristic (year of publication or completion) were excluded as moderator variables in tests of multivariate models because they did not meet criteria for robustness in the presence of outliers.

Three separate weighted least squares multiple regressions were conducted to examine how well the following three remaining classes of moderator variables could account for unexplained variance in effect sizes in between-groups studies relying on partner reports of recidivism: 1) treatment interventions, 2) design characteristics, and 3) publication characteristics. Once again, effect size was the dependent variable, moderator 
variables were the dependent variables, and weights were the reciprocals of the sampling variances.

Table 1.2 displays the correlations between effect size and moderator variables, the unstandardized regression coefficients $(B)$ and intercept, standardized regression coefficients $(\beta)$, standard normal scores $(Z)$ for tests of individual coefficients, $R^{2}$, adjusted $R^{2}, R$, and weighted residual sums of squares $\left(Q_{E}\right)$ for the test of overall model fit for each set of moderator variables. In a few cases, moderator variables were excluded from analyses to address the problem of multicollinearity. For example, in the first regression analysis, sex role resocialization was strongly negatively correlated with another treatment intervention characteristic, assertiveness training. Since sex role resocialization was considered the more interesting of the two variables, given the politicized state of the debate about batterer treatment intervention, assertiveness was selected for exclusion. Variables deleted because of multicollinearity are noted in Table 1.2.

A regression model containing the two remaining treatment interventions, sex role resocialization and timeout, did not provide a satisfactory fit of the data (i.e., the hypothesis of model fit was rejected with $Q_{E}=13.13, d f=3, p<.05$ ). However, multiple $R$ was significant and both variables made unique contributions to effect size (i.e., $Z$-tests for individual regression coefficients were significant at $p<, 05$ ). Studies that mentioned sex role resocialization and timeout in program descriptions tended to have smaller effect sizes than those that did not mention them. Adjusted $R^{2}$ was $38 \%$. 
To reduce multicollinearity, type of group assignment was deleted from the regression model examining design characteristics. The single remaining variable, square root of the follow-up period, accounted for $28 \%$ of the variance in effect size (adjusted $\left.R^{2}=13 \%\right)$. Length of follow-up and effect size were positively correlated $(r=.53, p<.01)$. Publication, the only variable in the model examining publication characteristics, accounted for $62 \%$ of the variance in effect size (adjusted $R^{2}=54 \%$ ). Studies that were published tended to have significantly larger treatment effects than those that were not $(r=.77, p<.01)$. Neither of these two univariate models provided a satisfactory fit of the data.

A stepwise procedure (Hedges, 1994) was used to build a larger multivariate model combining classes of variables that moderated effect size in between-groups studies relying on partner reports of recidivism. All three classes of variables examined above were entered in the model because their multiple $R^{\prime}$ 's were statistically significant at $p<.05$. Note, however, that two variables--assertiveness training and clinic-based assignment--were excluded because of multicollinearity. A class of moderator variables was retained in the final model if it improved the model fit by significantly reducing the weighted residual sums of squares, $Q_{E}$, as described above. The final model is presented in Table 1.2.

The final model, which included intervention and design characteristics, provided a good fit of the data $(Q E=6.56, d f=3, n s)$. Sex role resocialization, timeout, and square root of months follow-up accounted for $83 \%$ of the variance in effect size (adjusted $R^{2}=66 \%$ ). All three variables made unique contributions to effect size. Publication did not significantly improve the model fit, in part because of its strong correlation with the 
other variables. Keep in mind, however, that publication accounted for over $50 \%$ of the variance on its own. A more parsimonious, alternative model might contain publication variable as a sole predictor of effect size.

Between-groups studies relying on official records. Table 1.3 summarizes results of five weighted least squares multiple regression analyses examining how program, intervention, design, measurement, and publication characteristics moderate effect size in studies relying on official reports of recidivism. Excluded from analyses were three moderator variables that did not meet criteria for robustness in the presence of effect size outliers: number of sessions, agency type, and assertiveness training.

No single class of moderator variables provided a satisfactory fit of the data. The model containing program characteristics provided the worst fit. The sole variable in the model, percentage of clients who were court-involved, accounted for $6 \%$ of the variance in effect size, $0 \%$ after adjusting for random sampling variations in small samples.

The model containing intervention characteristics provided the best fit. Sex role resocialization, timeout, communication skills and relaxation training accounted for $54 \%$ of the variance in effect size, $30 \%$ after adjusting for random sampling variation. Multiple $R$ was statistically significant. However, only two variables, timeout and communication skills, made unique contributions to effect size. Once again, it is important to note the negative relationship between interventions and effect size. Studies that mentioned timeout and communication skills tended to have smaller effect sizes than those that did not.

Whereas square root of the follow-up period was positively correlated with effect size in studies relying on partner reports of recidivism ( $r=.53)$, it was weakly negatively 
correlated with effect size in studies relying on official reports $(r=-.22)$. The strength of this relationship was magnified $(\beta=-.68)$ when coupled with method of assignment to comparison group in a case of cooperative suppression. Multiple $R$ was statistically significant and both follow-up and method of assignment made unique contributions to effect size $(p<.01) . R^{2}$ and adjusted $R^{2}$ were $32 \%$ and $15 \%$, respectively.

The model containing measurement characteristics--measure inclusiveness and study participation rate--accounted for $23 \%$ of the variance in effect size, $4 \%$ after adjusting for random sampling variations in small samples. Multiple $R$ was statistically significant. Only measure inclusiveness made a unique contribution to effect size in the model. Studies using more conservative measures of recidivism (e.g., conviction) tended to have larger effects for treatment than studies using more liberal measures (e.g., calls to police).

The model containing publication characteristics--study publication and year of publication or completion--accounted for $17 \%$ of the variance in effect size, $0 \%$ after adjusting for random sampling variations. Multiple $R$ was statistically significant. Only study publication made a unique contribution to effect size. As observed earlier, published studies tended to show larger treatment effects than unpublished studies.

Intervention, design, measurement, and publication characteristics with significant regression coefficients were examined in a stepwise manner, class by class, with the goal of model building. Program characteristics did not meet criteria for inclusion. A final model is presented in Table 1.3. Measure inclusiveness (the sole variable representing the measurement class of study characteristics), and timeout and communications skills 
(representing the treatment intervention class) were excluded because they failed to improve model fit. The three remaining variables, clinic-based assignment, square root of the follow-up period, and publication, provided a good fit of the data $\left(Q_{E}=10.7, d f=10\right.$, ns). Together they accounted for $77 \%$ of the variance in effect size across studies.

Adjusted $R^{2}$ was $67 \%$. All three variables made unique contributions to effect size. The suppression effect noted earlier is present here.

An alternative final model which retained intervention and publication characteristics and excluded design and measurement characteristics accounted for nearly the same amount of variance in effect size $\left(R^{2}=75 \%\right.$, adjusted $\left.R^{2}=64 \%, R=.86, p<.05\right)$. The three variables in the model--timeout, communication skills, and study publication-made unique contributions to effect size and provided a good fit of the data $\left(Q_{E}=11.73\right.$, $d f=10, \mathrm{~ns})$.

All outcome studies reporting post-treatment rates of recidivism. Three separate weighted least squares multiple regression analyses were conducted to examine how well study design, measurement, and publication variables could account for unexplained variance in post-treatment recidivism rates across studies. Recidivism rate was the dependent variable, moderator variables were the dependent variables, and treatment group sample sizes were weights. Results are summarized in Table 1.4.

Only one class of moderator variables, measurement characteristics, provided a satisfactory fit of the data and yielded a significant multiple R. The three measurement variables, measure inclusiveness, data source, and study participation rate, accounted for $36 \%$ of the variance in recidivism rates (adjusted $R^{2}=30 \%$ ). However, only measure inclusiveness and data source made unique contributions to reported rates. As we might 
expect, studies relying on partner reports and more inclusive measures tended to report higher rates of recidivism than studies relying on men's reports or official records, or on measures that were more conservative.

Design characteristics accounted for $8 \%$ of the variance (adjusted $R^{2}=2 \%$ ), and publication characteristics accounted for $3 \%$ (adjusted $R^{2}=0 \%$ ). None of the variables examined in the two models made unique contributions to recidivism rate.

The final model included only two measurement characteristics meeting selection criteria: measurement inclusiveness and data source. The $R^{2}$ and adjusted $R^{2}$ for the final model were $34 \%$ and $30 \%$, respectively. The hypothesis of model fit was retained.

\section{Discussion}

Three meta-analyses of batterer treatment outcome studies were conducted. Two evaluated the effectiveness of treatment in reducing violence recidivism in abusive men and identified factors that moderate measures of effect size. The third assessed the overall rate of recidivism among treatment completers and identified factors that moderate measures of recidivism. Before discussing the results and their implications, it is important to mention two caveats that apply especially to the findings on treatment efficacy. First, the findings are based on a small number of studies--7 studies relying on partner reports of recidivism in the first analysis, and 11 studies relying on official records in the second. Although these studies comprise the bulk of the batterer treatment outcome research conducted to date, and despite the increased statistical power of metaanalytic approaches (e.g., large combined $n$ 's), the methods used to guard against spurious findings (e.g., including only moderator variables robust in the presence of outliers), and evidence of statistical reliability of the findings (e.g., $p<.05$ in tests of 
significance), inferences drawn from samples of 7 and 11 must be considered tentative and preliminary. It might be helpful to consider the present study a first snapshot. With additional outcome research and perhaps improved meta-analytic methods, we can expect our image of batterer treatment and its efficacy to grow in clarity and completeness over time. Still, at the moment, we can--and should--ask, "What do the studies conducted to date have to tell us?" What do we see in this snapshot?

The second caveat concerns outliers. Harrell (1991), the only study to find a negative effect for treatment, contributed more than $50 \%$ of the variance in effect size among studies relying on partner reports of recidivism. Harrell and two other studies contributed more than $90 \%$ of the variance in studies relying on official records. We might discard these studies as aberrations. However, by excluding outliers at this early stage we delete parts of the picture that are potentially rich sources of information. The approach taken here was not only to include outliers, but to increase understanding by identifying factors that might explain why these studies vary so much from others in terms of effect size. As outliers in otherwise homogeneous samples, these studies have a huge impact on results of multiple regression analyses conducted to identify moderator variables; as sources of most of the variance, they should have a huge impact. Whether or not these findings will hold up over time is unclear. However, they do help us to understand the studies conducted to date.

The effect of treament. What do these studies tell us? First, the effect of treatment is small at best. There is no effect for treatment in studies relying on victim reports of recidivism (Cohen's $h .=.06$ ), and a small effect in studies relying on official records (Cohen's $h .=.19$ ). In response to the question, "Does treatment work?" we might 
answer, "A little, probably." But it is safe to say that there is room for improvement in programs designed to help men end their violence against their partners. Across all studies examined, the mean weighted rate of recidivism among treatment completers was $21.6 \%$

Measurement characteristics. The selection of outcome measures in studies of treatment efficacy is a critical task for researchers. Data source and measure inclusiveness were the strongest predictors of post-treatment recidivism rates in studies that followed treatment participants over time. Together, they accounted for about a third of the variance in recidivism rates across 38 studies examined. As we might expect, higher rates were found among studies relying on partner reports--either alone or in combination with client reports and/or official records--and studies that used more inclusive or liberal measures of recidivism.

But do measurement characteristics influence measures of effect size? We did not formally test the difference between effect sizes for studies relying on partner and official reports of recidivism because the two samples overlapped somewhat (three studies relied on both sources of data and thus were included in both samples). Also, data source may also interact with other study characteristics, such as length of follow-up, to moderate efficacy measures. Measurement inclusiveness warrants further empirical investigation, especially in studies relying on official records. To illustrate the impact of this variable, the weighted mean effect size for studies defining recidivism as conviction or prosecution $(n=2)$, arrest or criminal charges $(n=5)$, and police contacts for partner assault or threats $(n=4)$ were $.54, .30$, and .07 , respectively. Measure inclusiveness did not make a unique contribution to effect size in final multivariate models, however. 
There are other important issues to keep in mind when selecting outcome measures. Study participation rates were far higher for studies relying on criminal records than on victim reports. This difference becomes more impressive when we take length of follow-up into account. Between-groups studies relying on criminal records lost an average of $6 \%$ of their samples over an average follow-up period of 19.5 months, whereas studies relying on partner reports lost an average of $33 \%$ of their samples over an average follow-up period of only 7.3 months.

Design characteristics. In about half of between-groups studies, comparison groups were composed at least in part of men who dropped out of treatment, refused treatment, or were deemed inappropriate for treatment for some reason. Can we assume that treatment and comparison samples are equivalent in these studies? Or do they differ on important dimensions, such as level of motivation for change, that can influence outcomes and confound results? The present findings are consistent with the hypothesis of sample non-equivalence: the meta-analyses found that studies using clinic-based assignment had significantly larger effect sizes than studies using court-based or random assignment.

The picture becomes more complicated, however, when we take into account another design characteristic, length of follow-up. Three findings were unanticipated: 1) studies using clinic-based assignment had longer follow-up periods than other studies; 2) effect size increased with length of follow-up in studies relying on partner reports, but deteriorated over time in studies relying on official records; and 3) length of follow-up served as a suppressor variable in studies relying on official records, but not in those relying on partner reports. The meaning of these findings is not immediately obvious. It 
is probably prudent to simply note them at the moment, and wait to see if they hold up with additional data before generating explanations to account for them. In the larger group of studies that followed treatment participants over time, recidivism rates increased marginally with length as follow-up, as men had more time and opportunity to reoffend.

Participant sample characteristics. In studies relying on official reports of recidivism, participant samples were composed essentially of men court-referred to treatment; in studies relying on partner reports, samples had greater representations of men who were self-referred. There is no evidence that sample make-up on this dimension impacts measures of treatment effectiveness. One- to two-thirds of studies neglected to report other sample characteristics such as age, education, ethnicity, employment and marital status, preventing their inclusion in the present analyses. Researchers are encouraged to provide more detailed descriptions of their samples for readers and to facilitate formal and informal research synthesis efforts.

Program and intervention characteristics. All of the programs assessed in between-group studies used some form of anger management training to help men end their violence against their partners. A most disconcerting finding is the negative correlation between effect size and all other treatment interventions except assertiveness training. Does this mean that these interventions are ineffective?

Intervention techniques were coded as present if they were mentioned in the program description, and absent if they were not. The decision to mention or not mention an intervention may be a function of what really happened in the treatment, what the researcher believed was important enough to mention, the researcher's attention to this level of detail, and perhaps even space limitations in published studies. (There were 
strong inverse relationships between publication and some interventions). In future research, meta-analysts might supplement data culled from the studies with survey or interview data from researchers or program staff familiar with the programs assessed.

Once again, do the data collected to date suggest that our most widely used interventions are ineffective? Not necessarily. But they don't suggest that they work, either. What they do indicate is that current efforts to establish standards for the certification and funding of batterer treatment programs are premature. We have no data upon which to base recommendations of one type of treatment, intervention, or theoretical approach above another.

Publication characteristics. Published studies had larger effect sizes than studies that were unpublished, suggesting a publication bias. This relationship held up after taking into account year of publication or completion in studies relying on official reports of recidivism. (Conceivably, study age and not publication, per se, could have accounted for differences in effect size if later studies--which have less time to make it to press-remedied methodological weaknesses of earlier studies). Year of publication was too unstable in the presence of outliers for inclusion in analyses of studies relying on partner reports.

Published studies are probably more fully represented than unpublished studies in the present work since unpublished studies are more difficult to identify and obtain. If this is the case, our present estimates of effect size may be too high. For example, two identified between-groups studies that clearly met study inclusion criteria (e.g., large enough $n$ 's, dichotomous measures of recidivism) could not be recovered. In the first case, the author could be not be located with three or fewer phone calls, and in the second 
case, the author considered the data too preliminary for dissemination. Both studies surveyed victims at follow-up and the latter examined criminal records as well; neither found significant effects for treatment. Based on this data alone we might suspect that the current estimates of effect size for studies relying on partner reports and especially criminal records are too high.

Simes (1986), who found a publication bias in a meta-analytic review of research comparing two forms of treatment for ovarian cancer, recommended that an international registry of clinical trials be established to help with study identification and recovery and guard against publication bias. The Association for the Treatment of Sexual Abusers has recently begun to coordinate efforts among sexual violence researchers to compile and organize data sets and bring some conformity to data collection procedures (Hanson et al., 1997). Family violence researchers might consider using field-wide collaborative approaches to documenting research and communicating findings so that valuable data are not lost.

Multivariate models. Two treatment interventions, sex role resocialization and timeout, and length of follow-up accounted for most of the variance in effect size in studies relying on partner reports of recidivism; in an alternative model, publication alone accounted for about $50 \%$ of the variance. Length of follow-up, type of group assignment, and study publication accounted for most of the variance in effect size in studies relying on official reports of recidivism; in an alternative model, two treatment interventions and publication accounted for most of the variance. 


\section{Where Do We Go From Here?}

The field of family violence is fraught with emotion and a sense of urgency. However, in our urgency, we may be settling on--even institutionalizing--interventions that do not work very well. As victims' advocates, lawmakers, treatment providers, and researchers become swept up in current efforts to establish standards for the certification and funding of batterer treatment programs, it is critical that we pause for a moment to consider the effectiveness of the programs we are mandating.

The results of the present meta-analysis suggest that batterer treatment programs are only mildly effective at best in eliminating male-to-female partner violence. This is not good enough. While it is important to foster accountability among programs that offer treatment to men who batter, the current standards probably do a disservice to victims and to the field by insisting on interventions that are sub-optimal, and by stifling innovation and experimentation. There are alternative methods of ensuring program accountability. For instance, programs might be required to clearly document their procedures and interventions, and incorporate an evaluation component into treatment.

Evaluation would allow programs to demonstrate treatment effectiveness, identify when changes are necessary, and potentially contribute to the field's understanding of what works and does not.

\section{References}

An asterisk indicates studies included in the meta-analysis.

*Adams, D., \& McCormick, A. (1982). Men unlearning violence: A group approach based on the collective model. In M. Roy (Ed.), The abusive partner: An analysis of domestic battering (pp. 170-197). New York: Van Nostrand Reinhold. 
Arias, I., \& Beach, S.R.H. (1987). Validity of self-reports of marital violence. $\underline{\text { Journal }}$ of Family Violence, 2, 139-149.

Avis, J.M. (1992). Where are all the family therapists? Abuse and violence in families and the family therapist's response. Journal of Marital and Family Therapy, $\underline{18}$, $225-232$.

*Baum, F., Brand, R., Colley, D., \& Cooke, R. (1987). Preventing family violence: The evaluation of a group of men who are violent toward their partners. Australian Journal of Sex, Marriage, \& Family, $\underline{8}, 173-183$.

*Beninati, J. (1989). Pilot project for male batterers. Social Work with Groups, $\underline{12}, 63$ 74.

*Brannen, S.J. (1994). Effectiveness of gender-specific versus couples' groups in a court-mandated spouse abuse treatment program: A comparative study (Doctoral dissertation, University of Texas at Austin, 1994). Dissertation Abstracts International, 56(02), 704B. (University Microfilms No. AAC 9519251)

Bograd, M. (1992). Values in conflict: Challenges to family therapists' thinking. Journal of Marital and Family Therapy, 18, 245-256.

Campbell, D.T., \& Stanley, J.C. (1963). Experimental and quasi-experimental designs for research. Chicago: Rand McNally College Publishing Company.

${ }^{*}$ Chen, H., Bersani, C., Meyers, S.C., \& Denton, R. (1989). Evaluating the effectiveness of a court-sponsored treatment program. Journal of Family Violence, 4, 309-322.

Cohen, J. (1988). Statistical power analysis for the behavioral sciences (2nd ed.). Hillsdale, NJ: Erlbaum. 
*Davis, R.C., \& Taylor, B.G. (1997, June). A randomized experiment of the effects of batterer treatment: Summary of preliminary research findings. Paper presented at the 5th International Family Violence Research Conference, Durham, NH.

*DeMaris, A., \& Jackson, J.K. (1987). Batterers' reports of recidivism after counseling. Social Casework, $\underline{68}, 458-465$.

*Dobash, R.E., \& Dobash, R.P. (1997). Men's violence and programs focused on change. Current Issues in Criminal Justice, $\underline{8}, 243-262$.

Dickersin, K. (1990). The existence of publication bias and risk factors for its occurrence. Journal of the American Medical Association, 263, 1385-1390.

*Dutton, D.G. (1986). The outcome of court-mandated treatment for wife assault: A quasi-experimental design. Violence and Victims, 1, 163-176.

*Dutton, D.G., Bodnarchuk, M., Kropp, R., Hart, S.D., \& Ogloff, J.R.P (1997). Wife assault treatment and criminal recidivism: An 11-year follow-up. International Journal of Offender Therapy and Comparative Criminology, 41, 9-23.

Dutton, D.G., \& Hemphill, K.J. (1992). Patterns of socially desirable responding among perpetrators and victims of wife assault. Violence and Victims, 7, 29-39.

Eddy, M., \& Myers, T. (1984). Helping men who batter: A profile of programs in the U.S. Texas Department of Human Resources.

Edleson, J.L. (1984). Working with men who batter. Social Work, 29, 237-242.

Edleson, J.L., \& Brygger, M.P. (1986). Gender differences in self-reporting of battering incidents. Family Relations, 35, 377-382. 
*Edleson, J.L., \& Grusznski, R.J. (1989). Treating men who batter: Four years of outcome data from the Domestic Abuse Project. Journal of Social Service $\underline{\text { Research, }}$ 12, 3-22.

*Edleson, J., Miller, D., \& Stone, G.W., \& Chapman, D.G. (1985). Group treatment for men who batter: A multiple baseline design. Social Work Research and Abstracts, 21(3), 18-21.

*Edleson, J.L., \& Syers, M. (1990). The relative effectiveness of group treatment for men who batter. Social Work Research and Abstracts, 26, 10-17.

*Edleson, J.L., \& Syers, M. (1991). The effects of group treatment for men who batter: An 18-month follow-up study. Research in Social Work Practice, 1, 227-243.

Eisenhart, C. (1947). Inverse sine transformation of proportions. In C. Eisenhart, M.W. Haysty, \& W.A. Wallis, (Eds.), Selected techniques of statistical analysis for scientific and industrial research production and management engineering (pp. 395-416). New York: McGraw-Hill.

Eisikovitz , Z.C., \& Edleson, J.L. (1989). Intervening with men who batter: A critical review of the literature. Social Service Review, 384-414.

Fagan, J. (1989). Cessation of family violence: Deterrence and dissuasion. In L. Ohlin \& M. Tonry (Eds.), Family violence. Chicago: University of Chicago Press.

Faulkner, K., Stoltenberg, C.D., Cogen, R., Nolder, M., \& Shooter, E. (1992). Cognitive-behavioral group treatment for male spouse abusers. Journal of Family Violence, $7,37-55$

Feazell, C.S., Mayers, R., \& Deschner, J.P. (1984). Services for men who batter: Implications for programs and policies. Family Relations, 33, 217-223. 
Feld, S.L., \& Straus, M.A. (1990). Escalation and desistance from wife assault in marriage. In M.A. Straus \& R.J. Gelles (Eds.), Physical violence in American families: Risk factors and adaptations to violence in 8,145 families (pp. 489-505). New Brunswick, NJ: Transaction Publishers.

Feldman, C.M., \& Ridley, C.A. (1995). The etiology and treatment of domestic violence between adult partners. Clinical Psychology: Science and Practice, 2, 317-348.

*Flournoy, P.S. (1992). A comparison of groups for men who batter (Doctoral dissertation, Washington State University). Dissertation Abstracts International, 53(11), 5974B. (University Microfilms No. AAC-9309051).

Ganley, A. (1981). Court mandated counseling for men who batter: A three-day workshop. Washington, D.C.: Center for Women's Policy Studies.

Glaser, D. (1973). Routinizing evaluations: Getting feedback on effectiveness on crime and delinquency programs. Rockville, MD: National Institute of Mental Health, U.S. Department of Health, Education, and Welfare.

Goldner, V., Penn, P., Sheinberg, M., Walker, G. (1990). Love and violence: Gender paradoxes in volatile attachments. Family Process, 29, 343-364.

Gondolf, E.W. (1988). The effect of batterer counseling on sheiter outcome. Journal of Interpersonal Violence, 3 , 275-289.

${ }^{*}$ Gondolf, E.W. (1997, June). A comparison of four batterer intervention systems: Do court-referral, program length, and services matter? Paper presented at the 5th International Family Violence Research Conference, Durham, NH. 
* Grusznski, R.J. (1985). Court-ordered treatment of men who batter (Doctoral dissertation, University of Minnesota) . Dissertation Abstracts International, 46(10), 3594B. (University Microfilms No. AAC 8526416).

*Hamberger, L.K., \& Hastings, J.E. (1988). Skills training for treatment of spouse abusers: An outcome study. Journal of Family Violence, 3, 121-130.

Hamberger, L.K., \& Hastings, J.E. (1990). Recidivism following spouse abuse abatement counseling: Treatment program implications. Violence and Victims, $\underline{4}, 275-286$.

Hamberger, L.K., \& Hastings, J.E. (1993). Court-mandated treatment of men who assault their partner: Issues, controversies, and outcomes. In Z. Hilton (Ed.), Legal responses to wife assault (pp. 188-229). Newbury Park, CA: Sage.

Hanson, R. K., Marques, J. K., Quinsey, V. L., Gordon, A., Murphy, W., Seto, M. C., \& Harris, A. (1997, October). Collaborative data base of sex offender treatment outcome. Presentation at the 16th Annual Research and Treatment Conference of the Association for the Treatment of Sexual Abusers, Arlington, VA.

*Harrell, A.V. (1991). Evaluation of court-ordered treatment for domestic violence offenders. Final report submitted to the State Justice Institute. Washington, D.C: The Urban Institute.

*Harris, J. (1986). Counseling violent couples using Walker's model. Psychotherapy, $\underline{23}, 613-621$.

*Harris, R., Savage, S., Jones, T., \& Brooke, W. (1988). A comparison of treatments for abusive men and their partners within a family service agency. Canadian Journal of Community Mental Health, 7, 147-155. 
Hart, B. (1992). Accountability: Program standards for batterer intervention services.

Reading, PA: Pennsylvania Coalition Against Domestic Violence.

*Hawkins, R., \& Beauvais, C. (1986, August). Evaluation of group therapy with abusive men: The police record. Paper presented at the Annual Meeting of the American Psychological Association, Los Angeles, CA.

Hedges, L.V. (1994). Fixed effects models. In H. Cooper \& L.V. Hedges (Eds.), The handbook of research synthesis (pp. 285-299). New York: Russell Sage Foundation.

Johnson, B.T. (1989). DSTAT: Software for the meta-analytic review of research literatures. Hillsdale, NJ: Lawrence Erlbaum Associates.

*Johnson, J.M., \& Kanzer, D.J. (1993). Treating domestic violence: Evaluating the effectiveness of a domestic violence diversion program. Studies in Symbolic Interaction, 15, 271-289.

Jouriles, E., \& O'Leary, K. (1985). Interspousal reliability of reports of marital violence. Journal of Consulting and Clinical Psychology, 53, 419-421.

Kaufman, G. (1992). The mysterious disappearance of battered women from family therapists' offices. Male privilege colluding with male violence. Journal of Marital and Family Therapy, 18, 233-243.

*Klein, P.A. (1992). Efficacy of conjoint group treatment in therapy for spouse abuse (Doctoral dissertation, Pacific Graduate School of Psychology). Dissertation Abstracts International, 53(01), 565B. (University Microfilms No: AAC 9216154). 
*Newell, R.G. (1994). The effectiveness of court-mandated counseling for domestic violence: an outcome study (Doctoral dissertation, University of Toledo). Dissertation Abstracts International, 55(05), 1193A. (University Microfilms No: ACC 9426446).

Maiuro, R.D. (1997, June). Are current standards for the treatment of domestically violent perpetrators adequately informed by research? A question of questions. Paper presented at the 5th International Family Violence Research Conference, Durham, $\mathrm{NH}$.

Massachusetts Guidelines and Standards for the Certification of Batterers' Treatment Programs (1994, May). Unpublished manuscript, Massachusetts Department of Public Health.

National Research Council \& Institute of Medicine. (1998). Violence in families: Assessing prevention and treatment programs. Washington, DC: National Academy Press.

*Palmer, S.E., Brown, R.A., \& Barrera, M.E. (1992). Group treatment program for abusive husbands: Longterm evaluation. American Journal of Orthopsychiatry, $62,276-283$.

*Poynter, T.L. (1989). An evaluation of a group programme for male perpetrators of domestic violence. Australian Journal of Sex, Marriage \& Family, 13(3), 133142.

*Poynter, T.L. (1991). An evaluation of a group programme for male perpetrators of domestic violence: A follow-up study. Australian Journal of Marriage \& Family, 12(2), 64-76. 
Pence, E. (1983). The Duluth Domestic Abuse Intervention Project. Hamline Law Review, $\underline{6}, 247-275$

Pence, E. (1985). Response to Peter Neidig's articles: “Women's shelters, men’s collectives and other issues in the freld of spouse abuse." Victimology: An International Journal, 9, 477-482.

Pence, E., \& Paymar, M. (1993). Education groups for men who batter. New York: Springer.

Petrik, N.D., Gildersleeve-High, L., McEllistrem, J.E., \& Subotnik, L.S. (1994). The reduction of male abusiveness as a result of treatment. Reality or myth? Journal of Family Violence, 9, 307-316.

Pirog-Good, M., \& Stets-Kealey, J. (1985). Male batterers and battering prevention programs: A national survey. Response, 8, 8-12.

Pirog-Good, M., \& Stets, J. (1986). Programs for abusers: Who drops out and what can be done? Response, 2 , 17-19.

*Purdy, F., \& Nickle, N. (1981). Practice principles for working with groups of men who batter. Social Work with Groups, 4 , 111-122.

*Rachor, R.E. (1995). An evaluation of the First Step "Passages" domestic violence program. Journal of Reality Therapy, 14(2), 29-36.

Rice, M.E., \& Harris, G.T. (1995). Violent recidivism: Assessing predictive validity. Journal of Consulting and Clinical Psychology, 63, 737-748.

Roberts, A. (1982). A national survey of services for batterers. In M. Roy (Ed.), The abusive partner (pp.230-243). New York: Van Nostrand Reinhold. 
Rosenbaum, A. (1988). Methodological issues in marital violence research. Journal of Family Violence, $\underline{3}, 91-104$.

*Rosenbaum, A. (1986). Group treatment of battering men: Process and outcome. Psychotherapy, 23, 607-612.

*Rosenbaum, A., Gearan, P.J., \& Ondovic, C. (1997, June). Completion and recidivism among court- and self-referred batterers in a psychoeducational group treatment program: Implications for intervention and public policy. Paper presented at the 5th International Family Violence Research Conference, Durham, NH.

Rosenfeld, B.D. (1992). Court-ordered treatment of spouse abuse. Clinical Psychology $\underline{\text { Review, } 12,205-226 .}$

Rosenthal, R. (1994). Parametric measures of effect size. In H. Cooper \& L.V. Hedges (Eds.), The handbook of research synthesis (pp. 231-244). New York: Russell Sage Foundation.

Rossi, J.S. (1985). Tables of effect size for Z score tests of differences between proportions and between correlation coefficients. Educational and Psychological Measurement, $\underline{45}, 737-743$.

Saunders, D.G (1984). Helping husbands who batter. Social Casework, 65, 347-353.

Saunders, D.G. (1988). Issues in conducting treatment research with men who batter. In G.T. Hotaling, D. Finkelhor, J.T. Kirkpatrick, \& M.A. Straus (Eds.), Coping with family violence: Research and policy perspectives. Newbury Park: Sage

*Saunders, D.G. (1989). Cognitive-behavioral interventions with men who batter: Applications and outcome. In P.L. Caesar \& L.K. Hamberger (Eds.), Treating 
men who batter: Theory, Practice, and Programs (pp. 77-100). New York: Springer.

*Saunders, D.G. (1996). Feminist-cognitive-behavioral and process-psychodynamic treatments for men who batter: Interaction of abuser traits and treatment models. Violence and Victims, 11, 393-413.

Saunders, D.G., \& Azar, S.T. (1989). Treatment programs for family violence. In L. Ohlin \& M. Tonry (Eds.), Family violence (pp. 481-546). Chicago: University of Chicago Press.

Shadish, W.R., \& Haddock, C.K. (1994). Combining estimates of effect size. In H. Cooper \& L.V. Hedges (Eds.), The handbook of research synthesis (pp. 261-281). New York: Russell Sage Foundation.

*Shepard, M. (1987, July). Intervention with men who batter: An evaluation of a domestic abuse program. Paper presented at the Third National Conference for Family Violence Researchers, Durham, NH.

*Shepard, M. (1992). Predicting batterer recidivism five years after community intervention. Journal of Family Violence, 1, 167-178.

Shepard, M.F., \& Campbell, J.A. (1992). The Abusive Behavior Inventory: A measure of psychological and physical abuse. Journal of Interpersonal Violence, 7, 291305.

*Shupe, A., Stacey, W., \& Hazelwood, L. (1987). Violent men, violent couples: The dynamics of domestic violence. Lexington, MA: Lexington Press.

Straus, M.A. (1979). Measuring intrafamily conflict and violence: The Conflict Tactics (CT) Scales. Journal of Marriage and the Family, 41,75-88. 
Straus, M.A. (1990). The Conflict Tactics Scales and its critics: An evaluation and new date on validity and reliability. In M.A. Straus \& R.J. Gelles (Eds.), Physical violence in American families: Risk factors and adaptation to violence in 8,145 families. New Brunswick, NJ: Transaction Publishers.

Straus, M.A., \& Gelles, R.J. (1990). How violent are American families? Estimates from the National Family Violence Resurvey and other studies. In M.A. Straus \& R.J. Gelles (Eds.), Physical violence in American families: Risk factors and adaptations to violence in 8,145 families (pp. 95-112). New Brunswick, NJ: Transaction Publishers.

Straus, M.A., Gelles, R.J., \& Steinmetz, S.K. (1980). Behind closed doors: Violence in American families. New York: Anchor Press/Doubleday.

Sugarman, D.B., \& Hotaling, G.T. (1989). Dating violence: prevalence, context, and risk markers. In M.A. Pirog-Good \& J.E. Stets (Eds.), Violence in dating relationships: Emerging social issues (pp. 3-32). New York: Praeger.

*Shepard, M. (1987, July). Intervention with men who batter: An evaluation of a domestic abuse program. Paper presented at the Third National Conference for Family Violence Researchers, Durham, NH.

*Shepard, M. (1992). Predicting batterer recidivism five years after community intervention. Journal of Family Violence, $\underline{7}, 167-178$.

Simes, R.J. (1986). Publication bias: The case for an international registry of clinical trials. Journal of Clinical Oncology, $\underline{4}, 1529-1541$.

Szinovacz, M.E. (1983). Using couple data as a methodological tool: The case of marital violence. Joumal of Marriage and the Family, 45, 633-644 
Tolman, R.M. \& Bennett, L.W. (1990). A review of quantitative research on men who batter. Journal of Interpersonal Violence, $\underline{5}, 87-118$.

*Tolman, R.M., \& Bhosley, G. (1991). The outcome of participation in a sheltersponsored program for men who batter. In D.D. Knudsen \& J.L. Miller (Eds.), Abused and battered: Social and legal responses to family violence (pp. 113-122). New York: Aldine de Gruyter.

Tolman, R.M., \& Edleson, J.L. (1995). Effectiveness of batterer intervention. In S.R. Stith \& M.A. Straus (Eds.), Understanding partner violence: Prevalence, causes, consequences, and solutions (pp. 262-273??). Minneapolis, MN: National Council on Family Relations.

Waldo, M. (1986). Group counseling for military personnel who battered their wives. Journal for Specialists in Group Work, 9, 132-138.

*Waldo, M. (1988). Relationship enhancement counseling groups for wife abusers. Journal of Mental Health Counseling, 10, 37-45.

Wampold, B.E., Mondin, G.W., Moody, M., Stich, F., Benson, K., \& Ahn, N. (1997). A meta-analysis of outcome studies comparing bona fide psychotherapies: Empirically, "All must have prizes." Psychological Bulletin, 122, 203-215. Walker, L. (1979). The battered woman. New York: Harper \& Row Zamora, E. (December, 1995). State statutes regarding mandatory treatment for batterers and treatment program Standards. Minneapolis, MN: Criminal Justice Center, Battered Women's Justice Project. 


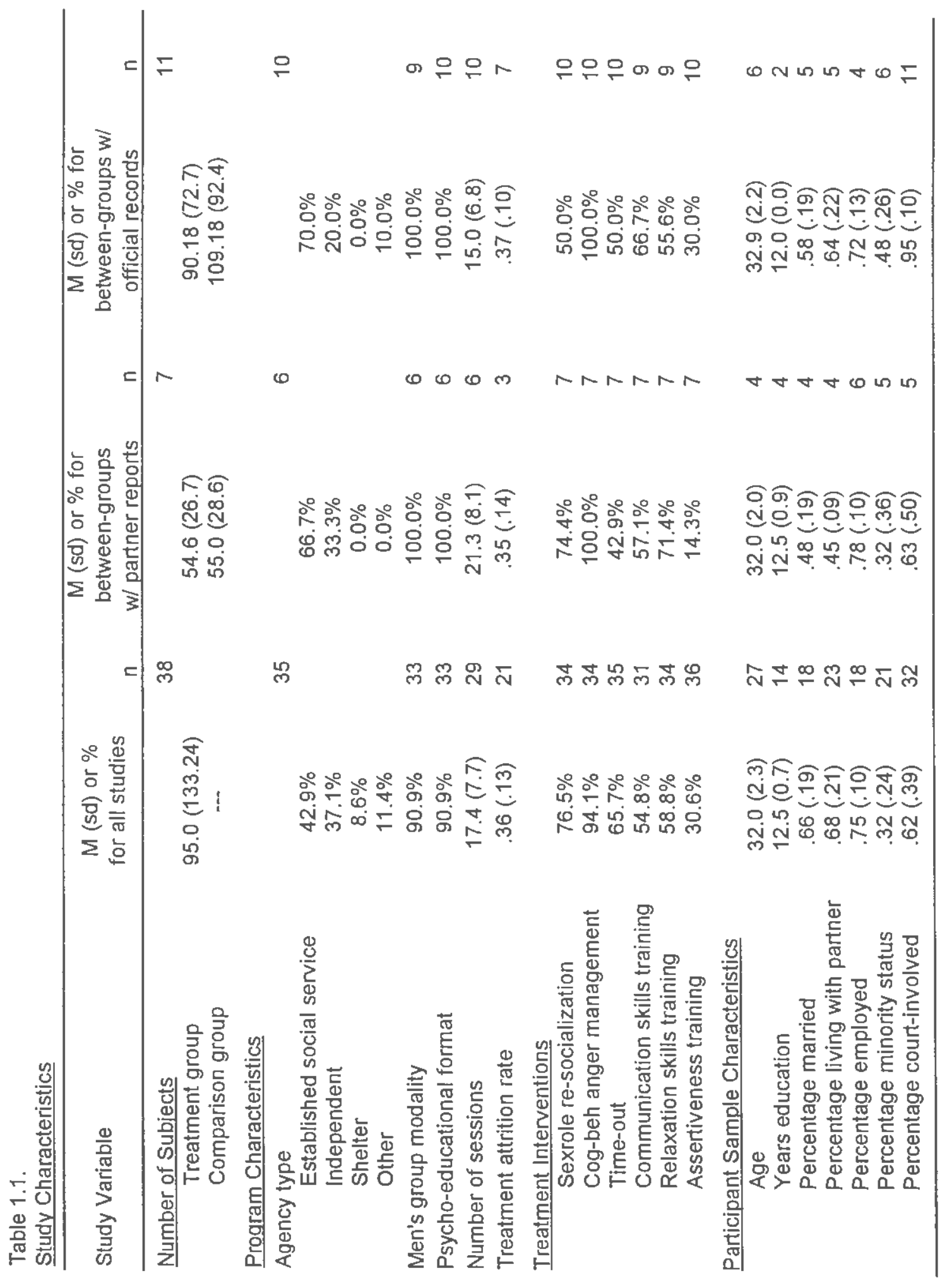




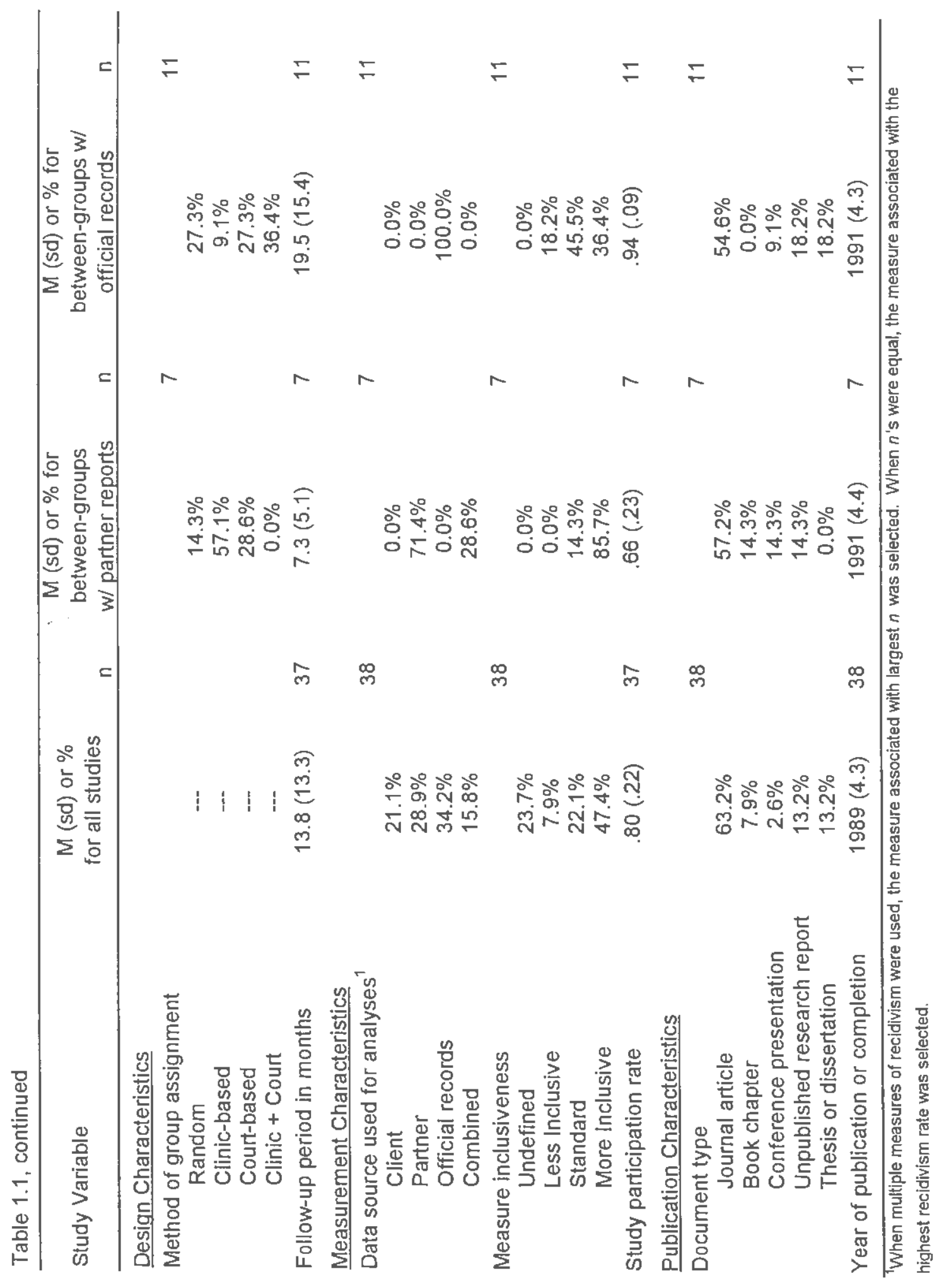


Table 1.2.

Weighted Least Squares Multiple Regressions of Study Characteristics on Treatment Effect Size in Between-Groups Studies Relying on Partner Reports of Recidivism

Zero-Order Correlations

$\begin{array}{lll}B & \beta & Z\end{array}$

Intervention Characteristics ( $n=7)$

\begin{tabular}{rrr}
\hline Effect & 1 & 2 \\
\hline-.57 & & \\
-.65 & .16 & \\
.23 & -.59 & .29
\end{tabular}

1 Sexrole resocialization

2 Time-out

$23-.59$

.29

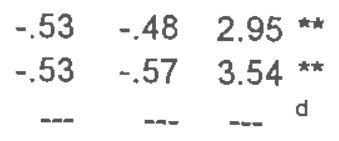

$R^{2}=.65$

Adjusted $R^{2}=.48$

Constant $=.77$

$$
\begin{aligned}
R & =.81^{\star \star} \\
Q_{E} & =13.51
\end{aligned}
$$

Design Characteristics $(n=7)$

1 Clinic-based assignment

2 Follow-up period (sq root)

$R^{2}=.28$

Adjusted $R^{2}=.13$

$R=.53^{\text {* }}$

$Q_{E}=27.99$

$\overline{\text { Effect } 1}$

.45

$.53 \quad .68$

$\begin{array}{llll}-- & -.- & \ldots & d\end{array}$

$.32 \quad .53 \quad 3.27$ \#

Constant $=-.71$

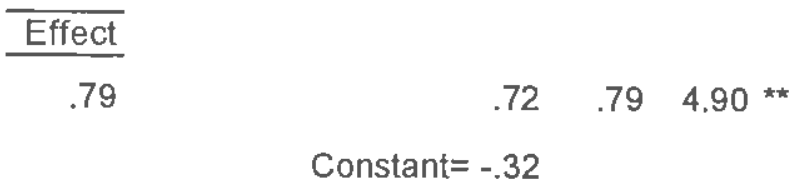

Adjusted $R^{2}=.54$

$R=.79^{\star \star}$

$Q_{E}=14.84$

Final Model $(n=7)$

1 Sexrole resocialization

2 Timeout

3 Follow-up period (sq root)

4 Published

$R^{2}=.83$

Adjusted $R^{2}=.66$

$R=.91^{\text {\#\# }}$

$Q_{E}=6.56^{\mathrm{f}}$

\begin{tabular}{llll}
\hline Effect & 1 & 2 & 3 \\
\hline
\end{tabular}

$-.57$

$-.65 \quad .16$

$\begin{array}{lll}.53 & -.02 & -.17\end{array}$

$\begin{array}{lll}.79 & -.50 & -.83\end{array}$ $\begin{array}{lll}-.53 & -.48 & 2.96\end{array}$

$\begin{array}{lll}-.46 & -.50 & 3.04 * \star\end{array}$

$.26 \quad .43 \quad 2.64$ *k

Constant $=-.10$

${ }^{\star} p<.05$

** $p<.01$

${ }^{f}$ hypothesis of model fit retained

deleted to reduce multicollinearity 
Table 1.3.

Weighted Least Squares Multiple Regressions of Study Characteristics on Treatment Effect Size in Between-Groups Studies Relying on Official Reports of Recidivism

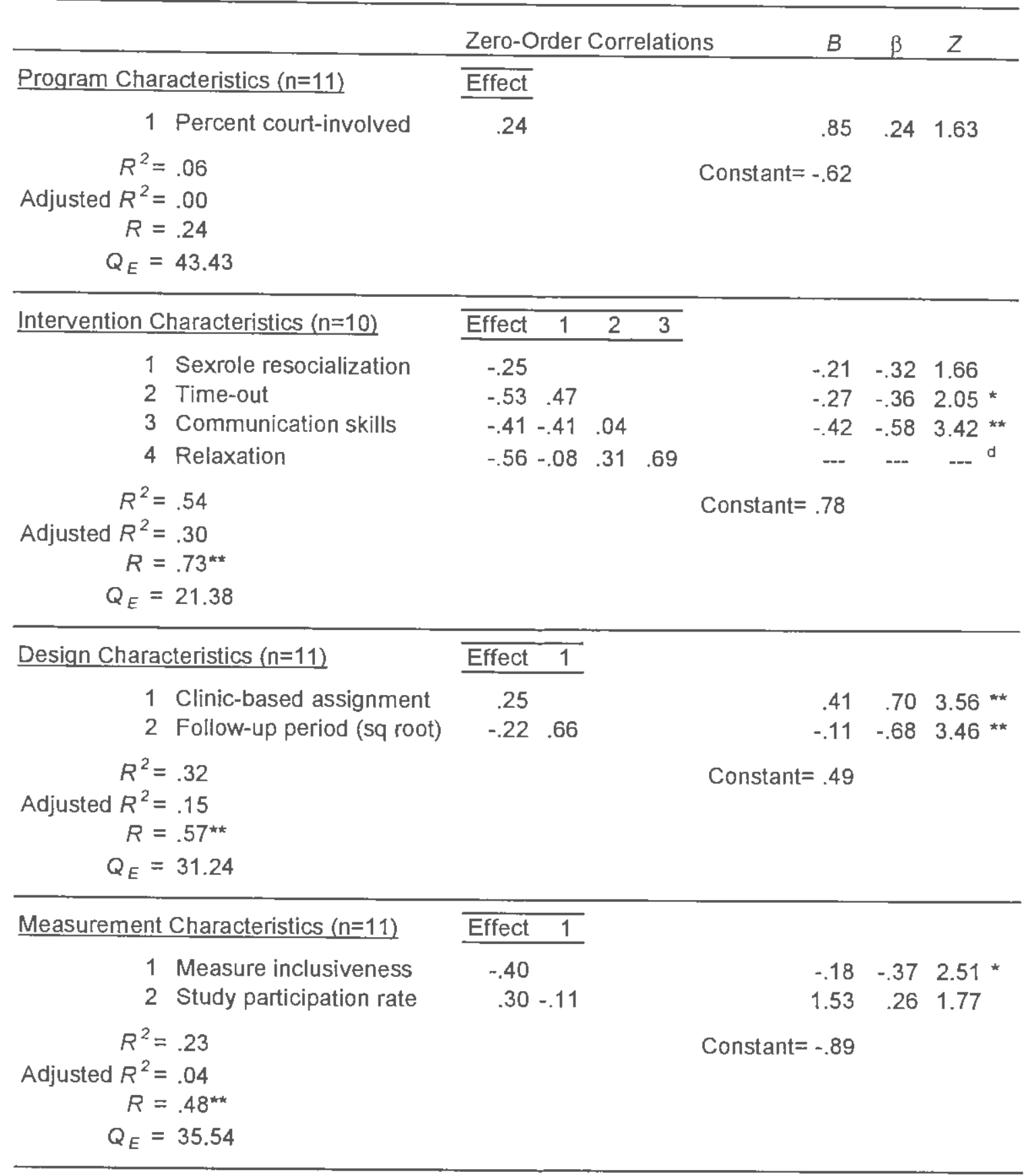


Table 1.3, continued

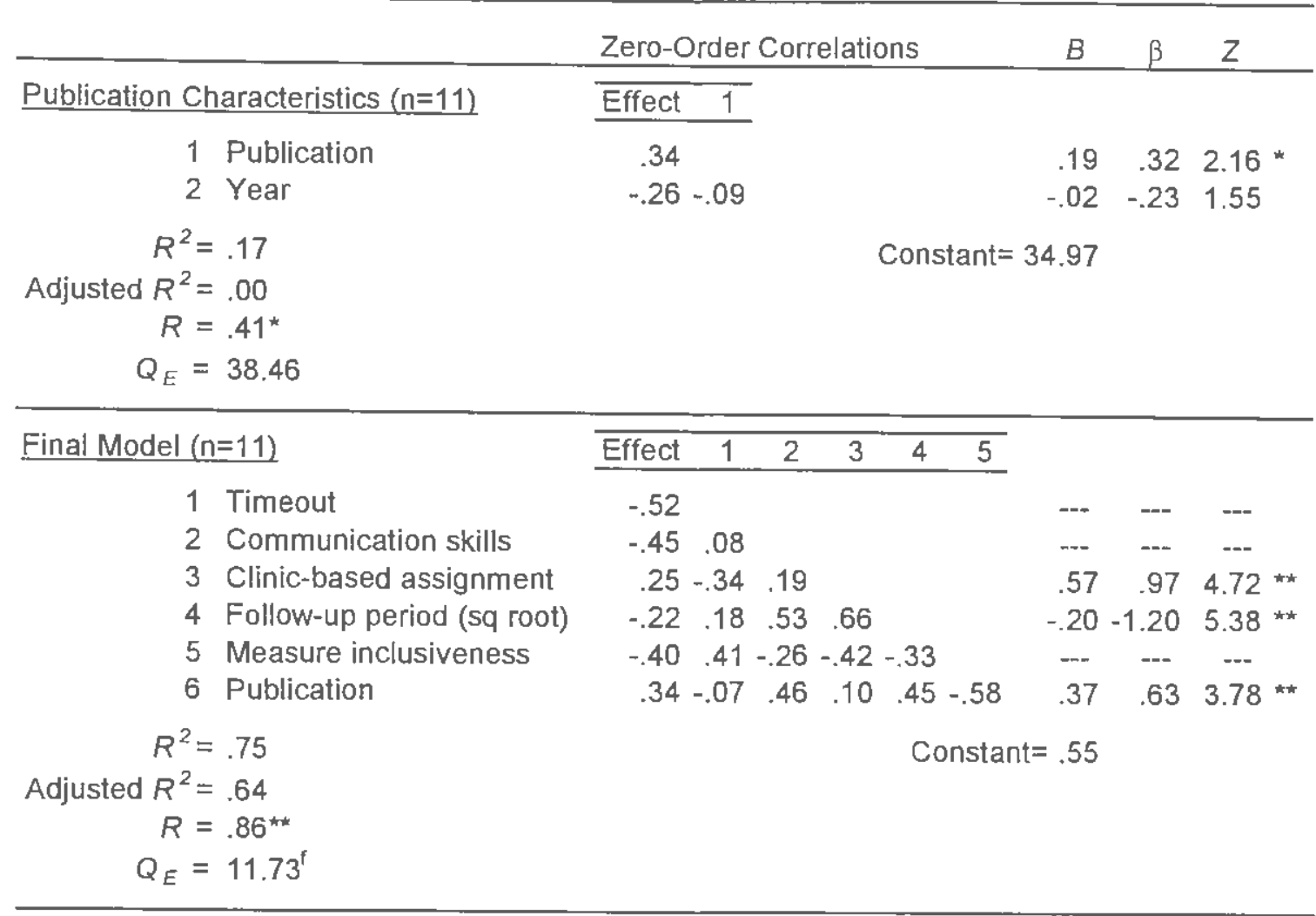

${ }^{*} \mathrm{p}<.05$

${ }^{* \star} p<.01$

' hypothesis of model fit retained

a deleted to reduce multicollinearity 
Table 1.4.

Weighted Least Squares Multiple Regressions of Study Characteristics on Recidivism Rates

Zero-Order Correlations

\begin{tabular}{|c|c|c|c|c|c|}
\hline \multirow{2}{*}{ Design Characteristics ( $n=38$ ) } & \\
\hline & Effect & 1 & & & \\
\hline 1 Between-groups study & -.17 & & -.07 & -.23 & 1.83 \\
\hline 2 Follow-up period (sq root) & .16 & .28 & .02 & .22 & 1.75 \\
\hline
\end{tabular}

$R^{2}=.08$

Constant $=.16$

Adjusted $R^{2}=.02$

$R=.28$

$Q_{E}=61.79$

Measurement Characteristics $(n=38)$

Effect $11 \overline{2}$

1 Measure inclusiveness

.37

$\begin{array}{lll}.38 & -.19\end{array}$

$\begin{array}{lll}-.16 & -.16 & -.45\end{array}$

Constant $=.15$

Adjusted $R^{2}=.30$

3 Study participation rate

$R^{2}=.36$

$R=.60^{\text {*t }}$

$Q_{E}=42.937^{\mathrm{f}}$

Publication Characteristics $(n=38)$

1 Published

2 Year

$R^{2}=.03$

Adjusted $R^{2}=.00$

$R=.18$

$Q_{E}=64.80$

\begin{tabular}{rr}
\hline Effect & 1 \\
\hline .04 & \\
-.17 & -.48
\end{tabular}

$\begin{array}{lll}-.02 & -.06 & 0.42\end{array}$

$\begin{array}{lll}-.01 & -.20 & 1.63\end{array}$

onstant $=12.31$

Final Model $(n=38)$

1 Measure inclusiveness

2 Partner reports

$\begin{array}{lll}.08 & .45 & 3.64\end{array}$

$.13 \quad .46 \quad 3.72$ **

$R^{2}=.34$

Adjusted $R^{2}=.30$

Constant $=.-.02$

$R=.58^{* *}$

$Q_{E}=44.19^{f}$

* $p<.05$

${ }^{\star \star \star} p<.01$

${ }^{f}$ hypothesis of model fit retained 


\section{CHAPTER 2}

The Neglect of Individual Change Principles and Strategies in Social Change Efforts:

A Case for the Application of the Transtheoretical Model of Change

to the Problem of Male-to-Female Partner 


\section{Introduction}

Male-to-female partner violence poses a major threat to the physical and emotional well-being of women. Data from the 1992-1993 National Crime Victimization Survey of a representative sample of approximately 60,000 US households indicate that each year 9 in 1,000 females age 12 or older are assaulted by a past or present spouse or partner. Over $50 \%$ of victims sustain injuries in their assaults, and over $20 \%$ seek medical attention for their injuries (Bachman \& Saltzman, 1995). The 1992 National Family Violence and Alcohol Survey of 1,970 married and cohabiting couples found the annual rate of male-to-female intimate violence to be far higher: during the year of the study, 111 per 1,000 women experienced some degree of violence at the hands of a partner, and 19 per 1,000 experienced severe violence likely to cause injury (Straus \& Kaufman Kantor, 1992). Male-to-female intimate violence accounts for $26 \%$ of violence-related injuries in women presenting in hospital emergency departments (Rand, 1997 ) and $30 \%$ of adult female homicides (Federal Bureau of Investigation, 1997). The psychological sequelae of partner violence include post-traumatic stress disorder (Astin, Lawrence, \& Foy, 1993; Astin, Ogland Hand, Coleman, \& Foy, 1995; Browne, 1993; Dutton, 1992; Gleason, 1993; Houskamp \& Foy, 1991; Kemp, Green, Hovanitz, \& Rawlings, 1995; Kemp, Rawlings, \& Green, 1991; Saunders, 1994; Vitanza, Vogel, \& Marshall, 1995; West, Fernandez, Hillard, Schoof, \& Parks, 1990), and elevated levels of somatic disturbances, depression, and suicide attempts (Campbell, Kub, Belknap, \& Templin, 1997; Gelles \& Harrop, 1989; Gleason, 1993; Jaffe, Wolfe, Wilson, \& Zak, 1986; McCauley et al,, 1995; Riggs, Kilpatrick, \& Resnick, 1992; Sato \& Heiby, 1992;

Straus \& Smith, 1990; Vitanza, Vogel, \& Marshall, 1995; Walker,1991). 
The problem of male-to-female partner violence has gained recognition as a major public health problem only in the last 25 years. In 1974, in the introduction to the first book reporting on research on the topic of domestic violence, Straus described researchers' "perceptual blackout" of wife abuse, and adherence to beliefs that the family is by nature non-violent (Straus, 1974). In the 1970's, studies began to chart the prevalence of wife abuse and its socio-demographic risk factors (Straus, Gelles, \& Steinmetz, 1980). Arising from the data were the first theories explaining how men develop and maintain violent behavior. According to the social learning/structural theory, violent behavior is learned early in life, when children experience or observe familial aggression, and is more prevalent in social structures high in stress, such as lowincome families (Gelles, 1974). The exchange/social control theory postulated that individuals use violence as long as rewards outweigh the costs. Given the privacy of the family and the absence of effective social controls, the costs of violence historically have remained low (Gelles, 1983; Gelles \& Straus, 1979).

The battered women's movement, which emerged from the women's liberation movement in the 1970's, was perhaps most instrumental in raising violence against women in public consciousness. Its leaders criticized early learning theories and other causal models of violence, stating, "In individual cases, such factors may contribute to abuse or heighten the likelihood of its occurrence, but they do not explain the consistent target--women. The task is to discover what social conditions produce this target generation after generation" (Schechter, 1982, p. 216). The movement articulated clearly, and with emotional appeal, what has become the prevailing conceptualization of male-tofemale partner violence: violence against women is a problem that has existed for 
centuries, rooted in the patriarchal belief that men have the right to dominate women, and supported by societal norms and institutions. Violence and the threat of violence serve to maintain power and control (Martin, 1976; Dobash \& Dobash, 1979).

The first interventions--hot lines, crisis centers, and refuges or shelters--seemed to meet the immediate needs of women in crisis. Following the founding of the first battered women's shelter, Chiswick Women's Aid in a London suburb in 1971 (Pizzey, 1974), shelters proliferated in Europe and US, primarily through the efforts of the women's movement and, then, the battered women's movement. Shelters provide sanctuary and emotional support for battered women and their children, and may offer counseling, treatment referral, legal aid advocacy, professional skills training and a variety of other services as well (Johnson, Crowley, \& Sigler, 1992; Roberts, 1981). Often, the implicit goals of sheltering are to provide battered women with a political understanding of male violence, and to empower women to leave their relationships permanently. However, studies examining shelter outcomes find that between $30 \%$ and $80 \%$ of the women who seek shelter return to their partners and the risk of further violence (e.g., Herbert, Silver, \& Ellard, 1991--34\%; Johnson, 1992--81\%; Okun, 1988-70\%; Rounsaville, 1978--68\%; Strube \& Barbour, 1984--30\%). Furthermore, women who do leave their violent partners face increased risk of homicide during the first two months following separation, as their partners seek them out with rage and desperation (Wilson and Daly, 1993). Finally, it is commonly believed that when a woman leaves, her abuser simply moves on to other victims in a process that has been termed "displacement" (Fagan, 1989). If this is the case, sheltering and other attempts to remove victims from danger may have little impact on the prevalence of intimate violence in our 
society. Although shelters provide valuable, even lifesaving services for victims, interventions must be directed at the batterers themselves if the extent of violence against women is to be reduced.

The battered women's movement, however, historically has viewed male-tofemale partner violence as a socio-political problem, and society--not batterers--as the principal target of intervention (Dobash \& Dobash, 1979; Martin, 1976; Schechter, 1982). It sees little possibility of real change in men as long as societal structures, norms, and policies continued to condone and reinforce male domination and control of women. Men simply have too much to gain and too little to lose from their violence. Over the last 20 years the movement has worked to win the support of law makers and bring about significant legislative and policy reform to increase protection and services for victims, toughen criminal sanctions for offenders, and communicate clearly that intimate violence against women is unacceptable. However, as we will see, social change can be slow and unpredictable; it may not translate quickly or reliably into changes in individual behavior.

The present chapter examines two interventions for battering men that evolved out of the social change efforts of the battered women's movement--court-mandated treatment and arrest--and summarizes research on their efficacy. It is argued that these potentially powerful individual-level interventions are of limited efficacy and may in some cases be detrimental to the welfare of women for the following reasons: 1) they are based on a socio-political understanding of violence and change rather than empirically validated theories of individual behavior change; 2) they tend to be codified in state law, standardized, and "one size fits all," neglecting individual differences in attitudes toward 
violence and readiness to change; 3) they tend to be confrontational and coercive, and thus run the risk of alienating and angering men who may benefit from more rehabilitative approaches. The key assumption of the paper is that successful social change requires individual change; successful individual change in this case requires a better understanding of how, when, and why men end their violence against their partners.

In the last 15 years the Transtheoretical Model of Change has been shown to be remarkably robust in its ability to explain individual change across a variety of addictions and other maladaptive behaviors which, like partner violence, are considered to be major public health problems (e.g., DiClemente \& Hughes, 1990; Prochaska \& DiClemente, 1983; Prochaska, Norcross, Fowler, Follick, \& Abrams, 1992; Prochaska, Redding, Harlow, Rossi, \& Velicer, 1994). The Transtheoretical Model integrates a number of theoretical constructs central to change: stages of change, processes or strategies of change, decisional balance (Janis \& Mann, 1977), and self-efficacy (Bandura, 1977). A large body of empirical data supports the validity of the model's theoretical constructs as well as the hypothesized relationships between them. Experts in the field have already begun to anticipate the model's usefulness in enhancing the motivation of batterers in group treatment (Begun et al., 1997; Daniels \& Murphy, 1997; Dutton, 1995; Dutton, Bodnarchuk, Kropp, Hart, Ogloff, 1997; Levesque \& Gelles, 1997; Levesque, Gelles, \& Velicer, 1997; Murphy \& Baxter, 1997), in understanding college women's decisions to leave violent dating relationships (Levesque, 1995), and in facilitating change among battered women seeking sheiter services (Brown, 1997). The present chapter goes one step further and examines how the Transtheoretical Model of 
Change and social change approaches can be systematically integrated in a synergistic fashion to increase the speed and success of change at both the individual and social levels.

\section{The Evolution of Interventions for Battering Men}

\section{Early Treatment Programs}

As the shelter movement burgeoned, shelter workers received more and more requests for treatment from batterers themselves. In 1976, Chiswick Women's Aid established Men's Aid House, the first facility to address the needs of battering men (Deschner, 1984). It closed down two years later for lack of funding. In April, 1977, at the urging of Boston shelter workers, eight men formed the first US program exclusively for battering men, the Emerge Collective (Adams \& McCormick, 1982). Blending social learning theory and feminist ideology, Emerge viewed partner violence as the product of learning that begins around preschool age and is reinforced throughout the lifespan. The training ground is not limited to the family, but includes all of society that inculcates sexist male attitudes and behaviors. The goals of treatment were to help men recognize their responsibility for violent behavior, question their socialized ideas about sex roles, and become more attuned to their emotional needs and dependence on women. Emerge chose an unstructured group format to foster development of interpersonal skills and ease isolation.

In the 1980's programs became more structured and psychoeducational in nature (e.g., Edleson, 1984; Ganley, 1981; Pence, 1983; Saunders, 1984). Most were timelimited, ranging from 6 to 32 weeks in duration (Eisikovits \& Edleson, 1989; Tolman \& Bennett, 1990). Programs continued to endorse a pro-feminist analysis of partner 
violence. Indeed, a central goal of treatment was to "resocialize" men by confronting them about patriarchal sex role expectations and the acceptability of violence. However, a growing number of programs (e.g., Ganley, 1981; Edleson, 1984; Purdy \& Nickle, 1982; Saunders, 1984) also began to draw from general theories of aggression, such as Bandura's social learning theory (1973), to integrate cognitive-behavioral interventions, such as Novaco's stress inoculation techniques for anger management (1975) and Ellis's cognitive restructuring to reduce irrational beliefs (1970), and to help men develop selfcare, assertiveness, relaxation, and communication skills.

Debates raged over the new directions treatment was taking. Jennings (1987) criticized the structured psychoeducational approach because it assumes that batterers are incapable of insight, and limits therapists' ability to tailor individual sessions to men's needs. Jennings (1990) also stated that programs expect too much from men in too little time, and do not prepare them adequately in relapse prevention. Gondolf (1987) complained that the various interventions for batterers have competing goals, and are administered in a piecemeal fashion in the absence of an integrative theory of change. Furthermore, cognitive-behavioral techniques merely provide a "quick fix," allowing men to maintain underlying patriarchal attitudes and continue more subtle forms of abuse (Gondolf \& Russell, 1986; also see Tolman \& Saunders, 1988). When 33 batterers from a model program were asked to report on the strategies that worked best for them in ending their violence, those relying most heavily on anger management strategies reported the fewest insight-oriented and help-seeking strategies, raising further concern about anger management. However, not a single man surveyed reported that he found that sex role resocialization strategies worked best (Gondolf, 1988a). In the last decade 
the field has made little progress in determining what works (Levesque, this volume; National Research Council \& Institute of Medicine, 1998).

\section{Men Can't Change}

Despite their early involvement in the development of programs for assaultive men, many battered women's advocates questioned whether battering men could benefit from treatment. Early qualitative research contributed to this pessimistic view of men's capacity to change. Based on interviews with battered women in shelters, Walker (1979) proposed that violence is cyclical, characterized by repeating periods of tension building, acute battering, and contrition, and that it necessarily increases in frequency and severity over time; any lulls in the violence are short-lived, merely part of the cycle. Advocates may also underestimate men's capacity for change because the battered women's movement historically has viewed intimate violence as a structural social problem (Dobash \& Dobash, 1979, 1992; Martin, 1986; Schechter, 1982). This position creates a catch-22 for men who are asked to take responsibility for their violence while hearing messages that powerful social forces make personal change unlikely. In addition, advocates are experts in social change, not individual change. In fact, social change strategies and interventions prevail over more traditional behavior change strategies and interventions in batterer programs closely aligned with the advocacy movement. For example, in one of the nation's model programs for battering men, the Domestic Abuse Intervention Program in Duluth, Minnesota, clients are asked to view partner violence as a socio-political issue, and not a merely a personal one; in a confrontational environment, their sexist attitudes and beliefs are exposed and challenged as a profeminist world view is presented (Pence, 1983; Pence \& Paymar, 1993). Some profeminist counselors even 
insist that rehabilitation be considered complete only when abusers become activists and take some form of social action to address the problem of male domination and control over women (Gondolf, 1987). If advocates had greater interest and expertise in individual change, they might hold out more optimism for such change.

Data from the 1985 Second National Family Violence Survey of 6,002 households and a 12-month follow-up (Feld \& Straus, 1990) suggest that a sizeable percentage of batterers can and do end their violence, even without formal intervention. Forty-two percent of the men who severely assaulted their female partners during the year prior to the survey committed no more assaults the following year. Although it is possible that these men at the time of follow-up were in what Waiker (1979) calls the "contrition phase" of the cycle of violence, the lack of violence likely represents more permanent desistance, at least in some men. Advocates, however, have continued to underestimate men's capacity for positive, intentional change. In an interview for a 1992 New York Times Magazine story about partner violence, Ellen Pence, founder of the Domestic Abuse Intervention Program, advised female victims to "...Leave. Leave because even the best programs, even Duluth's, cannot insure that a violent man will change his ways" (Hoffman, cited in Satel, 1997).

Arrest

The battered women's movement has viewed legislation, or the "force of law," as the primary vehicle for change (Martin, 1987, p. 16). Despite prior periods of social and legal reform, the criminal justice system and policy makers in the early 1970 s remained ambivalent about intervening in the private sphere of the family and limiting the traditional rights of husbands. Arrest, prosecution, and conviction for partner violence 
were rare, and sentences for batterers were lighter than sentences for other violent offenders. Restraining orders were available only if women were willing to file for a divorce (Fagan, 1996; Hilton, 1993; Pleck, 1989; Schechter, 1982). In the feminist view, social institutions collude with battering men to maintain male power and control over women (Dobash \& Dobash, 1992; Ritmeester \& Pence, 1992).

Grass roots activists publicized the experiences of battered women through radio, television, marches and rallies. Banding in state coalitions, activists lobbied for shelter funding, and for statutory and policy changes that placed the protection of women above the privacy and sanctity of the family: they wanted batterers arrested and punished to communicate clearly that violence against family members is unacceptable and will be treated like other violent crimes. They also organized class-action law suits and threats of suits against police departments that failed to protect battered women who sought their help (Ferraro, 1989; Buzawa \& Buzawa, 1990; Schechter, 1982). By the late 1970's, states began expanding police powers to permit presumptive arrest without a warrant for misdemeanor domestic assault, as long as it appeared likely that an offense had occurred. Previously, in most states arrest had been possible only if officers had witnessed the assault. By the late 1970's, orders of protection became available to female victims of partner violence on an emergency basis.

During this same period, deterrence theory was gaining popularity among police administrators and academicians (Blumstein, Cohen, \& Nagin, 1978; Gibbs, 1975), and the criminal justice system was beginning to impose stricter penalties for many types of offenses (Buzawa \& Buzawa, 1990, 1993; Mederer \& Gelles, 1989; Fagan, 1996). According to deterrence theory, arrest and other sanctions discourage criminal activity 
among offenders (specific deterrence) and potential offenders (general deterrence) by increasing fear of punishment. The exchange/social control theory of domestic violence (Gelles, 1983; Gelles \& Straus, 1979), which incorporates deterrence theory, would predict arrest to have specific and general deterrent effects because it increases the costs of violence relative to its rewards.

Feminists' efforts to criminalize partner violence were initially bolstered by data from the Minneapolis Police Experiment showing the specific deterrent effect of arrest among offenders (Sherman $\&$ Berk, 1984). In this study funded by the National Institute of Justice to test deterrence theory, Minneapolis police officers responding to misdemeanor domestic violence calls randomly assigned suspects to one of three experimental conditions: arrest, separation, or advice/mediation. Six months later, criminal records were examined, and interviews with victims were conducted to assess recidivism. The study found the lowest rate of subsequent violence for the arrest condition (10\%), followed by the separation (19\%) and advice/mediation conditions (24\%). The results, publicized both in scholarly journals and in the mass media, were followed by a request by the US Attomey General's Task Force on Family Violence that police departments and the criminal justice system recognize family violence as a serious offense and respond with arrest and prosecution (1984). At least 27 states and the District of Columbia now have laws mandating arrest in cases of misdemeanor domestic assault when there is probable cause; the remaining states allow arrest without a warrant (Violence Against Women Office, 1996).

Court-Mandated Treatment 
To handle the influx of cases brought by the new mandatory and presumptive arrest laws, the courts began to experiment with mandatory batterer treatment as a sentencing alternative for men convicted of domestic assault and battery, or as a condition of deferred judgment or an order of protection. With such a viable sentencing alternative, police, prosecutors, and judges could now arrest and convict even first-time offenders (Ganley, 1987; Pence 1989; Soler, 1987; Dutton, 1986; Harrell, 1991). In 1985, an estimated 89 programs existed nationwide (Pirog-Good and Stets-Kealey, 1985). Although there have been no published estimates since that time, it is probably safe to say that program prevalence has increased at least 10-fold. Rhode Island has 17 programs, approximately 18 programs per million residents. Today, eight states have statutes mandating treatment for men convicted of domestic assault and battery, or as a condition of deferred judgment or an order of protection, and four states have statutes allowing treatment as a sentencing option (Zamora, 1995).

Given battered women's movement's skepticism about men's capacity for change, it is ironic that its social change efforts created a growing reliance on behavior change interventions for batterers. Uncomfortable with this development, domestic violence coalitions have worked to establish state standards for batterer program certification-ostensibly to assure program quality and accountability, but also to assure that programs are organized around the movement's socio-political principles and goals. For example, the Massachusetts Guidelines state that while psychodynamic, cognitive-behavioral, and other approaches and interventions "may, from time to time, be incorporated into a treatment model that focuses on power and control in relationships, they are inadequate and inappropriate if they stand alone as the focus of treatment" (Massachusetts 
Guidelines and Standards for the Certification of Batterers" Treatment Programs, Section $4.6,1994)$. Twelve states now have standards for certification or funding, two have recommended standards, and twelve have standards under development (Zamora, 1995).

\section{The Success of Social and Individual Change Interventions}

\section{Policy Changes}

The success of the social change efforts of the battered women's movement is perhaps best reflected in the historic Violence Against Women Act (VAWA), passed in 1994 as part of the Violent Crime Control and Law Enforcement Act. The VAWA represents lawmakers" commitment to end domestic violence and other "gendermotivated" violence (p. 3). For example, the Act appropriated $\$ 325$ million to support battered women's sheiters through the year 2000 , and $\$ 110$ million between 1996-1998 for state grants to encourage mandatory arrest and pro-arrest policies and programs for men who assault their partners or violate orders of protection. The Act makes it a federal offense for abusers to cross state lines for the purpose of harassing or injuring an intimate partner or violating a restraining order. It also provides for the development of a research agenda by the National Research Council of the National Academy of Sciences, which established the Panel on Research on Violence Against Women in 1995 to review the major literature and formulate research recommendations (National Research Council, 1996). It is important to note that despite the criminal justice system's growing reliance on mandated treatment as a sentencing option for assaultive men, the VAWA makes no provisions for the development, maintenance, evaluation, or monitoring of rehabilitative programs--and in fact makes no mention of them whatsoever in the legislative code-- 
betraying the movement's skepticism about batterers' ability to change, even with the help of treatment.

The impact of the social change efforts of the battered women's movement on the prevalence of violence over the last 20 years is less evident. Comparisons of data from national family violence surveys conducted by researchers at the University of New Hampshire in 1976 (Straus, Gelles, \& Steinmetz, 1980), 1985 (Straus \& Gelles, 1986), and 1992 (Straus \& Kaufman Kantor, 1994) show a decrease in the yearly prevalence of male-to-female partner violence between 1976 and 1985, and then an increase between 1985 and 1992. However, the rate of more severe violence likely to cause injury dropped $48 \%$ between 1976 and 1992 , from 39 to 19 per 1000 . The authors of the 1992 study question whether this decrease represents a teal change in the assault rate, or a change in men's willingness to disclose their criminal behavior. The latter interpretation, while less encouraging than the former, suggests at least a heightened awareness that partner violence is unacceptable and a crime (Straus \& Kaufman Kantor, 1994).

The rate of intimate homicides by males remained unchanged at about 1.5 or 1.6 per 100,000 from 1977 to 1993 , even as the nation's overall homicide rate declined steadily (U.S. Department of Justice, 1994). It then dropped to 1.4 per 100,000 in 1994 and to 1.3 per 100,000 in 1995 (Bureau of Justice Statistics, 1996). Although it is tempting to attribute this recent decline in female fatalities to the VAWA or the larger Violent Crime Control and Law Enforcement Act, it is important to consider the impact of another historic event: the highly publicized trial of sports hero O.J. Simpson for the murder of his ex-wife, Nicole Brown Simpson, and Ronald Goldman. The improvement 
in the US economy is yet another explanation for the decline. It is impossible to tell whether this trend will continue, level off, or reverse itself.

Paradoxically, the impact of the battered women's movement may be most evident in the dramatic decrease in the rate of male homicide by female intimates. The rate of male homicide fell in a nearly monotonic fashion from 1.5 to 100,000 in 1977 to 0.5 per 100,000 in 1995. Browne and Williams (1989) suggest that battered women's shelters, arrest policies, and other support and protective services have provided victims with means of escaping violence and alternatives to murdering their partners in selfdefense.

Arrest

Replications of the Minneapolis Police Experiment have yielded inconsistent findings on the effects of arrest. Whereas studies in Colorado Springs and Dade County found specific deterrent effects for arrest, (Berk, Campbell, Klap, \& Western, 1992; Pate, Hamilton, \& Annan, 1991), replications in Omaha, Charlotte, and Milwaukee found either no differences or an escalation in violence (Dunford, Huizinga, \& Elliott, 1990; Hirschel, Hutchison, \& Dean, 1992; Sherman et al., 1991). Subsequent analyses of the data suggest that arrest increases violence among perpetrators who have low "stake in conformity"--those who are unemployed or unmarried and have less to lose by the stigmatization associated with arrest (Berk, Campbell, Klap, \& Western, 1992; Pate \& Hamilton, 1992; Sherman, Smith, Schmidt, \& Rogan, 1992). Domestic violence researchers have since concluded that pro-arrest policies in cases of male-to-female intimate violence require further evaluation (Garner, Fagan, \& Maxwell, 1995) and at the 
moment are inadvisable (Sherman, 1992). Despite these caveats, the battered women's movement and the US Department of Justice continue to promote pro-arrest policies.

\section{Batterer Treatment}

Research findings raise serious questions about the impact of batterer treatment programs as well. Most qualitative reviews of the treatment outcome research withhold judgment about treatment efficacy, given methodological flaws in the research and difficulty synthesizing results across studies (Eisikovits \& Edleson, 1989; Hamberger \& Hastings, 1993; Rosenfeld, 1992; Tolman \& Bennett, 1990; Tolman \& Edleson, 1995; also see Feldman \& Ridley, 1995; Saunder \& Azar, 1989). A meta-analysis of seven treatment outcome studies relying on partner reports of recidivism found no effect for treatment when comparing the post-treatment recidivism rates of program completers and non-completers across studies; a meta-analysis of 11 outcome studies relying on police reports and court records found only a small treatment effect (Levesque, this volume). However, it is important to note that study design characteristics and other moderator variables accounted for about two-thirds of the variance in effect size. Sex-role resocialization, one of the moderator variables examined, had a small negative zero order correlation with effect size.

Furthermore, the overall impact of treatment on the problem of male-to-female violence is diluted if a significant portion of the target group does not complete treatment. In a nation-wide survey of batterer treatment programs, Pirog-Good and Stets (1986) found estimates of program attrition to average $40 \%$ across programs. A similar rate of $39 \%$ was found in a meta-analysis of 21 treatment outcome studies reporting on treatment drop-out (Levesque, this volume). In an exploratory study of 15 "model" and 15 
randomly selected batterer programs, Gondolf (1990) found the highest attrition rates among the model programs, which were longer, but were also more confrontational and profeminist, and served more court-mandated offenders.

Given the data, it is alarming that most states with standards for batterer program certification or funding are now insisting that treatment be organized around profeminist principles and interventions. Such political coups of the battered women's movement may unwittingly place women at further risk of violence. Like mandatory arrest, the legitimization through law of any approach to batterer treatment is premature and potentially harmful to the victims they are designed to help. One of the best predictors of whether or not a woman will return to her partner after a shelter stay is whether or not her partner is in treatment (Gondolf, 1988b). Programs that are "state certified" may encourage even greater optimism and an unwarranted sense of safety among victims.

\section{A Statue with Feet of Clav}

When faced with the disappointing results of research on arrest and batterer treatment we must question whether the feminist paradigm provides an adequate foundation upon which to build effective models of intervention. In deference to the battered women's movement, its energy, and accomplishments, and perhaps in deference to "political correctness," only a few experts in the field have been willing to challenge the movement's assumptions about the etiology of male-to-female violence and how to stop it. Dutton (1994), for one, reviews research findings that call into question the validity of the feminist paradigm (e.g., research showing that patriarchal beliefs are unrelated to violent behavior, that women are as violent as men, that partner violence is more prevalent in lesbian relationships than in heterosexual relationships), and concludes 
that we've fallen victim to the "ecological fallacy" (Dooley \& Catalano, 1984), incorrectly believing that broad features of our social environment can adequately explain human behavior. While certain socio-political conditions may be necessary to sustain male-to-female partner violence generation after generation, they cannot account for individual differences in the use of violence. Dutton suggests in a conciliatory manner that psychopathology can account for these differences, and that men with some types of pathology may adopt patriarchal attitudes and beliefs in order to justify their violent behavior. Yllo, a feminist researcher, similarly suggests that we turn to psychological variables to account for individual differences in behavior. Yllo asks, "Why is a subordinate, cowering wife pleasing to some men and not to others? (1993, p. 57).

We are probably incorrect, as well, to assume that broad social changes are sufficient to bring about changes in individual behavior. Batterers differ in their motivation to end their violence, and in levels of knowledge and skill required to manage anger and relate to their partners as equals. Arrest and batterer treatment, individual-level interventions arising from the social change efforts of the battered women's movement, provide communities ready to end partner violence with additional opportunities to facilitate change among men who lag behind, unprepared to adopt new attitudes and behaviors. However, these interventions are of limited efficacy and in some cases may be detrimental to the welfare of women for the following reasons:

\section{They are based on a socio-political understanding of violence and change rather} than empirically validated theories of individual behavior change.

Mandatory arrest and profeminist batterer treatment advance the socio-political aims of the batterered women's movement by representing society's intolerance of 
violence against women and imparting a profeminist view of the problem. While these interventions have clearly changed the backdrop for male violence against women, they have been insufficient to bring about behavior change. A synergistic combination of effective social and individual change approaches will be necessary in order to to identify, evaluate, and ultimately implement, society-wide, the best available individuallevel interventions for ending male-to-female partner violence.

One of the first goals in this endeavor is to develop a better understanding of how, when and why men change to end the violence in their relationships We must look to promising models of behavior change open to empirical validation. Tolman, Edleson, and Fendrich (1997) have begun to examine the usefulness of Azjen's $(1988,1991)$ Theory of Planned Behavior (TPB) in explaining violence desistance in battering men. The researchers hypothesized that offenders' intentions to end their violence, and thus their subsequent behavior, can be determined by the following dimensions included in the TPB model: 1) attitudes toward the behavior--evaluations of possible outcomes of the behavior; 2) subjective norms--perceptions of the expectations of others concerning violence, and their importance; and 3) perceived behavioral control--the degree to which they believe they can control their violent behavior.

Tolman, Edleson, and Fendrich reanalyzed data from an earlier batterer treatment outcome study (Harrell, 1991), creating measures of the above constructs from the study's original scales. Subjects included 176 treatment completers (men who were court-referred) and non-completers (men not court-referred) who participated in an initial interview and for whom partners' reports of recidivism were available six months later. Regression analyses provided only modest support for the model, with perceived 
behavioral control as the only TPB variable predicting subsequent violence. The authors concluded that more refined measures of the TPB variables are required, but that they will probably be insufficient to explain the complex process of change.

2. Existing interventions tend to be codified in state law, standardized, and "one size fits all," neglecting individual differences and readiness to change.

In replications of the Minneapolis Police Experiment, arrest decreased the likelihood of further violence in men who were employed or married, and increased it in those who weren't. One interpretation of the findings, mentioned earlier, is that arrest decreases violence among individuals who have a "stake in conformity" and fear the stigmatization associated with arrest (Berk, Campbell, Klap, \& Western, 1992; Pate \& Hamilton, 1992; Sherman, Smith, Schmidt, \& Rogan, 1992). The costs of arrest are in part subjectively determined (Mederer \& Gelles, 1989; Williams, 1992). Another interpretation of the findings is that arrest increases the likelihood of violence in men who are unprepared for change and experience the intervention as imposed. The theory of psychological reactance (Brehm, 1966; Hong \& Page, 1989) might predict these men to respond with anger and arousal when they feel their personal freedoms have been violated. Interventions that are codified in state law and standardized neglect readiness to change, subjective evaluations of the costs of arrest, and other individual differences that may have a powerful impact on the magnitude and valence of intervention effects. Existing "one size fits all" interventions work in some cases and increase risk to women in others.

Leaders in the field have recommended client-treatment matching to help men remain in treatment and increase efficacy. Efforts are underway to identify subtypes of 
batterers who may benefit from alternative interventions or therapeutic approaches (Cadsky \& Crawford, 1988; Gondolf, 1988c; Holtzworth-Munroe \& Stuart, 1994; Saunders, 1992; also, Levesque, this volume). The Transtheoretical Model of Change provides a stage-based classification system and stage-matched interventions suited to individuals' readiness to change. Our criminal justice system and state standards for program certification and funding would need to be far more flexible to allow clienttreatment matching.

3. Arrest and batterer treatment tend to be coercive and confrontational, and thus run the risk of angering and alienating men who may benefit from more rehabilitative approaches.

As mentioned earlier, arrest and batterer treatment provide communities ready to end partner violence with valuable opportunities to facilitate change among men who are unprepared to follow suit. However, these interventions are imposed from without and often confrontational, and may evoke psychological reactance or withdrawal. Miller and Rollick (1991) have developed motivational interviewing techniques that use confrontation to help clients with addictions see reality and their need for help; however, they recommend a gentle, persuasive style, and warn that heavy-handed and argumentative approaches can increase resistance and treatment attrition. Murphy and Baxter (1997) point out that batterers often have low self-esteem and unstable personalities and thus may experience some degree of psychological decompensation with heavy confrontation. They recommend that batterers can benefit from more supportive strategies, and recommend that Transtheoretical Model stage approach 
combined with Miller \& Rollnick's motivational interviewing techniques to increase motivation among men in treatment.

\section{The Transtheoretical Model of Change}

The Transtheoretical Model, which integrates constructs from several different theories of change, can be of use to researchers and practitioners wvanting to move beyond a socio-policitical conceptualization of partner violence and intervention. Central to the model is the notion that change occurs in stages, and ends when individuals reach a final stage in which there is little likelihood of relapse. Nearly 20 years of research on the addictions and other maladaptive behaviors have produced reliable and valid measures of change and identified several other dynamic dimensions that are powerful predictors of success and relapse. Measures of stage and other dimensions are used to monitor progress and guide intervention. Below are brief descriptions of the model's major constructs.

Stage of Change. Stages of Change is the Transtheoretical Model's central organizing construct. Longitudinal studies of change have found that people move through a series of six stages when modifying addictive behavior on their own, or with the help of formal intervention (DiClemente \& Prochaska, 1982; Prochaska \& DiClemente, 1983). In the first stage of change, the precontemplation stage, individuals may deny they have a problem and thus are resistant to change, underestimate the negative consequences of their behavior, or have given up the thought of changing because they are demoralized. They are not thinking about taking action in the next six months. Individuals in the contemplation stage are more likely to recognize or acknowledge the negative consequences of their problem behaviors and to consider the 
benefits of changing. They are seriously considering taking action within the next six months. Individuals in the preparation stage have decided to make an overt change in the next 30 days, and have already begun to take small steps toward that goal. Individuals in the action stage are overtly engaged in modifying their problem behaviors or acquiring new, healthy behaviors. Individuals in the maintenance stage have been able to sustain new patterns for at least six months, and are actively striving to prevent relapse. The maintenance stage lasts until termination, when there is negligible chance of relapse. For most people the change process is not linear, but spiral, with several relapses to earlier stages before they attain permanent behavior change (Prochaska \& DiClemente, 1983, 1986).

Research has begun to chart the stages of change people are in when offered interventions. Across a set of 15 different health and mental health problems, $40-60 \%$ of a representative sample of 6000 people still engaging in the behaviors (i.e., not yet in the action stage) were in the precontemplation stage, and the rest were in the contemplation or preparation stages (Rossi, 1992). These data suggest that when we offer "one-size-fitsall" interventions that assume readiness to change on the part of batterers, we mis-serve the majority who are in the early stages. Furthermore, we risk arousing psychological reactance. A recent study shows that cigarette smokers in precontemplation and contemplation stages are significantly more likely than smokers in the later stages to get angry and want to smoke more when pressured to quit (Levesque, Velicer, Norman, Prochaska, \& Fava, 1997).

Research on the Transtheoretical Model has shown that the mechanisms of change differ across stages (Prochaska \& DiClemente, 1983), and that stage-appropriate 
interventions out-perform stage-inappropriate interventions in longitudinal studies of change (Prochaska, DiClemente, Velicer, \& Rossi, 1993). Stage-matched interventions are likely to reduce treatment attrition and increase success among batterers in treatment because they represent an empathic and optimistic--rather than confrontational--approach to change. Violent offenders might be assigned to stage-matched psychoeducational groups, or provided with stage-matched interventions that are adjuncts to traditional treatment in mixed groups. Daniels and Murphy (1997) have described how facilitators in mixed groups might tailor comments to batterers in different stages of change to enhance motivation.

Decisional Balance. According to Janis and Mann (1977), sound decision-making requires the consideration of the following potential gains (pros) and the potential losses (cons) associated with a behavior's consequences: 1) utilitarian gains and losses for self; 2) utilitarian gains and losses for others; 3) self-approval and self-disapproval; 4) approval and disapproval from others. In a recent integrative report on Transtheoretical Model research on 12 difference problem behaviors, Prochaska et al. (1994) found that the balance of pros and cons was systematically related to stage of change in all behaviors examined: the cons of changing to a health- promoting behavior outweighed the pros in the precontemplation stage, the pros surpassed the cons in the middle stages, and the pros outweighed the cons in the action stage. From these 12 studies Prochaska et al. discovered even the degree of change in pros and cons needed to progress across the stages of change: to progress from precontemplation to action involved approximately a one standard deviation increase in the pros of making the healthy behavior change, and a .5 standard deviation decrease in the cons of making the change. 
The notion of decisional balance is reflected in the exchange/social control theory of intimate violence, which postulates that individuals will continue to use violence as long as rewards outweigh the costs (Gelles \& Straus, 1979). Social control strategies such as arrest aim to deter offenders primarily by increasing the costs of violence (i.e., increasing the pros of change). Williams (1992) found only a weak relationship between men's assessments of the costs of arrest and violence, and questioned whether intense emotional arousal during conflict impairs rational decision-making processes. An adequate test of the decisional balance construct would require the development of decisional balance measures with greater breadth. Avoiding arrest is only one pro of ending the violence; other pros include receiving more affection from one's partner, gaining the respect of one's children, avoiding social disapproval, and feeling less guilt. Longitudinal studies of change have found decisional balance measures to be among the best available predictors of future change. In smoking cessation, pros and cons predict whether or not subjects classified as Precontemplators progress to more advanced stages of change (Velicer, DiClemente, Prochaska, \& Brandenburg, 1985). It is important to keep in mind, however, that it not the mere presence of costs and benefits of change that predict future behavior, but individual's perceptions of their salience in their personal lives. Batterers who have a greater stake in conformity and have more committed relationships may place a higher value on the benefits of desistance and the costs of violence than batterers who have less to lose. However, most individuals can come to value these benefits and costs with time and effective treatment.

Self-Efficacy. Self-efficacy, or the degree to which an individual believes he or she has the capacity to attain a desired goal, can influence motivation and persistence 
(Bandura, 1977). Levels of self-efficacy differ systematically across the stages of change, with subjects further along in the stages of change experiencing greater self-efficacy and less temptation to relapse. Longitudinal studies of smoking cessation show that selfefficacy predicts both attempts to quit smoking and the maintenance of abstinence (DiClemente, 1981; DiClemente, Prochaska, \& Gilbertini, 1985; Prochaska, DiClemente, Velicer, Ginpil, \& Norcross, 1985).

Research has identified three categories of tempting situations for smokers: positive/social (e.g., with friends at a party), negative/affective (e.g., when I'm extremely anxious and stressed), and habit/addictive (e.g., when I am desiring a cigarette) (Velicer, DiClemente, Rossi, \& Prochaska, 1990). Measures of self-efficacy are obtained by asking subjects to indicate how confident they are that they could abstain from smoking in these different situations, and how tempted they would be to smoke. In batterer treatment, assessing temptations to engage in violence in various situations becomes important in the action and maintenance stages, where the focus should be on relapse prevention.

Processes of Change. In a comparative analysis of 24 major systems of psychotherapy, Prochaska (1984) distilled a set of 10 fundamental processes, or basic patterns of activity that clinicians encourage or elicit in treatment to help clients change problem behaviors, affects, cognitions, or interpersonal relationships. Following further theoretical analyses (Prochaska \& DiClemente, 1984) and empirical studies (Prochaska \& DiClemente, 1985, 1986), the list was further refined. These change processes and conceptual definitions adapted to the goals of batterer treatment are presented in Table 2.1. 
Stages of change, decisional balance, and processes of change together were able to predict with $93 \%$ accuracy whether or not clients will drop out of psychotherapy prematurely (Medieros \& Prochaska, 1992). Premature terminators are more likely to be in the precontemplation stage at the beginning of therapy, to rate the cons of changing higher than the pros, and to rely more on stimulus control and willpower than subjects who remain in treatment or terminate appropriately. Among batterers, stimulus control strategies might include time-outs, or leaving the relationship more permanently.

Early data on the integration of stage and processes were provided by selfchangers in different stages of change for smoking cessation and weight loss (DiClemente et al., 1991; Norcross, Prochaska, \& DiClemente, 1998; Prochaska \& DiClemente, $1983 ; 1984)$. The data show that self-changers in different stages rely on different processes of change, naturally integrating change strategies and processes often considered incompatible. People in the early stages rely more on cognitive, affective, and evaluative processes of change; people in the later stages rely more on social support, commitments, and behavior management techniques (see Prochaska, DiClemente, \& Norcross, 1992). Table 2.2 summarizes the current understanding of self-changers' patterns of process use as they progress through the stages, and suggests stage-matched interventions that might be used in batterer treatment programs.

Batterer programs currently make use of several of the change processes identified in the Transtheoretical Model of Change. For instance, sex-role resocialization raises consciousness about patriarchal norms and sex-role stereotypes that support male domination and control of women. There is some question, however, whether this sociopolitical analysis of the problem, useful in guiding social change, is compelling enough 
for many men being asked to engage in individual change. Experientially-oriented processes that encourage men to focus on their personal experiences, feelings, and selfperceptions regarding their violent behavior may be more likely to facilitate movement among batterers in the early stages. Counter-conditioning is perhaps the most widely used behaviorally-oriented process. Anger management, stress management, and communicating needs and feelings appropriately are all healthy alternatives to violence. Helping relationships that develop with counselors and other men in treatment are an important benefit of the group treatment modality. Arrest relies primarily on contingency management. The Transtheoretical Model allows the systematic integration of these various interventions and others that may be under-utilized in the present treatment paradigm by matching interventions to stage of change.

\section{Conclusions and Directions for Future Research}

The last 20 years have seen dramatic changes in our society's response to male-tofemaie partner violence. The battered women's movement raised public consciousness by revealing the extent and consequences of male-to-female violence. It helped the nation engage in dramatic relief and self-reevaluation by uncovering the horrors of partner violence and presenting it as a public health problem requiring attention. It facilitated social liberation by providing protection to victims, criminalizing partner assault, and lobbying for other policy reforms that communicate the unacceptability of violence. While these societal-level interventions clearly indicate a nation in the action stage in its efforts to end partner violence, research suggests that there has been less success in fostering change at the individual level. Better theories are necessary to 
understand how men change to end the violence in their lives. The Transtheoretical Model of Change is one theory that deserves serious consideration.

The impact of social change efforts can also be bolstered by the integration of individual change principles and strategies. First, social change agents can tailor messages and interventions at the community level to take into account readiness to change. For example, a community composed primarily of precontemplators will benefit most from consciousness raising (e.g., public service announcements), while a community heavily represented by individuals in preparation can gain more from selfliberation (e,g., rallies to stimulate commitment to change). Second, for men who lag behind their communities and continue to aggress against their partners, social change agents can help institutionalize new approaches to batterer treatment that take into account individual readiness to change and integrate stage-matched interventions to decrease attrition and recidivism. Finally, social change agents might consider using proactive methods to identify and intervene with men who are violent but have not come to the attention of the criminal justice system. Transtheoretical model researchers have intervened on entire populations (e.g., in HMOs, worksites, schools), assessed stage and other Transtheoretical Model dimensions, and delivered stage-matched interventions via manuals, telephone counselor calls, and expert systems (Prochaska, Velicer, Fava, Rossi, \& Tsoh, 1998; Velicer \& Prochaska, 1997).

The first step in the application of the Transtheoretical Model of Change to the problem of maie-to-female partner violence is to develop psychometrically sound and externally valid instruments to measure the core constructs of the model in male batterers in treatment. This instrument development research will allow theory testing to assess 
the applicability of the Transtheoretical Model of Change to this important problem and lay the groundwork for the longitudinal study of change by providing the tools to measure change over time, readiness for change, and the efficacy of existing treatment interventions.

The next chapter describes the development and initial validation of stages of change measures for men in batterer treatment. Chapter Four describes the development and initial validation of decisional balance and self-efficacy measures, and examines the relationships among the various Transtheoretical Model constructs in this population. The distinctiveness of the Transtheoretical Model of Change lies in its integration of several theories of change--in the hypothesized and empirically validated relationships among the various theoretical constructs. It is these relationships among the constructs that contribute most to the understanding of change and can be most useful in the development of effective interventions. 


\section{References}

Adams, D., \& McCormick, A. (1982). Men unlearning violence: A group approach based on the collective model. In M. Roy (Ed.), The abusive partner: An analysis of domestic battering (pp. 170-197). New York: Van Nostrand Reinhold.

Astin, M.C., Lawrence, K.J., \& Foy, D.W. (1993). Posttraumatic stress disorder among battered women: Risk and resiliency factors. Violence and Victims, $\underline{8}$, 17-28.

Astin, M.C., Ogland-Hand, S.M., Coleman, E.M., \& Foy, D.W. (1995). Posttraumatic stress disorder and childhood abuse in battered women: Comparisons with maritally distressed women. Journal of Clinical and Consulting Psychology, $\underline{63}$, 308-312.

Azjen, I. (1988). Attitudes, personality, and behavior. Chicago, IL: Dorsey Press.

Azjen, I. (1991). The Theory of Planned Behavior. Organizational Behavior and Human Decision Processes, 50, 179-211.

Bachman, R., \& Saltzman, L.E. (1995). Violence against Women: Estimates from the redesigned survey (Special Report No. NCJ-154348). Washington, DC: Bureau of Justice Statistics, U.S. Department of Justice.

Bandura, A. (1973). Aggression: A social learning analysis. Englewood Cliffs, NJ: Prentice Hall.

Bandura, A. (1977). Self-efficacy: Toward a unifying theory of behavior change. Psychological Review, $\underline{84}, 191-215$.

Begun, A., Strodhoff, T., Weinstein, B., Shelley, G., Short, L. (1997, June). Development of an instrument to assess readiness to change battering behavior: 
Preliminary results. Paper presented at the 5th International Family Violence Research Conference, Durham, NH.

Berk, R.A., Campbell, A., Klap, R., \& Western, B. (1992). The deterrent effect of arrest in incidents of violence: A Bayesian analysis of four field experiments. American Sociological Review, 57, 698-708.

Blumstein, A., \& Cohen, J., \& Nagin, D. (Eds.). (1978). Deterrence and incapacitation: Estimating the effects of criminal sanctions on crime rates. Washington, DC: National Academy Press.

Brehm, J.W. (1966). A theory of psychological reactance. New York: Academic Press. Brown, J. (1997). Working toward freedom from violence: The process of change in battered women. Violence against women, $\underline{3}, 5-26$.

Browne, A. (1993). Violence against women by male partner: Prevalence, outcomes, and policy implications. American Psychologist, $\underline{48}$, 1077-1087.

Browne, A., \& Williams, K.R. (1989). Exploring the effect of resource availability and the likelihood of female-perpetrated homicides. Law and Society Review, $\underline{23}, 75-$ 94.

Buzawa, E.S., \& Buzawa, C.G. (1990). Domestic violence: The criminal justice response. Newbury Park, CA: Sage.

Cadsky, O., \& Crawford, M. (1988). Establishing batterer typologies in a clinical sample of men who assault their female partners. Canadian Journal of Community Mental Health, 7, 119-127.

Campbell, J.C., Kub, J., Belknap, R.A., \& Templin, T.S. (1997). Predictors of depression in battered women. Violence Against Women, 3 , 271-293. 
Daniels, J.W., \& Murphy, C.M. (1997). Stages and processes of change in batterers' treatment. Cognitive and Behavioral Practice, 4, 123-145.

Deschner, J.P. (1984). How to end the hitting habit: Anger control for battering couples. New York: The Free Press.

DiClemente, C.C. (1981). Self-efficacy and smoking cessation maintenance: A preliminary report. Cognitive Therapy and Research, $\underline{5}, 175-187$.

DiClemente, C.C., \& Prochaska, J.O. (1982). Self-change and therapy change of smoking behavior: A comparison of processes of change in cessation and maintenance. Addictive Behaviors, 7, 133-142.

DiClemente, C.C., Prochaska, J.O., \& Gibertini, M. (1985). Self-efficacy and the stages of self-change of smoking. Cognitive Therapy and Research, $9,181-200$.

DiClemente, C.C., \& Hughes, S.O. (1990). Stages of change profiles in outpatient alcoholism treatment. Journal of Substance Abuse, 2, 217-235.

Dobash, R.E., \& Dobash, R.P. (1979). Violence against wives: A case against the patriarchy. New York: Free Press.

Dobash, R.E., \& Dobash, R.P. (1992). Women, violence, and social change. New York: Routledge.

Dooley, D.G., \& Catalano, R. (1984). The epidemiology of economic stress. American Journal of Community Psychology, 12, 387-409.

Dunford, F.W., Huizinga, D., \& Elliott, D.S. (1990). The role of arrest in domestic assault: A quasi-experimental evaluation. Violence and Victims, 1, 163-175.

Dutton, D.G. (1986). The outcome of court-mandated treatment for wife assault: A quasi-experimental evaluation. Violence and Victims, 1, 163-176. 
Dutton, D.G. (1994). Patriarchy and wife assault: The ecological fallacy. Violence and Victims, 9 , 167-182.

Dutton, D.G. (1995). The domestic assault of women. Vancouver: UBC Press.

Dutton, D.G., Bodnarchuk, M., Kropp, R., Hart, S.D., \& Ogloff, J.R.P (1997). Wife assault treatment and criminal recidivism: An 11-year follow-up. International Journal of Offender Therapy and Comparative Criminology, 41, 9-23.

Dutton, M.A. (1992). Assessment and treatment of post-traumatic stress disorder among battered women. In D.W. Foy (Ed.), Treating PTSD: Cognitive behavioral stategies (pp. 69-97). New York: Guilford Press.

Edleson, J.L. (1984). Working with men who batter. Social Work, 29, 237-242.

Ellis, A. (1970). The Essence of rational psychotherapy: A comprehensive approach to treatment. New York: Institute for Rational Living.

Eisikovitz, Z.C., \& Edleson, J.L. (1989). Intervening with men who batter: A critical review of the literature. Social Service Review, 384-414.

Fagan, J. (1989). Cessation of family violence: Deterrence and dissuasion. In L. Ohlin \& M. Tonry (Eds.), Family violence. Chicago: University of Chicago Press.

Fagan, J. (1996). The criminalization of domestic violence: Promises and limits [Online series: NIJ Research Report]. Available: ncjrs.aspensys.com:81/new2/ crimdom.txt.

Federal Bureau of Investigation. (1997). Crime in the United States 1996. Washington, DC: U.S. Department of Justice.

Feld, S.L., \& Straus, M.A. (1990). Escalation and desistance from wife assault in marriage. In M.A. Straus \& R.J. Gelles (Eds.), Physical violence in American 
families: Risk factors and adaptations to violence in 8,145 families (pp. 489-505).

New Brunswick, NJ: Transaction Publishers.

Feldman, C.M., \& Ridley, C.A. (1995). The etiology and treatment of domestic violence between adult partners. Clinical Psychology: Science and Practice, 2, 317-348.

Ferraro, K.J. (1989). Policing women battering. Social Problems, 36, 61-74.

Ganley, A. (1981). Paricipant and trainer's manual for working with men who batter.

Washington, D.C.: Center for Women's Policy Studies.

Ganley, A. (1987). Perpetrators of domestic violence: An overview of counseling the court-mandated client. In D.J. Sonkin (Ed.), Domestic violence on trial: Psychological and legal dimensions of family violence (pp. 155-173). New York: Springer.

Garner, J., Fagan, J., \& Maxwell, C. (1995). Published findings from the NIJ Spouse Assault Replication Program: A Critical Review. Journal of Quantitative Criminology, 11, 3-28.

Gelles, R.J. (1974). The violent home. Beverly Hills, CA: Sage.

Gelles, R.J. (1983). An exchange/social control theory. In D. Finkelhore, R.J. Gelles, G.T. Hotaling, \& M.A. Straus (Eds.), The dark side of families: Current family violence research (pp. 151-165). Beverly Hills, CA: Sage.

Gelles, R.J., \& Harrop, J.W. (1989). Violence, battering, and psychological distress among women. Journal of Interpersonal Violence, 4, 400-420.

Gelles, R.J., \& Straus, M.A. (1979). Determinants of violence in the family: Toward a theoretical integration. In W.R. Burr, R. Hill, F.I. Nye, \& I.L. Reiss (Eds.), 
Contemporary theories about the family (Vol. 1, pp. 549-581). New York: Free Press.

Gibbs, J. (1975). Crime, punishment, and deterrence. New York: Elsevier.

Gleason, W.J. (1993). Mental disorders in battered women: An empirical study. Violence and Victims, $\underline{8}, 69-84$.

Gondolf, E.W. (1987). Changing men who batter: A developmental model for integrated interventions. Journal of Family Violence, 2 , 335-349.

Gondolf, E.W. (1988a). How some men stop their abuse: An exploratory program evaluation. In G.T. Hotaling, D. Finkelhor, J.T. Kirkpatrick, \& M.A. Straus (Eds.), Coping with family violence: Research and policy perspectives. Newbury Park: Sage.

Gondolf, E.W. (1988b). The effect of batterer counseling on shelter outcome. Journal of Interpersonal Violence, $3,275-289$.

Gondolf, E.W. (1988c). Who are those guys? Towards a behavioral typology of men who batter. Violence and Victims, 3 , 187-203.

Gondolf, E.W. (1990). An exploratory survey of court-mandated batterer programs.

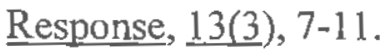

Gondolf, E.W., \& Russell, D. (1986). The case against anger control treatment programs for batterers. Response, 9(3), 2-5.

Hamberger, L.K., \& Hastings, J.E. (1993). Court-mandated treatment of men who assault their partner: Issues, controversies, and outcomes. In Z. Hilton (Ed.), Legal responses to wife assault (pp. 188-229). Newbury Park, CA: Sage. 
Harrell, A.V. (1991). Evaluation of court-ordered treatment for domestic violence offenders. Final report submitted to the State Justice Institute. Washington, D.C: The Urban Institute.

Herbert, T.B., Silver, R.C., \& Ellard, J.H. (1991). Coping with an abusive relationship: 1. How and why to women stay? Journal of Marriage and the Family, 53, 311325.

Hilton, N.Z. (Ed.). (1993). Legal responses to wife assault. Current trends and evaluation. Newbury Park, CA: Sage.

Hirschel, J.D., Hutchison, I.W., \& Dean (1992). Female spouse abuse and the police response: The Charlotte, North Carolina experiment. Journal of Criminal Law and Criminology, $\underline{83}, 73-119$.

Holtzworth-Munroe, A., \& Stuart, G.L. (1994). Typologies of male batterers: Three subtypes and differences among them. Psychological Bulletin, 116, 476-497.

Hong, S-M., \& Page, S. (1989). A psychological reactance scale: Development, factor structure and reliability. Psychological Reports, 64, 1323-1326.

Houskamp, B.M., \& Foy, D.W. (1991). The assessment of posttraumatic stress disorder in battered women. Journal of Interpersonal Violence, $\underline{6}, 367-375$.

Jaffe, P., Wolfe, D.A., Wilson, S., \& Zak, L. (1986). Emotional and physical health problems of battered women. Canadian Journal of Psychiatry, 31, 625-629.

Janis, I.L., \& Mann, L. (1977). Decision making: A psychological analysis of conflict, choice and commitment. New York: Free Press.

Jennings, J.L. (1987). History and issues in the treatment of battering men: A case for unstructured group therapy. Journal of Family Violence, 2, 193-213. 
Jennings, J.L. (1990). Preventing relapse versus "stopping" domestic violence: Do we expect too much too soon from battering men? Journal of Family Violence, $\underline{5}, 43$ 60.

Johnson, I.M. (1992). Economic, situational, and psychological correlates of the decision-making process of battered women. Families in Society, 57, 168-176. Johnson, I.M., Crowley, J., \& Sigler, R.T. (1992). Agency reponse to domestic violence: Services provided to battered women. In E.C. Viano (Ed.), Intimate violence: Interdisciplinary perspectives (pp. 191-202). Washington, DC: Hemisphere Publishing Corporation.

Kemp, A., Green, B.L., Hovanitz, C., \& Rawlings, E.T. (1995). Incidence and correlates of posttraumatic stress disorder in battered women: Shelter and community samples. Journal of Interpersonal Violence, $\underline{10}, 43-55$.

Kemp, A., Rawlings, E.T., \& Green, B.L. (1991). Posttraumtic stress disorder (PTSD) in battered women: A shelter sample. Joumal of Traumatic Stress, 4 , 137-148.

Kohlberg, L. (1981). The philosophy of moral development. San Francisco: Harper \& Row.

Levesque, D.A. (1995, May). Battering men and battered women: Applying the trantheoretical model to desistance and change. Invited address Brown/Yale/University of Rhode Island Collaborative Research Meeting. Providence, RI.

Levesque, D., \& Gelles, R. (1997, June). Battering men: Applying the transtheoretical model to desistance and change. Paper presented at the 5th International Family Violence Research Conference, Durham, NH. 
Levesque, D.A, Gelles, R.J., \& Velicer, W.F. (1997, August). Battering men and courtmandated treatment: Applying the Transtheoretical Model to desistance and change. Paper presented at the $105^{\text {th }}$ annual meeting of the American Psychological Association, Chicago, IL.

Levesque, D.A., Velicer, W.F., Norman, G.J., Prochaska, J.O., \& Fava, J.L. (1998). Development of measures of "negative processes of change" in cigarette smokers. Unpublished data.

Loseke, D.R., \& Berk, S.F. (1982). The work of shelters: Battered women and initial calls for help. Victimology: An International Journal, I, 35-48.

Martin, D. (1976). Battered wives. New York: Pocket Books.

Massachusetts Guidelines and Standards for the Certification of Batterers' Treatment Programs (1994, May). Massachusetts Department of Public Health. McCauley, J., Kern, D.E., Kolodner, K., Dill, L., Schroeder, A.F., DeChant, H.K., Ryden, J., Bass, E.B., \& Derogatis, L.R. (1995). The "battering syndrome": Prevalence and clinical characteristics of domestic violence in primary care medicine practices. Annals of Internal Medicine, 123, 737-746.

Mederer, H.J., \& Gelles, R.J. (1989). Compassion or control: Intervention in cases of wife assault. Journal of Interpersonal Violence, 4, 25-43.

Medieros, M., \& Prochaska, J.O. (1992). Predicting premature termination from psychotherapy. Unpublished manuscript.

Miller, W.R., \& Rollnick, S. (1991). Motivational interviewing: Preparing people to change addictive behavior. New York: The Guilford Press. 
Murphy, C.M., \& Baxter, V.A. (1997). Motivating batterers to change in the treatment context. Journal of Interpersonal Violence, $12,07-619$.

National Research Council. (1996). N.A. Crowell \& W.A. Burgess (Eds.), Understanding violence against women. Washington, DC: National Academy Press.

National Research Council \& Institute of Medicine. (1998). R. Chalk \& P.A. King (Eds.), Violence in families: Assessing prevention and treatment programs. Washington, DC: National Academy Press.

Norcross, J.C., Prochaska, J.O., \& DiClemente, C.C. (1998). The stages and processes of behavior change: Two replications with weight control. Manuscript submitted for publication.

Novaco, R.W. (1975). Anger control: The development and evaluation of an experimental treatment. Lexington, MA: Lexington Books.

Novaco, R.W. (1975). Anger control: The development and evaluation of an experimental treatment. Lexington, MA: Lexington Books.

Okun, L. (1988). Termination or resumption of cohabition in woman battering relationships: A statistical study. In G.T. Hotaling, D. Finkelhor, J.T. Kirkpatrick, \& M. Straus (Eds.), Coping with family violence: Research and public policy perspectives (pp. 107-119). Newbury Park: Sage.

Pate, A.M., \& Hamilton, E.E. (1992). Formal and informal deterrents to domestic violence: The Dade County spouse assault experiment. American Sociological Review, 57, 691-697. 
Pate, A.M., Hamilton, E.E., \& Annan, S. (1991). Metro-Dade Spouse Abuse Replication Project: Final draft report. National Institute of Justice, Washington, DC.

Pence, E. (1983). The Duluth Domestic Abuse Intervention Project. Hamline Law Review, 6, 247-275.

Pence, E, \& Paymar, M. (1993). Education groups for men who batter. New York: Springer.

Pence, E. (1989). Batter programs: Shifting from community collusion to community confrontation. In P.L. Caesar \& L.K. Hamberger (Eds.), Treating men who batter: Theory. Practice, and Programs (pp. 24-50). New York: Springer.

Pirog-Good, M., \& Stets-Kealey, J. (1985). Male batterers and battering prevention

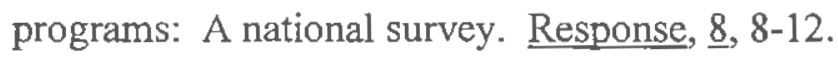

Pirog-Good, M., \& Stets, J. (1986). Programs for abusers: Who drops out and what can be done? Response, 2, 17-19.

Pizzey, E. (1974). Scream quietly or the neighbors will hear. London: Penguin.

Pleck, E. (1989). Criminal approaches to family violence, 1640-1980. In L. Ohlin \& M. Tonry (Eds.), Family violence (pp. 19-57). Chicago: University of Chicago Press.

Prochaska, J.O. (1984). Systems of psychotherapy: A transtheoretical approach. Homewood, Illinois: The Dorsey Press.

Prochaska, J.O., \& DiClemente, C.C. (1983). Stages and processes of self-change of smoking: Toward and integrative model of change. Journal of Consulting and Clinical Psychology, 51, 390-395. 
Prochaska, J.O., \& DiClemente, C.C. (1984). The transtheoretical approach: Crossing traditional boundaries of change. Homewood, IL: Dorsey Press.

Prochaska, J.O. \& DiClemente, C.C. (1985). Common processes of change in smoking, weight control, and psychological distress. In S. Shiffman and T. Wills (Eds.), Coping and substance use: A conceptual framework (pp. 345-363). New York: Academic Press.

Prochaska, J.O., \& DiClemente, C.C. (1986). Toward a comprehensive model of behavior change. In W.R. Miller \& N. Heather (Eds.), Treating additictive behaviors: Processes of change (pp. 3-27). New York: Plenum Press.

Prochaska, J.O., DiClemente, C.C., \& Norcross, J.C. (1992). In search of how people change: Applications to addictive behaviors. American Psychologist, 47, $1102-$ 1114.

Prochaska, J.O., DiClemente, C.C., Velicer, W.F., Ginpil, S., \& Norcross, J. (1985). Predicting change in smoking status for self-changers. Addictive Behavior, $\underline{10}$, 395-406.

Prochaska, J.O., DiClemente, C.C., Velicer, W.F., \& Rossi, J.S. (1993). Standardized, individualized, interactive, and personalized self-help programs for smoking cessation. Health Psychology, 12, 399-405.

Prochaska, J.O., Norcross, J.C., Fowler, J.L., Follick, M.J., \& Abrams, D.B. (1992). Attendance and outcome in a work-site weight control program: Processes and stages of change as process and predictor variables. Addictive Behaviors, 17, 3545. 
Prochaska, J.O., Redding, C.A., Harlow, L.L., Rossi, J.S., \& Velicer, W.F. (1994). The transtheoretical model of change and HIV prevention: A review. Health Education Quarterly, 21, 471-486.

Prochaska, J.O., Velicer, W.F., Fava, J.L., Rossi, J.S., \& Tsoh, J. (1998). A stagematched expert system intervention for a total population of smokers. Manuscript submitted for publication.

Prochaska, J.O., Velicer, W.F., Rossi, J.S., Goldstein, M.G., Marcus, B.H., Rakowski, W., Fiori, C., Harlow, L.L., Redding, C.A., Rosenbloom, D., \& Rossi, S.R. (1994). Stages of change and decisional balance for twelve problem behaviors. Health Psychology, 13, 39-46.

Purdy, F., \& Nickle, N. (1981). Practice principles for working with groups of men who batter. Social Work with Groups, 4, 111-122.

Rand, M.J. (1997). Violence-related injuries treated in hospital emergency departments (Special Report No. NCJ-156921). Washington, DC: Bureau of Justice Statistics, U.S. Department of Justice.

Riggs, D.S., Kilpatrick, D.G., \& Resnick, H.S. (1992). Long-term psychological distress associated with marital rape and aggravated assault: A comparison to other crime victims. Journal of Family Violence, 7, 283-296.

Ritmeester, T., \& Pence, E. (1992). A cynical twist of fate: How processes of ruling in the criminal justice system and the social sciences impede justice for battered women. Review of Law and Women's Studies, 2, 255-292.

Roberts, A.R. (1981). Sheltering battered women: A national study and service guide. New York: Springer. 
Rosenfeld, B.D. (1992). Court-ordered treatment of spouse abuse. Clinical Psychology Review, 12, 205-226.

Rossi, J.S. (1992, March). Stages of change for 15 health risk behaviors in an HMO population. Paper presented at the annual meeting of the Society of Behavioral Medicine, New York, NY.

Rounsaville, B. J. (1978), Theories in marital violence: Evidence from a study of battered women. Victimology: An International Journal, 3 , 11-31.

Satel, S.L. (1997). It's always his fault. The Women's Quarterly, Summer(12), 4-10. Sato, R.A., \& Heiby, E.M. (1992). Correlates of depressive symptoms among battered women. Journal of Family Violence, 7, 229-245,

Saunders, D.G (1984). Helping husbands who batter. Social Casework, 65, 347-353.

Saunders, D.G. (1992). A typology of men who batter: Three types derived from cluster analysis. American Journal of Orthopsychiatry, $\underline{62}, 264-275$.

Saunders, D.G. (1994). Posttraumatic stress symptom profiles of battered women: A comparison of survivors in two settings. Violence and Victims, 9 , 31-44.

Saunders, D.G., \& Azar, S.T. (1989). Treatment programs for family violence. In L. Ohlin \& M. Tonry (Eds.), Family violence (pp. 481-546). Chicago: University of Chicago Press.

Schechter, S. (1982). Women and male violence: The visions and struggles of the battered women's movement. Boston: South End Press.

Seligman, M.E.P. (1975). Helplessness: On depression, development and death. San Francisco: Freeman. 
Sherman, L.W. (1992). Policing domestic violence. New York: Free Press.

Sherman, L., \& Berk, R. (1984). The specific deterrent effects of arrest for domestic assault. American Sociological Review, 49, 261-272.

Sherman, L.W., Schmidt, J.D., Rogan, D.P., Gartin, P., Cohen, E.G., Collins, D.J., \& Bacich, A.R. (1991). From initial deterrence to long-term escalation: Short custody arrest for poverty ghetto domestic violence. Criminology, 29, 821-850.

Sherman, L.W., Schmidt, J.D., \& Rogan, D.P. (1992). Policing domestic violence: Experiments and Dilemmas. New York: Free Press.

Soler, E. (1987). Domestic violence is a crime: A case study of the San Francisco family violence project. In D.J. Sonkin (Ed.), Domestic violence on trial (pp. 2138). New York: Springer.

Straus, M.A. (1974). Introduction. In R.J. Gelles, The violent home. Beverly Hills, CA: Sage

Straus, M.A., \& Gelles, R.J. (1986). Societal change and changes in family violence from 1975 to 1985 as revealed by two national surveys. Journal of Marriage and the Family, $\underline{48}, 465-479$.

Straus, M.A., Gelles, R.J., \& Steinmetz, S.K. (1980). Behind closed doors: Violence in the American family. Garden City, NY: Anchor.

Straus, M.A., \& Kaufman Kantor, G. (1992, July). Change in spouse assault rates from 1975 to 1992: A comparison of three national surveys in the United States. Paper presented at the 13th World Congress of Sociology, Bielefeld, Germany.

Straus, M.A., \& Smith, C. (1990). Family patterns and primary prevention of family violence. In M.A. Straus \& R.J. Gelles (Eds.), Physical violence in American 
families: Risk factors and adaptations to violence in 8.145 families (pp. 507-526).

New Brunswick, NJ: Transaction Publishers.

Strube, M.J., \& Barbour, L.S. (1984). Factors associated with the decision to leave an abusive relationship. Journal of Marriage and the Family, 46, 837-844.

Tolman, R.M. \& Bennett, L.W. (1990). A review of quantitative research on men who batter. Journal of Interpersonal Violence, $\underline{5}, 87-118$.

Tolman, R.M., \& Edleson, J.L. (1995). Effectiveness of batterer intervention. In S.R. Stith \& M.A. Straus (Eds.), Understanding partner violence:_Prevalence, causes, consequences, and solutions (pp. 262-273??). Minneapolis, MN: National Council on Family Relations.

Tolman, R.M., Edleson, J.L., \& Fendrich, M. (1996). The applicability of the Theory of Planned Behavior to abusive men's cessation of violent behavior. Violence and Victims, $11,341-354$.

Tolman, R.M., \& Saunders, D.G. (1988). The case for the cautious use of anger control with men who batter. Response, 11(2), 15-20.

US Attorney General's Task Force on Family Violence. (1984). Final report.

Washington, DC: US Government Printing Office.

US Department of Justice. (1995). Uniform crime reports for the United States, 1994.

Washington, DC: US Department of Justice, Federal Bureau of Investigation.

Velicer, W.F., DiClemente, C.C., Prochaska, J.O., \& Brandenburg, N. (1985).

Decisional balance measure for assessing and predicting smoking status. Journal of Personality and Social Psychology, 48, 1279-1289. 
Velicer, W.F., DiClemente, C.C., Rossi, J.R., \& Prochaska, J.O. (1990). Relapse situations and self-efficacy: An integrative model. Addictive Behaviors, 15 , 271283.

Velicer, W.F., \& Prochaska, J.O. (in press). An expert system intervention for smoking cessation. Patient Education and Counseling.

Vitanza, S., Vogel, L.C.M., \& Marshall, L.L. (1995). Distress and symptoms of Posttraumatic stress disorder in abused women. Violence and Victims, 10, 23-34. Walker, L. (1979). The battered woman. New York: Harper and Row.

Walker, L.E.A. (1991). Posttraumatic stress disorder in women: Diagnosis and treatment of battered woman syndrome. Psychotherapy, 28(1), 21-29.

West, C.G., Fernandez, A., Hillard, J.R., Schoof, M., \& Parks, J. (1990). Psychiatric disorders of abused women at a shelter. Psychiatric Quarterly, 61, 295-301.

Williams, K.R. (1992). Social sources of marital violence and deterrence: Testing an integrated theory of assaults between partners. Journal of Marriage and the Family, 54, 620-629.

Wilson, M., \& Daly, M. (1993). Spousal homicide risk and estrangement. Violence and victims, $\underline{8}, 3-16$.

Yllo, K. (1993). Through a feminist lens: Gender, power, and violence. In R.J. Gelles \& D.R. Loseke (Eds.), Current controversies on family violence. Newbury Park, CA: Sage.

Zamora, E. (December, 1995). State statutes regarding mandatory treatment for batterers and treatment program Standards. Minneapolis, MN: Criminal Justice Center, Battered Women's Justice Project. 
Table 2. 1 .

Processes of Change in the Desistance of Male-to-Female Partner Violence

Experiential Processes

Consciousness raising

Seeking new information to support the change to a non-violent lifestyle

Dramatic relief

Experiencing strong negative emotions about one's violence

Social liberation

Realizing that the social norms are changing to support non-violence

Environmental reevaluation

Realizing the negative impact of violence on others

Self-reevaluation

Realizing that being non-violent is an important part of one's identity

Behavioral Processes

Helping relationships

Seeking and using social support to end one's violence and maintain changes

Counter-conditioning

Substituting violence with healthier behaviors and cognitions

Contingency management Increasing the rewards for non-violence, and decreasing the rewards for violence

Stimulus control

Removing reminders or cues to engage in violence, and adding cues to engage in healthier behavior

Self-liberation

Realizing one's ability to choose to be nonviolent and making a commitment to change 

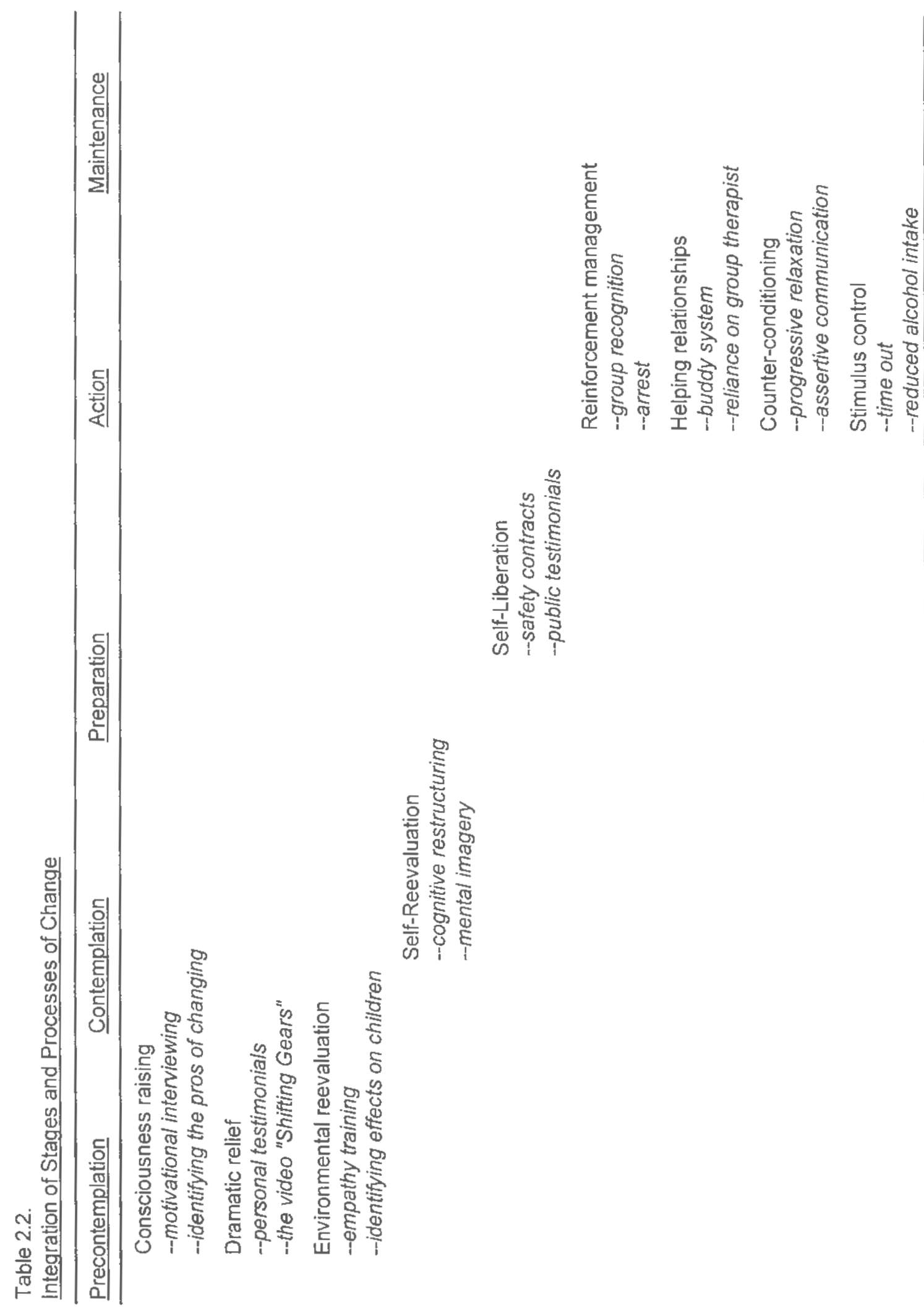


\section{CHAPTER 3}

Development and Initial Validation of Transtheoretical Model Stages of Change

Measures for Battering Men in Treatment 


\section{Introduction}

Court-ordered psychotherapeutic batterer treatment is emerging as one of society's interventions of choice for men who assault their wives and partners (National Research Council \& Institute of Medicine, 1998). Despite its growing prevalence, however, treatment is unlikely to have a significant impact on the problem of partner violence in the US. First, the treatment outcome research suggests that programs are only mildly effective, at best, in reducing the likelihood of future violence. A meta-analysis of seven outcome studies relying on partner reports of recidivism found no effect for treatment when comparing the post-treatment recidivism rates of treatment completers and comparison groups across studies; an analysis of 11 outcome studies relying on police reports and court records found a small effect (Levesque, this volume). Second, programs are plagued by drop-out rates of 35-40\% (Levesque, this volume; Pirog-Good $\&$ Stets, 1986), further diluting impact. Third, programs reach only a small proportion of the men who engage in partner violence. Ten years ago, it was estimated that self- and court-referred men in treatment together represented less than $1 \%$ of the batterer population (Gondolf, 1988a). Even if mandatory arrest and treatment laws have increased participation rates 10 - to 20 -fold in the last decade, a large majority of men still remain without treatment. Given treatment's low efficacy, high drop-out rates, and low participation rates, it is unlikely to reduce the prevalence of partner violence in our society by more than a small fraction of a percentage point.

In recent years, the field has displayed a growing interest in client-treatment matching to increase the impact of interventions for battering men. Treatment tends to be highly structured, psycho-educational, and "one-size-fits-all," neglecting individual 
differences that may influence treatment compliance and effectiveness. In my review of the literature, I have found that research has focused on three sets of client characteristics that may be useful in treatment matching: 1) personality and behavioral characteristics, 2) treatment goals, and 3) readiness to change. These dimensions and their implications for client-treatment matching are described below.

\section{Personality and Behavioral Characteristics}

Efforts are underway to identify subtypes of batterers who may benefit from alternative interventions or therapeutic approaches. The subtypes identified to date have been based on an array of personality and behavioral dimensions measured using a variety of assessment techniques (for a review of the typology literature, see HoltzworthMunroe \& Stuart, 1994). Gondolf(1988b), for instance, drew from the interview data of women in shelters to construct three indices of antisocial personality (substance abuse, violence outside the home, previous arrests) and abusive behavior (physical abuse, verbal abuse, victim blame following abuse). Measures on the six dimensions were then entered into a cluster analysis to group women's partners into a small number of homogeneous subtypes. Three clusters were identified : 1) Typical, 2) Antisocial, and 3) Sociopathic. In contrast, Saunders (1992) selected men's self-report measures of depression, anger, generalized violence, severity of the violence, attitudes toward women, and alcohol abuse as the dimensions to include in a cluster analysis of battering men seeking treatment. Again, three clusters were identified: 1) Family Only Aggressors, 2) Generalized Aggressors, and 3) Emotionally Volatile Aggressors. Others have kept it simple and classified batterers based on scores on uni-dimensional scales measuring frequency of the violence (Sweeney \& Key, 1982), generality of the violence, (Cadsky \& Crawford, 1988; 
Shields, McCall, \& Hanneke, 1988), and level of overcontrolled hostility (Hershorn \& Rosenbaum, 1991). In one study, men were classified along a single physiological dimension, heart rate reactivity. Gottman et al. (1995) found that violent husbands who display lower heart rate reactivity during marital conflict were more verbally aggressive toward their wives, more violent toward others outside the home, and more antisocial and sadistic than those who displayed higher reactivity. However, the modal study of batterer subtypes (e.g., Flournoy \& Wilson, 1991; Hamberger \& Hastings, 1986; Hamberger, Lohr, Bonge, \& Tolin, 1996) has classified men based on score profiles on multidimensional standardized psychological assessments such as the Minnesota Multiphasic Personality lnventory (MMPI--Hathaway \& McKinley, 1967) or the Millon Clinical Multiaxial Inventory (MCMI--Millon, 1983).

In a review of the literature on batterer typologies, Holtzworth-Munroe and Stuart (1994) found that researchers tend to classify batterers along three dimensions--severity of marital violence, generality of the violence, and psychopathology--and proposed that a typological system based on the three dimensions would identify three subtypes of batterers: 1) Family Only, 2) Dysphoric/Borderline, and 3) Generally Violent/Antisocial. Hamberger et al. (1996) suggest that Holtzworth-Munroe and Stuart confound behavior with psychopathology, and that a typology based on personality characteristics alone should allow us to predict the frequency, severity, and generality of the violence. In cluster analysis of 833 offenders court-referred for treatment evaluation, Hamberger et al. identified three batterer subtypes based on MCMI subscales (Millon, 1983): 1) Nonpathological, 2) Passive Aggressive-Dependent, and 3) Antisocial. Patterns of violence were examined in an assessment of the external validity of the 
clusters and generally confirmed predictions.

No doubt, the classification of batterers using one or more of these descriptive dimensions--which do seem to overlap and may represent one or two higher-order constructs such as sociopathy and/or emotional volatility--produces groups of men who look different from each other. The real question is whether or not these subtypes--or the dimensions upon which they are based--are meaningful in treatment planning. First of all, because the subtypes are based on past behaviors and on personality characteristics that are static or resistant to change, the resulting classifications are also static and unlikely to represent change in clients over time. Second, there are no data demonstrating the predictive validity of any of the typological systems except for those based on standardized personality measures. There is preliminary evidence that personality pathology predicts drop-out from batterer treatment (Hamberger \& Hastings, 1989; Hamberger et al., 1996) and violence recidivism after treatment (Hamberger \& Hastings, 1990; Bodnarchuk, Knopp, Ogloff, Hart, \& Dutton, 1995). Drug and especially alcohol abuse, overlooked in most typological systems, is another consistent predictor of dropout (Cadsky et al., 1996; DeMaris \& Jackson, 1987; Hamberger \& Hastings, 1989) and recidivism (DeMaris \& Jackson, 1987; Hamberger \& Hastings, 1990; Shepard, 1992). But once again, it is possible that substance abuse is an indicator of a higher-order construct such as sociopathy or emotional volatility. Research has consistently shown that violence outside the home does not predict violence recidivism post-treatment (DeMaris \& Jackson, 1987; Hamberger \& Hastings, 1990; Harrell, 1991).

Finally, the treatment implications for the proposed typological systems are unclear. Given the present sociopolitical climate, such systems are likely to lead to 
increased reliance on criminal justice interventions, rather than increased efforts to improve rehabilitative interventions. Some have argued that sociopathic batterers are unlikely to benefit from treatment, and should be rejected from programs to avoid presenting "false hopes" to their partners (e.g., Gondolf, 1988a). Others believe that treatment can be successful in these men only in conjunction with community-wide efforts to increase monitoring and criminal sanctions for non-compliance (Walker, 1995; Jacobson, Gottman, \& Shortt, 1995). In contrast, Saunders (1993) has recommended that these difficult clients receive increased legal supervision coupled with long-term treatment emphasizing a diverse set of interventions to develop impulse control, increase awareness of childhood traumas, and reduce rigid sex-role beliefs. Hamberger et al. (1996) have suggested that we turn to work by Beck, Freeman, and Associates (1990) for guidance on how gear batterer treatment to men with personality disorders.

There is one piece of encouraging news. In a comparison of feminist cognitivebehavioral and psychodynamic group treatment for batterers, Saunders (1996) found no main effect for therapeutic approach, but an interaction between personality traits and approach. Clients with dependent personality traits were less likely to recidivate following psychodynamic group treatment, and those with antisocial traits responded better to feminist cognitive-behavioral treatment. The interaction accounted for less than $4 \%$ of the variance in recidivism rates, however.

\section{Treatment Goals}

Cadsky, Hanson, Crawford, and Lalonde (1996) note that variables predicting dropout from other forms of treatment tend to fall into one of two categories: those representing lifestyle instability, and those representing client-treatment incongruence 
(Baekeland \& Lundwall, 1975; Wierzbicki \& Pekarik, 1993). Factors representing lifestyle stability, such as age, employment, and marital status, have been measured repeatedly in studies of batterer treatment attrition and completion, and predict completion more times than not (e.g., Cadsky et al., 1996; DeMaris, 1989; Gruznski \& Carrillo, 1988; Hamberger \& Hastings, 1988; 1989; Harrell, 1991; Petrik, Gildersleeve-High, McEllistrem, \& Subotnik, 1994; Saunders \& Hanusa, 1986; Saunders \& Parker, 1989). Cadsky et al. (1996) suggest that impulsivity underlies the relationship between lifestyle instability and attrition. Men with low self-control have more difficulty maintaining jobs and relationships, and following through with treatment mandates and recommendations. These lifestyle instability variables tend to be associated with criminal deviance (Cadsky et al., 1996) and may tap the sociopathy dimension that appears in the typology research above. However, while these variables tend to predict violence recidivism in criminal populations (e.g., Rice \& Harris, 1995), there is little evidence that they predict post-treatment recidivism in battering men (Bidgood, Tutty, \& Rothery, 1991; Edleson \& Syers, 1990; Hamberger \& Hastings, 1990; Harrell, 1991; Shepard, 1992; Rosenbaum, 1997).

Cadsky et al. (1996) conceptualized client-treatment congruence as the degree of match between clients' perceptions of their problems and the benefits of treatment, and suggested that we focus on congruence since it is easier to change than impulsivity. Cadsky et al. examined several indicators of client-treatment congruence in a study of 526 battering men seeking treatment, including treatment referral source (self versus probation or parole) and measures of partner violence (Conflict Tactics Scales--Straus, 1979), hostility (Buss-Durkee Hostility Inventory--Buss \& Durkee 1957), and 
relationship problems (Dyadic Adjustment Scale--Spanier, 1976). It was predicted that men who sought treatment voluntarily rather than through the courts, and who admitted having probiems with partner violence, hostility, and their relationships would be more likely to complete batterer treatment, which tends to focus on these issues. Predictions were confirmed. ${ }^{1}$

There are two implications of these findings for client-treatment matching: 1) we can reduce treatment attrition by focusing on problems clients find most pressing, and 2) we can reduce attrition by helping clients to see how treatment benefits them. The first approach holds promise, but will work only to the extent that individual goals are aligned with batterer treatment program goals, which tend to be quite rigid, often established in state standards for program certification and funding. The second approach also holds promise. Tolman and Bhosley (1989), found that an intensive $11 / 2$ day pre-group workshop reduced program attrition more than four weekly 1-hour sessions. The study's authors speculate that the intensive group was more effective because it increased group cohesion and communicated the importance of making a commitment to the treatment process. Cadsky et al. (1996) suggest that the intensive workshop helped men understand how treatment could be be helpful to them. No doubt, the workshop helped prepare men for treatment. But a number of questions remain: Exactly what helped, and what else can we do to prepare battering men for treatment? And what do we do with men who are not prepared to change?

\section{Readiness to Change}

The Stage of Change construct of the Transtheoretical Model offers an alternative approach to client-treatment matching that addresses some of the problems of the 
typological and goal-matching approaches described above. First, intervention decisions are based not on past behavior, or on demographic or personality characteristics that are static or resistant to change, but on a number of dynamic variables that reflect change over time: 1) readiness to change, 2) decisional balance, 3) self-efficacy, and 4) processes or strategies for change. Second, the model's dimensions have predictive validity. For instance, stages of change, decisional balance, and processes of change together are able to predict with $93 \%$ accuracy whether or not psychotherapy clients will drop out of treatment prematurely (Medieros \& Prochaska, 1998). Third, the approach allows programs and practitioners to establish the change agenda. Although tailoring treatment to batterers' individual goals is clearly important in alliance-building, success hinges on engaging men in the treatment process while remaining focused on the most critical problem at hand: partner violence. A Transtheoretical approach would aim to engage and retain all individuals in the change process--even those who are least prepared to participate--by providing stage-matched interventions suited to their readiness to end the violence. Fourth, implications for treatment are clear. Fifteen years of Transtheoretical Model research on other problem behaviors has identified interventions that work best in each stage to encourage healthy change. This research can serve a foundation upon which to build stage-matched interventions for battering men. Finally, the stage approach of the Transtheoretical Model is ideally suited to proactive outreach to increase participation in the treatment process.

\section{Application of the Transtheoretical Model of Change to Violence Desistance}

Measure development is the first step in the application of the Transtheoretical Model of Change to the problem of partner violence. Psychometrically sound and 
externally valid measures of stages of change, decisional balance, self-efficacy, and processes of change are critical initially in model testing to examine how well the Transtheoretical Model constructs and the established relationships between them characterize the process of change in men who assault their partners. Measures also provide the tools for assessing change over time, and provide the data upon which to base decisions regarding client-treatment matching to increase the impact of interventions. The present study focuses on the development and initial validation of stages of change measures in battering men. First, however, more background on the Transtheoretical model and stages of change is presented below.

\section{The Transtheoretical Model of Change}

In the last 15 years the Transtheoretical Model of Change has been shown to be remarkably robust in its ability to explain individual change across a variety of addictions and other maladaptive behaviors which, like partner violence, are considered to be major public health problems (e.g., Prochaska \& DiClemente, 1983; DiClemente \& Hughes, 1990; Prochaska, Norcross, Fowler, Follick, \& Abrams, 1992; Prochaska, Redding, Harlow, Rossi, \& Velicer, 1994). The Transtheoretical Model integrates a number of theoretical constructs central to change: stages of change, processes or strategies of change, decisional balance (Janis \& Mann, 1977), and self-efficacy (Bandura, 1977). A large body of empirical data supports the validity of the model's theoretical constructs as well as the hypothesized relationships between them. Experts in the field have already begun to anticipate the model's usefulness in batterer treatment (Begun, Strodhoff, Weinstein, Shelley, \& Short, 1997; Daniels \& Murphy, 1997; 
Dutton, 1995; Levesque \& Gelles, 1997; Levesque, Gelles, \& Velicer, 1997; Murphy \& Baxter, 1997).

Stages of Change is the Transtheoretical Model's central organizing construct. Longitudinal studies of change have found that people move through a series of five stages when modifying addictive behavior on their own, or with the help of formal intervention (DiClemente \& Prochaska, 1982; Prochaska \& DiClemente, 1983). In the first stage of change, the Precontemplation Stage, individuals deny they have a problem and thus are resistant to change, are unaware of the negative consequences of their behavior, believe the consequences are insignificant, or have given up the thought of changing because they are demoralized. They are not thinking about changing in the next six months. Individuals in the Contemplation Stage are more likely to recognize or acknowledge the negative consequences of their problem behaviors and to consider the benefits of changing. They are seriously considering making a change within the next six months. Individuals in the Preparation Stage have decided to make a change in the next 30 days, and have already begun to take small steps toward that goal. Individuals in the Action Stage are actively engaged in modifying their problem behaviors or acquiring new, healthy behaviors. Individuals the Maintenance Stage have been able to sustain change for at least six months, and are actively striving to prevent relapse. The Maintenance stage lasts until Termination, when there is negligible chance of relapse. For most people the change process is not linear, but spiral, with several relapses to earlier stages before they attain permanent behavior change (Prochaska \& DiClemente, I983, 1986). The stages form a simplex pattern in which adjacent stages are more highly 
correlated with each other than with more distant stages (Prochaska, DiClemente, Velicer, Ginpil, \& Norcross, 1985).

The stage construct has received empirical support across studies of behavior cessation in the areas of alcohol abuse (DiClemente \& Hughes, 1990), psychological distress (Prochaska, Rossi, and Wilcox, 1991), and sun exposure (Rossi, Blais, Redding, \& Weinstock, 1995), and behavior acquisition in the areas of exercise (Marcus, Rossi, Selby, Niaura, \& Abrams, 1992), safe sex practices (Prochaska, Redding, Harlow, Rossi, \& Velicer, 1994) and mammography screening (Rakowski et al., 1996), among others. Extensive research on smoking cessation shows that Stage of Change is a better predictor of future behavior than demographic variables (Prochaska et al., 1985). Smokers in Preparation are twice as likely to be abstinent at one month post-treatment than Contemplators, who in turn are twice as likely to be abstinent than Precontemplators. The pattern continues at six months post-treatment (DiClemente, Prochaska, Fairhurst, Velicer, Velasquez, \& Rossi, 1991).

Research has begun to chart the stages of change people are in when we offer interventions. Across a set of 15 different health and mental health problems, $40-60 \%$ of a representative sample of 6000 people still engaging in the behaviors (i.e., not yet in the Action stage) were in the Precontemplation stage, and the rest were in the Contemplation or Preparation stages (Rossi, 1992). Research comparing stage distributions across behaviors and populations found that about $40 \%$ of pre-action individuals were in Precontemplation, $40 \%$ in Contemplation, and only $20 \%$ in Preparation (Velicer et al., 1995; Laforge, Velicer, Richmond, \& Owen, 1998). These data suggest that if we offer action-oriented interventions to all batterers in treatment, we are mis-serving the majority 
who are not prepared to change. Violent offenders might be assigned to stage-matched psycho-educational groups, or provided with adjuvant stage-matched interventions in traditional mixed groups.

The findings of Cadsky et al. (1996), summarized above, can be understood using stage paradigm. Treatment as we know it tends to be Action-oriented. Men who seek treatment voluntarily and admit having problems with violence and relationship issues are probably further ahead in the stages and thus better matched to programs than men who are court-mandated or deny having problems. Once again, stage-treatment mismatching is more likely to lead to program attrition and treatment failure.

Stage of Change is also an informative outcome measure. Desistance and recidivism are distal measures of change, assessed after the fact. Good proximal measures would provide more immediate feedback about treatment efficacy by tapping dimensions associated with future violence, and provide guidance in treatment and discharge planning at both the programmatic and individual level. In a field that can settle for no less than absolute desistance, an important implication of the stage paradigm is that programs will need to be of variable length and content to assure that all men have reached at least the maintenance stage and developed the skills necessary to prevent relapse. Stage measures allow us to chart progress and relapse and provide guidance in the selection of interventions most likely to encourage positive change.

Stage of change can be assessed using two self-report methods. In the first, a classification algorithm is used to place individuals in one of five mutually exclusive stage categories based on their responses to a few questions about past behavior, present behavior, and their intentions (DiClemente et al., 1991). Alternatively, change can 
assessed using continuous measures that represent the degree to which individuals' attitudes and behaviors characterize each of the different stages. Although subjects progress from one stage to another, they may have attitudes and exhibit behaviors that characterize more than one stage at the same time. Their profiles or patterns of scores on the various measures characterize their readiness to change (McConnaughy, DiClemente, Prochaska, \& Velicer, 1987; McConnaughy, Prochaska, \& Velicer, 1983).

\section{Measure Development}

The development of measurement instruments is a critical preliminary step in the application of the Transtheoretical Model of problem of violence desistance and change in battering men. The present study focuses on the development and initial validation of four Stages of Change measures for men involved in batterer treatment: three staging algorithms and a multi-dimensional continuous measure that yields change profiles. The three staging algorithms represent different sets of decision rules for classifying men in the Precontemplation, Contemplation, Preparation, and Action stages. The continuous measure is adapted from the University of Rhode Island Change Assessment Scale originally developed to assess readiness for psychotherapy (URICA-- McConnaughy, DiClemente, Prochaska, \& Velicer, 1987; McConnaughy, Prochaska, \& Velicer, 1983). Research has demonstrated the predictive validity of the URICA for a variety of problems and populations, such as treatment outcome among brain-impaired patients in rehabilitation programs (Lam, McMahon, Priddy, \& Gehred-Schultz, 1988) and substance abusers in residential treatment programs (Tsoh, 1995), attendance and weight loss in a worksite weight control program (Prochaska, Norcross, Fowler, Follick, \& Abrams, 1992), and medication compliance among oral contraception users (Johnson, 
1997). How much people change following a brief course of therapy is directly related to their URICA stage prior to therapy. The URICA also predicts who will terminate from psychotherapy prematurely (Medieros \& Prochaska, 1992).

\section{Method}

\section{Item Generation}

The sequential system for scale development described by Jackson $(1970,1971)$ and Comrey (1988) was used. At the outset, the URICA (McConnaughy, Velicer, \& Prochaska, 1983) and conceptual definitions of the Stages of Change constructs from the Transtheoretical Model guided item generation for the five URICA-B1 scales: 1) Precontemplation, 2) Contemplation, 3) Preparation, 4) Action, and 5) Maintenance. Ten focus groups, each consisting of 8 to 15 assaultive men in group treatment, were conducted at two agencies in Rhode Island to provide further information necessary for item development, such as the depth and breadth of ideas that characterize clients' phenomenological view, and the language they use to describe their attitudes and behaviors. The programs offered by the agencies, typical of programs available today for men who assault their partners, are 18 to 25 weeks in length, psycho-educational, and stress anger management, sex role and gender issues, and coping and communication skills. One of the agencies also specializes in the treatment of substance abuse. Treatment group leaders who participated in a 4-hour training session on the Transtheoretical Model of Change conducted the focus groups in lieu of regularly scheduled program activities. Focus groups were conducted until little new information was forthcoming. The group leaders and the author generated items for the five URICAB1 scales, incorporating the men's ideas and the language noted during the focus groups. 
All items employed a 5-point Lickert-type response format ( 1 =strongly disagree to $5=$ strongly agree).

Two experts on the Transtheoretical Model of Change from the Self-Change Laboratory at the University of Rhode Island sorted items into five categories based on the conceptual definitions of the stage dimensions to assess face validity. Items that were sorted into different categories by the experts were dropped from the item pool or rewritten. A final list of 53 items was selected for administration on the basis of clarity of expression, lack of redundancy with other items, and the degree to which they represented the five stages as conceptually defined. Seven to eighteen items represented each of the stage dimensions.

\section{Participants}

Study participants were 292 males involved in group counseling for partner violence. They were drawn from the two Rhode Island agencies mentioned above. Data were collected by group facilitators during group sessions 3 to 12 months following the focus groups, once again in lieu of regularly scheduled activities. Men were informed of the nature of the research, assured of anonymity, and given the opportunity to decline without penalty. The handful of men who did decline most often cited difficulty reading or understanding English as their reason. Eleven participants were excluded because their survey responses were clearly bogus, and 23 were excluded because their surveys were largely incomplete, leaving an $\underline{\mathrm{N}}$ of 258.

Of the 258 participants retained for the study, $40 \%$ were under 30 years of age, $40 \%$ were $30-39$ years of age, and $20 \%$ were 40 years of age or older. A majority were white $(78 \%)$, held at least a high school degree (65\%), and were employed full-time 
(62\%). Thirty percent were married, and $78 \%$ had one or more children. Seventy-five percent had lived at some point with their most recent victim. Ninety-four percent of the study participants were mandated to treatment by the courts, and $26 \%$ reported prior involvement in treatment to address the problem of partner violence.

\section{Procedure}

The staging algorithm and URICA-B1 items were administered as part of a 240item paper-and-pencil survey (see Appendix B) that took approximately 45 minutes to complete. The survey included questions to assess demographics, treatment history, and drug and alcohol problems, and participants' relationships with their partners. Social desirability was assessed using a short form of the Marlowe-Crowne Social Desirability Scale (Crowne \& Marlowe, 1960; Reynolds, 1982).

\section{Measure Development}

Staging Algorithms. Immediately preceding the staging questions, subjects read the following operational definition of violence: "Violence refers to your physical aggression toward your partner. This includes all the behaviors listed below, and other acts that can cause physical pain or injury." Listed were all 11 items from the minor and severe physical aggression scales of the Modified Conflict Tactics Scales (Pan, Neidig, \& O'Leary, 1994), such as "trying to control your partner physically (holding down, etc.)," "throwing something at your partner," "slapping your partner," and "threatening your partner with a gun or knife." Subjects then answered a series of questions regarding their intentions to end their violence and their use of concrete strategies to achieve this goal. The violence cessation strategies included: 1) talking to partner, 2) talking to friends or family, 3) talking to priest, pastor, or rabbi, 4) talking to medical health professional, 5) 
one-on-one counseling, 6) couple's counseling, 7) batterers' group, 8) other group therapy, 9) self-help manual or books, 10) leaving the relationship temporarily, and 11) leaving the relationship permanently. Subjects were asked how often they used each of the strategies in the last five years ( $1=$ never to $5=$ very often), and when they most recently used any of the strategies.

Three staging algorithms were developed. The first algorithm consisted only of an intentional component. Participants were asked whether they were seriously considering ending their violent behavior in their relationship. Those who reported that their relationships were fine the way they were or that they planned to end the violence only in the distant future were classified in the Precontemplation stage; individuals who reported that they were seriously considering ending their violent behavior within the next six months or within the next 30 days were classified in the Contemplation or Preparation stage, respectively; and individuals who reported that they were currently doing something to end the violence were classified in the Action stage.

The second algorithm added a cognitive component. Participants were asked if they'd ever considered doing anything to put an end to their violent behavior. Individuals who answered "No" were re-classified as Precontemplators, regardless of their stated intentions in response to the first staging question above.

The third algorithm added a behavioral component. Individuals were asked if and when they most recently used strategies to end their violent behavior. In answering this question, men were asked to consider 11 concrete strategies listed in the questionnaire (e.g., "talking to my partner about my violent behavior," "talking to a priest, pastor, or rabbi," "one-on-one counseling or therapy," "leaving the relationship for a short while"), 
as well as any other strategies they might have used. Individuals previously staged in Action remained in Action if they had used any strategies within the last six months. They were re-classified into Preparation if they had most recently used strategies in the last 6 to 12 months, and into Contemplation if they had never used strategies or had done so more than 12 months ago. This component incorporates the notion that people in Preparation should be taking preliminary steps toward behavior change. In the algorithm for smoking cessation, for instance, smokers in Preparation are required to have had one quit attempt in the last year.

Given the relatively short duration of batterers' programs, the staging algorithms were not designed to classify batterers into the Maintenance stage. An algorithm that could classify men in Maintenance would need to include a temporal component that takes into account how long men have managed to remain violence free. It would be important to include Maintenance in an instrument designed to follow men posttreatment.

URICA-B1 Scales. A $53 \times 53$ matrix of inter-item correlations was calculated for the URICA-B1. In cases in which less than $10 \%$ of the URICA-B1 values were missing, pairwise deletion was used to deal with missing values in the inter-item correlation. In cases in which $10 \%$ or more of the values were missing, data were deleted in a listwise fashion, resulting in an $\underline{\mathrm{N}}$ of 257.

Given what we know a priori about the content and dimensionality of URICA measures in other behavior domains, two confirmatory factor analyses were conducted using the SPSS LISREL program (Joreskog \& Sorbom, 1989) to compare two measurement models most likely to represent the data. The first was a 5-factor correlated 
factors model that included all five stage dimensions; the second was a 4-factor correlated factors model that excluded the Preparation dimension and items. In both models, items were loaded on the factors they were designed to represent. Support for the five factor model would suggest that individuals tend to discriminate between all five stage dimensions simultaneously, but that these dimensions overlap somewhat and are not orthogonal. Support for the 4-factor model would suggest that individuals tend to discriminate best between four overlapping dimensions. Past research suggests that the 4-factor model will provide a better fit of the data. In the development of the URICA for psychotherapy clients, for example, McConnaughy, Prochaska, and Velicer (1983) found that subjects did not discriminate Preparation from Contemplation and Action; items designed to measure the Preparation dimension tended to load on the other two dimensions. As a result, the researchers chose to exclude the Preparation dimension and items from the final version of the URICA.

Goodness of fit was assessed using the Nonnormed Fit Index (NNFI--Tucker \& Lewis, 1973) and the Comparative Fix Index (CFI--Bentler, 1990), two fit indices that performed well in a simulation study examining the robustness of six fit indices against various study conditions (Ding, Velicer, \& Harlow, 1995). Given the present study's sample size (>250), anticipated factor loadings (>.50), and estimation method (maximum likelihood), the NNFI and CFI are expected to perform well. Potential values for these fit indices range from .00 to 1.00 , with values above .90 indicating good to excellent fit. Associated parsimonious fit indices were calculated to adjust for the greater parsimony of the 4-factor model. 
Factor loadings and modification indices generated by the LISREL program, as well as Coefficient Alphas for each scale, with and without particular items included, were used to select the best items for each of the URICA-B1 scales.

\section{Subtype Analysis}

URICA-B1 Stage Profiles. A clustering process (see Milligan \& Cooper, 1987) was used to classify the heterogeneous pool of participants into a small number of homogeneous batterer groups based on their URICA-B1 score profiles. Squared Euclidean distance was selected as the similarity/dissimilarity measure, and Ward's method (1963) as the clustering method. Before beginning, participants' scores on the separate URICA-BI dimensions were summed and standardized by converting them to $T$ scores. Standardization is particularly important when a squared Euclidean distance measure is used (Aldenderfer \& Blashfield, 1984; Everitt, 1980). Without standardization, variables with higher means tend to have more influence than variables with lower means (Everitt, 1980). Squared Euclidean distance is recommended as a similarity/dissimilarity measure because it is sensitive to elevation, scatter, and shape (Edelbrook, 1979; Blashfield, 1980). Ward's method (1963), a sequential hierarchical agglomerative procedure, was used to cluster cases, and then groups of cases, in a manner that minimized within-groups error sums of squares. The clustering procedure continues until all cases are combined in a single cluster. In a review of the research on clustering procedures, Milligan and Cooper (1987) concluded that Ward's method was generally the best hierarchical agglomerative clustering technique for recovering underlying structure. The cluster analysis was conducted using SAS (SAS Institute, 1985). Since there are no completely satisfactory methods available for determining the number of clusters to retain 
(Everitt, 1980), the decision in this case was based on hierarchical dendrogram inspection and profile interpretability (Aldendefer \& Blashfield, 1984). Three- to fifteen-cluster solutions were specified and examined.

\section{Comparison of Stage Measures}

Three separate profile $\mathrm{x}$ stage chi square tests were conducted to examine the relationship between the URICA-B1 profiles and stage of change based on the three different staging algorithms. The overlap in stage assignments based on the URICA-1 clusters and the three staging algorithms were examined.

\section{Discriminant and Convergent Validity of Stage Measures}

A final set of analyses examined the relationship between stage of change and social desirability, demographics, drinking behaviors, treatment history, and relationship status for each stage measure. Stage of change should be relatively independent of social desirability, demographics, drinking behavior, and relationship status. However, we might expect to find that individuals in the later stages have been in treatment longer.

$$
\text { Results }
$$

\section{Measure Development}

Staging Algorithms. Stage frequency distributions based on the three staging algorithms are presented in Table 3.1. Algorithm 1, which stages perpetrators according to their intention to end the violence in their relationships, classified $13.6 \%$ of study participants in Precontemplation, and $73.3 \%$ in Action. Adding the cognitive component in Algorithm 2 more than doubled the percentage of participants in Precontemplation, and adding the behavioral component in Algorithm 3 reduced by more than half the percentage of batterers in Action. Algorithm 3 is the most stringent because it requires 
men in the Action stage to have considered ending the violence and to have taken behavioral steps to achieve that end in the last six months.

URICA-BI Scales: Two confirmatory factor analyses were conducted to compare the 5-factor correlated factors model that included the Precontemplation, Contemplation, Preparation, Action, and Maintenance factors and a 4-factor correlated factors model that excluded Preparation. The solution to the 5-factor correlated factors model would not converge, indicating that it is a faulty model (Joreskog \& Sorbom, 1989). It was suspected that the problem with the model lay in the high correlation between the Preparation and Action factors, so a simpler correlated factors model that included only Preparation and Action was run to allow a closer look. This simpler model would not converge, either. The correlation between the Preparation and Action factors could not be identified in the psi matrix, providing evidence that the individuals in our study could make little distinction between the Preparation and Action constructs as represented by the items.

The Nonnormed Fit Index (Tucker \& Lewis, 1973) and the Comparative Fix Index (Bentler, 1990) suggested that the four correlated factors model that excluded the Preparation factor and items provided a good fit of the data. The model was refined using factor loadings, modification indices generated by the SPSS LISREL program, and Coefficient Alphas to select the five best items for each of the four scales with the goal of optimizing model fit, survey length, and internal reliability. The NNFI and CFI for this refined model were .92 and .93 , respectively, indicating very good fit. The results of the confirmatory factor analyses suggest that subjects were able to discriminate between four overlapping dimensions representing Precontemplation, Contemplation, Action, and 
Maintenance, but not between five dimensions when Preparation was added. As in the work of McConnaughy, Prochaska, and Velicer (1983), Preparation did not emerge as a unique dimension. Figure 3.1 presents the four correlated factors model for the URICA$\mathrm{B} 1$ and the final items for the four stage dimensions.

Overall, the model represents the expected simplex pattern in which adjacent stages are more highly correlated than non-adjacent stages. For example, Precontemplation and Contemplation are relatively strongly correlated, whereas Precontemplation and Maintenance are virtually uncorrelated $\left(\mathrm{r}^{\prime} \mathrm{s}=-.602\right.$ and -.030 , respectively). There is one deviation from the simplex pattern: Contemplation is slightly more highly correlated with Maintenance than with Action ( $\mathrm{r}^{\prime} \mathrm{s}=.554$ and .504 , respectively), when the reverse would be expected.

Scale scores were calculated for each stage dimension by taking the unweighted sum of the five items representing the dimension. Inter-scale correlations and scale Alphas, means, standard deviations, and correlations with the Marlowe-Crowne SF-13, a measure of social desirability, are presented in Table 3.2. Coefficient Alphas ranged from .83 for the action scale to .68 for the Maintenance scale, representing good to fair internal reliability. The Alphas may be relatively low for Maintenance because its items are more demanding of subjects: they are lengthy (an average of 20 words each), and require batterers to consider two ideas simultaneously (the idea that they have changed, and the idea that they might relapse). The four URICA-B1 scales were uncorrelated with social desirability.

Subtype Analysis 
URICA-BI Stage Profiles. The cluster analysis yielded a 6-cluster solution.

These six clusters accounted for all but 4 of the 247 subjects who had complete data. The cluster profiles for male batterers in treatment will be described and interpreted below, in an order that appears to represent a progression from the least to the most advanced in the change process. They will be compared to the cluster profiles identified by McConnaughy, Prochaska, and Velicer (1983) in their original work on URICA in a sample of psychotherapy clients. The standardized mean scale scores on the URICA-B1 Precontemplation, Contemplation, Action, and Maintenance scales for each cluster are presented in Figures 3.2 to 3.7.

(1) Resistant Cluster. The 11 subjects in this cluster were about average on Precontemplation, and extremely low ( 2 to $2 \mathrm{l} / 2$ standard deviations below the mean) on Contemplation, Action, and Maintenance, representing a resistant or possibly even a negative reactive stance. This profile has a below average level, a moderate degree of scatter, and its shape resembles a linear decreasing function with a slight rise in the right tail. The work of McConnaughy et al. yielded a similar cluster, labeled "Reluctant." However, the Contemplation level for their Reluctant cluster was closer to the mean, and thus does not suggest the kind of resistance seen in our subgroup.

(2) Immotive Cluster. The profile pattern of the 31 batterers in this cluster is similar to that of the Resistant cluster, but elevated by about one standard deviation on all four dimensions. These batterers scored higher than average on Precontemplation, and lower than average on Contemplation and Action, suggesting that they are not engaged in the change process. The profile is characterized by an average level, a high degree of scatter, and a wide U shape. McConnaughy et al. identified a similar cluster in their 
work. They labeled it "Immotive" because clients with such a profile are likely to retain the status quo.

(3) Non-Reflective Action Cluster. In the profile of the 23 batterers in this cluster, Precontemplation, Contemplation, and Maintenance levels are similar to those in the Immotive profile, described above. However, the Action level has risen by approximately two standard deviations. Overall, the profile is average in level and scatter, and is has a jagged shape with peaks in the first and third dimensions. Because batterers have not yet done the reflective work that should precede action, the cluster is labeled "Non-Reflective Action." McConnaughy et al. identified two clusters with this type of profile and labeled them Non-Reflective and Non-Contemplative.

(4) Ambivalent Cluster. The 61 batterers in this cluster display a leveling out of Precontemplation and Contemplation at the mean (hence, the label "Ambivalent"), representing progress over the earlier clusters in which Precontemplation was higher than Contemplation. These batterers were average on Action, and a little higher on Maintenance, possibly representing some concern about engaging in further violence. The profile is average in level, has minimal scatter, and is roughly a horizontal line. This cluster is most similar to McConnaughy et al.'s Uninvolved, Pre-participation, and Maintenance profiles, which all have rather flat profiles. Whereas mean scores for McConnaughy et al.'s Uninvolved cluster were a little below the mean, mean scores for the Pre-participation cluster were above the mean; mean scores in the Maintenance cluster were about average, except for an elevation in Maintenance.

(5) Decision-Making Cluster. Sixty-four batterers appeared in this cluster. In comparison to batterers in the Ambivalent cluster, these batterers were lower on 
Precontemplation and Maintenance, and higher on Contemplation and Action. The profile is characterized by an average level, a moderate degree of scatter, and an inverted U shape. This cluster emerged in the work of McConnaughy et al. as well. They labeled it "Decision-Making" because it represents a transitional stage in which subjects are contemplating change and beginning to take action.

(6) Participation Cluster. The 53 batterers in this cluster are lower on Precontemplation, and higher on Contemplation, Action, and Maintenance than all previous clusters. They are thinking about the benefits of changing, actively working on ending their violence, and are acutely aware of the potential for relapse. The profile is above average in level and has a moderate degree of scatter with a sharp initial rise and then leveling. McConnaughy identified a similar cluster and named it the "Participation" cluster.

\section{Comparison of Stage Measures}

Based on the cluster profiles, we might hypothesize that the Resistant and lmmotive clusters both represent Precontemplation, the Ambivalent cluster represents Contemplation, the Decision-Making cluster represents a combination of Contemplation and Preparation, and the Participation cluster represents Action. The Non-Reflective Action cluster has characteristics of both the Precontemplation and Action stages. Three separate profile $\mathrm{x}$ stage chi square tests were conducted to examine the relationship between the URICA-B1 profiles and stage of change measured by the three Algorithms. All three tests were significant at $\mathrm{p}<.01\left(\chi^{2}(15, \underline{N}=241)=53.27,55.72\right.$, and 50.59 for Algorithms 1, 2, and 3, respectively), suggesting dependence. However, the chi square 
tests must be considered unreliable because of low frequencies in many cells. Table 3.3 summarizes the data by presenting three sets of stage distributions (based on Algorithms 1,2 , and 3 , respectively) for each of the six profiles.

The hypothesized relationships between the URICA-B1 clusters and the traditional Transtheoretical Model stages of change are most clearly evident in the comparison of the URICA clusters to the Algorithm 3 stage classifications. Using Algorithm 3, a majority of individuals in the Resistant and Immotive clusters were classified in the Precontemplation stage and a majority of individuals in the DecisionMaking cluster were classified in the Contemplation and Preparation stages, as expected. Nearly half of the men in the most advanced cluster, Participation, were classified in the Action stage. We expected that a majority of men in the Ambivalent cluster would be classified as Contemplators, but this was not the case. Instead, they were distributed across the stages with a sizable proportion in Action.

It is interesting to note that although $47 \%$ of batterers in the Non-Reflective Action cluster were classified in the Action stage using Algorithm 2, a majority of them were reclassified to the Contemplation stage using Algorithm 3 because they had not used concrete strategies to end the violence in the last year. This finding raises a couple of questions. First, if a majority of men $(87 \%)$ in the Non-Reflective Action cluster have not used strategies to end the violence in the last year, why does the group as a whole score relatively high on the Action dimension of the URICA-B1? Are they overstating their engagement in the change process in the URICA? And second, if individuals haven't used concrete strategies in the last year, is it sensible to re-classify them from Action to Contemplation using Algorithm 3, or should they be re-classified to the 
Precontemplation stage? About one third of the men in the Immotive and Non-Reflective Action clusters were classified as Contemplators using Algorithm 3's decision rules.

These rates seem high when we consider that both clusters scored relatively low on the Contemplation scale of the URICA-B1.

In general, the percentage of battering men classified as Precontemplators decreases gradually as we move from the least advanced to the most advanced clusters. This pattern is especially clear when using Algorithms 2 and 3, which classify as Precontemplators all men who have never considered ending the violence in their relationships. Subjects in the Decision-Making cluster were least likely to be classified as Precontemplators. This is not surprising because decision-making implies a contemplative process.

For Algorithms 1 and 2, the percentage of battering men classified in the Action stage increased gradually and was greater in the more advanced than the less advanced cluster subgroups. The only departure from this trend occurred in the Immotive cluster, which had the lowest percentage of people in Action. For Algorithm 3--which adds the rather incisive action component to the classification scheme--there was more of a split rather than a gradual increase, with men in the last three clusters two or more times as likely to be in Action as men in the first three clusters.

The percentage of battering men classified in the Preparation stage using the three algorithms is relatively low and varies relatively little across the six profiles. The Decision-Making cluster has the highest percentage of men in Preparation (17.2\% when Algorithm 3 is used), but not as high as expected for this cluster. 


\section{Discriminant and Convergent Validity of Stage Measures}

A final set of analyses were conducted to examine the relationship between stage of change and social desirability, demographic variables, treatment history, and substance abuse history to assess external validity. In each analysis the grouping variable was stage cluster or stage of change measured by the three staging algorithms. Results significant at the .05 level are reported in Table 3.4 .

In the first set of analyses, the dependent measure was social desirability. A oneway analysis of variance (ANOVA) revealed no significant differences in MarloweCrowne SF-13 scores across the stages for each of the staging algorithms. However, significant differences in social desirability did exist among the URICA-B1 stage clusters. A Newman-Keuls post hoc test found that Resistant cluster scored significantly lower on social desirability than the Immotive, Non-Reflective, Ambivalent, and Decision-Making clusters. The Participation cluster scored significantly lower than the Decision-Making cluster. Social desirability score means and standard deviations for the six stage clusters are presented in Table 3.5 .

Chi square tests were conducted to assess differences on demographic and treatment variables across the stage groups for each of the four stage classification schemes. Once again, results are summarized in Table 3.4. Significant differences were found in chi square tests examining URICA-B1 stage cluster by income, children, and length of time in treatment. The percentage of subjects in each stage cluster who had incomes greater than $\$ 10,000 /$ year, who had any children, and who had been in treatment more than three months are listed in Table 3.5. As expected, men in the more advanced stage clusters were more likely than men in the earlier clusters to have been in treatment 
awhile. Differences across stage clusters in income and number of children were unexpected. Subjects in the Resistant cluster were only half as likely as subjects in all other clusters to have yearly incomes above $\$ 10,000$. All men in Resistant cluster had fathered children, whereas only $63 \%$ of men in the Ambivalent cluster had.

There are two trends in the data that deserve mention. Though the trends did not quite reach statistical significance, they provide additional information about the types of men classified in the various stage clusters. Chi square tests revealed differences across the clusters in full-time employment and binge drinking $\left(\chi^{2}(5, \underline{\mathrm{N}}=241)=10.43, \mathrm{p}=.06\right)$ and $\left(\chi^{2}(6, N=223)=9.80, \mathrm{p}=.08\right)$, respectively. Men in the Participation cluster were three times as likely as men in the Resistant cluster to have full-time jobs ( $73.6 \%$ vs. $27.3 \%$, respectively, with the rest of the clusters ranging from 56.5 to $66.7 \%$ ). Men in the NonReflective Action cluster were most likely to drink six or more drinks in one sitting ( $71.4 \%)$, followed by men in the Resistant cluster $(55.8 \%)$, and then the rest of the clusters ( $35.6 \%$ to $40.4 \%)$.

A final unplanned comparison, a multivariate analysis of variance (MANOVA), was conducted to provide additional information about the types of men classified in the various stage clusters. Specifically, did the different types differ in preferred strategies for ending the violence? The dependent variables were the 11 violence cessation strategies listed above. The MANOVA resulted in significant differences among the stage clusters (Wilks' Lambda $=.654$, approximate $\underline{\mathrm{F}}(55,1022)=1.78, \mathrm{p}<.001$ ). The results of significant follow-up univariate analyses of variance (ANOVAs) and Newman-Keuls multiple comparison tests are reported in Table 3.6. Men in the Immotive cluster talked 
to their partners about their violence significantly less often than men in the three most advanced clusters did; men in the Resistant cluster sought help from the clergy more often than all other clusters; and men in the Non-Reflective Action cluster permanently left relationships more often than all but the Resistant cluster in efforts to end the violence.

Significant results were found only in the stage $\mathrm{x}$ race tests for Algorithms 1, 2 and 3, and the stage $x$ age test for Algorithm 3. As presented in Table 3.7, Caucasians were under-represented in the Contemplation stage for all three staging algorithms, though the effect is mitigated somewhat with Algorithm 3. Men above the age of 30 were under-represented in the Preparation stage for Algorithm 3.

\section{Discussion}

As the first step in the application of the Transtheoretical Model of Change to the problem of male-to-female partner violence, four stage of change measures--three staging algorithms and the URICA-B1--were developed to assess battering men's readiness to end their violence. The URICA-B1 is composed of four 5-item scales that measure four correlated but distinct constructs representing Precontemplation, Contemplation, Action, and Maintenance in individuals with a history of partner violence. The four scales are psychometrically sound and uncorrelated with social desirability, and for the most part form the expected simplex pattern in which dimensions representing adjacent stages are more highly correlated with each other than with dimensions represeting more distant stages (Prochaska, DiClemente, Velicer, Ginpil, \& Norcross, 1985). Six profiles emerged when men were clustered on their four URICA-B1 scale scores: 1) Resistant, 2) Immotive, 3) Non-Reflective Action, 4) Ambivalent, 5) Decision-Making and 6) 
Participation. The Resistant cluster was the only cluster identified here that did not emerge in the development of the original URICA for outpatient psychotherapy clients (McConnaughy, Prochaska, \& Velicer, 1983; McConnaughy, DiClemente, Prochaska, \& Velicer, 1987).

Differences in social desirability, demographics, binge drinking, and violence cessation strategies across URICA-B1 clusters suggest that at least two of the clusters may be tapping personality characteristics in addition to change readiness. For instance, men in the Resistant cluster seem to be somewhat antisocial. They demonstrate an especially low need for social approval and a relatively high rate of binge drinking; they are less than half as likely as men in the other clusters to be employed full-time and to have incomes above $\$ 10,000$. It is unclear, however, why they would seek help from the clergy more often than their counterparts do in efforts to end the violence. Men in the Non-Reflective Action cluster are probably impulsive and may have coping deficits as well. A majority of them are binge drinkers. They are more likely than all other clusters but the Resistant cluster to end the violence simply by leaving the relationship. Although potentially effective in the short run, this strategy allows men to escape conflict and the difficult task of learning to tolerate and work through difficulties in relationships.

The remaining clusters, the Immotive, Ambivalent, Decision-Making, and Participation clusters, seem to be be roughly comparable to the traditional Precontemplation, Contemplation, Preparation, and Action stages of change. It is important to note, however, that men in the Participation cluster scored significantly lower on social desirability than men in the Decision-Making cluster. Low social desirability in the Participation cluster probably does not indicate social deviance, as it 
seems to in the Resistant cluster. Participators are more likely than all other groups to have full-time jobs and incomes above $\$ 10,000$, and they report a relatively low rate of binge-drinking. Instead, low social desirability in this most advanced cluster may indicate reduced psychological defensiveness. The high mean Contemplation and Maintenance scores on Participators' URICA-Bl profiles suggest that they are willing to admit that their violence is a problem and that they recognize the risk of relapse. We can hypothesize that this openness--even anxiety--around issues of violence is both a product and facilitator of the change process.

The three staging algorithms represent three different sets of decision rules for classifying men in the Precontemplation, Contemplation, Preparation, and Action stages. The first algorithm considered only intention in the classification scheme; the second considered intention and cognition, and the third considered intention, cognition, and behavior. Compared to the URICA-BI cluster profiles, algorithm-based stage classifications appear to be simpler, purer indicators of change readiness that are independent of personality style. It is of concern, however, that Caucasions were underrepresented in the Contemplation stage for all three staging algorithms, and that younger men were over-represented in the Preparation stage for Algorithm 3. These findings are difficult to interpret.

Algorithm 3 performed best in comparisons of algorithm-based stage assignments to URICA-B1 cluster groups, yielding an interpretable pattern of results that most closely matched predictions. However, the comparison highlighted potential problems with Algorithm 3's decision rules. Algorithm 3 classifies people in Action if they state that they've seriously considered ending the violence, are currently doing something about it, 
and have used concrete strategies to achieve that end in the last six months. Individuals who state that they're currently doing something are re-classified into Preparation if they most recently used strategies in the last 6 to 12 months, and into Contemplation if they never used strategies or did so more than 12 months ago. About one third of the men in the Immotive and Non-Reflective Action clusters were classified as Contemplators using Algorithm 3's decision rules. These rates seem high when we consider that both clusters scored relatively low on the Contemplation scale of the URICA-B1. It is may be helpful at the moment to take a step back and collect more data before settling on rules for stagere-classification using behavioral criteria. For instance, we might develop an algorithm that retains a separate classification for men Action who haven't used concrete strategies. By keeping these men separate, rather than re-classifying them into earlier stage groups, we can examine how they compare to men in Precontemplation, Contemplation, Preparation, and Action.

In general, we expect men to procede throught the stages of change sequentially. All individuals begin in Precontemplation and can reach Action only by progressing first to Contemplation and then Preparation ${ }^{2}$. This may not be the case with the stage clusters, however. A number of scenarios are possible. For example, all men may begin in the Immotive cluster. With pressure to change via court-mandate or partner ultimatums, some men may develop an angry reactive stance and dig in their heals (Resistant cluster), while others passively comply with mandates without thinking much about it (NonReflective Action cluster), or begin to seriously consider the real benefits of change (Ambivalent cluster). How men progress from the Resistant or Non-Reflective cluster to Participation is another question worthy of study. Non-Reflectives who begin to 
contemplate the benefits of changing may skip the Ambivalent stage and move right to Decision-Making since they're already active. Resistant men could conceivably progress to either Non-Reflective Action or Ambivalence. Given the trait-like qualities embedded in the Resistant and Non-Reflective Action clusters, we should examine whether men in these clusters are less likely than men in other early stage clusters to make any movement at all. Latent transition analysis has been used with stage data to assess the probability of progression, regression, and no movement through the stages (Velicer, Martin, \& Collins, 1996).

The issue of stage distribution deserves attention. Only $5 \%$ of the sample was classified in the Resistant cluster and 12\% in the Immotive cluster based on their URICAB1 profiles. Twenty-seven percent were classified as Precontempiators using Algorithm 3. This rates seem low, given the general impression among clinicians that most batterers are unmotivated to end their violence (e.g., Ganley, 1987; Daniels \& Murphy, 1997; Hamberger \& Hastings, 1986). However, it is important to keep in mind that $80 \%$ of the sample had been in treatment for three months or longer (apparently group facilitors felt more comfortable recruiting research participation from more advanced groups). A far different stage distribution might be found if men were assessed early in their involvement with probation or at treatment intake. As expected, men in the more advanced stage clusters were more likely than men in the earlier clusters to have been in treatment for three months. It unclear from the data whether men persist in treatment because they're in the later stages, or whether they're in the later stages because they've had greater exposure to treatment. Still, even though $80 \%$ of men are more than half-way through their programs, only about one-third of the sample was classified in the Action 
stage using Algorithm 3, and one-fifth in the Participation cluster using the URICA-B1. A majority of men have a great deal of work left to do before the change process is complete.

\section{Implications for Client-Treatment Matching}

The Transtheoretical Model of Change offers a promising approach to clienttreatment matching to increase the impact of rehabilitative treatment for men who assault their partners. Over 15 years of research on the Model in other behavior domains has identified critical behavior change dimensions that can shed insight into how, when, and why battering men end the violence in the lives and provide guidance in the development of interventions that match men's readiness to change. Development of stages of change measures for battering men is the first step in the application of the model to this new area.

The data so far are encouraging. The new stage measures--especially the URICAB1--have good face validity, strong psychometric qualities, and preliminary evidence of external validity. But a great deal of work remains to be done. First, we need to experiment with the staging algorithms to address problems identified with re-staging decisions based on behavioral criteria for Action. Second, we need to evaluate further the construct validity of the stage measures, and examine predictive validity. Third, we need to develop other measures of other Transtheoretical Model of Change constructs, including decisional balance, self-efficacy, and processes of change. Fourth, we need to test the applicability of the applicability of the model to partner violence. Do behavioral and Transtheoretical Model constructs vary by stage in a fashion predicted by Transtheoretical Model research in other problem areas? Finally, stage-matched 
interventions developed for other problem areas would need to adapted to battering men in treatment, implemented and tested.

\section{Notes}

'It is important to mention that effect sizes were small. In fact, Cadsky et al. (1996) began with a list of 150 predictors and found that only three made unique contributions to treatment completion: number of moves in the last five years (low number indicates of lifestyle stability), self-referral to treatment, and level of relationship cohesion (indicators of client-treatment congruence). The three variables together accounted for $13 \%$ of the variance.

${ }^{2}$ However, there is a problem with Algorithm \#3 and some algorithms that include a behavioral criterion (e.g., a quit attempt in the last year for cigarette smokers; use of a concrete violence cessation strategy in the last year for battering men) for classification in the Preparation stage: Individuals need to take action--and thus be in the Action stage at least briefly--before they can be classified in the Preparation stage for the first time. This problem can be avoided by using a behavioral criterion that does not characterize Action (e.g., delaying the first cigarette as a preparatory step in smoking cessation).

References

Baekeland, F., \& Lundwall, L. (1975). Dropping out of treatment: A critical review.

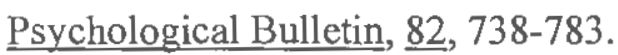

Bandura, A. (1977). Self-efficacy: Toward a unifying theory of behavior change. Psychological Review, 84, 191-215.

Beck, A.T., Freeman, A., \& Associates (1990). Cognitive therapy of personality disorders. New York: Guilford Press. 
Begun, A., Strodhoff, T., Weinstein, B., Shelley, G., Short, L. (1997, June).

Development of an instrument to assess readiness to change battering behavior:

Preliminary results. Paper presented at the 5th International Family Violence

Research Conference, Durham, NH.

Aldenderfer, M.S., \& Blashfield, R.K. (1984). Cluster analysis. Newbury Park, CA:

Sage

Bidgood, B., Tutty, L.M., \& Rothery, M. (1991). An evaluation of the Coordinated

Family Violence Treatment Program in the Waterloo area: A summary report.

Waterloo, Ontario, Canada: Centre for Social Welfare Studies.

Blashfield, R.K. (1980). Propositions regarding the use of cluster analysis in clinical

research. Journal of Consulting and Clinical Psychology, $\underline{48}, 456-459$.

Bodnarchuk, M., Knopp, P.R., Ogloff, J.R.P., Hart, S.D., \& Dutton, D.G. (1995).

Predicting cessation of intimate assaultiveness after group treatment. Report

\#4887-10-91-106 submitted to Family Violence Prevention Division, Health

Canada, Ottawa, Canada.

Buss, A.H., \& Durkee, A. (1957). An inventory for assessing different kinds of hostility. Journal of Consulting Psychology, 2, 513-524.

Cadsky, O., \& Crawford, M. (1988). Establishing batterer typologies in a clinical sample of men who assault their female partners. Canadian Journal of Community Mental Health, 7, 119-127.

Cadsky, O., Hanson, R.K., Crawford, M., \& Lalonde, C. (1996). Attrition from a male batterer treatment program: Client-treatment conguence and lifestyle instability. Violence and Victims, 11, 51-64. 
Comrey, A.L. (1988). Factor-analytic methods of scale development in personality and clinical psychology. Journal of Consulting and Clinical Psychology, 56, 754-761.

Crowne, D.P., \& Marlowe, D. (1960). A new scale of social desirability independent of psychopathology, Journal of Clinical and Consulting Psychology, 349-354.

Daniels, J.W., \& Murphy, C.M. (1997). Stages and processes of change in batterers' treatment. Cognitive and Behavioral Practice, 4 , 123-145.

DeMaris, A. (1989). Attrition in batterers' counseling: The role of social and demographic factors. Social Service Review, $\underline{63}, 142-154$.

DeMaris, A., \& Jackson, J.K. (1987). Batterers' reports of recidivism after counseling. Social Casework, $\underline{68}, 458-465$.

DiClemente, C.C., \& Hughes, S.O. (1990). Stages of change profiles in outpatient alcoholism treatment. Journal of Substance Abuse, 2, 217-235.

DiClemente, C.C., \& Prochaska, J.O. (1982). Self-change and therapy change of smoking behavior: A comparison of processes of change in cessation and maintenance. Addictive Behaviors, 7 , 133-142.

DiClemente, C.C., Prochaska, J.O., Fairhurst, S.K., Velicer, W.F., Velasquez, M.M., \& Rossi, J.S. (1991). The process of smoking cessation: An analysis of precontemplation, contemplation, and preparation stages of change. Journal of Consulting and Clinical Psychology, 59, 295-304.

Ding, L., Velicer, W.F., \& Harlow, L.L. (1995). Effects of estimation methods, number of indicators per factor, and improper solutions on structural equation modeling fit indices. Structural Equation Modeling, 2, 119-144. 
Dutton, D.G. (1995). The domestic assault of women. Vancouver: UBC Press.

Edelbrook, C. (1979). Mixture models of hierarchical clustering algorithms: The problems of classifying everybody. Multivariate Behavioral Research, $14,367-$ 384.

Edleson, J.L., \& Syers, M. (1990). The relative effectiveness of group treatment for men who batter. Social Work Research and Abstracts, 26, 10-17.

Everitt, B. (1980). Cluster analysis (2 ${ }^{\text {nd }}$ ed.) New York: Halsted Press.

Flournoy, P.S., \& Wilson, G.L. (1991). Assessment of MMPI profiles of male batterers. Violence and Victims, $\underline{6}$, 309-320.

Ganley, A. (1987). Perpetrators of domestic violence: An overview of counseling the court-mandated client. In D.J. Sonkin (Ed.), Domestic violence on trial: Psychological and legal dimensions of family violence (pp. 155-173). New York: Springer.

Gondolf, E.W. (1988a). The effect of batterer counseling on shelter outcome. Journal of Interpersonal Violence, 3 , 275-289.

Gondolf, E.W. (1988b). Who are those guys? Towards a behavioral typology of men who batter. Violence and Victims, $\underline{3}, 187-203$.

Gottman, J., Jacobson, N., Rushe, R., Short, J., Babcock, J., LaTaillade, J., \& Waltz, J. (1995). The relationship between heart rate reactivity, emotionally aggressive behavior, and general violence in batterers. Journal of Family Psychology, $\underline{9}$, $227-248$.

Gruznski, R.J., \& Carillo, R.P. (1988). Who completes batterer treatment groups? An empirical investigation. Journal of Family Violence, $\underline{3}, 141-150$. 
Janis, I.L., \& Mann, L. (1977). Decision making: A psychological analysis of conflict. choice and commitment. New York: Free Press.

Hamberger, L.K., \& Hastings, J.E. (1986). Characteristics of spouse abusers: Predictors of treatment acceptance. Journal of Interpersonal Violence, 1, 323-341.

Hamberger, L.K., \& Hastings, J.E. (1988). Skills training for treatment of spouse abusers: An outcome study. Journal of Family Violence, $\underline{3}$, 121-130.

Hamberger, L.K., \& Hastings, J.E. (1989). Counseling male spouse abusers:

Characteristics of treatment completers and dropouts. Violence and Victims, $\underline{4}$, 275-286.

Hamberger, L.K., \& Hastings, J.E. (I990). Recidivism following spouse abuse abatement counseling: Treatment program implications. Violence and Victims, $4,275-286$.

Hamberger, L.K., Lohr., Bonge, D., \& Tolin, D.E. (1996). A large sample empirical typology of male spouse abusers and its realtionship to dimensions of abuse. $\underline{\text { Violence and Victims, }} \underline{11}, 277-292$.

Harrell, A.V. (1991). Evaluation of court-ordered treatment for domestic violence offenders. Final report submitted to the State Justice Institute. Washington, D.C: The Urban Institute.

Hathaway, S.R., \& McKinley, J.C. (1967). MMPI inventory manual. New York: Psychological Press.

Hershorn, M., \& Rosenbaum, A. (1991). Over-vs. Undercontrolled hostility: Application of the construct to the classification of maritally violent men. $\underline{\text { Violence and Victims, }} \underline{6}, 151-158$. 
Holtzworth-Munroe, A., \& Stuart, G.L. (1994). Typologies of male batterers: Three subtypes and differences among them. Psychological Bulletin, 116, 476-497. Jackson, D.N. (1970). A sequential system for personality scale development. Current Topics in Clinical and Community Psychology, 2, 61-96.

Jackson, D.N. (1971). The dynamics of structured personality tests. Psychological Review, 78, 229-248.

Jacobson, N.S., Gottman, J.M., \& Shortt, J.W. (1995). The distinction between type 1 and type 2 batterers--Further considerations: Reply to Ornduff et al. (1995), Margolin et al., (1995), and Walker (1995). Joumal of Family Psychology, 9 , $272-279$

Johnson, S.S. (1997). Oral contraceptive use: The application of the Transtheoretical Model. Unpublished doctoral dissertation, University of Rhode Island, Kingston, RI.

Joreskog, K.G., Sorbom, D. (1989). LISREL 7: A guide to the program and applications (2nd ed.). Chicago: SPSS, Inc.

Laforge, R.G., Velicer, W.F., Richmond, R.L., \& Owen, N. (1998). Stage distributions for five health behaviors in the USA and Australia. Manuscript submitted for publication.

Lam, C.S., McMahon, B.T., Priddy, D.A., \& Gehred-Schultz, A. (1988). Deficit awareness and treatment performance among traumatic head injury adults. Brain Injury, 2, 235-242. 
Levesque, D., \& Gelles, R. (1997, June). Battering men: Applying the transtheoretical model to desistance and change. Paper presented at the 5th International Family Violence Research Conference, Durham, $\mathrm{NH}$.

Levesque, D.A, Gelles, R.J., \& Velicer, W.F. (1997, August). Battering men and courtmandated treatment: Applying the Transtheoretical Model to desistance and change. Paper presented at the $105^{\text {th }}$ annual meeting of the American Psychological Association, Chicago, IL.

Marcus, B.H., Rossi, J.S., Selby, V.C., Niaura, R.S., \& Abrams, D.B. (1992). The stages and processes of exercise adoption and maintenance. Health Psychology, $\underline{11}, 386-$ 395.

McConnaughy, E.A., DiClemente, C.C., Prochaska, J.O., \& Velicer, W.F. (1989).

Stages of change in psychotherapy: A follow-up report. Psychotherapy, 26, 494503.

McConnaughy, E.A., Prochaska, J.)., \& Velicer, W.F. (1983). Stages of change in psychotherapy: Measurement and sample profiles. Psychotherapy: Theory, Research and Practice, 20, 368-375.

Medieros, M., \& Prochaska, J.O. (1998). Predicting premature termination from psychotherapy. Manuscript submitted for publication.

Milligan, G.W., \& Cooper, M.C. (1987). Methodology review: Clustering methods. Applied Psychological Measurement, 11, 329-354.

Millon, T. (1983). Millon Clinical Multiaxial Inventory Manual. Minneapolis, MN: Interpretive Scoring Systems. 
Murphy, C.M., \& Baxter, V.A. (1997). Motivating batterers to change in the treatment context. Journal of Interpersonal Violence, $12,07-619$.

National Research Council \& Institute of Medicine. (1998). National Research Council. (1996). N.A. Crowell \& W.A. Burgess (Eds.), Understanding violence against women. Washington, DC: National Academy Press.

Pan, H.S., Neidig, P.H., \& O’Leary, K.D. (1994). Male-female and aggressor-victim differences in the factor structure of the Modified Conflict Tactic Scale. Journal of Interpersonal Violence, 9 , 366-382.

Petrik, N.D., Gildersleeve-High, L., McEllistrem, J.E., \& Subotnik, L.S. (1994). The reduction of male abusiveness as a result of treatment. Reality or myth? Journal of Family Violence, 9 , 307-316.

Pirog-Good, M., \& Stets, J. (1986). Programs for abusers: Who drops out and what can be done? Response, 2, 17-19.

Prochaska, J.O., \& DiClemente, C.C. (1983). Stages and processes of self-change of smoking: Toward and integrative model of change. Joumal of Consulting and Clinical Psychology, 51, 390-395.

Prochaska, J.O., \& DiClemente, C.C. (1986). Toward a comprehensive model of behavior change. In W.R. Miller \& N. Heather (Eds.), Treating additictive behaviors: Processes of change (pp. 3-27). New York: Plenum Press

Prochaska, J.O., DiClemente, C.C., Velicer, W.F., Ginpil, S., \& Norcross, J. (1985). Predicting change in smoking status for self-changers. Addictive Behavior, $\underline{10}$, 395-406. 
Prochaska, J.O., Norcross, J.C., Fowler, J.L., Follick, M.J., \& Abrams, D.B. (1992).

Attendance and outcome in a work-site weight control program: Processes and stages of change as process and predictor variables. Addictive Behaviors, 17, 3545.

Prochaska, J.O., Redding, C.A., Harlow, L.L., Rossi, J.S., \& Velicer, W.F. (1994). The transtheoretical model of change and HIV prevention: A review. Health Education Quarterly, 21, 471-486.

Prochaska, J.O., Rossi, J.S., \& Wilcox, N.S. (1991). Change processes and psychotherapy outcomes in integrative case research. Journal of Psychotherapy Integration, 1(2), 103-119.

Rakowski, W., Ehrich, B., Dube, C.E., Pearlman, D.N., Goldstein, M.G., Peterson, K.K., Rimer, B.K., \& Woolverton, H. (1996). Screening mammography and constructs from the transtheoretical modal: Associations using two definitions of the stagesof-adoption. Society of Behavioral Medicine, 18, 91-100.

Reynolds, W.M. (1982). Development of reliable and valid short forms of the MarloweCrowne Social Desirability Scale. Journal of Clinical Psychology, 33, 119-125. Rice, M.E., \& Harris, G.T. (1995). Violent recidivism: Assessing predictive validity.

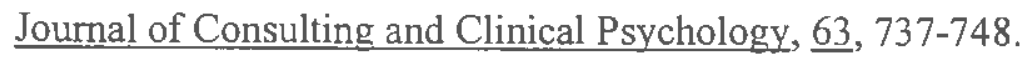

Rosenbaum, A., Gearan, P.J., \& Ondovic, C. (1997, June). Completion and recidivism among court- and self-referred batterers in a psychoeducational group treatment program: Implications for intervention and public policy. Paper presented at the 5th International Family Violence Research Conference, Durham, NH. 
Rossi, J.S., Blais, L.M., Redding, C.A., \& Weinstock, M.A. (1995). Preventing skin cancer through behavior change: Implications for interventions. Dermatologic Clinics, $13,613-622$.

SAS Institute, Inc. (1989). SAS/STAT user's guide. version 6 (4th ed., vol. 1). Cary, NC: SAS Institute, Inc.

Saunders, D.G. (1992). A typology of men who batter: Three types derived from cluster analysis. American Journal of Orthopsychiatry, 62, 264-275.

Saunders, D.G. (1993). Husbands who assault: Multiple profiles requiring multiple responses. In Z. Hilton (Ed.), Legal responses to wife assault. Newbury Park, CA: Sage.

Saunders, D.G. (1996). Feminist-cognitive-behavioral and process-psychodynamic treatments for men who batter: Interactioin of abuse traits and treatment models. Violence and Victims, 11, 393-413.

Saunders, D.G., \& Hanusa, D. (1986). Cognitive-behavioral treatment of men who batter: The short-term effects of group therapy. Journal of Family Violence, 1 , $357-372$.

Saunders, D.G., \& Parker, J.C. (1989). Legal sanctions and treatment follow-through among men who batter: A multivariate analysis. Social Work Research and Abstracts, September, 1989, 21-29.

Shepard, M. (1992). Predicting batterer recidivism five years after community intervention. Journal of Family Violence, 7, 167-178. 
Spanier, G.B. (1976). Measuring dyadic adjustment: New scales for assessing the quality of marriage and similar dyads. Journal of Marriage and the Family, 38 , $15-38$.

Straus, M.A. (1979). Measuring intrafamily conflict and violence: The Conflict Tactics (CT) Scales. Journal of Marriage and the Family, 41, 75-88.

Sweeney, S., \& Key, L.J. (1982). Psychological issues in counseling batterers. Theology, News, and Notes, June, 12-16.

Tolman, R.M., \& Bhosley, G. (1989). A comparison of two types of pregroup preparation for men who batter. Journal of Social Science Research, 13, 33-43.

Tsoh, J.Y. (1995). Stages of change, dropouts, and outcome in substance abuse treatment. Unpublished doctoral dissertation, University of Rhode Island, Kingston, RI.

Tucker, L.R., \& Lewis, C. (1973). A reliability coefficient for maximum likelihood factor analysis. Psychometrika, $\underline{38}, 1-10$.

Velicer, W.F., Fava, J.L., Prochaska, J.O., Abrams, D.B., Emmons, K.M., \& Pierce, J.P. (1995). Distribution of smokers by stage in three representative samples. Preventive Medicine, 24, 401-411.

Velicer, W.F., Martin, R.A., \& Collins, L.M. (1996). Latent transition analysis for longitudinal data. Addiction, 91 (Supplement), 197-209.

Walker, L.E.A. (1995). Current perspectives on men who batter women--Implications for intervention and treatment to stop violence against women: Comment on Gottman et al. (1995). Journal of Family Psychology, 9, 264-271. 
Ward, J.H. (1963). Hierarchical grouping to optimize an objective function. Journal of the American Statistical Association, 58, 236-244.

Wierzbicki, M., \& Pekarik, G. (1993). A meta-analysis of psychotherapy dropout.

Professional Psychology: Research and Practice, 24, 190-195. 


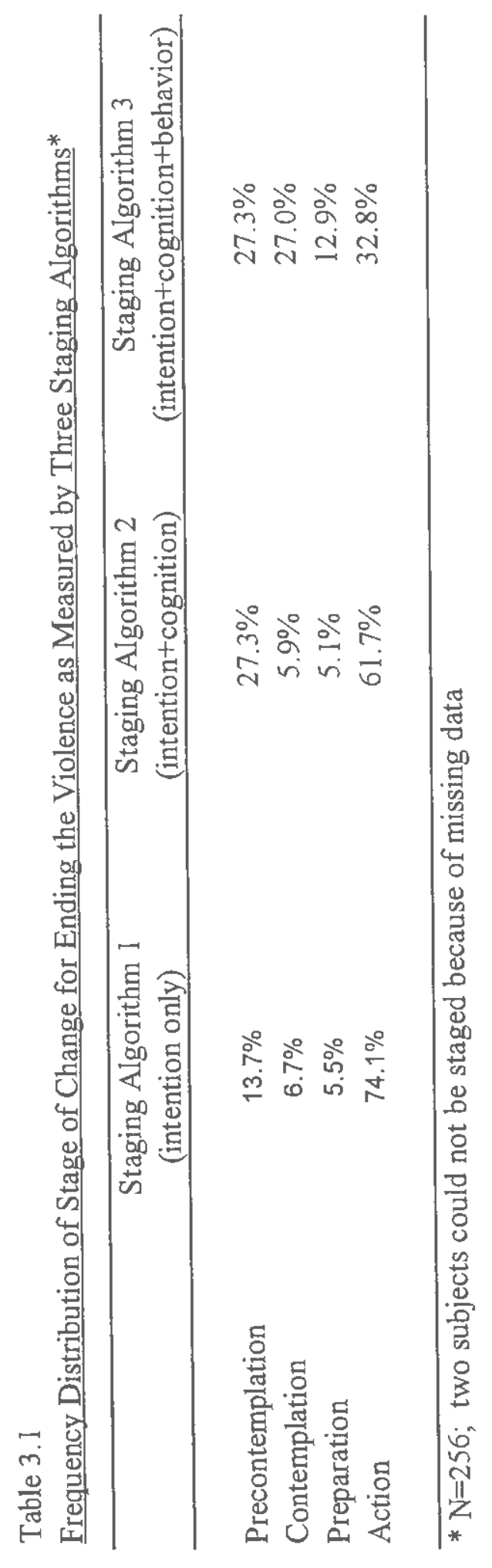




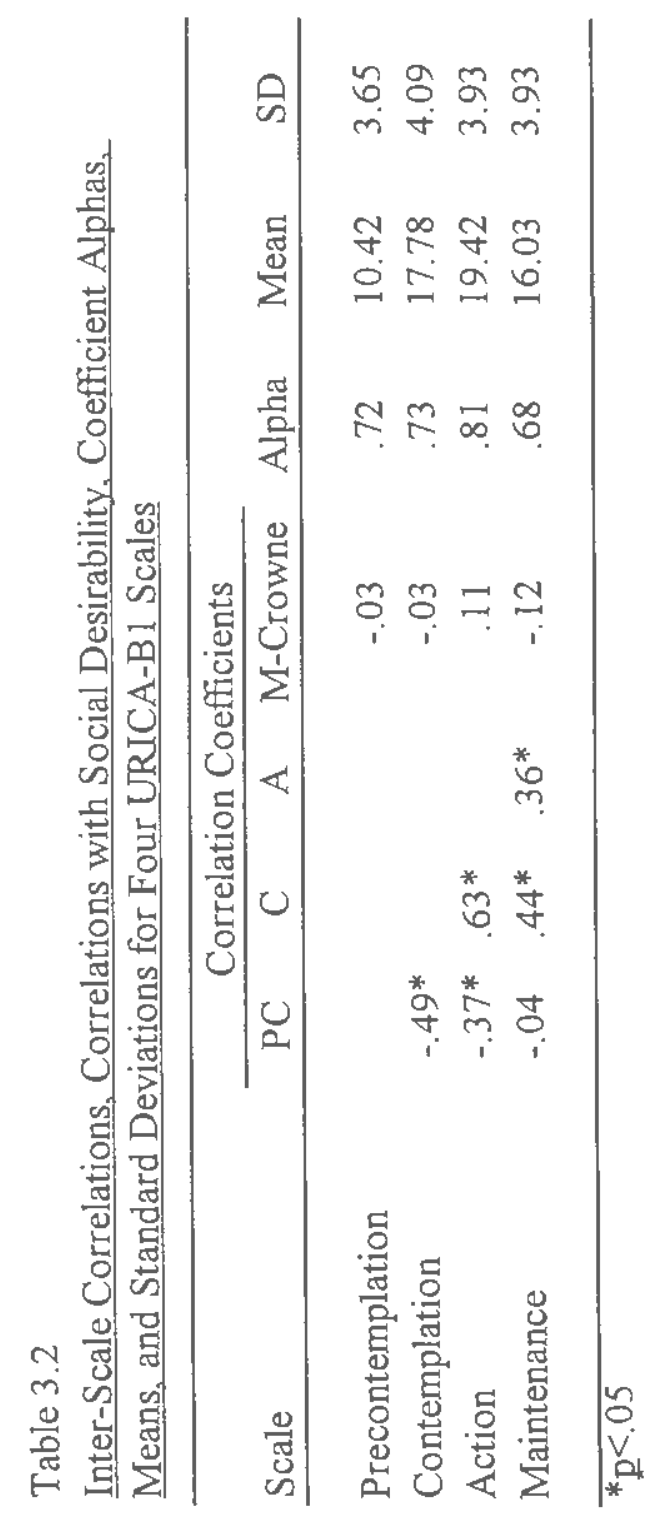




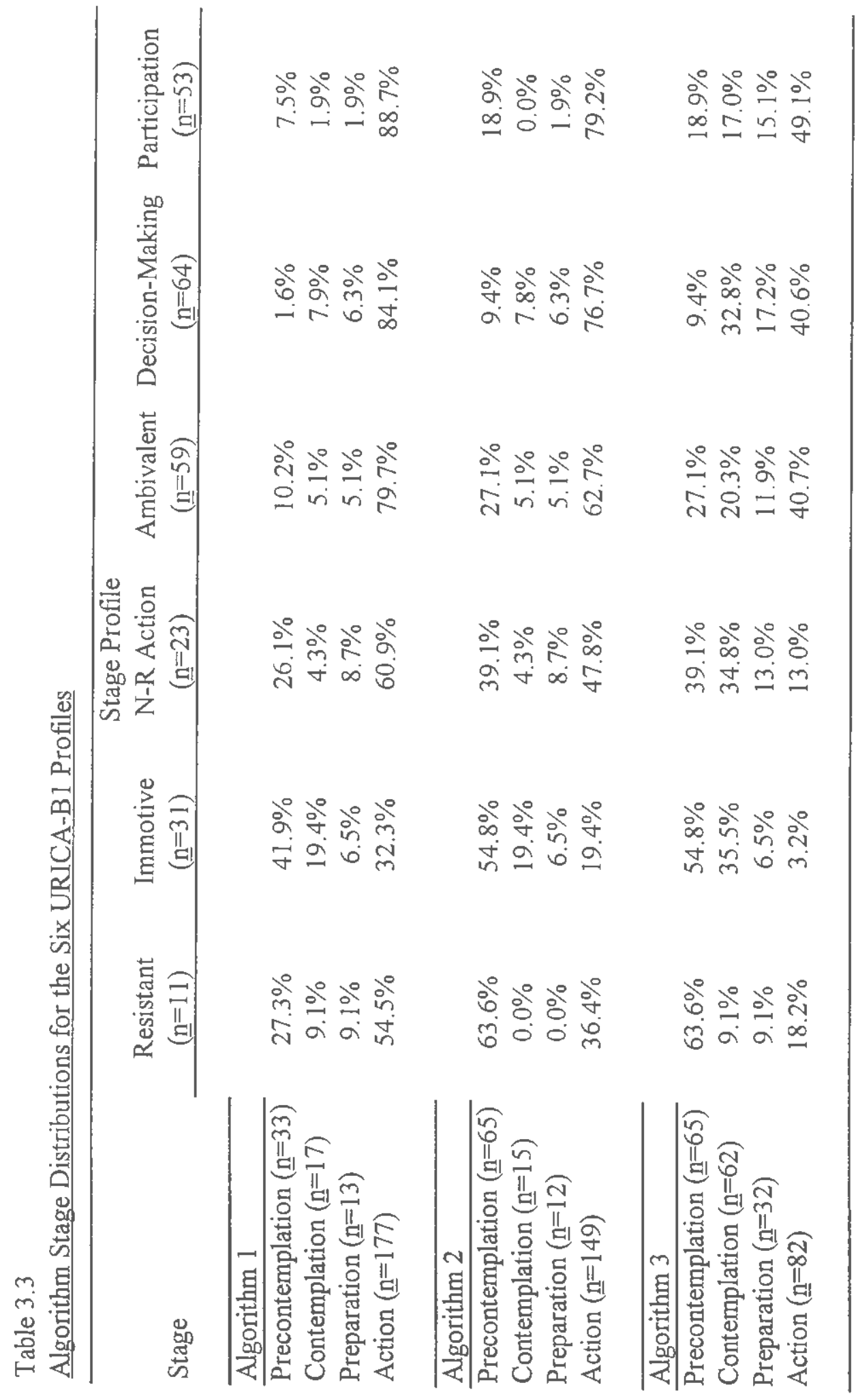




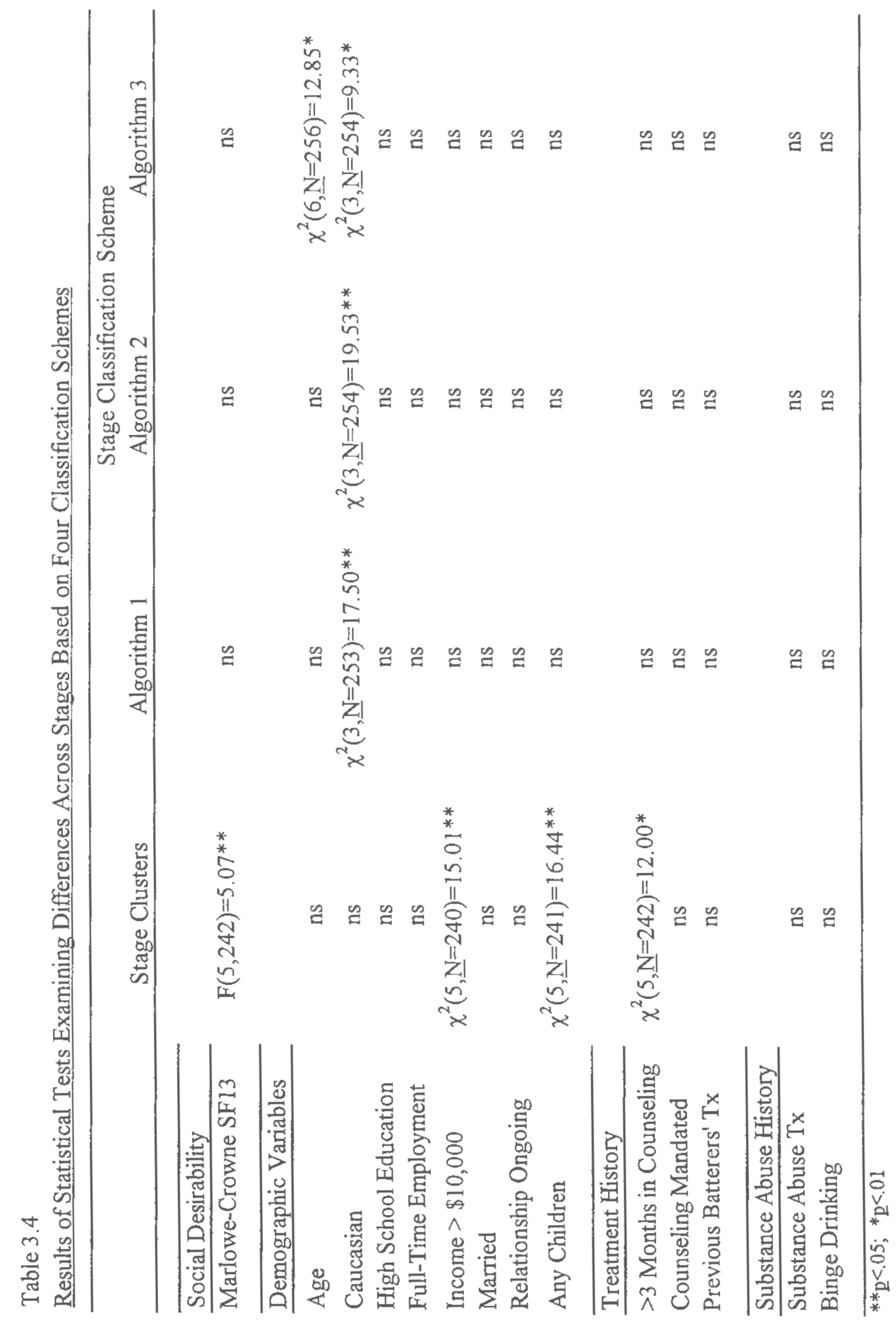




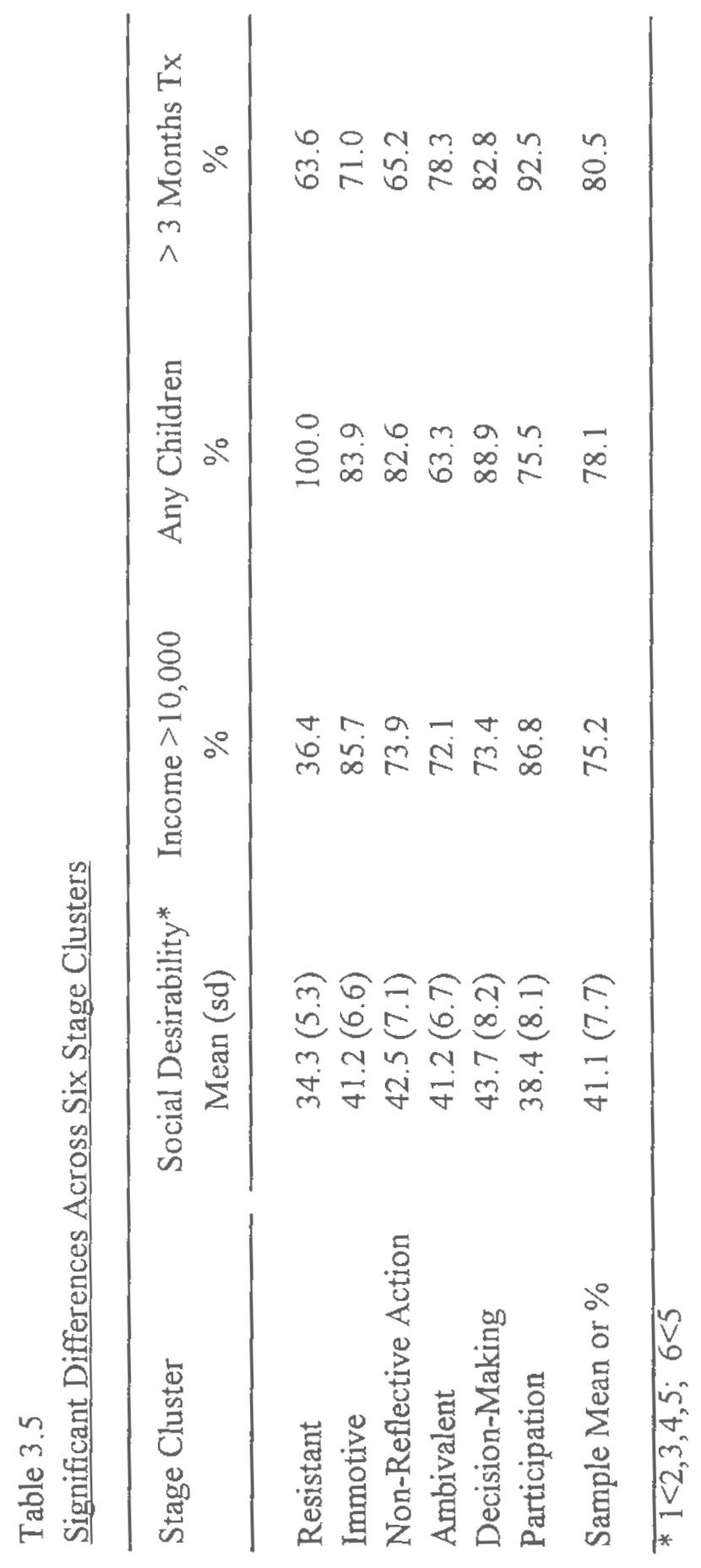




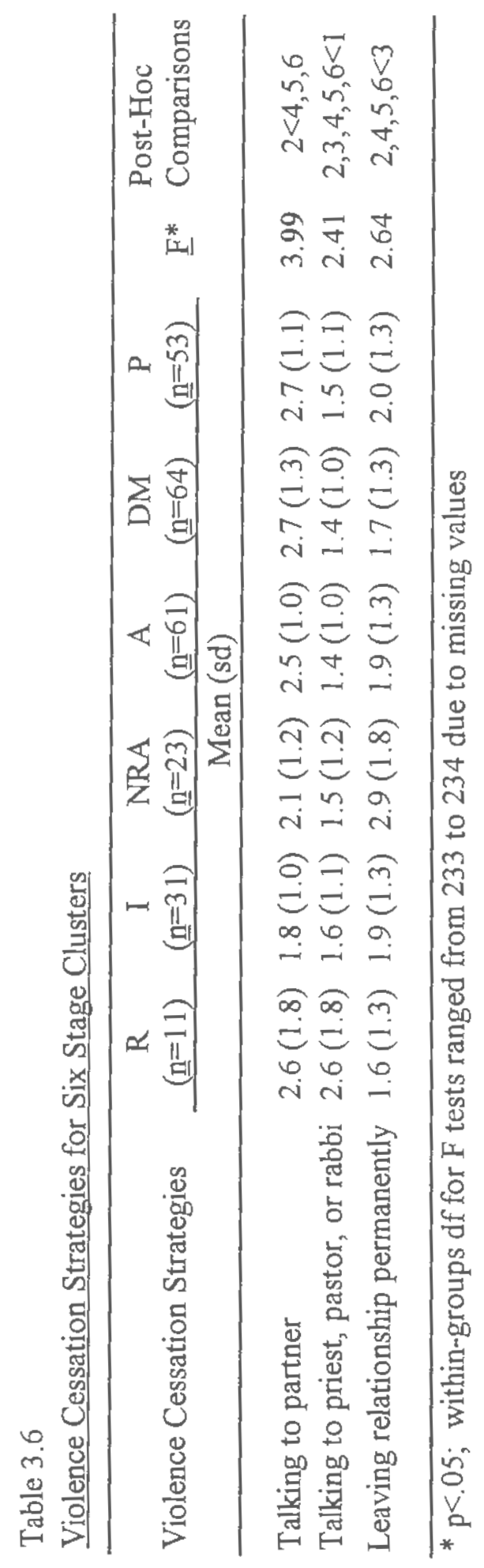




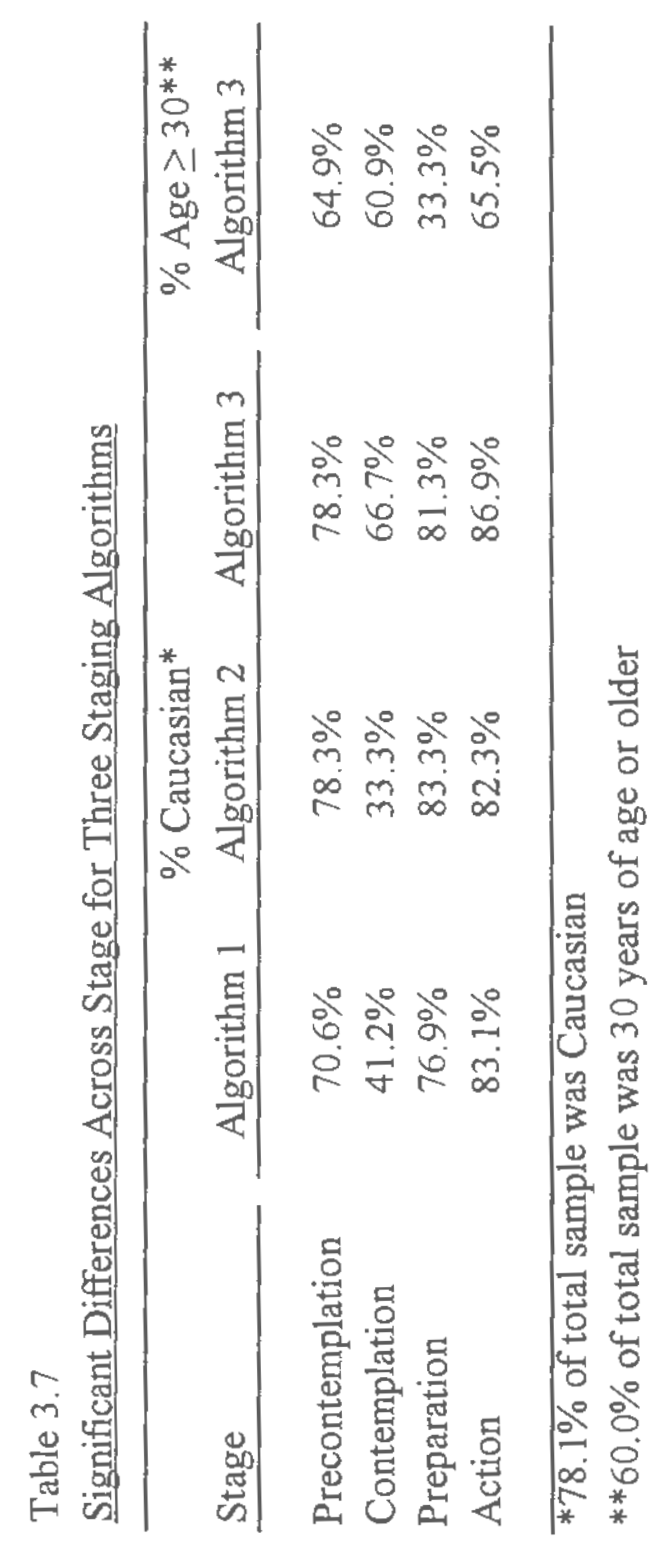




\section{Figure 3.1.}

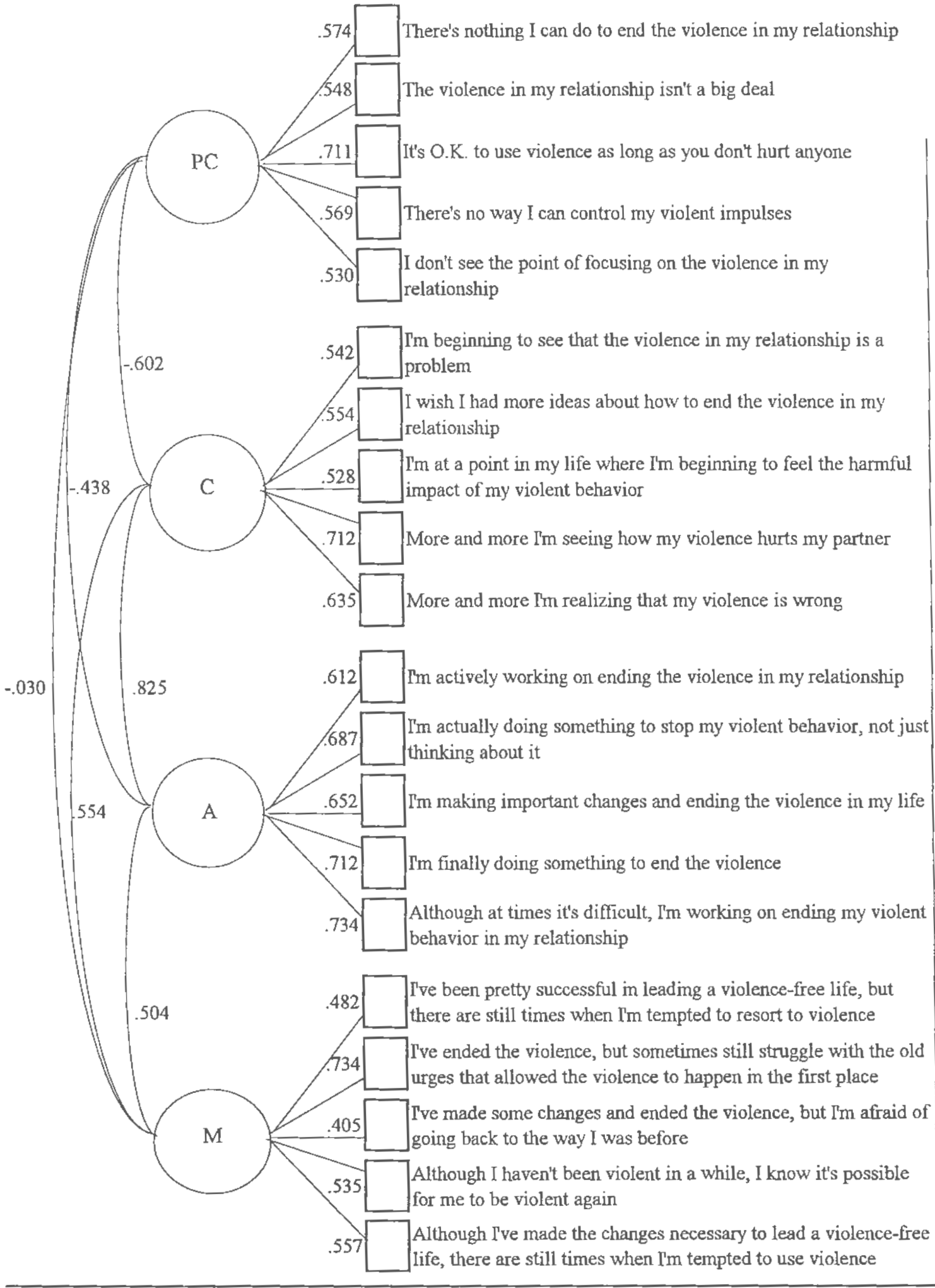




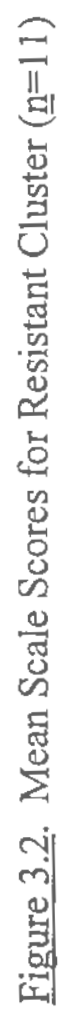

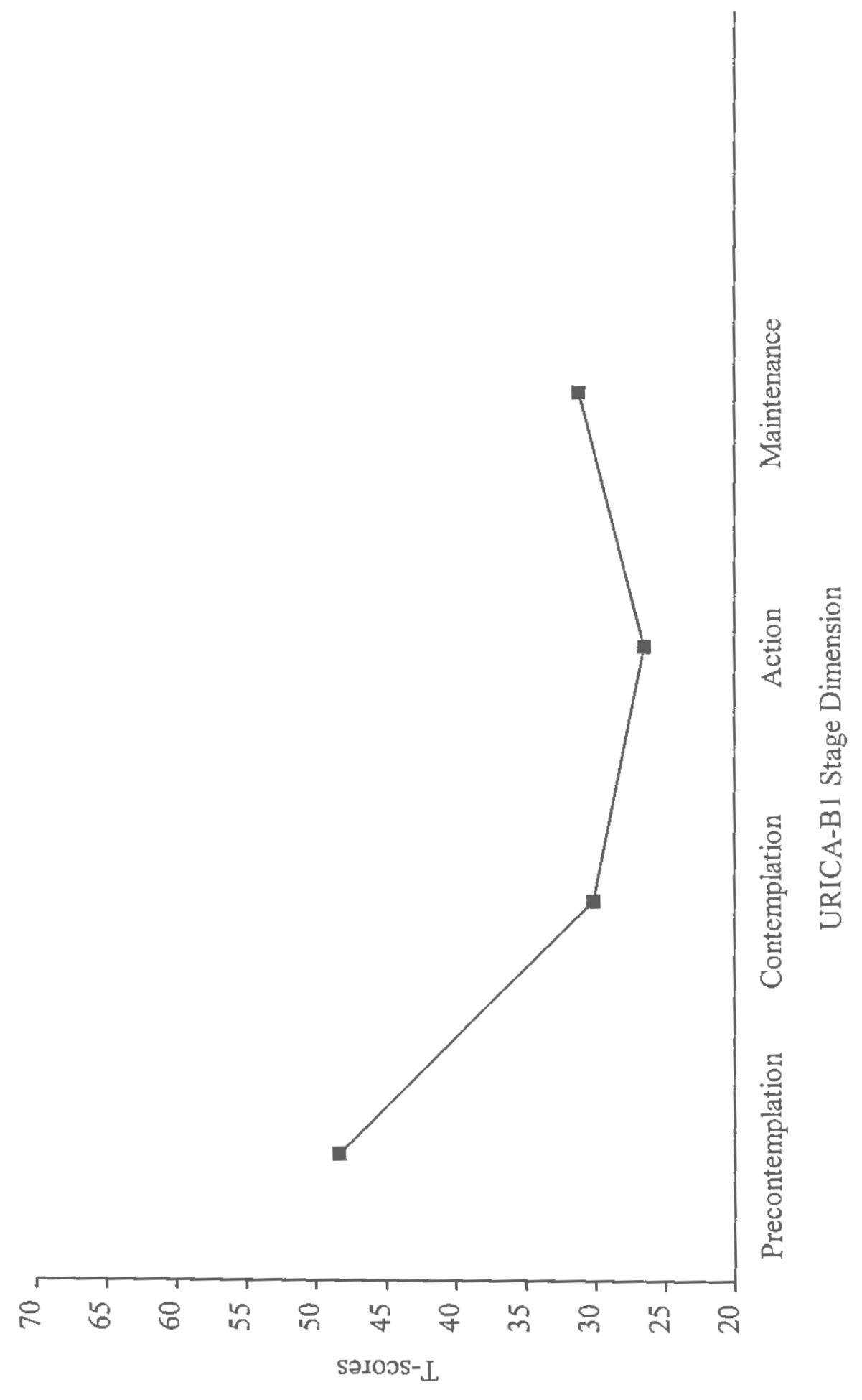


苛

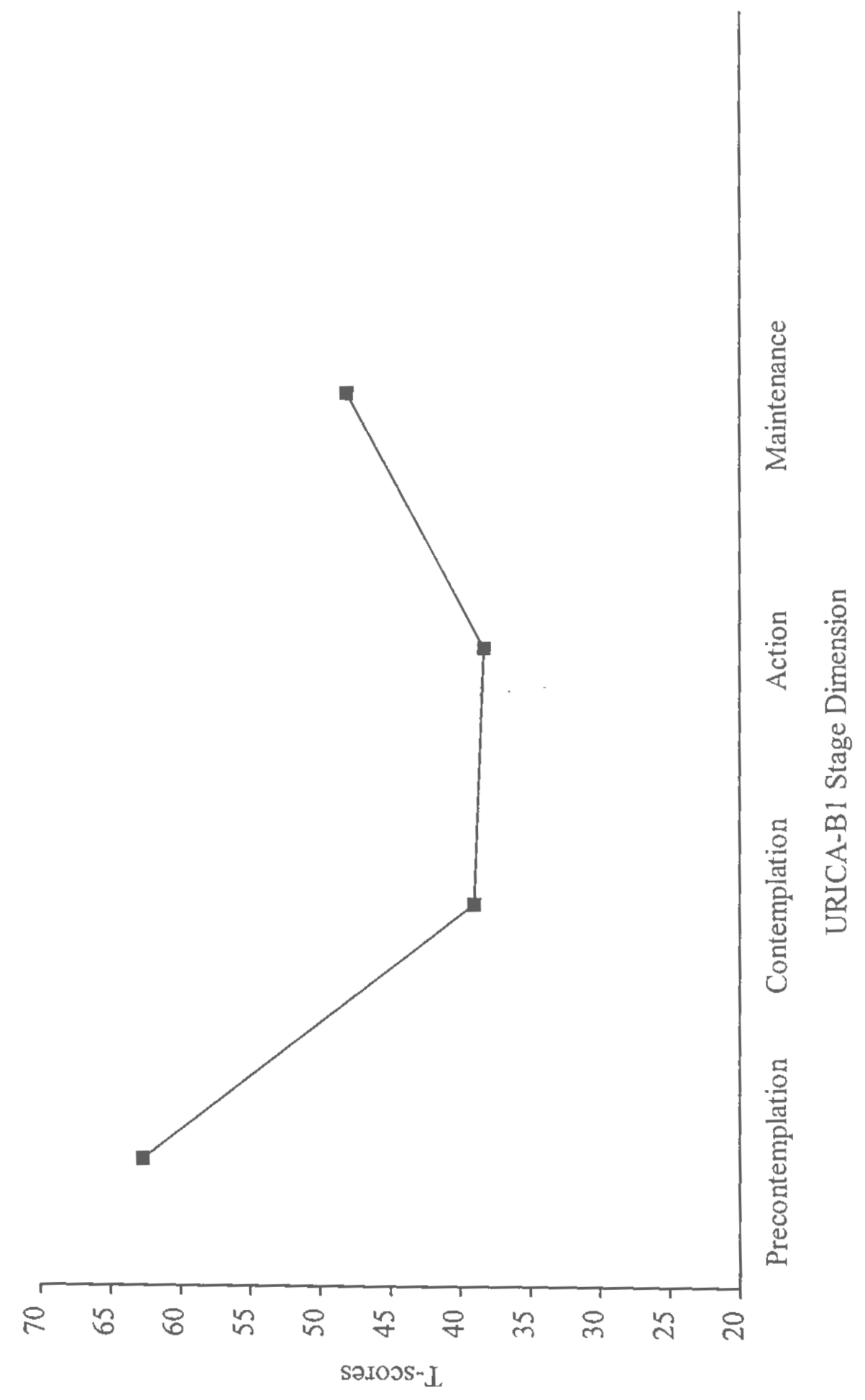




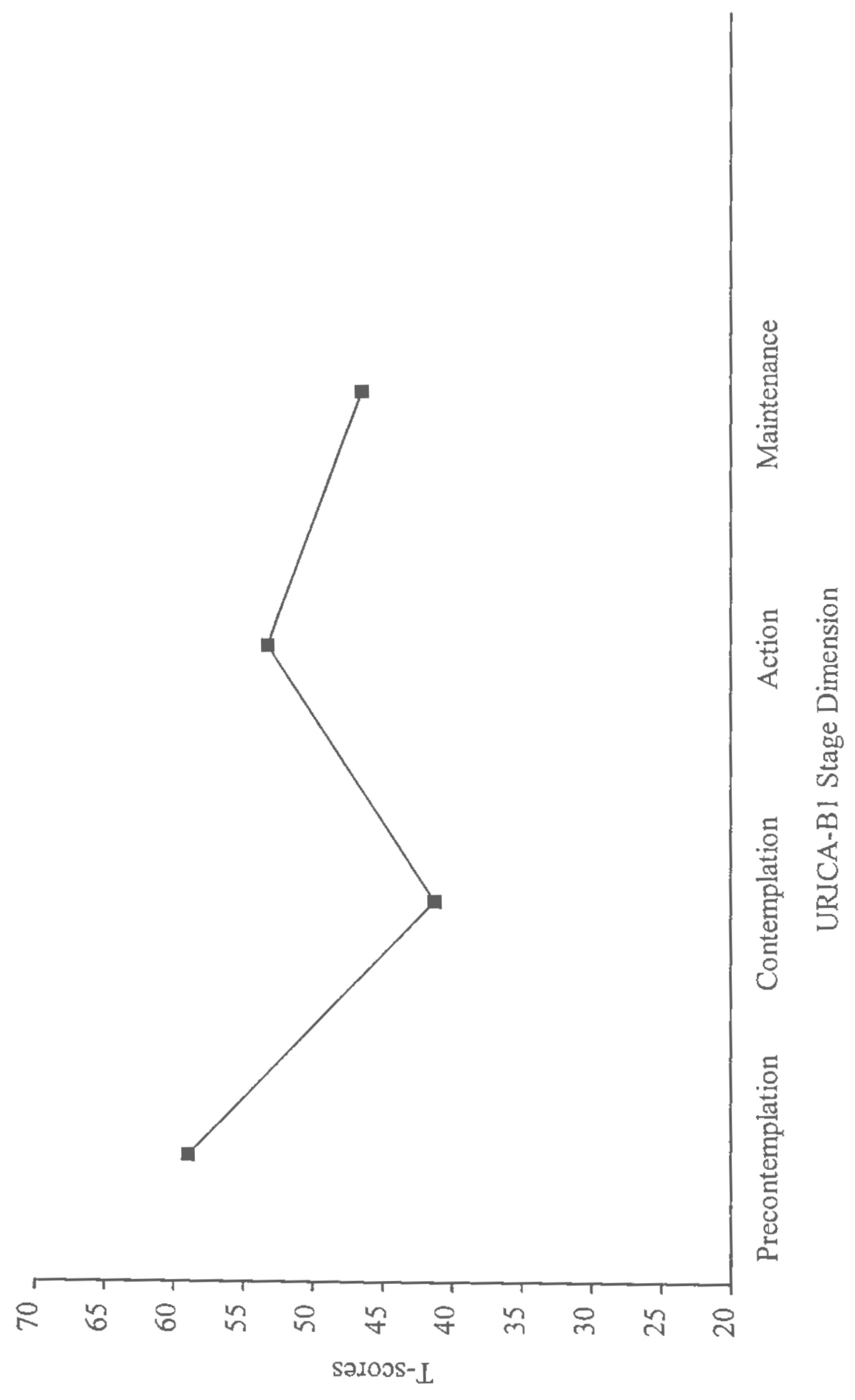




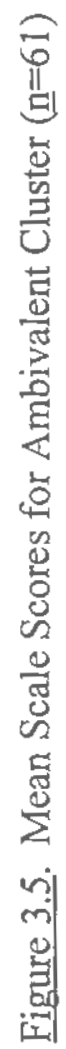

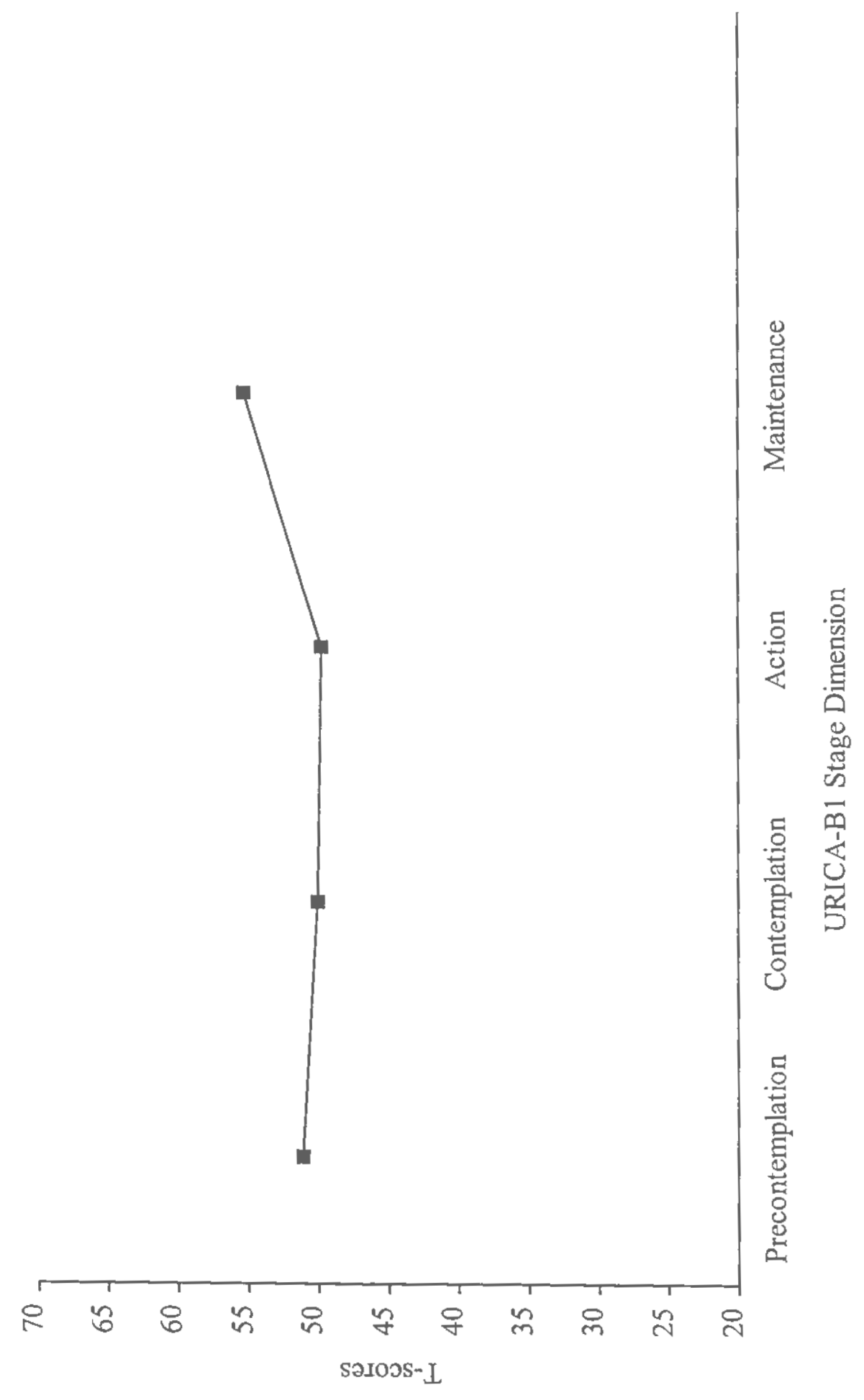




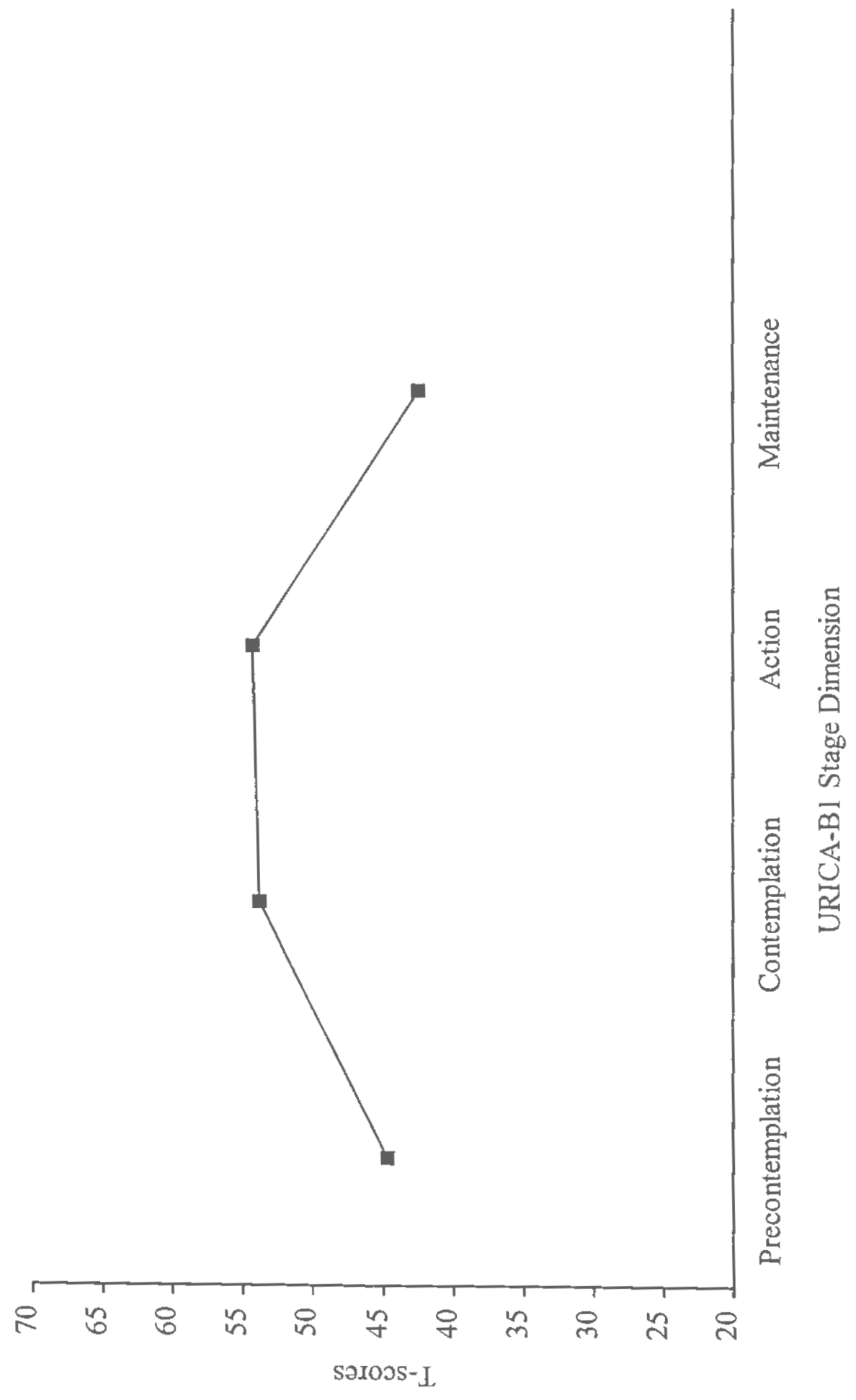




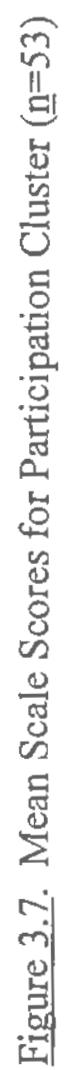

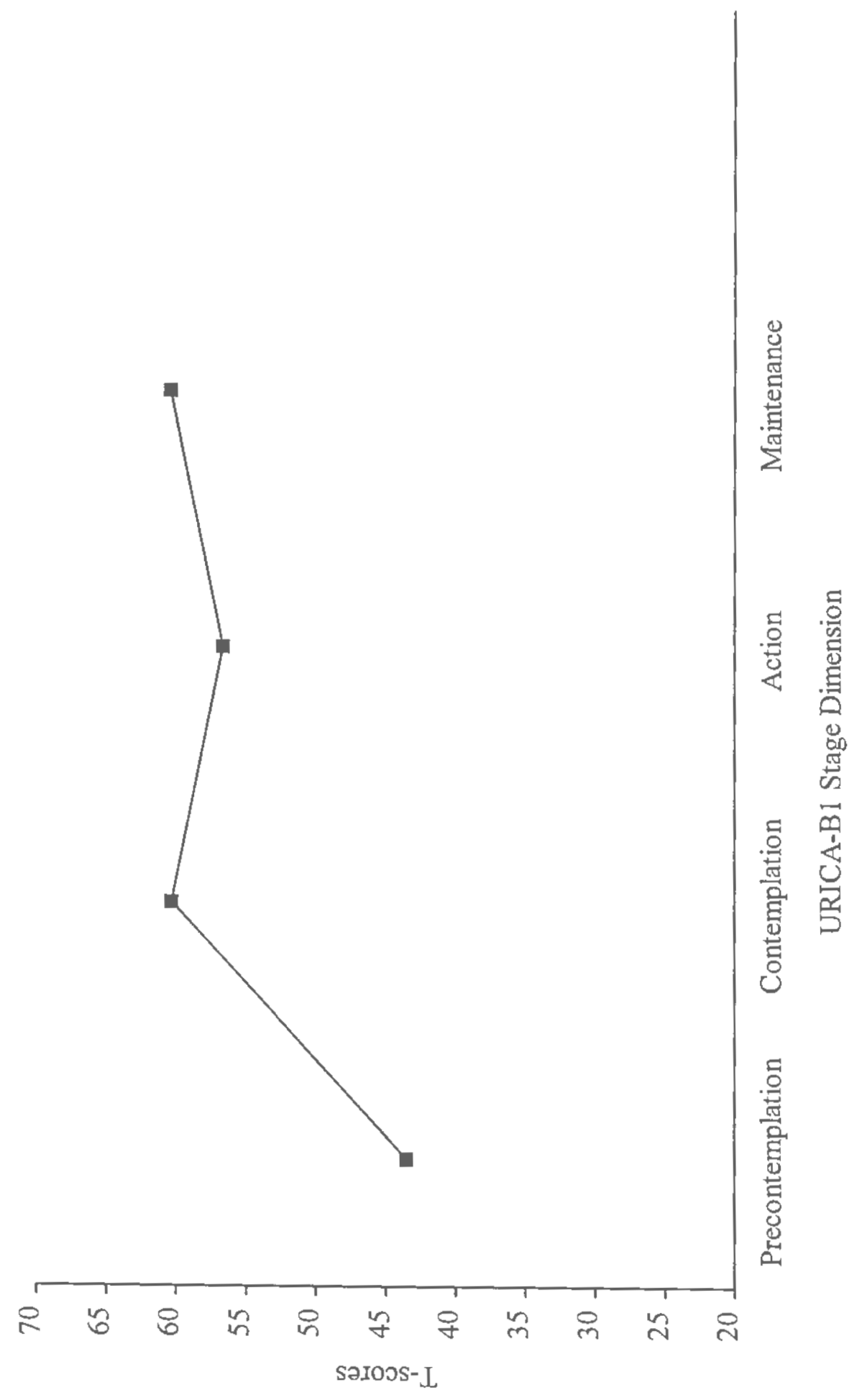




\section{CHAPTER 4}

Tests of the Applicability of the Transtheoretical Model of Change to Violence Desistance among Battering Men 


\section{Introduction}

Ten years ago, Gondolf (1987) proposed that change in battering men be conceptualized as a developmental process. Drawing from Kohlberg's theory of moral development (1981), Gondolf hypothesized that battering men progress through a series of six stages of change that represent different levels of moral reasoning and behavior: 1) Defiance; 2) Self-Justification; 3) Self-Change; 4) Relationship Building; 5) Community Service; and 6) Social Action. What is particularly appealing about the model is the notion that stage of change can serve as a central organizing construct around which to integrate disparate--and often competing--interventions and intervention modalities that exist for men who batter. For instance, Gondolf recommended constraint via divorce or jailing for men in the Defiance stage, confrontation via court-mandated counseling for men in the Self-Justification stage, and behavior management via self-help groups for men in the Self-Change stage. The six stages of change, levels of moral development, and stage-matched modalities and interventions are presented in Table 4.1. In Gondolf's view, the ultimate goal of the change process is not merely violence desistance, but taking social action to help solve the problem of partner violence.

Although innovative, compelling, and well-known to the field, the model's applicability to the problem of violence desistance and change among battering men remains questionable. First, while Gondolf's stages of change represent a plausible sequence of points in the change process, the associated stages of moral development do not. Kohlberg found that moral development continues into one's late 20 , but that after high school it is characterized primarily by stabilization, or a preference for the highest level attained (Kohlberg \& Kramer, 1969; Rest, 1973). Thus, level of moral 
development is probably not as dynamic or amenable to change as Gondolf suggests. Second, interventions seem to mirror men's level of moral development rather than facilitate movement to later stages. Men having an obedience and punishment orientation are met with punishment; those having an egoistic orientation are met with a contrasting world view that may dismiss their own; those having a good boy orientation are met with the help they request. These interventions may be appropriate if we view level of moral development as a stable personality characteristic: some men may indeed respond best to jailing. But it seems unlikely that jailing would facilitate movement from the Defiance to the Self-Justification stage, or from an obedience and punishment to an egoistic orientation. A final problem with the theory is that it lacks empirical support. Despite the field's interest in the model, there is no evidence in the literature that researchers have tried to measure its core constructs, test assumptions about the relationships among it constructs, or test the efficacy of the recommended stage-matched interventions.

The Transtheoretical Model of Change is an altemative integrative model that may help explain the process of change in battering men and guide intervention. Over the last 20 years the Transtheoretical Model has been shown to be remarkably robust in its ability to explain individual change across a variety of addictions and other maladaptive behaviors (Prochaska \& DiClemente, 1983; DiClemente \& Hughes, 1990; Prochaska, Norcross, Fowler, Follick, \& Abrams, 1992; Prochaska, Redding, Harlow, Rossi, \& Velicer, 1994). The Transtheoretical Model integrates a number of theoretical constructs central to change: stages of change, processes or strategies of change, decisional balance (Janis \& Mann, 1977), and self-efficacy (Bandura, 1977). As in Gondolf's model, stage of change serves as a central construct around which to organize interventions. However, 
in this case stage of change is a dynamic variable representing individuals' readiness to change. The interventions recommended for each stage meet individuals where they are in their readiness to change--not by mirroring stage of readiness, but by encouraging the use of change strategies shown empirically to facilitate movement to the next stage. A large body of empirical data supports the validity of the model's theoretical constructs and the hypothesized relationships between them. Experts in the field have already begun to anticipate the model's usefulness in enhancing the motivation of batterers in group treatment (Begun, Strodhoff, Weinstein, Shelley, \& Short, 1997; Daniels \& Murphy, 1997; Dutton, 1995; Dutton, Bodnarchuk, Kropp, Hart, \& Ogloff, 1997; Levesque \& Gelles, 1997; Levesque, Gelles, \& Velicer, 1997; Murphy \& Baxter, 1997), and have begun to develop measures of stage of change for battering men (Begun et al., 1997; Levesque \& Gelles, 1997; Levesque, Gelles, \& Velicer, 1997). However, the applicability of the model to this new behavior domain has yet to be demonstrated.

The development of psychometrically sound measures of the core constructs of the Transtheoretical Model is the first step in the application of the model to violence desistance. The testing of assumptions about the relationships between the model's constructs is the second step. Two studies are reported here. In Study 1, stage of change, decisional balance, and self-efficacy measures for battering men are developed to continue instrument development work reported in Chapter 3. In Study 2, seven tests of the model are conducted to assess whether relationships between stage of change and behavior, decisional balance and self-efficacy found in research on other types of behavior change hold for violence desistance as well. Once the core constructs of the Transtheoretical Model of Change and their hypothesized relationships have been applied 
to the problem of partner violence, the model and measurement tools can help guide intervention. Researchers and practitioners can consider adapting for batterers some of the interventions developed and tested by Transtheoretical Model of Change researchers for other problem behaviors.

Provided below is a description of the core constructs of the Transtheoretical Model of Change, the state of the instrument development work, and seven tests that will be conducted to assess the applicability of the model to violence desistance among battering men.

\section{The Transtheoretical Model of Change}

Stages of Change is the Transtheoretical Model's central organizing construct. Longitudinal studies of change have found that people move through a series of five stages when modifying addictive behavior on their own, or with the help of formal intervention (DiClemente \& Prochaska, 1982; Prochaska \& DiClemente, 1983). In the first stage of change, the Precontemplation Stage, individuals deny they have a problem and thus are resistant to change, are unaware of the negative consequences of their behavior, believe the consequences are insignificant, or have given up the thought of changing because they are demoralized. They are not thinking about changing in the next six months. Individuals in the Contemplation Stage are more likely to recognize the benefits of changing. However, they continue to overestimate the costs of changing and therefore are ambivalent and not quite ready to change. They are seriously considering making a change within the next six months. Individuals in the Preparation Stage have decided to make a change in the next 30 days, and have already begun to take small steps toward that goal. Individuals in the Action Stage are overtly engaged in modifying their 
problem behaviors or acquiring new, healthy behaviors. Individuals the Maintenance Stage have been able to sustain change for at least six months, and are actively striving to prevent relapse. The Maintenance stage lasts until Termination, when there is negligible chance of relapse. For most people the change process is not linear, but spiral, with several relapses to earlier stages before they attain permanent behavior change (Prochaska \& DiClemente, 1983, 1986).

The men in Gondolf's (1987) Defiance and Self-Justification stages would be classified as Precontemplators using the Transtheoretical Model stage construct; men in the Self-Change stage would be classified in Action. Relationship Building, Community Service, and Social Action describe three additional behavior change goals. Men would conceivably need to progress from Precontemplation to Action and Maintenance for these behaviors.

The stage construct has received empirical support across studies of behavior cessation in the areas of alcohol abuse (DiClemente \& Hughes, 1990), psychological distress (Prochaska, Rossi, and Wilcox, 1991), and sun exposure (Rossi, Blais, Redding, \& Weinstock, 1995), and behavior acquisition in the areas of exercise (Marcus, Rossi, Selby, Niaura, \& Abrams, 1992), safe sex practices (Prochaska, Redding, Harlow, Rossi, \& Velicer, 1994) and mammography screening (Rakowski et al., 1996), among others. Extensive research on smoking cessation shows that Stage of Change is a better predictor of future behavior than demographic variables (Prochaska, DiClemente, Velicer, Ginpil, $\&$ Norcross, 1985). Smokers in Preparation are twice as likely to be abstinent at one month post-treatment than Contemplators, who in turn are twice as likely to be abstinent 
than Precontemplators. The pattern continues at six months post-treatment (DiClemente, Prochaska, Fairhurst, Velicer, Velasquez, \& Rossi, 1991).

Stage of change can be assessed using two self-report methods. In the first, a classification algorithm is used to place individuals in one of five mutually exclusive stage categories based on their responses to a few questions about their intentions, past behavior, and present behavior (DiClemente et al., 1991). Chapter 3 describes the development and initial validation of three staging algorithms that represent different sets of decision rules for classifying men in the Precontemplation, Contemplation, Preparation, and Action stage for violence desistance. The most complex algorithm, which re-classified men from the Preparation and Action stage to earlier stages if they hadn't taken any concrete steps to end their violence (e.g., speaking to a friend or the clergy, leaving the relationship), seemed to work best. However, the data suggest that we need to take a step back and look more closely at men who say they are in Action but report making no overt efforts to change. By keeping these men separate, rather than reclassifying them into earlier stage groups, we can examine how they compare to men in Precontemplation, Contemplation, Preparation, and Action. Stage of change was unrelated to social desirability and to all treatment history, substance abuse, and demographic variables examined, with two exceptions: Caucasians were underrepresented in the Contemplation stage for all three staging algorithms, and men above the age of 30 were under-represented in the Preparation stage for the most complex algorithm.

Change can also be assessed using continuous measures that represent the degree to which individuals' attitudes and behaviors characterize each of the different stages. 
Although subjects progress from one stage to another, they may have attitudes and exhibit behaviors that characterize more than one stage at the same time. Their profiles or patterns of scores on the various measures characterize their readiness to change. The first measure of this kind, the University of Rhode Island Change Assessment Scale (URICA), was developed to assess readiness for psychotherapy (McConnaughy, Prochaska, \& Velicer, 1983; McConnaughy, DiClemente, Prochaska, \& Velicer, 1987). Research has demonstrated the predictive validity of the URICA for a variety of other populations, such as brain-impaired patients in rehabilitation programs (Lam, McMahon, Priddy, \& Gehred-Schultz, 1988), and substance abusers in residential treatment programs (Tsoh, 1995). How much people change following a brief course of therapy is directly related to their URICA stage prior to therapy. The URICA also predicts who will terminate from psychotherapy prematurely (Medieros \& Prochaska, 1992).

Chapter 3 describes the development and initial validation of a URICA scale, the URICA-Bl, for men in court-mandated treatment for partner violence. When men's scores on the four URICA-B1 dimensions (Precontemplation, Contemplation, Action, and Maintenance) were standardized and entered into a cluster analysis, six clusters emerged representing different levels of readiness to end the violence. The six cluster profiles are presented in Figure 4.1. Based on interpretations of the shape, level, and scatter of the profiles and their similarity with the profiles identified in psychotherapy patients using the original URICA (McConnaughy, Prochaska, \& Velicer, 1983), the clusters of battering men were labeled: 1) Resistant; 2) Immotive; 3) Non-Reflective Action; 4) Ambivalent; 5) Decision-Making; and 6) Participation. This sequence 
tentatively represents a progression from the least to the most advanced in the process of ending violence against a partner.

Differences in social desirability, demographics, binge drinking, and violence cessation strategies across URICA-BI clusters suggest that at least two of the clusters may be tapping personality characteristics in addition to change readiness. For instance, men in the Resistant cluster seem to be somewhat antisocial. They demonstrate a very low need for social approval and a high rate of binge drinking; they are less than half as likely as men in the other clusters to be employed full-time. Another curious finding was that they seek help from the clergy more often than men do in other stage clusters in efforts to end the violence. Men in the Non-Reflective Action cluster are probably impulsive as well. A majority of them are binge drinkers. They are more likely than all other clusters but the Resistant cluster to end the violence simply by leaving the relationship.

The remaining clusters, the Immotive, Ambivalent, Decision-Making, and Participation clusters, seem to represent the Precontemplation, Contemplation, Preparation, and Action stages of change, respectively. It is important to note, however, that men in the Participation cluster scored significantly lower on social desirability than men in the Decision-Making cluster, possibly indicating reduced psychological defensiveness. As expected, men in the more advanced stage clusters were more likely than men in the earlier clusters to have been in treatment for some time. It unclear from the data whether men persist in treatment because they're in the later stages, or whether they're in the later stages because they've had greater exposure to treatment. 
Processes of Change. In a comparative analysis of 24 major systems of psychotherapy, Prochaska (1984) distilled a list of 10 fundamental processes by which people change. The list was refined following further theoretical analyses (Prochaska \& DiClemente, 1984) and empirical studies (Prochaska \& DiClemente, 1985, 1986). These processes describe the basic patterns of activity the various systems of therapy try to encourage or elicit in clients to help them change problem behaviors, affects, cognitions, or interpersonal relationships. The list of the ten change processes and definitions, adapted to the problem of male-to-female partner violence, is presented in Table 4.2. Five of the processes are experientially-oriented, and five are behaviorally-oriented (see Prochaska, Velicer, DiClemente, \& Fava, 1988).

Early data on the integration of stage and processes were provided by selfchangers in different stages of change for smoking cessation and weight loss (DiClemente et al., 1991; Norcross, Prochaska, \& DiClemente, 1998; Prochaska \& DiClemente, $1983 ; 1984)$. The data show that self-changers in different stages rely on different processes of change, naturally integrating change strategies and processes often considered incompatible. Table 4.3 summarizes the current understanding of selfchangers' patterns of process use as they progress through the stages. People in the early stages rely more on cognitive, affective, and evaluative processes of change; people in the later stages rely more on social support, commitments, and behavior management techniques (see Prochaska, DiClemente, \& Norcross, 1992). These findings have two important implications for intervention: 1) we can help facilitate the change process by providing stage-matched interventions to all individuals, even those who aren't prepared to change, and 2) stage-matched interventions will out-perform action-oriented and "one 
size fits all" interventions. Stage-based interventions for smokers more than double the quit rates of the best traditional interventions available (Prochaska, DiClemente, Velicer, \& Rossi, 1993).

Batterer treatment programs make use of several of the change processes identified in the Transtheoretical Model of Change (see Levesque, this volume). Experientially-oriented processes that encourage men to think more about the costs of violence and the benefits of change, and to develop a new view of themselves as nonviolent can help facilitate movement among batterers in the early stages. Counterconditioning is perhaps the most widely used behaviorally-oriented process appropriate for men in the later stages: anger management, stress management, and communicating needs and feelings non-violently are all healthy alternatives to violence. Stimulus control is involved in the "time-out" technique for interrupting escalating conflict. Helping relationships that develop with counselors and other men in treatment are an important benefit of the group treatment modality. By stage-matching, the Transtheoretical ModeI allows the systematic integration of these various interventions and others that may be under-utilized in the present treatment paradigm.

Stage-based intervention programs for battering men could take a variety of forms. Violent offenders might be assigned to stage-matched psycho-educational groups, or provided with stage-matched interventions (e.g., homework exercises, videos, reading materials) that are adjuncts to traditional treatment in mixed groups. Daniels and Murphy (1997) have described how facilitators in mixed groups might use motivational interviewing techniques to enhance motivation by tailoring comments to batterers in different stages of change. It is also possible to intervene proactively by identifying 
battering men before they reach the criminal justice system and delivering individualized interventions to their homes (Prochaska, Velicer, Fava, Rossi, \& Tsoh, 1998; Velicer \& Prochaska, 1997). Before developing stage-matched interventions, however, it is necessary demonstrate the applicability of the Transtheoretical Model of Change to violence desistance. Measures of processes of change for battering men remain under development (Levesque, Gelles, \& Velicer, unpublished measures) and will not be examined here.

Decisional Balance. According to Janis and Mann (1977), sound decision-making requires the consideration of the following potential gains (pros) and losses (cons) associated with a behavior's consequences: 1) utilitarian gains and losses for self; 2) utilitarian gains and losses for others; 3) self-approval and self-disapproval; 4) approval and disapproval from others. Factor analytic work across a number of behavior domains has failed to produce the 8-dimensional model of decisional balance proposed by Janis and Mann. Instead, research consistently yields a simpler 2-dimensional model representing simply Pros and Cons (Prochaska, Redding, \& Evers, 1997).

Longitudinal studies of change have found the decisional balance measures to be among the best available predictors of future change. In one study of smoking cessation, the Pros and Cons scales were powerful predictors of whether or not subjects initially classified as Precontemplators progressed to more advanced stages of change (Velicer, DiClemente, Prochaska, \& Brandenburg, 1985). In a recent integrative report of 12 studies, Prochaska et al. (1994) found that the balance of Pros and Cons was systematically related to stage of change in all 12 behaviors examined: the Cons of changing to a health- promoting behavior outweighed the Pros in the Precontemplation 
stage, the Pros surpassed the Cons in the middle stages, and the Pros outweighed the Cons in the Action stage. From these 12 studies Prochaska (1994) discovered even the degree of change in Pros and Cons needed to progress across the stages of change: to progress from Precontemplation to Action involved approximately a one standard deviation increase in the Pros of making the healthy behavior change, and a .5 standard deviation decrease in the Cons. Decisional balance measures for violence desistance will be developed in Study I below.

Self-Efficacy. Self-efficacy, or the degree to which an individual believes he or she has the capacity to attain a desired goal, can influence motivation and persistence (Bandura, 1977). Self-efficacy has two parts that are distinct but related: confidence to make and sustain changes, and temptation to relapse. Like decisional balance, levels of self-efficacy differ systematically across the stages of change, with subjects further along in the stages of change generally experiencing greater confidence and less temptation. A number of studies have shown the predictive power of self-efficacy for smoking cessation and the maintenance of abstinence (DiClemente, 1981; DiClemente, Prochaska, \& Gibertini, 1985; Prochaska, DiClemente, Velicer, Ginpil, \& Norcross, 1985). In these studies, measures of self-efficacy were obtained by asking subjects to indicate how confident they were that they could abstain from smoking in a variety of situations, and how tempted they would be to smoke in these situations. The research has identified three categories of tempting situations for smokers: positive/social (e.g., with friends at a party), negative/affective (e.g., when I'm extremely anxious and stressed), and habitaddictive (e.g., when I am desiring a cigarette) (Velicer, DiClemente, Rossi, \& 
Prochaska, 1990). A measure of temptation to engage in partner violence will be developed in Study 1 below.

\section{Tests of the Applicability of the Transtheoretical Model}

One way to demonstrate the applicability of the model is to test whether the well established relationships between the constructs described above replicate for violence desistance. The model space includes not only the Transtheoretical model constructs, but concrete behaviors as well (e.g., violence, violence cessation activities). After developing measures of stage, decisional balance, and self-efficacy, seven tests of the model will be conducted:

- Test \#1: Individuals in the later stages of change should be more likely to have used strategies in the last year to end the violence in their relationships. Individuais in Preparation should be taking small steps toward their behavioral goal. Individuals in Action should be most active.

- Test \#2: Individuals in the later stages of change should report fewer incidents of violence in the last year. A decrease in violence should accompany a commitment to change and efforts to end the violence.

- Test \#3: Partner Blame should decrease with progression through the stages of change. Men in Precontemplation should display the highest levels of defensiveness and resistance to change.

- Test \# 4: The Pros of ending the violence should increase with progression through the stages of change 
- Test \#5: The Cons of ending the violence should decrease with progression through the stages of change

- Test \#6: The Pros and Cons of ending the violence should intersect somewhere before Action. This test is based on the strong and weak principles, but also has intuitive appeal. As rational decision-makers, men should make a change only when the Pros of doing so outweigh the Cons.

- Test \#7: Temptation should decrease with progression through the stages

These tests of the model will also serve as tests of the external validity of the stages of change measures, the URICA-B1 and the new staging algorithm under development.

Study 1

Method

\section{Item Generation for the New Transtheoretical Model Measures}

The sequential system for scale development described by Jackson $(1970,1971)$ and Comrey (1988) was used. At the outset, conceptual definitions of Janis and Mann's (1977) eight decisional balance dimensions (i.e., utilitarian gains and losses for self, utilitarian gains and losses for others, self-approval and disapproval, approval and disapproval from others) guided item generation for the new decisional balance measure for battering men. The dimensionality of the new temptation measure was not specified $a$ priori, and temptation was conceptualized as the universe of cues (events, feelings, and situations) that might tempt an individual to engage in violence against a partner. To assure that items represented the real experiences of men struggling with the issue of 
partner violence, 10 focus groups, each composed of 8 to 15 male batterers in treatment, were conducted at two Rhode Island agencies to generate as many items as possible within each of the eight decisional balance categories and the broad temptation category. These are the same focus groups that generated items for the URICA-B1 scale (see Chapter 3). Treatment group leaders who participated in a 4-hour training session on the Transtheoretical Model of Change conducted the focus groups in lieu of regularly scheduled program activities. Focus groups were conducted until little new information was forthcoming.

A total of 105 decisional balance items were generated with 4 to 22 items representing each of the eight Janis and Mann (1977) categories; a total of 40 temptations items were generated. It is interesting to note that men had the most difficulty identifying utilitarian losses for others (how ending the violence might hurt others). The group leaders and the author reviewed and refined items, and selected a final list of 67 decisional balance and 30 temptation items for administration based on clarity and simplicity, lack of redundancy with other selected items, and representativeness of the conceptual definitions. All items employed a 5-point Lickert-type response format. The Decisional Balance Scale for Battering Men (DB-B1) asked men to rate the importance of each item in their decision to end the violence. Response options ranged from $1=$ not at all important to $5=$ extremely important. The Tempting Situations Scale (TS-B1) asked them to rate how tempted they would be to engage in violence in each situation. Response options ranged from $1=$ not at all tempted to $5=$ extremely tempted.

\section{Participants}


Study participants were 258 males involved in group counseling at two Rhode Island agencies that provide treatment to battering men. This is the same sample used in the development of the URICA-B1 and the staging algorithms (see Chapter 3). Forty percent of participants were under 30 years of age, $40 \%$ were $30-39$ years of age, and $20 \%$ were 40 years of age or older. A majority were white $(78 \%)$, held at least a high school degree (65\%), and were employed full-time (62\%). Thirty percent were married, and $78 \%$ had one or more children. Seventy-five percent had lived at some point with their most recent victims. Ninety-four percent of the study participants were mandated to treatment by the courts, and $26 \%$ reported prior involvement in treatment to address the problem of partner violence.

\section{Procedure}

Four Transtheoretical Model of Change measures--the staging algorithm and URICA B1 described above, and the decisional balance and temptation measures under development--were administered as part of a 240 -items paper-and-pencil survey that took approximately 45 minutes to complete (see Appendix B). This is the same survey that was administered for the development of three preliminary algorithms and the URICABl (see Chapter 3). The survey included questions to assess demographics, treatment history, drug and alcohol problems, and participants' relationships with their partners. Social desirability was assessed using a 13-item short form of the Marlowe-Crowne Social Desirability Scale (Crowne \& Marlowe, 1960; Reynolds, 1982). Three additional measures were included to evaluate the external validty of the stage measures and test the applicability of the Transtheoretical Model to violence desistance in battering men: 
Strategies for Ending the Violence. A series of questions assessed if participants used any strategies in the last six months and in the last 12 months to end their violent behavior. Individuals were asked to consider the following 11 strategies and list any others they may have used: 1) talking to partner, 2) talking to friends or family, 3) talking to priest, pastor, or rabbi, 4) talking to medical health professional, 5) one-on-one counseling, 6) couple's counseling, 7) batterers' group, 8) other group therapy, 9) selfhelp manual or books, 10) leaving the relationship temporarily, and 11) leaving the relationship permanently.

Relationship Violence. History of relationship violence was assessed using the Modified Conflict Tactics Scales (MCTS--Pan, Neidig, \& O'Leary, 1994), which has an improved factor structure over the original Conflict Tactics Scales developed by Straus in 1971 (Straus, 1979). The MCTS asks subjects how often their partners, and how often they themselves, used each of a series of strategies to resolve conflict in their relationships over the past year, beginning with "rational" strategies, and progressing to strategies representing verbal aggression (e.g., "did something to spite your partner"), minor physical aggression (e.g., "pushed, grabbed, or shoved your partner"), and severe physical aggression (e.g., "beat your partner up").

Partner Blame. This 4-item scale, which emerged as a by-product of earlier instrument development work by the author ${ }^{1}$, assesses the extent to which battering men attribute blame for their violence to their partners. Men are asked to indicate their level of agreement ( $1=$ strongly disagree to $5=$ strongly agree) with each of the following statements: 1) "My partner was to blame for my violent behavior"; 2) "If my partner would just leave me alone I wouldn't have a problem with violence"; 3) "If my partner 
treated me better I wouldn"t have a problem with violence"; and 4) "My partner is the one with the problem, not me." The scale has adequate internal consistency with a Cronbach's Alpha of .67.

\section{Measure Development}

Decisional Balance and Temptation Scales. The 67 decisional balance items were arranged in random order in the survey. Using Component Analysis Extended Program (CAX--Velicer, Fava, Zwick, \& Harrop, 1988), principal component analysis (PCA) with varimax rotation was performed on the $67 \times 67$ matrix of DB-BI inter-item correlations to examine the measure's dimensionality as the first step in its refinement. The Minimum Average Partial procedure (MAP--Velicer, 1976) and a Parallel Analysis approximation procedure (Horn, I965) were employed to determine how many components to retain. These two decision rules are among the most accurate available (Eaton, Velicer, \& Fava, 1992; Zwick \& Velicer, 1986). Component interpretability, component loadings, items' correlations with social desirability, and Coefficient Alphas including and excluding particular items determined the final number of components to retain and their composition. Complex items (items that loaded $>.40$ on two or more components), items with low loadings (loadings of $<.40$ on all components), items that were correlated with social desirability (correlations of $<-.30$ or $>.30$ with the Marlowe-Crowne scale), and items that contributed negatively to the reliability of the scale were deleted. Scale scores for each of the decisional balance components were calculated by taking the unweighted sum of the final items comprising the components.

The same procedure was repeated on the $30 \times 30$ matrix of temptation inter-item correlations. 
Stage of Change. The staging algorithm consisted of three components. First, participants were asked whether they were seriously considering ending their violent behavior in their relationship. Those who reported that their relationships were fine the way they were or that they planned to end the violence only in the distant future were classified in the Precontemplation stage; individuals who reported that they were seriously considering ending their violent behavior within the next six months or within the next 30 days were classified in the Contemplation or Preparation stage, respectively; and individuals who reported that they were currently doing something to end the violence were classified in the Action stage. Next, they were asked if they'd ever considered doing anything to put an end to their violent behavior. Individuals who answered "No" were re-classified as Precontemplators, regardless of their stated intentions in response to the first staging question above. Finally, individuals were asked if and when they most recently use strategies to end their violent behavior. In answering this question, men were asked to consider the 11 violence cessation strategies listed listed above as well as any other strategies they might have used. Individuals previously staged in Action remained in Action if they had used any strategies within the last 12 months. They were re-classified into to Pseudo-Action stage if they had never used strategies or had done so more than 12 months ago.

A set of analyses examined the relationship between stage of change and social desirability, demographics, drinking behaviors, treatment history, and relationship status for the new stage measure. Stage of change should be relatively independent of social desirability, demographics, drinking behavior, and relationship status. However, we 
might expect to find that individuals in the later stages have been exposed to more treatment.

Comparison of Stage Measures. A cross-classification table was generated to examine the level and pattern of agreement between the algorithm stage assignments and the URICA-B1 clusters. Based on the cluster profiles and earlier work with staging algorithms for battering men (Levesque, this volume), we can hypothesize that the Resistant and Immotive clusters most closely represent Precontemplation, the Ambivalent and Decision-Making clusters represent Contemplation and Preparation, respectively, and the Participation cluster represents Action. The Non-Reflective Action cluster has characteristics of both the Precontemplation and Pseudo-Action stages.

Results

Decisional Balance and Temptation Scales. In the development of the decisional balance measure, optimal results were achieved for a 3-component solution. Seven items were retained in each scale to satisfy competing goals of keeping the measure as brief as possible while preserving the internal reliability of the individual scales. Results of the PCA performed on the reduced $21 \times 21$ matrix of inter-item correlations for the final version of the DB-B1 are summarized here. Table 4.4 lists the $2 \mathrm{I}$ retained items and the varimax rotated pattern matrix. All items loaded heavily on their respective components (average loading $=.71$ ) and did not load heavily on other components (absolute value of the average loading $=.13$ ). The three components accounted for $50 \%$ of the total variance.

The first decisional balance component, labeled "Pros-General" represents all four categories of potential benefits identified in Janis and Mann's (1977) theory of decisionmaking: utilitarian gains for self, utilitarian gains for others, self-approval, and social 
approval. The second decisional balance component, labeled "Pros-Children," also represents the four categories of benefits, but is limited in focus to children (e.g., how children would benefit from the change, how the change would eam children's respect). The third decisional balance component, labeled "Cons-General," represents all of Janis \& Mann's categories of potential costs except utilitarian losses for others.

In the development of the temptation measure, optimal results were achieved for a 1-component solution. All but 2 of the 30 items had loadings of .50 or higher on the one component. The only substance abuse item, "when I'm high on alcohol or drugs," had the lowest loading with .35 . However, several items had to be deleted because they were too highly correlated with social desirability. Table 4.5 lists the final eight items selected for the TB-Bl and loadings (average loading $=.716$ ). The single component accounted for $51 \%$ of the total variance.

Scale scores were calculated for the three DB-B1 dimensions and the single TPB1 dimension by taking the unweighted sum of the items representing each dimension. Scale means, standard deviations, Cronbach's Alphas, correlations with the MarloweCrowne SF-13, and scale inter-correlations are presented in Table 4.6. Cronbach's Alphas ranged from .85 to .87 , indicating good internal reliability. There were statistically significant correlations between social desirability and measures on the ProsChildren, Cons-General, and Tempting Situations scales. Men's rating of the importance of children-related benefits of ending the violence tended to increase with need for social approval, while the importance of the costs of changing and admission of temptation tended to decrease. As we might expect, men who gave greater weight to the Cons of 
changing tended to report greater temptation to engage in further violence. The two Pros scales were relatively highly correlated and may represent a single higher-order construct.

Stage of Change. The 3-component staging algorithm assessing readiness to end the violence yielded the following stage distribution: Precontemplation--27.1\%; Contemplation--5.8\%; Preparation--5.0\%; Pseudo-Action--21.1\%; and Action--40.6\%. Contemplation and Preparation were combined into a single stage category in the analyses below. Chi square tests found that stage of change was independent of social desirability, demographics, drinking behavior, and relationship status with one exception: Caucasians were under-represented in the Contemplation/Preparation stage and over-represented in the Action stage $\left(\chi^{2}(3, \underline{N}=253)=13.54, \mathrm{p}<.01\right)$. Caucasions composed $70.6 \%, 56.7 \%, 78.4 \%$, and $86.1 \%$ of the Precontemplation, Contemplation/Preparation, Pseudo-Action, and Action stage groups, respectively. There was also a trend in the data that deserves mention. Men the Action stage were nearly twice as likely as men in Precontemplation and Pseudo-Action to have had prior treatment for partner violence. Rates of prior treatment for the four stage groups were $20.3 \%, 26.9 \%, 18.5 \%$, and $35 . \%$, respectively $\left(\chi^{2}(3, \underline{N}=252)=6.90, \mathrm{p}<.08\right)$.

Comparison of Stage Measures. The URICA-B1 profile cluster distribution was as follows: Resistant--4.5\%; Immotive--12.8\%; Non-Reflective Action--9.5\%; Ambivalent--25.1\%; Decision-Making--26.3\%; and Participation--21.8\%. A profile $x$ stage chi square test examined the relationship between the algorithm stage assignments and URICA-B 1 profiles. Results were significant at $\mathrm{p}<.001\left(\chi^{2}(15, \underline{N}=241)=61.85\right)$, suggesting dependence. However, the chi square tests must be considered unreliable 
because of low frequencies in many cells. Table 4.7 summarizes the data by presenting algorithm stage distributions for each of the six profiles.

As predicted, a majority of individuals in the Resistant and Immotive clusters were classified in the Precontemplation stage using the algorithm and majority of individuals in the Participation cluster were classified in Action; most of the individuals in the Non-Reflective Action cluster were classified in either Precontemplation or Pseudo-Action. There were two unexpected findings: about half the people in the Ambivalent cluster and the Decision-Making cluster were classified in the Action stage using the algorithm.

Study 2

Method

\section{Procedure}

Two sets of planned comparisons then evaluated the external validity of the two staging methods and the applicability of the Transtheoretical Model of Change to violence desistance in this population. Stage of change based on the staging algorithm was the grouping variable in the first set of analyses; URICA-B1 stage cluster was the grouping variable in the second. In both sets of analyses, the dependent variables represented the kinds of behavioral and Transtheoretical Model constructs shown to vary by stage in a predictable and theory-concordant manner in other problem behaviors studied. The dependent variables were: 1) use of violence cessation strategies in the last 12 months; 2) verbal, minor physical, and severe physical aggression in the last year; 3) partner blame; 4) pros and cons of ending the violence; and 5) temptation to engage in violence against a partner. Predicted findings are outlined in the "Model Tests" above. 
Test \#6, that the pros should surpass the cons of ending one's violence before the Action stage, was conducted simply by plotting standardized measures of pros and cons together and examining how they vary across the stages. The two dimensions should intersect before Action.

\section{Results}

Stage of change based on the staging algorithm was the grouping variable in the first set of analyses and URICA-B1 profile cluster was the grouping variable in the second set. The dependent variables were behavioral and Transtheoretical Model constructs expected to vary by stage or profile cluster in the manner outlined in the Model Tests above. Findings for the two sets of analyses are summarized in Tables 4.8 and 4.9 , respectively.

In Model Test \#1, the dependent variable was use of strategies to end the vioience (yes/no) in the last 12 months. Since violence cessation activity in the last 12 months was the behavioral criterion used to discriminate between Action and Pseudo Action in the staging algorithm (by definition, $100 \%$ of individuals in Action and $0 \%$ of individuals in Pseudo Action used strategies to end the violence), these two stage groups were combined in this analysis. A chi square test found a significant difference in use of concrete strategies among the algorithm stages. Men classified in the Precontemplation stage were least likely to have used strategies in the last year to end their violence (38.6\%), and men in the combined Pseudo Action and Action group were most likely $(65.8 \%)$. A significant difference in strategy use was also found among the URICA-B1 clusters. Men in the Participation cluster were almost three times as likely as men in the Immotive cluster to have used strategies to end the violence in the last year (25.8\% vs. 
$75.5 \%$ ). Rates among the four remaining groups ranged from $53.5 \%$ to $63.6 \%$. What is surprising is the high rate of violence cessation activity among men in the Resistant cluster $(63.6 \%)$.

In Model Test \#2, the dependent variables were MCTS measures of verbal, minor, and severe aggression in the last year, and in Model Test \#3, the dependent variable was Partner Blame. Scale means, standard deviations, and medians for the aggression and blame measures are presented in Table 4.10 along with Cronbach's Alphas, correlations with the Marlowe-Crowne Sf-13, and scale inter-correlations. All three aggression measures are skewed to the right. For instance, while the sample averaged 15 incidents of minor physical aggression in the last year, $50 \%$ of men reported five or fewer incidents; while the sample averaged five incidents of severe aggression, more than $50 \%$ of men reported no severe violence whatsoever. A square root transformation of the aggression measures was used to help normalize the distributions in the analyses that follow. Cronbach's Alphas ranged from .67 for the Partner Blame scale to .84 for the MCTS minor physical aggression scale, indicating adequate internal reliability. Reports of verbal and minor physical aggression--but not severe physical aggression or partner blame--tended to decrease with need for social approval. Correlations between the three MCTS aggression measures are statistically significant.

A multivariate analysis of variance (MANOVA) was conducted for the stage and cluster variables with square root of total incidents of verbal, minor physical, and severe physical aggression in the last year as the dependent variables. The MANOVA resulted in significant differences among the algorithm stages of change (Wilks' Lambda $=.930$, approximate $\underline{F}(9,596)=1.99, \mathrm{p}<.05)$ and the URICA-B1 cluster profiles (Wilks' 
Lambda $=819$, approximate $\underline{F}(15,641)=3.20, \underline{\mathrm{p}}<, 001)$. The results of follow-up univariate analyses of variance (ANOVAs) and Newman-Keuls multiple comparison tests are summarized in Tables 4.8 and 4.9.

The follow-up tests showed that the algorithm stages differed significantly in their use of verbal aggression. Surprisingly, men in the Action stage reported significantly more incidents of verbal aggression in the last year than men in the Precontemplation and Pseudo-Action stages. Follow-up tests showed a similar pattern of differences across the URICA-BI profile clusters. Men in the most advanced cluster, Participation, reported significantly more incidents of verbal aggression than men in most of the other clusters. Also, they reported significantly more incidents of minor physical violence than men in the Immotive, Ambivalent, and Decision-Making clusters.

Univariate ANOVAs showed that individuals in different stages of change and in different profile clusters also differed significantly in degree of partner blame. NewmanKeuls multiple comparisons found that men classified in the Action stage using the staging algorithm engaged in less partner blame than men classified in Precontemplation, Contemplation/Preparation, and Pseudo-Action (see Table 4.8). Men classified in the Decision-Making and Participation clusters using the URICA-B1 engaged in less partner blame than men classified in the Immotive and Non-Reflective Action clusters. The NonReflective Action cluster engaged in more partner blame than all other clusters but the Immotive cluster (see Table 4.9).

In Model Tests \#4 and \#5, differences across the algorithm stages and across the URICA-B1 clusters were examined using MANOVAs in which the dependent variables were the Pros of ending the violence (General, Children) and the Cons of ending the 
violence. The MANOVAs resulted in significant differences among the algorithm stages (Wilks' Lambda $=.943$, approximate $\underline{\mathrm{F}}(9,584)=4.71, \mathrm{p}<.001)$ and the URICA-BI clusters (Wilks' Lambda $=.599$, approximate $\underline{F}(15,624)=8.49, \underline{p}<, 001)$. Once again, the results of follow-up ANOVAs and Newman-Keuls muitiple comparison tests are summarized in Tables 4.8 and 4.9 .

The follow-up tests showed that men in the different algorithm stage groups differed significantly in their ratings of the importance of the two kinds of Pros and the Cons of ending the violence. Men in the later stages, especially Action, gave significantly higher ratings on the General and Children Pros and lower ratings on the Cons than men in the earlier stages. Follow-up tests showed a similar pattern of differences across the URICA-Bl profile clusters. In general, men in the more advanced profile clusters gave significantly higher ratings on the Pros and lower ratings on the Cons than men in the less advanced clusters. The decisional balance measures did not discriminate between the two earliest clusters, Resistant and Immotive, or between the two most advanced clusters, Decision-Making and Participation.

In Model Test \#6, the decisional balance measures were converted to standardized $\mathrm{T}$-scores and plotted together in an order representing progression through the algorithm stages (Figure 4.2) and the URICA-Bl clusters (Figure 4.3). There is little divergence in the lines representing the two types of Pros of ending the violence. In both Figures, the Cons of changing outweigh the Pros in the early stages, and the Pros outweigh the Cons in the later stages. It is important to note that for the algorithm stages, the crossover takes place after the Pseudo-Action stage. For the URICA-Bl profile clusters, the crossover aptly takes place at point in the change process labeled Ambivalence. The strong and 
weak principles of behavior change are evident in the profile clusters. The Pros of changing increased by over one standard deviation and the Cons of changing decreased by about $1 / 2$ standard deviation with progression from the Resistant and Immotive clusters to the Participation cluster.

Finally, in Model Test \#7, the dependent variable was TB-BI score. Univariate ANOVAs showed that individuals in different stages of change did not differ in their temptation to engage in further violence, but that individuals in different stage clusters did. Newman-Keuls multiple comparisons found that men in the Decision-Making cluster experienced significantly less temptation to engage in violence than individuals in the Immotive, Non-Reflective Action, and Participation cluster. The high level of temptation among men in the Participation cluster was unanticipated.

\section{Discussion}

Overall, results support the application of the Transtheoretical Model of Change to violence desistance among battering men. Measures of three of the model's core constructs--stage of change, decisional balance, and self-efficacy--were developed to extend earlier instrument development work. The development, implementation, and testing of Transtheoretical Model interventions depends on accurate and reliable measurement. The new decisional balance measure is composed of three 7 -item scales that measure two Pros constructs (general and children-focused) and a single general Cons construct. It is unusual to end up with three interpretable and distinct decisional balance components; two components representing simply Pros and Cons are the norm. Given the high correlation between the two sets of Pros, and similarities in their relationship to stage of change and the stage clusters, it will be necessary to examine 
whether the children-focused Pros contribute enough additional information to warrant their inclusion in assessment packages.

The new self-efficacy measure is a single-dimensional scale assessing temptation to engage in violence in a variety of situations. There is some concern that alcohol and drug-related cues are not represented on the scale, since substance abuse is one of the most reliable predictors of partner violence recidivism (DeMaris \& Jackson, 1987; Hamberger \& Hastings, 1990; Shepard, 1992). The single substance abuse item included in the initial item pool did not load on the self-efficacy dimension, leaving open the possibility that a second, alcohol and drug-related self-efficacy dimension exists. Future instrument development work should attempt to tap this hidden dimension.

The seven tests of the applicability of the Transtheoretical Model to male-tofemale partner violence are encouraging, although they yielded a few unanticipated results. As expected, the likelihood of using violence cessation strategies in the last year tended to increase with progression through the three algorithm classifications examined (Precontemplation, Contemplation/Preparation, and Pseudo-Action/Action) and the six URICA-B1 clusters. There was one important exception, however: the rate of strategy use among men in the Resistant cluster strategies equaled that of men in the more advanced Ambivalent and Decision-Making clusters. And recall that earlier it was found that Resistors sought help from the clergy far more often than men in other stage clusters did (Levesque, this volume). It is peculiar to find such activity among batterers whose URICA-B1 profiles indicate extreme resistance to change. Given the small number of subjects in the Resistant cluster ( $n=11$ ), these findings must be viewed as tentative untiI replicated in another sample. 
Another unanticipated finding was the high frequency of verbal aggression reported by men classified in algorithm Action stage and in the URICA-BI Participation cluster. Men in the Participation cluster also reported significantly more incidents of minor physical aggression than men in the Immotive, Ambivalent, and Decision-Making clusters. It was hypothesized that individuals in the later stages of change would report fewer incidents of violence as they increase their commitment to ending the violence and begin to take small steps to achieve that goal.

One possible explanation is that men in the Action stage and in the Participation cluster are indeed more verbaily and/or physically abusive and become engaged in treatment out of desperation. Dutton \& Starzomski (1994) have identified a subgroup of batterers who display characteristics of borderline personality pathology and seek treatment out of desperation to save their relationships. However, help-seeking in these men is associated with crisis in the relationship (often violence-related)--rather than the frequency of aggression, per se. Furthermore, their commitment to treatment diminishes as the crisis subsides. Men in the Participation cluster appear more stable. They are more likely than men in all other clusters to have been in treatment for three months or longer and are more likely to have full-time jobs (Levesque, this volume).

Battered women's advocates might say that these findings confirm their worst fears: that anger management approaches to violence desistance among battering men are misguided and create "nonviolent terrorists" (Gondolf, 1986; Hart, 1986). In their view, partner violence has little to do with anger; rather, it is rooted in the socially imposed patriarchal belief that men have the right to dominate and control women. When men 
cannot use physical violence to maintain control, they rely on verbal threats and other forms of psychological abuse.

A most likely explanation, however, is that men furthest along in the change process are more sensitized to the abusiveness of their behavior and its consequences and more willing to admit to past verbal and minor physical aggression. There is other evidence of this phenomenon in the literature. Barrera, Palmer, Brown, \& Kalaher (1994) found that men who sought treatment voluntarily scored lower on a measure of denial and reported more incidents of violence than court-involved men (cf. Dutton $\&$ Starzomski, 1994). Holtzworth-Munroe and Ghose (1997) found that interspousal agreement in reports of verbal and minor physical aggression tended to increase with treatment, as men's under-reporting diminished. (Agreement in reports of severe violence were relatively high to begin with, probably because severe incidents--which by definition include the use of weapons to threaten or ham--are momentous events with little ambiguity).

These findings have important implications for the assessment of treatment outcome: men who are furthest along in the change process may end up looking most like treatment failures when outcome is assessed using only self-report measures. These findings also suggest that we need to identify better behavioral criterion measures of violence and violence desistance if we want to monitor treatment progress. Partner reports may hold the most promise. Official records would reveal only the most egregious offenses, and therapists' ratings would be subject to the same kinds of biases found in self-reports (men furthest along in the change process would be most willing to disclose incidents of verbal and physical aggression). 
As expected, partner blame tended to decrease with progression through the stages, with a couple of exceptions. Men in the Resistant cluster engaged in surprisingly low levels of partner blame. Given their low need for social approval, they may not feel compelled to justify their violent behavior. Men in the Non-Reflective Action cluster engaged in especially high levels of partner blame. This sheds light on the earlier finding that men in the Non-Reflective cluster often ended the violence simply by leaving the relationship. If the partner is perceived as the problem, leaving seems a sensible solution. As expected, the pros of ending the violence increased with progression through the stages and profile clusters, and the cons decreased. The pros surpassed the cons before the algorithm's Action stage and at the URICA-B1's Ambivalent cluster. This is the hallmark pattern identified in Transtheoretical Model research and provides strong evidence of the applicability of the Model to violence desistance among battering men. Self-efficacy was unrelated to stage of change based on the staging algorithm. It decreased somewhat with progression through the stage clusters, then rose sharply among men the Participation cluster. Like acknowledgment of verbal and minor physical aggression, acknowledgment of temptation to relapse in this cluster may indicate decreased denial and engagement in the treatment process.

Finally, it is important to note that men in the Pseudo-Action and Action stages of change yielded significantly different scores on the verbal aggression, partner blame, and cons scales. In fact, Pseudo-Action scores most closely matched the scores of men in Precontemplation. Although men in Pseudo-Action rated the general pros of changing scored significantly higher men in Precontemplation, their cons continued to outweigh the pros. In general, they seem to the support the notion of change, but are also aware of 
the costs and thus remain unprepared to take action. In this respect, they appear most like Contemplators.

In conclusion, data on the applicability of the Transtheoretical Model to violence desistance are encouraging. In general, tests of the model in a sample of battering men found theory-consistent relationships between stage of change, behavior, and newly developed measures of other Transtheoretical Model constructs. Some of the unexpected findings for men in the Resistant cluster may be attributed to small sample size.

Replication of the study with larger n's is critical. Unexpected findings for men in the Participation cluster are interpretable but require further investigation. Is acknowledgment of high levels of verbal abuse and temptation to relapse necessarily a good thing? Only longitudinal research allow us to answer these questions.

\section{References}

Bandura, A. (1977). Self-efficacy: Toward a unifying theory of behavior change.

Psychological Review, 84, 191-215

Barrera, M., Palmer, S., Brown, R., \& Kalaher, S. (1994). Characteristics of courtinvolved men and non-court-involved men who abuse their wives. Journal of Family Violence, 9 , 333-345.

Begun, A., Strodhoff, T., Weinstein, B., Shelley, G., Short, L. (1997, June).

Development of an instrument to assess readiness to change battering behavior: Preliminary results. Paper presented at the 5th International Family Violence Research Conference, Durham, NH.

Comrey, A.L. (1988). Common methodological problms in factor analytic studies. Journal of Consulting and Clinical Psychology, 46, 648-659. 
Crowne, D.P., \& Marlowe, D. (1960). A new scale of social desirability independent of psychopathology, Journal of Clinical and Consulting Psychology, 349-354.

Daniels, J.W., \& Murphy, C.M. (1997). Stages and processes of change in batterers' treatment. Cognitive and Behavioral Practice, 4, 123-145.

DeMaris, A., \& Jackson, J.K. (1987). Batterers' reports of recidivism after counseling. Social Casework, 68, 458-465.

DiClemente, C.C. (1981). Self-efficacy and smoking cessation maintenance: A preliminary report. Cognitive Therapy and Research, 5, 175-187.

DiClemente, C.C., \& Hughes, S.O. (1990). Stages of change profiles in outpatient alcoholism treatment. Journal of Substance Abuse, 2 , 217-235.

DiClemente, C.C., \& Prochaska, J.O. (1982). Self-change and therapy change of smoking behavior: A comparison of processes of change in cessation and maintenance. Addictive Behaviors, $\underline{7}, 133-142$.

DiClemente, C.C., Prochaska, J.O., Fairhurst, S.K., Velicer, W.F., Velasquez, M.M., \& Rossi, J.S. (1991). The process of smoking cessation: An analysis of precontemplation, contemplation, and preparation stages of change. Journal of Consulting and Clinical Psychology, 59, 295-304.

DiClemente, C.C., Prochaska, J.O., \& Gibertini, M. (1985). Self-efficacy and the stages of self-change of smoking. Cognitive Therapy and Research, 9, 181-200.

Dutton, D.G. (1995). The domestic assault of women. Vancouver: UBC Press.

Dutton, D.G., Bodnarchuk, M., Kropp, R., Hart, S.D., \& Ogloff, J.R.P (1997). Wife assault treatment and criminal recidivism: An 11-year follow-up. International Journal of Offender Therapy and Comparative Criminology, 41, 9-23. 
Dutton, D. G., \& Starzomski, A.J. (1994). Psychological differences between courtreferred and self-referred wife assaulters. Criminal Justice and Behavior, 21, 203222.

Eaton, C.A., Velicer, W.F., \& Fava, J.L. (1992, October). Determining the number of components: An evaluation of alternative procedures. Paper presented at the annual meeting of the Society of Multivariate Experimental Psychology, Cape Cod, MA.

Gondolf, E.W., \& RusselI, D. (1986). The case against anger control treatment programs for batterers. Response, $9(3), 2-5$.

Gondolf, E.W. (1987). Changing men who batter: A developmental model for integrated interventions. Journal of Family Violence, 2, 335-349.

Hamberger, L.K., \& Hastings, J.E. (1990). Recidivism following spouse abuse abatement counseling: Treatment program implications. Violence and Victims, $4,275-286$

Holtzworth-Munre, A., \& Ghose, S. (1997, June). The reliability of violent husbands' self-reports: Examining interspousal agreement. Paper presented at the 5 th International Family Violence Research Conference, Durham, $\mathrm{NH}$.

Horn, J.L. (1965). A rationale and test for the number of factors in factor analysis. Psychometrika, 30, 179-185.

Janis, I.L., \& Mann, L. (1977). Decision making: A psychological analysis of conflict, choice and commitment. New York: Free Press. 
Jackson, D.N. (1970). A sequential system for personality scale development. In C.D. Spielberger (Ed.), Current topics in clinical and community psychology (vol. 2) (pp.61-96). Orlando, FL: Academic Press.

Jackson, D.N. (1970). The dynamics of structured personality tests. Psychological Review, 78, 229-248.

Kohlberg, L. (1981). Essays in moral development Volume I: The philosophy of moral development. New York: Harper \& Row.

Kohlberg, L., \& Kramer, R. (1969). Continuities and discontinuities in childhood and adult development. Human Development, 12, 93-120.

Lam, C.S., McMahon, B.T., Priddy, D.A., \& Gehred-Schultz, A. (1988). Deficit awareness and treatment performance among traumatic head injury adults. Brain Injury, 2, 235-242.

Levesque, D., \& Gelles, R. (1997, June). Battering men: Applying the transtheoretical model to desistance and change. Paper presented at the 5th International Family Violence Research Conference, Durham, NH.

Levesque, D.A, Gelles, R.J., \& Velicer, W.F. (1997, August). Battering men and courtmandated treatment: Applying the Transtheoretical Model to desistance and change. Paper presented at the $105^{\text {th }}$ annual meeting of the American Psychological Association, Chicago, IL.

Marcus, B.H., Rossi, J.S., Selby, V.C., Niaura, R.S., \& Abrams, D.B. (1992). The stages and processes of exercise adoption and maintenance. Health Psychology, 11, 386395. 
McConnaughy, E.A., Prochaska, J.O., \& Velicer, W.F. (1983). Stages of change in psychotherapy: Measurement and sample profiles. Psychotherapy: Theory, Research and Practice, 20, 368-375.

McConnaughy, E.A., DiClemente, C.C., Prochaska, J.O., \& Velicer, W.F. (1989).

Stages of change in psychotherapy: A follow-up report. Psychotherapy, 26, 494503.

Medieros, M., \& Prochaska, J.O. (1992). Predicting premature termination from psychotherapy. Unpublished manuscript.

Norcross, J.C., Prochaska, J.O., \& DiClemente, C.C. (1998). The stages and processes of behavior change: Two replications with weight control. Manuscript submitted for publication.

Pan, H.S., Neidig, P.H., \& O'Leary, K.D. (1994). Male-female and aggressor-victim differences in the factor structure of the Modified Conflict Tactic Scale. Journal of Interpersonal Violence, 9, 366-382.

Prochaska, J.O. (1984). Systems of psychotherapy: A transtheoretical approach. Homewood, Illinois: The Dorsey Press.

Prochaska, J.O., \& DiClemente, C.C. (1983). Stages and processes of self-change of smoking: Toward and integrative model of change. Journal of Consulting and Clinical Psychology, 51, 390-395.

Prochaska, J.O., \& DiClemente, C.C. (1984). The transtheoretical approach:_Crossing traditional boundaries of change. Homewood, IL: Dorsey Press.

Prochaska, J.O. \& DiClemente, C.C. (1985). Common processes of change in smoking, weight control, and psychological distress. In S. Shiffman and T. Wills (Eds.), 
Coping and substance use: A conceptual framework (pp. 345-363). New York: Academic Press.

Prochaska, J.O., \& DiClemente, C.C. (1986). Toward a comprehensive model of behavior change. In W.R. Miller \& N. Heather (Eds.), Treating additictive behaviors: Processes of change (pp. 3-27). New York: Plenum Press.

Prochaska, J.O., DiClemente, C.C., \& Norcross, J.C. (1992). In search of how people change: Applications to addictive behaviors. American Psychologist, 47, 1102 1114

Prochaska, J.O., DiClemente, C.C., Velicer, W.F., Ginpil, S., \& Norcross, J. (1985). Predicting change in smoking status for self-changers. Addictive Behavior, 10 , 395-406,

Prochaska, J.O., DiClemente, C.C., Velicer, W.F., \& Rossi, J.S. (1993). Standardized, individualized, interactive, and personalized self-help programs for smoking cessation. Health Psychology, 12, 399-405.

Prochaska, J.O., Norcross, J.C., Fowler, J.L., Follick, M.J., \& Abrams, D.B. (1992). Attendance and outcome in a work-site weight control program: Processes and stages of change as process and predictor variables. Addictive Behaviors, 17, 3545.

Prochaska, J.O., Redding, C.A., \& Evers, K.E. (1997). The transtheoretical model and stages of change. In K. Glanz, F.M. Lewis, \& B.K. Rimer (Eds.), Health behavior and health education: Theory, research, and practice ( 2 nd ed., pp. 60-84). San Francisco: Jossey-Bass. 
Prochaska, J.O., Redding, C.A., Harlow, L.L., Rossi, J.S., \& Velicer, W.F. (1994). The transtheoretical model of change and HIV prevention: A review. Health Education Quarterly, 21, 471-486.

Prochaska, J.O., Rossi, J.S., \& Wilcox, N.S. (1991). Change processes and psychotherapy outcomes in integrative case research. Journal of Psychotherapy Integration, 1(2), 103-119.

Prochaska, J.O., Velicer, W.F., DiClemente, C.C., \& Fava, J. (1988). Measuring processes of change: Applications to the cessation of smoking. Journal of Consulting and Clinical Psychology, 56, 520-528.

Prochaska, J.O., Velicer, W.F., Fava, J.L., Rossi, J.S., \& Tsoh, J. (1998). A stagematched expert system intervention for a total population of smokers. Manuscript submitted for publication.

Prochaska, J.O., Velicer, W.F., Rossi, J.S., Goldstein, M.G., Marcus, B.H., Rakowski, W., Fiori, C., Harlow, L.L., Redding, C.A., Rosenbloom, D., \& Rossi, S.R. (1994). Stages of change and decisional balance for twelve problem behaviors. Health Psychology, 13, 39-46.

Rakowski, W., Ehrich, B., Dube, C.E., Pearlman, D.N., Goldstein, M.G., Peterson, K.K., Rimer, B.K., \& Woolverton, H. (1996). Screening mammography and constructs from the transtheoretical modal: Associations using two definitions of the stagesof-adoption. Society of Behavioral Medicine, 18, 91-100.

Rest, J. (1973). The hierarchical nature of moral judgment. Journal of Personality, 41 , $86-109$. 
Reynolds, W.M. (1982). Development of reliable and valid short forms of the MarloweCrowne Social Desirability Scale. Journal of Clinical Psychology, 조, 119-125. Rossi, J.S., Blais, L.M., Redding, C.A., \& Weinstock, M.A. (1995). Preventing skin cancer through behavior change: Implications for interventions. Dermatologic Clinics, 13, 613-622.

Shepard, M. (1992). Predicting batterer recidivism five years after community intervention. Journal of Family Violence, 7, 167-178.

Straus, M.A. (1979). Measuring intrafamily conflict and violence: The Conflict Tactics (CT) Scales. Journal of Marriage and the Family, 41,75-88.

Tsoh, J.Y. (1995). Stages of change, dropouts, and outcome in substance abuse treatment. Unpublished doctoral dissertation, University of Rhode Island, Kingston, RI.

Velicer, W.F. (1976). Determining the number of components from the matrix of partial correlations. Psychometrika, $\underline{41}, 321-327$.

Velicer, W.F., DiClemente, C.C., Prochaska, J.O., \& Brandenburg, N. (1985).

Decisional balance measure for assessing and predicting smoking status. Journal of Personality and Social Psychology, 48, 1279-1289.

Velicer, W.F., DiClemente, C.C., Rossi, J.R., \& Prochaska, J.O. (1990). Relapse situations and self-efficacy: An integrative model. Addictive Behaviors, 15, 271283.

Velicer, W.F., Fava, J.L., Zwick, W.R., \& Harrop, J.W. (1988). Component Analysis Extended [Computer Software]. Kingston, RI: University of Rhode Island. 
Velicer, W.F., \& Prochaska, J.O. (in press). An expert system intervention for smoking cessation. Patient Education and Counseling.

Zwick, W.R., \& Velicer, W.F., (1986). Comparison of five rules for determining the number of components to retain. Psychological Bulletin, 99, 432-442. 


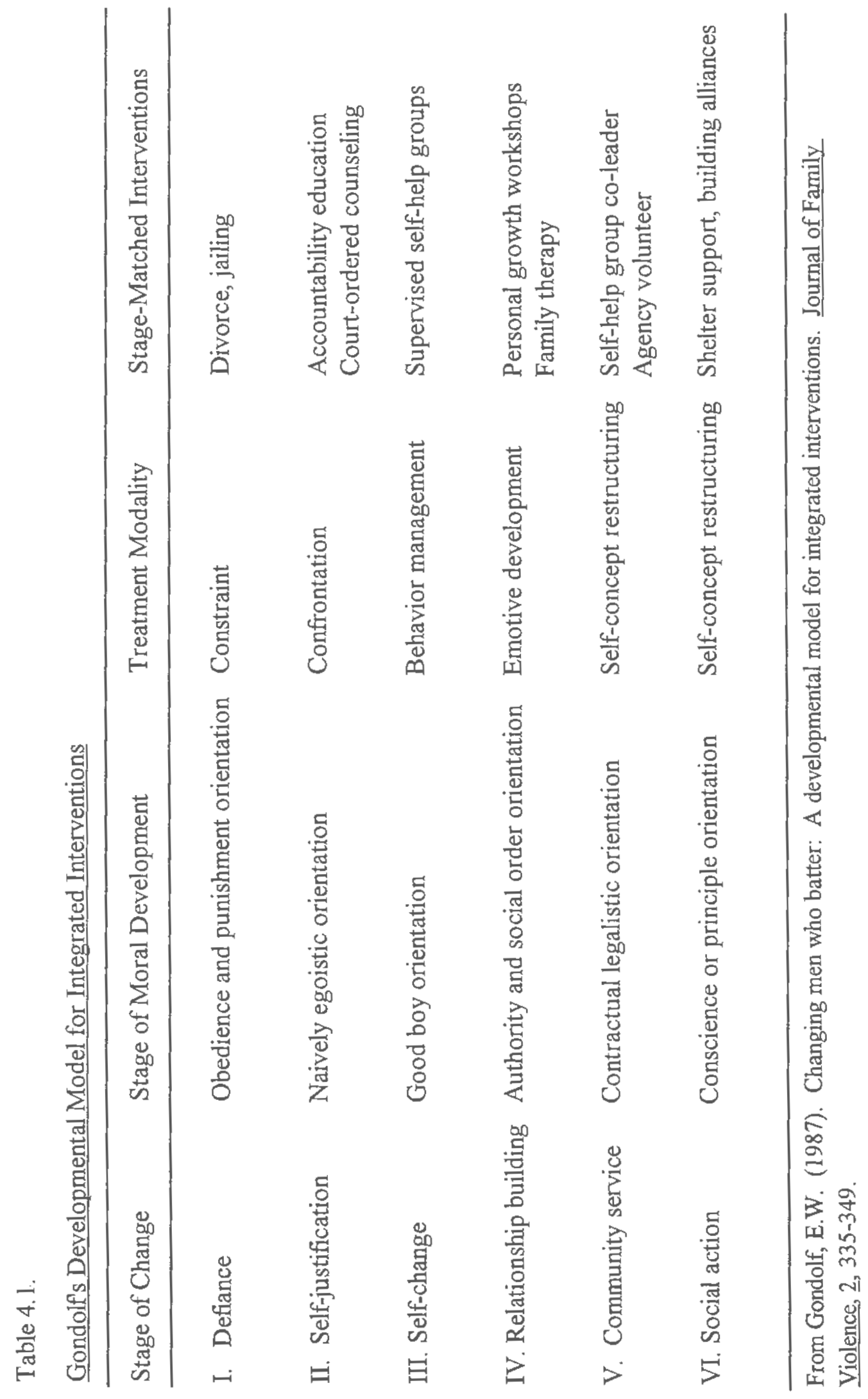


Table 4.2.

Processes of Change in Partner Violence Desistance

Experiential Processes

Consciousness raising

Dramatic relief

Social liberation

Environmental reevaluation

Self-reevaluation

Helping relationships

Counter-conditioning

Contingency management

Stimulus control

Self-liberation
Seeking new information to support the change to a non-violent lifestyle

Experiencing strong negative emotions about one's violence

Realizing that the social norms are changing to support non-violence

Realizing the negative impact of violence on others

Realizing that being non-violent is an important part of one's identity

Behavioral Processes

Seeking and using social support to end one's violence and maintain changes

Substituting violence with healthier behaviors and cognitions

Increasing the rewards for non-violence, and decreasing the rewards for violence

Removing reminders or cues to engage in violence, and adding cues to engage in healthier behavior

Realizing one's ability to choose to be non violent and making a commitment to change 


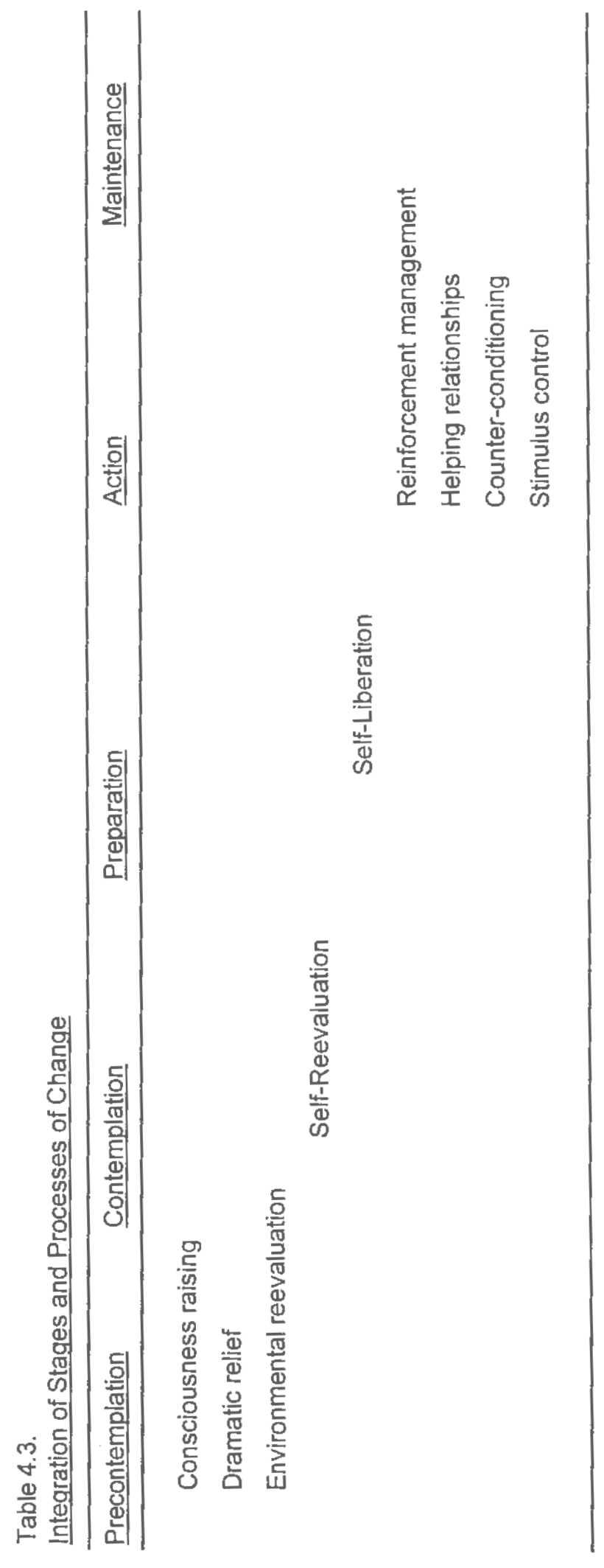




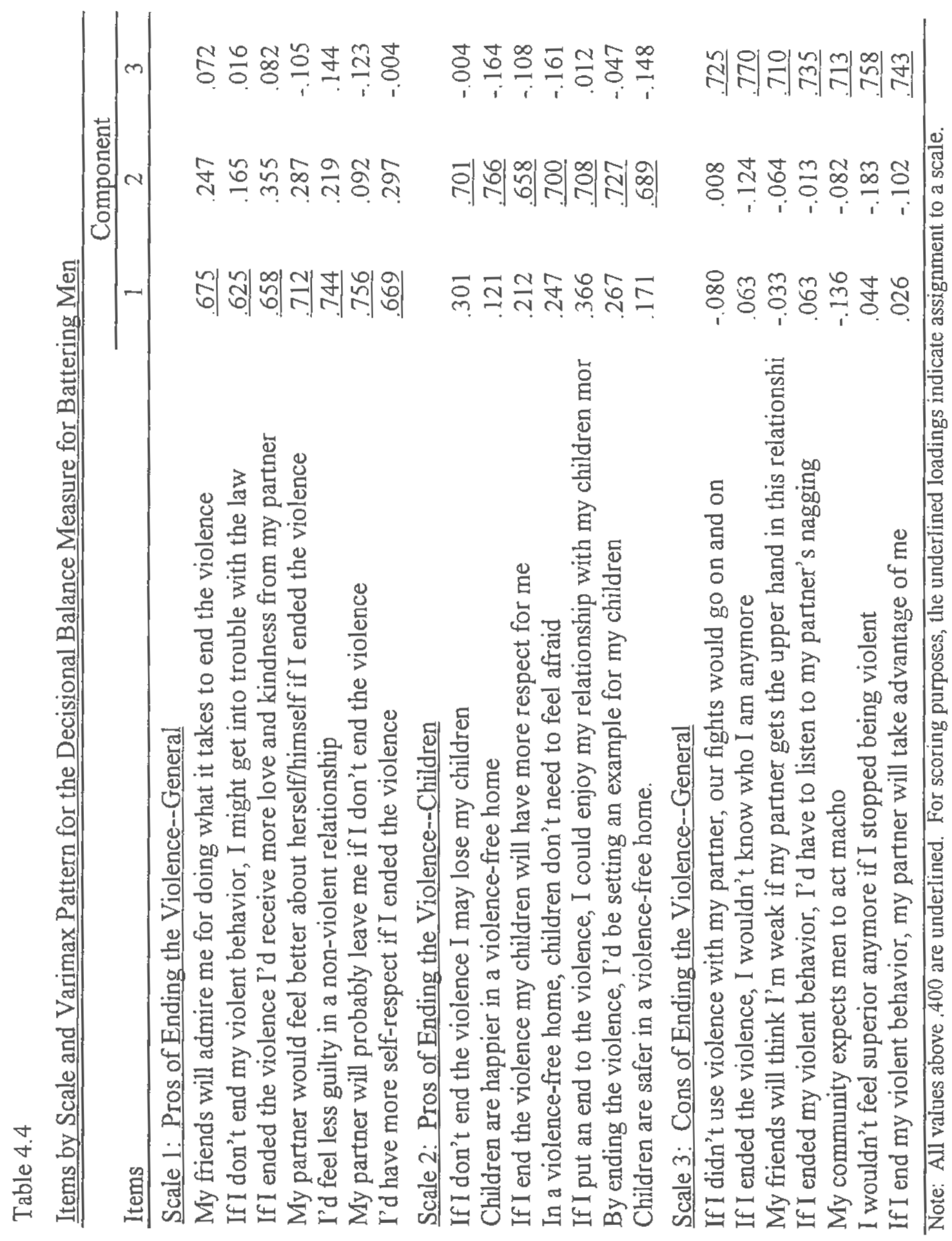




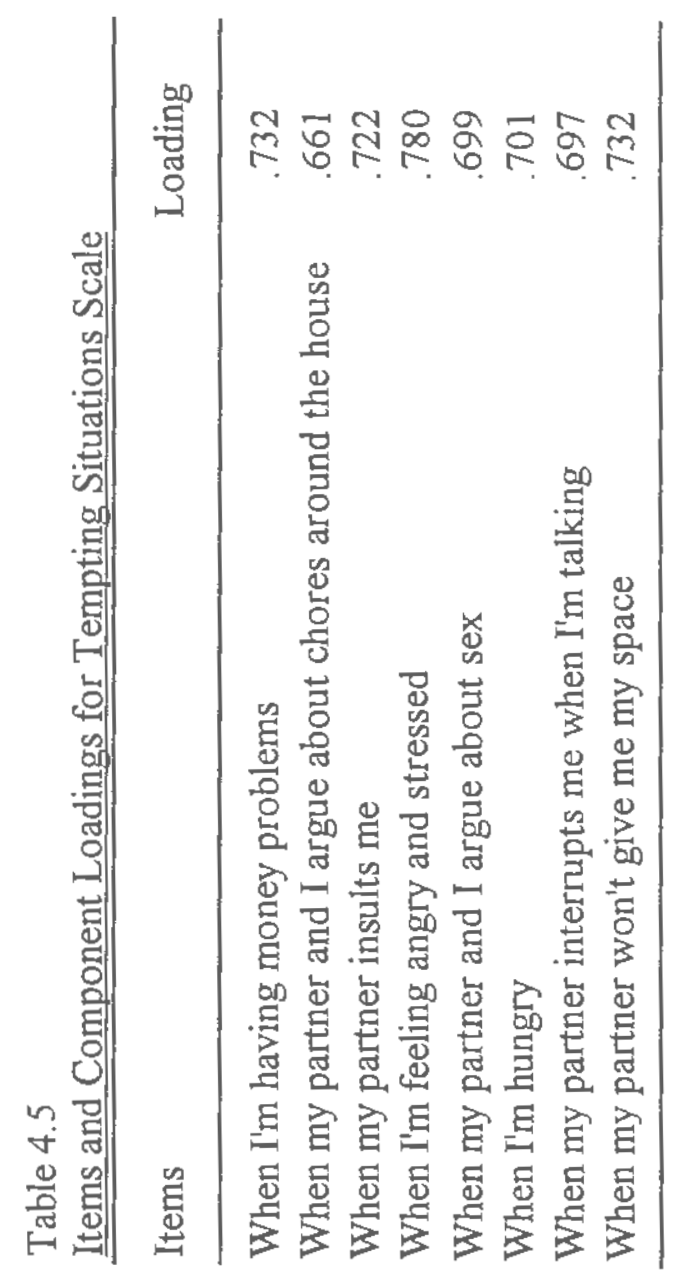




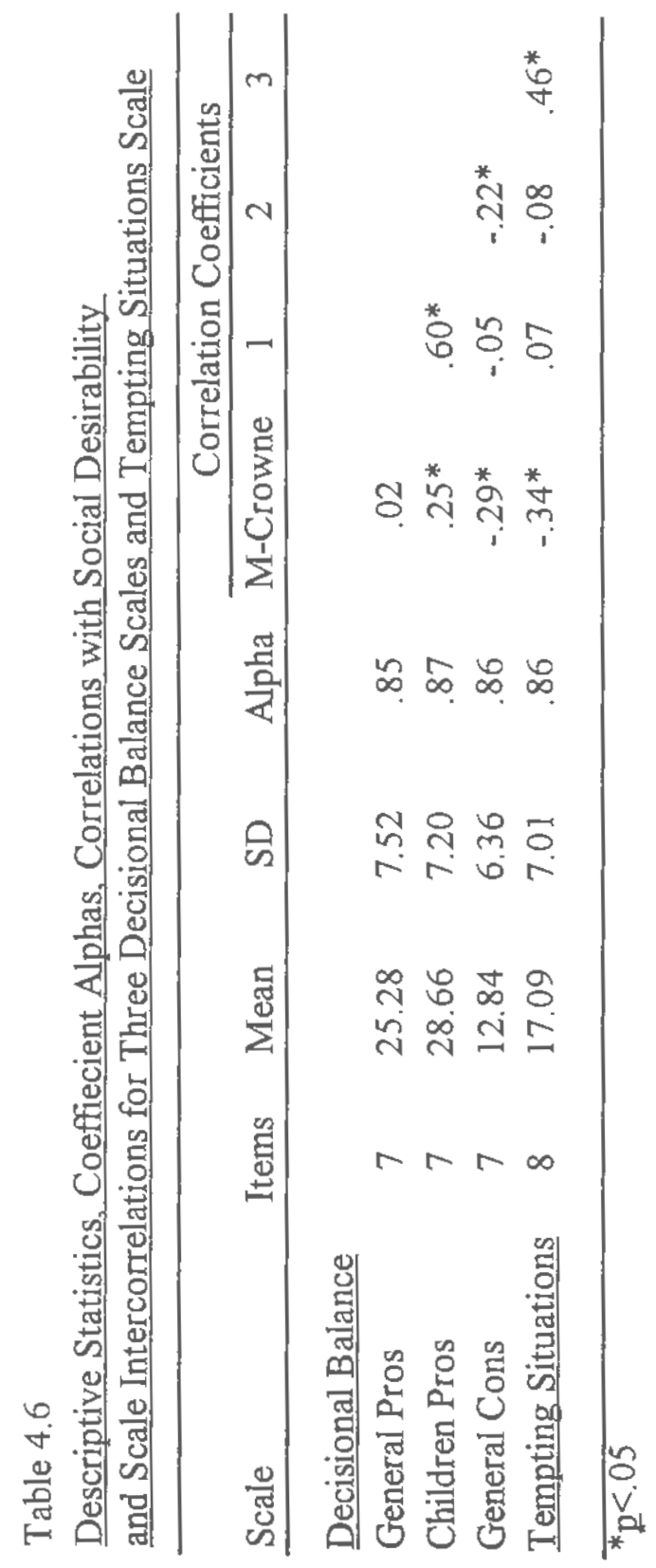




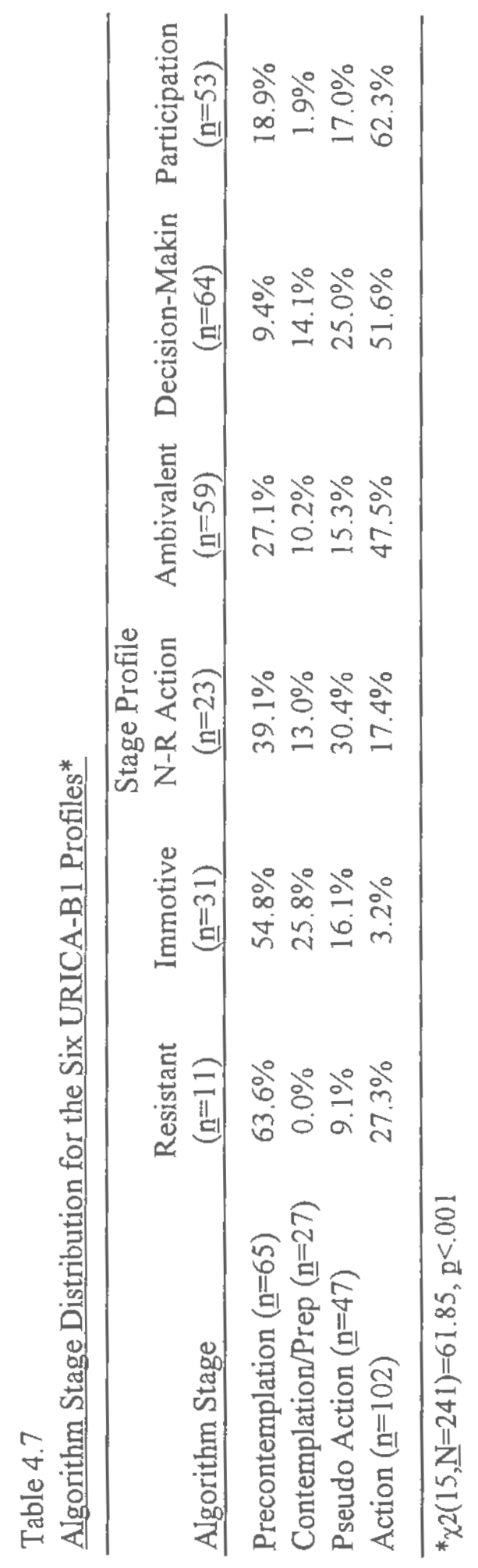




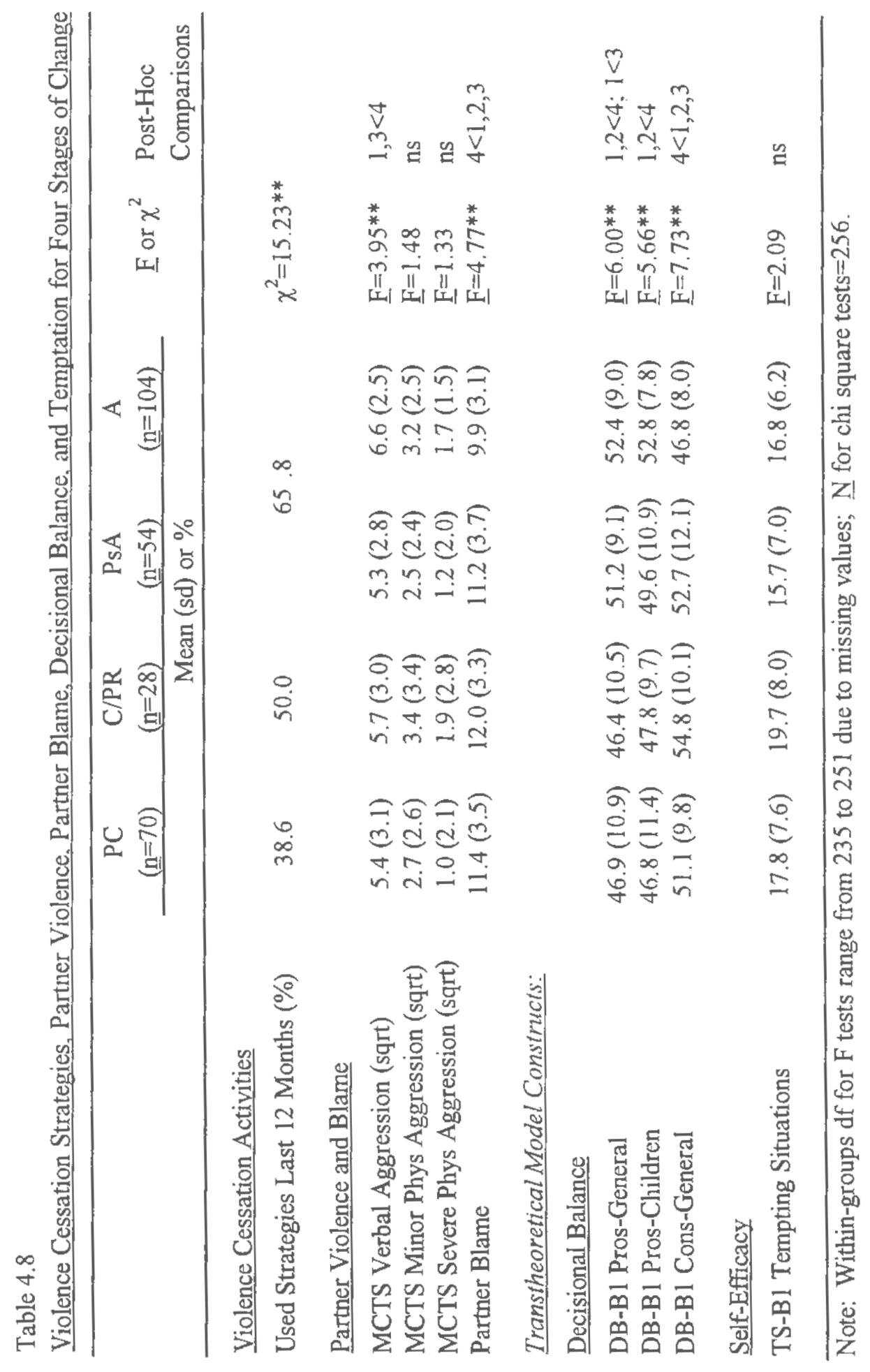




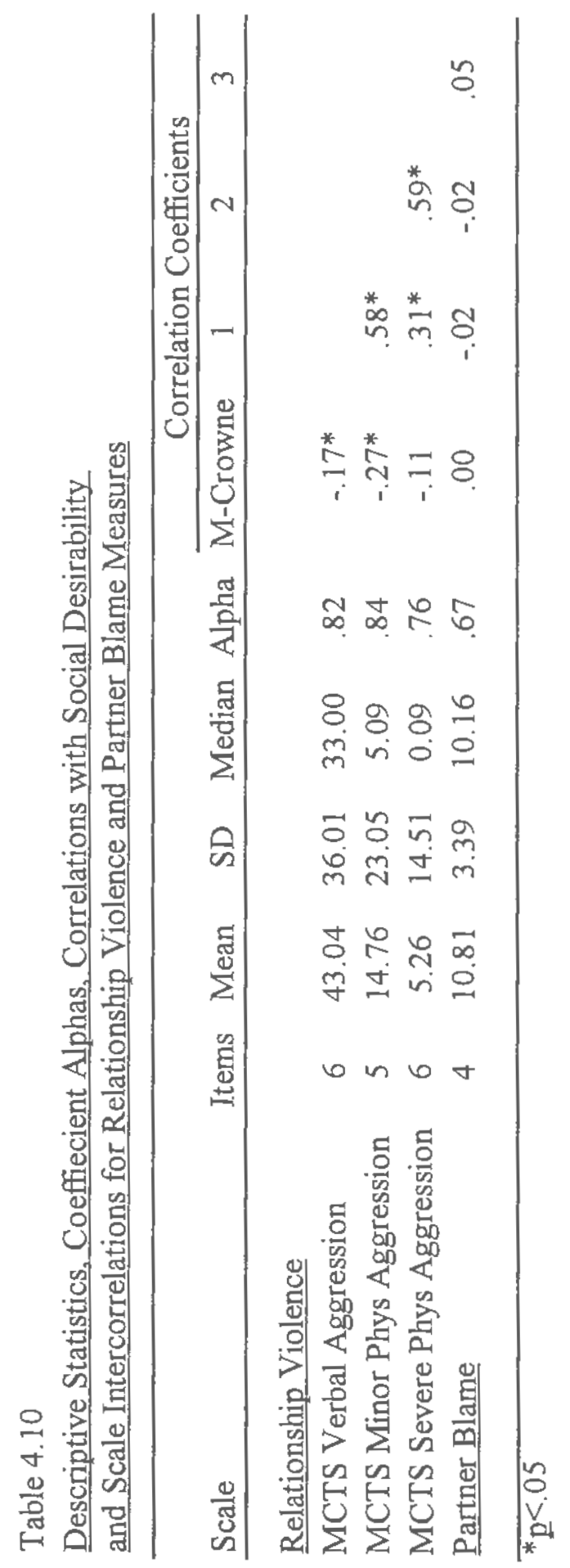




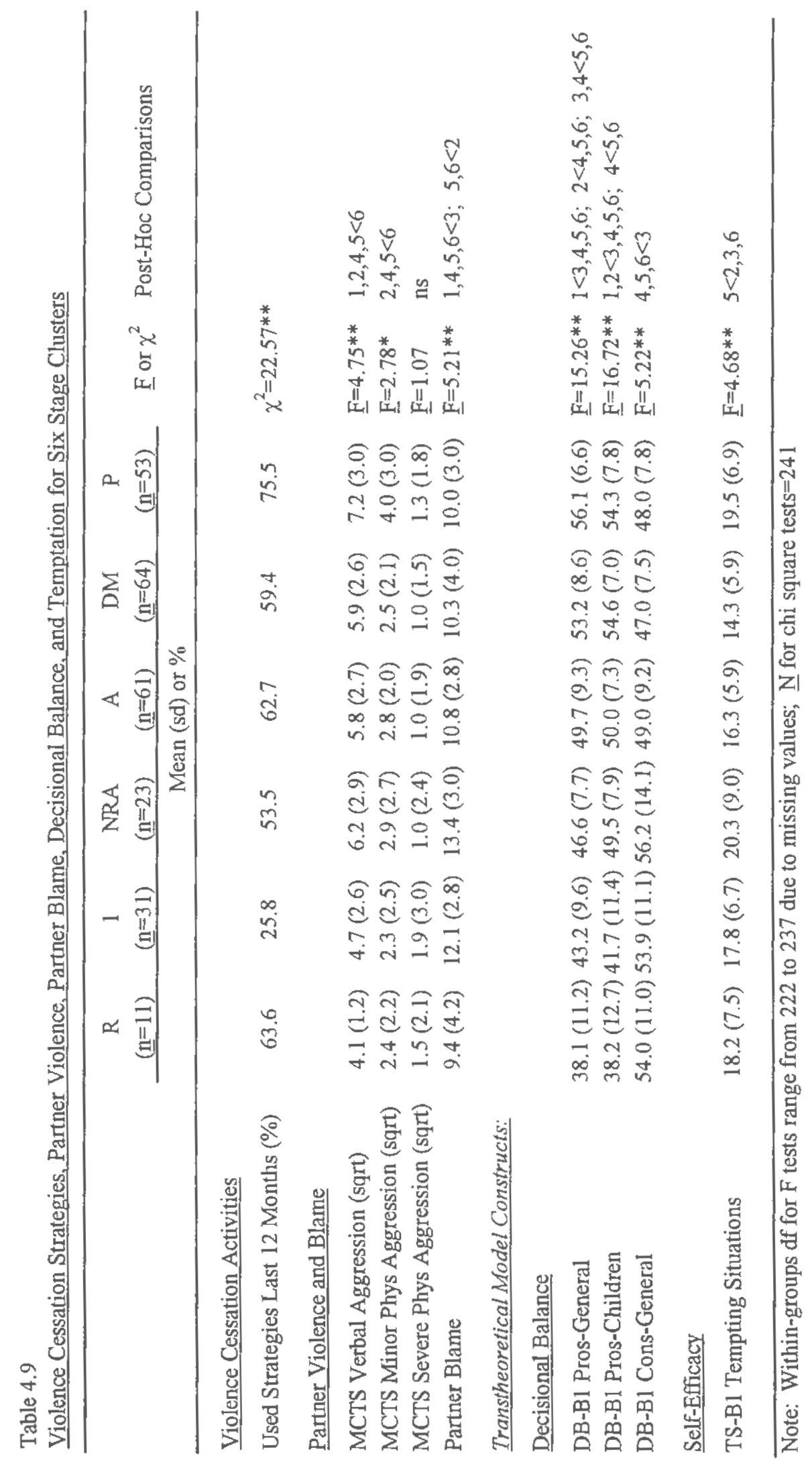


Figure 4.1 Six URICA-B1 Cluster Profiles

Resistant Cluster $(n=11)$

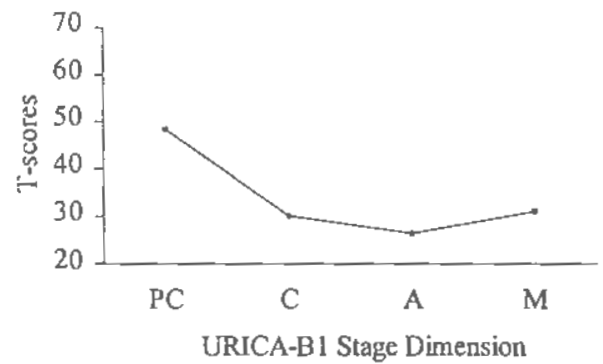

Non-Reflective Action Cluster ( $n=23$ )

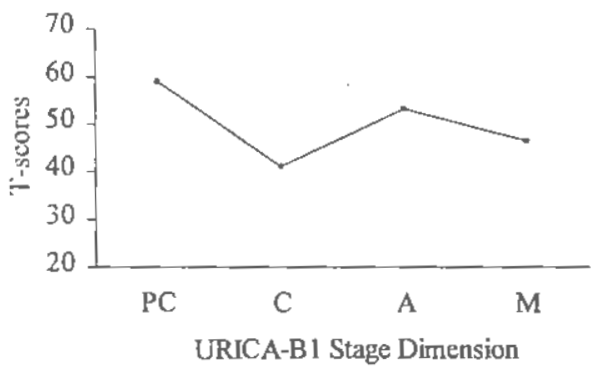

Decision-Making Cluster $(\underline{n}=64)$

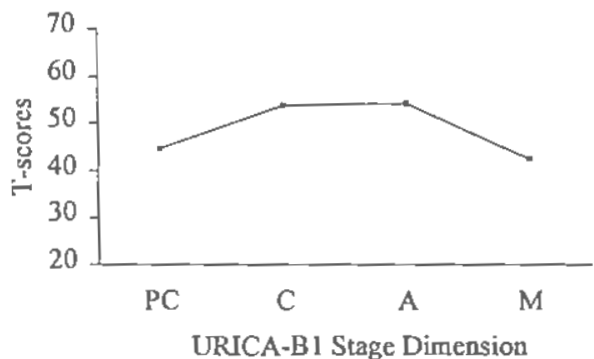

Immotive Cluster $(n=31)$

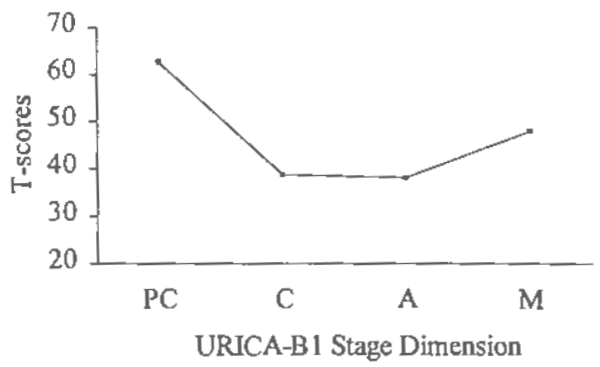

Ambivalent Cluster $(\underline{n}=61)$

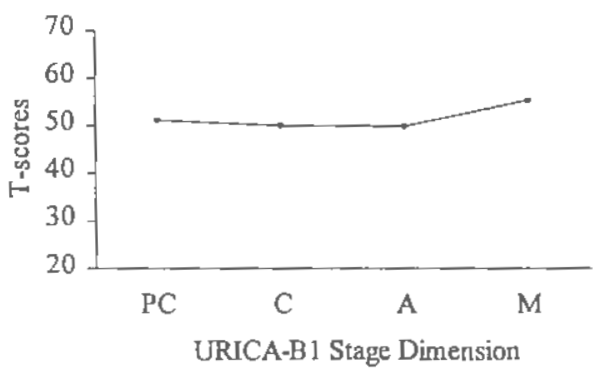

Participation Cluster $(\underline{n}=53)$

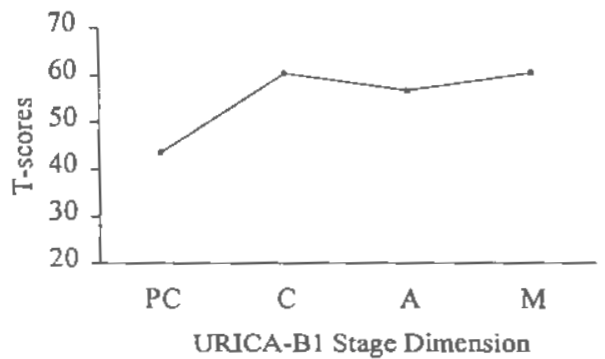



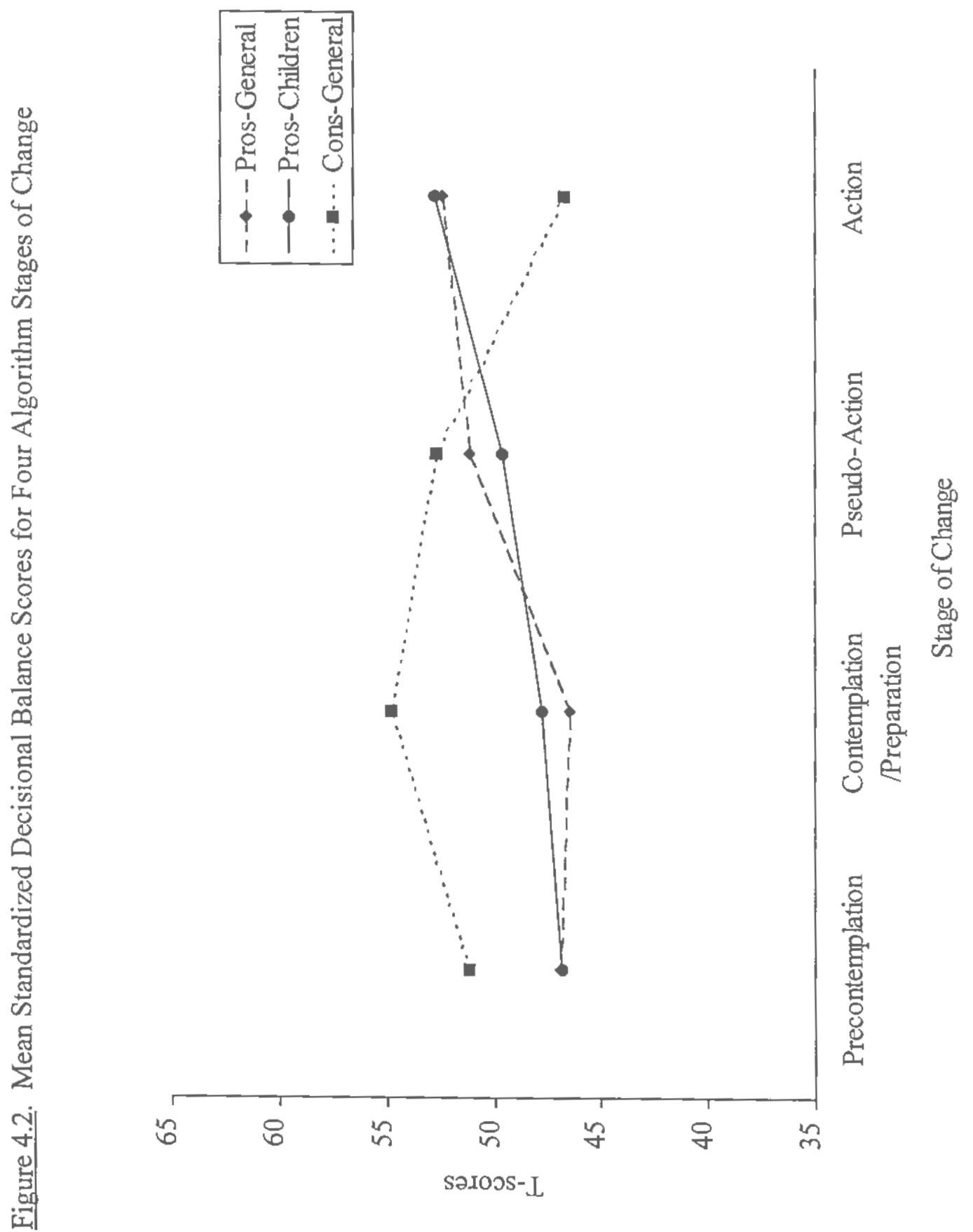


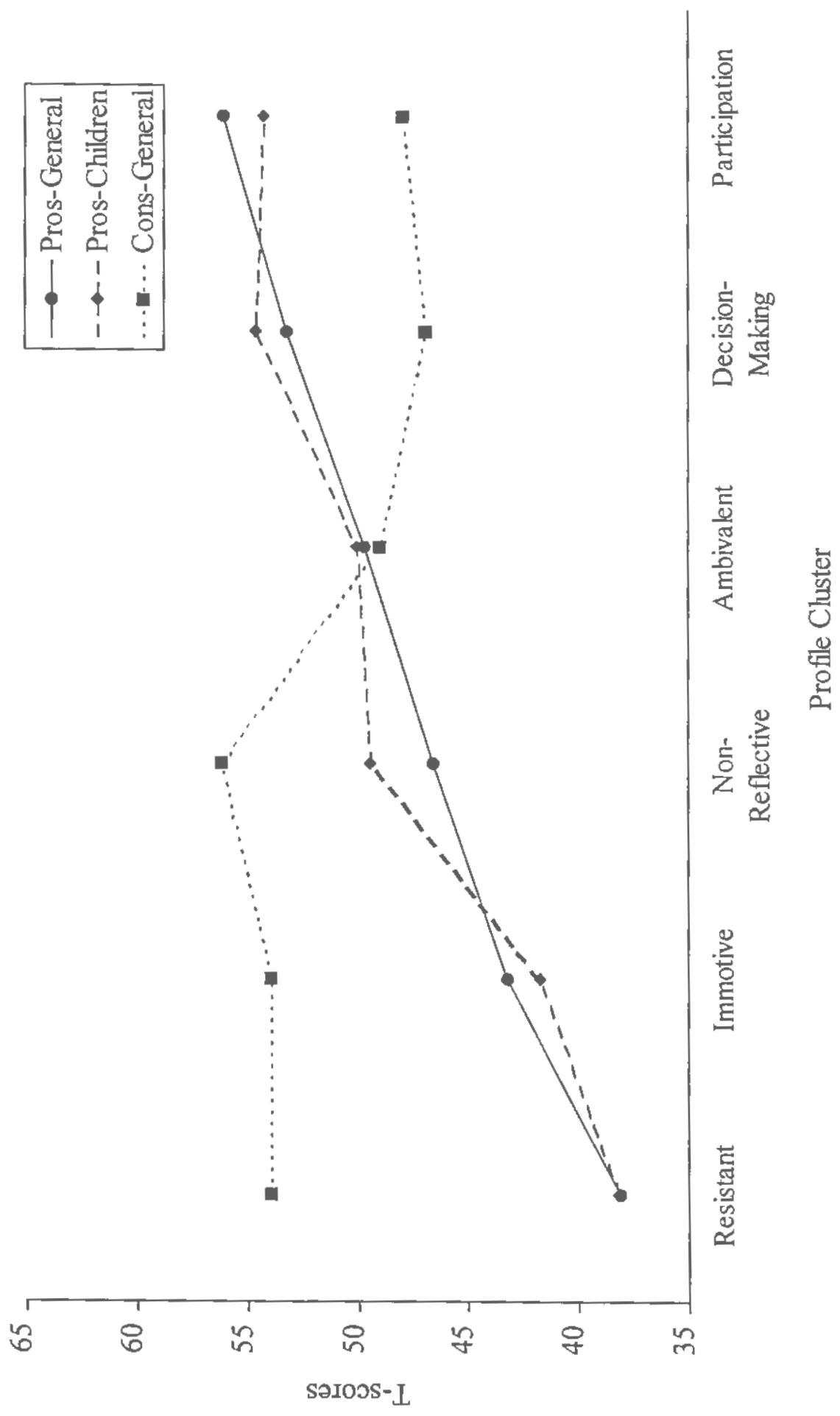


CHAPTER 5

Summary and Recommendations 
At the outset, this program of research aimed to answer four questions: 1) Do existing interventions for battering men work? 2) Why aren't interventions more effective? 3) How can the Transtheoretical Model of Change help us to understand violence desistance and change among battering men? and 4) Does the Transtheoretical Model apply to violence desistance? Below are conclusions drawn from this work, their practical implications, and recommendations for future research.

\section{Conclusion \#1: The effects of batterer treatment are small at best.}

A meta-analysis of batterer treatment outcome research found no effect for treatment in studtes relying on partner reports of recidivism, and only a small effect in studies relying on official records. A majority of the variance in effect sizes across studies was accounted for by study design, measurement, and publication characteristics. Sex-role resocialization, a common intervention strategy in batterer treatment programs, was negatively correlated with effect size. Though based on a small number of studies, these findings represent our accumulated knowledge about the efficacy of batterer treatment. They are cause for concern given the costs of partner violence to victims and society at large, and given efforts in many states to establish standards for program certification that specify the length, content, and theoretical approach to treatment. Implications:

1. Efforts to establish state standards for program certification and funding are premature. Designed to increase program accountability, standards may have a paradoxical effect and decrease program impact by institutionalizing interventions that may not work or that are sub-optimal. They may also stifle innovation and experimentation. 
2. To increase accountability, programs should be required to document their practices and interventions, and incorporate an evaluation component into treatment. Evaluation would allow programs to assess treatment effectiveness and contribute to the field's understanding of what works, for whom, and under what conditions.

3. All other program standards should represent only the most general guiding principles (e.g., that the goal of treatment is to help men end their violence).

\section{Research Recommendations:}

1. Using sound research methods and designs, the field should continue to assess and compare the efficacy of traditional and more innovative batterer treatment programs.

2. Researchers should continue efforts to synthesize findings across studies using qualitative (narrative) and quantitative (meta-analytic) techniques as new study results become available.

3. Researchers should consider using field-wide collaborative approaches to catalogue outcome studies and communicate findings to guard against publication bias.

\section{Conclusion \#2: Interventions for battering men are of limited efficacy because they} arose out of social change efforts that neglect individual change principles and strategies.

Without a doubt, arrest and batterer treatment are far more prevalent today than 20 years ago because the battered women's movement has provided a persistent and powerful impetus for social change. While these interventions support the movement's goals by serving as bold statements of society's intolerance of partner violence and by establishing penalties that may deter violence in some men, they are not very effective among known offenders who face the difficult task of individual behavior change. Given 
their roots in the movement's social change efforts, these interventions tend to neglect individual-level change strategies and principles. They tend to be standardized, "one size fits all," and thus insensitive to individual differences. They also tend to be confrontational and coercive.

\section{Practical Implications:}

1. The field must turn to empirically validated theories of individual behavior change to increase its understanding of change among battering men and to improve interventions. Ideally, these theories would be sensitive to individual differences, guide client-treatment matching, and create a treatment environment characterized by empathy and optimism.

2. More effective individual change programs for battering men would facilitate the social change goals of the battered women's movement by representing society's commitment to ending partner violence and by reducing the prevalence of violence.

Research Recommendations:

1. The field must identify empirically validated theories of individual behavior change and systematically test their applicability to the problem of violence desistance among battering men.

\section{Conclusion \#3: The Transtheoretical Model Offers a Promising Approach to Violence}

\section{Desistance and Change among Assaultive Men.}

Research has shown the Transtheoretical Model of Change to be remarkably robust in its ability to explain individual change across a variety of addictions and other maladaptive behaviors. It conceptualizes change as a process that unfolds in stages over time and provides an empirically-derived framework for the development and 
implementation of individualized, stage-matched interventions that can maximize progress and minimize resistance. Data on the applicability of the Transtheoretical Model to violence desistance are encouraging. The new stage measures developed here-especially the URICA-B1--have strong psychometric qualities and evidence of external validity. In general, tests of the model in a sample of battering men found theoryconsistent relationships between stage of change, behavior, and newly developed measures of other Transtheoretical Model constructs. For example, men in the later stages valued the pros more than the cons of changing, reported less partner blame, and were more willing to acknowledge incidences of verbal and minor physical aggression. Implications:

1. Measures of the Transtheoretical Model constructs developed here--stage of change, decisional balance, and self-efficacy--can serve as proximal measures of change to monitor progress and assess treatment effectiveness. Violence desistance is a more distal measure of effectiveness, assessed after the fact.

2. The application of the Transtheoretical Model must not be limited to program evaluation, however. While measurement is critical, it is only one step in a larger process: the development and implementation of stage-matched interventions that out-perform "one size fits all" programs. Clearly, we need to change the way we intervene if we want to have a greater impact on the problem of male-to-female partner violence.

3. Significant social change would be necessary to support an individualized stagematched approach to the problem of partner violence. Batterer treatment programs would need to be more flexible, and perhaps even of variable length to assure that all 
men have reached the Maintenance stage and developed adequate relapse prevention skills. Clinicians would need to be educated about the Model and its interventions, and address their own resistance to changing the way they work.

Research Recommendations:

1. Researchers should continue to refine the staging measures and assess their external validity. For example, does stage of change predict treatment attrition and posttreatment recidivism?

2. We need to develop measures of the remaining core constructs of the Transtheoretical Model, the processes of change, and examine how process use differs across the stages.

3. Stage-matched interventions developed for other problem areas should be adapted to battering men in treatment, implemented, and tested against the best available interventions. A close collaboration between experts on treatment and on the Transtheoretical Model will be necessary to address practical and empirical questions that arise. For example, should offenders be assigned to stage-matched psychoeducational groups, or provided with stage-matched interventions that are adjuncts to traditional treatment? This final task stands to have the largest impact on the problem of male-to-female partner violence. 


\section{APPENDIX A}

Coding Manual:

Meta-Analysis of Batterer Treatment Outcome Studies 
ID\#

Article:

Program description:

I. Study characteristics

Document type (circle one)

1. Family violence journal

2. Psychotherapy or family issues joumal

3. Book

4. Unpublished research report

5. Conference Presentation

6. Thesis or dissertation

7. Other

B. ___ Year of publication

C. ___ Grant-funded (yes/no)

D. Inclusion criteria

II. Agency characteristics

A. Geographical location

1. Northeast

2. South

3. Midwest

4. West

5. Foreign

B. Agency name

C. Agency type

1. Independent batterer program

2. Shelter-run

3. Social service agency

4. Other 
III. Multiple comparisons

IV. Treatment characteristics

A. Treatment modality

1. Men's group

2. Couple's group

3. Individual

4. Other

B. Number of sessions $(0=$ open-ended $)$

C. Program attrition (\%) original $\mathrm{N}$ final $N$ Definition:

D. Interventions (circle all that apply)

1. Relaxation training/Stress management

2. Communication skills

3. Time out

4. Assertiveness training

5. Cognitive-behavioral anger management training

6. Sex-role resocialization

a) Sex role stereotypes

b) Power and control

E. Treatment format

1. Psychoeducational

2. Process-oriented

F. Exclusion criteria

V. Client characteristics
A. Age
B. Education
C. Percent married
D. Percent living with partner
E. _ Percent employed
F. Percent minority status
G. Percent court-involved 
VI. Measure \#

Describe:

A. Data source (circle one)

1. Client

2. Partner

3. Criminal records

4. Combined

B. —CTS (yes/no)

C. Measure content (circle one)

1. Violence--recidivism

2. Threats or emotional abuse--recidivism

3. Violence--frequency or severity

4. Threats or emotional abuse--frequency or severity

5. Dyadic adjustment

6. Psychopathology

7. Other

D. Measure inclusiveness (violence measures only)

1. Less inclusive

2. Standard

3. More inclusive

4. Undefined

VII. Design Characteristics

A. Design type

1. Outcome only

2. Within groups

3. Between groups

a) Subject assignment (circle one)
(1) Random assignment
(2) Clinic-based assignment
(3) Court-based assignment 
B. Follow-up period (in months)

C. Sample size

1. Final N treatment comparison

2. Original $\mathrm{N}$

3. Response rate

___ treatment
comparison comparison

D. Summary data

1. Recidivism rates treatment

2. Means treatment comparison

3. SD's treatment comparison comparison

Notes:

Effect size: 
APPENDIX B

Readiness to Change Survey 
- Before beginning to fill out this questionnaire, please read the Consent Form

- Record your answers on the answer sheets provided.

- Use a H2 pencil.

1. What is your age?
A) 24 or under
B) $25-29$
C) $30-39$
D) $40-49$
E) 50 or older

2. Which of the following best describes your race or ethnic group?
A) White, non-Hispanic
B) Black, non-Hispanic
C) Hispanic
D) Asian E) other

3. How many years of school have you completed?
A) 0.8
B) 9.11
C) 12
D) $11-15$
E) 16 or more

4. What is your employment status?
A) employed full time
B) employed part time
C) unemployed
D) student
E) other

5. What is your yearly income?
A) less than $\$ 10,000$
B) $\$ 10,000-19,000$
C) $\$ 20,000-29,000$
D) $\$ 30,000-39,000$
E) $\$ 40,000$ or more

6. What is your marital status?
A) single B) married
C) unmarried, living with partner
D) divotced or separated
E) widow or widower

7. How many children do you have?
A) 0
B) 1
C) 2
D) 3
E) 4 or more

8. For how many months have you been in counseling at this agency?
$\begin{array}{lll}\text { A) less than } 1 \text { month } & \text { B) } 1-2 \text { months }\end{array}$
C) $3-5$ months
D) 6-12 months
E) more than 12 months

9. Is your counseling at this agency mandated by the court?
A) yes
B) no

10. Have you ever received counseling at any other agency to help you end your violence in relationships?
A) yes
B) no

11. Have you ever received counseling for alcohol or other substance abuse?
A) yes
B) no 


\section{Conflict History with Spouse/Parner}

No matter how well a couple gets along, there are times when they disagree, get annoyed with the other person, or just have spats or fights because they're in a bad mood or tired or for some other reason. They also use many different ways of trying to settle their differences. Listed below are some things that you and your partner might do when you have an argument.

Thinking back over the LAST YEAR, rate the number of times YOUR SPOUSE/ PARTNER used each of the following to settle differences with you. Choose the best response from the options below.

$$
\begin{aligned}
& A=\text { once } \\
& B=2-5 \text { times } \\
& C=6-20 \text { times } \\
& D=\text { more than } 20 \text { times } \\
& E=\text { never }
\end{aligned}
$$

12 Brought in or tried to bring in someone to help settle things

13. Refused to give affection/sex to you

14. Insulted or swore at you

15. Sulked and/or refused to talk (during a conflict)

16. Stomped out of the room, house, or yard

17. Did or said something to spite you

18. Threatened to leave the relationship

19. Threatened to hit or throw something at you

20. Threw, hit, or kicked something

21. Threw something at you

22. Pushed, grabbed, or shoved you

23. Slapped you

24. Kicked, bit, or hit you with a fist

25. Choked or strangled you

26. Physically forced you to have sex

27. Beat you up

28. Threatened you with a knife or gun

29. Used a knife or gun on you 
Once again, listed below are some things that you and your partner might do when you have an argument. Thinking back over the LAST YEAR, rate the number of times YOU used each of the following to settle differences with your spouse/partner. Choose the best response from the options below:

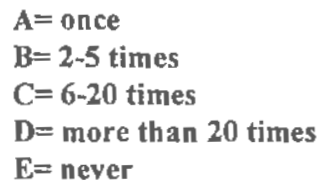

30. Brought in or tried to bring in someone to help settle things

31 Refused to give affection or sex to your partner

32. Insulted or swore at your partner

33. Sulked and/or refused to talk (during a conflict)

34. Stomped out of the room, house, or yard

35. Did or said something to spite your partner

36. Threatened to leave the relationship

37. Tried to control your partnet physically (held down, etc.)

38. Threatened to hit or throw something at your partner

39. Threw something at your partner

40. Pushed, grabbed, or shoved your partner

41. Slapped your partner

42. Kicked, bit, or hit your partner with a fist

43. Choked or strangled your partner

44. Physically forced your partner to have sex

45. Beat your partner up

46. Threatened your partner with a knife or gun

47. Used a knife or gun on your partner 
Definition: In the questions below, "violence" refers to your physical aggression toward your partner. This includes all the behaviors listed below, and other acts that can cause physical pain or injury.

--Trying to control your partner physically (holding down, etc.)

--Threatening to hit or throw something at your partner

--Throwing something at your partner

--Pushing, grabbing, or shoving your partner

--Slapping your partner

--Kicking, biting, or hitting your partner with a fist

-Choking or strangling your partner

--Physically forcing your partner to have sex

--Beating your partner up

--Threatening your partner with a knife or gun

--Using a knife or gun on your partner

48. How long ago did you first use violence in a dating or marital relationship?
A) less than one year ago
E) more than 10 years ago
B) $1-2$ years ago
C) 3-4 ago
D) 5-10 years ago

49. How long ago did you most recently use violence in a dating or marital relationship?
A) less than six months ago
B) 7-11 months ago
C) 1-2 years ago
D) 3-4 years ago
E) five years ago or more

50. Have you ever considered doing anything to put an end to your violent behavior?
A) yes
B) no 


\section{Ending the Violence: Strategies}

IN THE LAST FIVE YEARS, how often have you used each of the following in an effort to end your violent behavior in a dating or marital relationship? Think back to any and all relationships in which you used violence in the last five years.

$$
\begin{aligned}
& A=\text { never } \\
& B=\text { seldom } \\
& C=\text { sometimes } \\
& D=\text { often } \\
& E=\text { very often }
\end{aligned}
$$

51. talking to my partner about my violent behavior

52. talking to my friends and/or family about my violent behavior

53. talking to a priest, pastor, or rabbi

54. talking to a doctor, nurse or other medical health professional

55. counseling or therapy (one-on-one)

56. couple's therapy

57. group specifically for men who are violent and/or abusive

58. group therapy not specifically for men who are violent and/or abusive

59. self-help manuals or books

60. leaving the relationship for a short while

61. leaving the relationship permanently/divorcing my partner

62. How long ago did you first use any of the above strategies to end your violent behavior in your relationship?
A) I never used any of the above strategies
B) 6 months ago or less
C) 7-11 months ago
D) 1-2 years ago
E) 3 or more years ago

63. How long ago did you most recently use any of the above strategies to end your violent behavior in your relationship?
A) 1 never used any of the above strategies
B) 6 months ago or less
C) 7-11 months ago
D) 1-2 years ago
E) 3 or more years ago

64. Have you used any other strategies in your efforts to end your violent behavior in your relationship, and if so how long ago? (You can list the strategies somewhere in the shaded blue section of your answer sheet).
A) I never used any other strategies
C) 7-11 months ago
D) 1-2 years ago
B) 6 months ago or less
E) 3 or more years ago 
65. Are you seriousily considering ending your violent behavior in your relationship?
A) possibly, but only in the distant future
B) yes, in the next six months
C) yes, in the next 30 days
D) no, at the present time my relationship is $O . K$. the way it is
E) I am currently doing something to end the violence

\section{Ending the Violence; Atitudes and Behaviors}

Please indicate how much you disagree or agree with each of the following. Base your responses on how you're feeling and acting Now.

$$
\begin{aligned}
& A=\text { strongly disagree } \\
& B=\text { disagree } \\
& C=\text { no opinion } \\
& D=\text { agree } \\
& E=\text { strongly agree }
\end{aligned}
$$

66. As far as I'm concerned, violence was never a problem in my relationship.

67. I'm thinking that maybe I need to do something to end the violence in my relationship.

68. I am planning on making the changes necessary to put an end to my violent behavior.

69. There's nothing I can do to end the violence in my relationship.

70. I'm doing what it takes to end my violent behavior.

71. Although I've done what it takes to end the violence, I'm afraid I might fall back into my old relationship patterns again.

72. My partner was to blame for my violent behavior.

73. I think I might be happier in a relationship that is completely violence-free.

74. I can't cope with my violent behavior anymore. I want help now.

75. I have no intention of trying to end the violence in my relationship.

76. I'm doing something to put an end to the violence in my relationship.

77. I've been pretty successful in leading a violence-free life, but there are still times when tempted to resort to violence.

78. Every time I used violence toward my partner, I had a pretty good reason.

79. I'm thinking about talking to other people who can help me end the violence.

80. I've had enough. I'm prepared to end the violence.

81. If my partner would just leave me alone I wouldn't have a problem with violence.

82. I'm actively working on ending the violence in my relationship.

83. Although I've done a good job at ending the violence, I need to be on guard to make sure the problem doesn't happen again.

84. If my partner treated me better, I wouldn't have a problem with violence.

85. I'm wondering what I can do to end the violence in my relationship. 


\section{Ending the Violence: Attitudes and Behaviors (continued)}

Please indicate how much you disagree or agree with each of the following statements. Base your responses on how you're feeling and acting NOW.

$$
\begin{aligned}
& A=\text { strongly disagree } \\
& B=\text { disagree } \\
& C=\text { no opinion } \\
& D=\text { agree } \\
& E=\text { strongly agree }
\end{aligned}
$$

86. I'm making plans to live a life that's violence-free

87. A "real man" dominates his partner.

88. I'm actually doing something to stop my violent behavior, not just thinking about it.

89. I've ended the violence, but sometimes still struggle with the old urges that allowed the violence to happen in the first place.

90. I don't understand why people got so upset about the way I treated my partner.

91. I'm beginning to see that the violence in my relationship is a problem.

92. I've been talking to others about the steps I can take to live a violence-free life.

93. A lot of men use violence with their partners.

94. I'm making important changes and ending the violence in my life.

95. I've made some changes and ended the violence, but I'm afraid of going back to the way I was before.

96. The wiolence in my relationship isn't a big deal.

97. I wish I had more ideas about how to end the violence in my relationship.

98. I have a plan about how to end the violence, and am prepared to carry it out.

99. It doesn't make sense to change because my partner is violent, too.

100. I'm finalily doing something to end the violence.

101. Atthough I haven't been violent for a while, I know it's possible for me to be violent again.

102. All this talk about "domestic abuse" is boring.

103. I' $m$ at a point in my life where I'm feeling the harmful impact of my violent behavior.

104. I've decided to do something to end the violence.

105. My partner is the one with the problem, not me.

106. Although at times it's difficult, I'm working on ending my violent behavior in my relationship.

107. Although I've made the changes necessary to lead a violence-free life, there are times when I'm still tempted to use violence.

108. It's $\mathrm{OK}$ to use violence, as long as you don't burt anyone.

109. It might be worthwhile to work on leading a violence-free life.

110. I'm finding out who and what's out there to help me so I can make a change and end the violence.

111. There's no way I can control my violent impulses

112. I don't see the point of focusing on the violence in my relationship.

113. More and more I'm seeing how my violence hurts my partner.

114. I'm getting prepared to end the violence.

115. I feel hopeless when I think about ending the violence.

116. More and more $I^{\prime} \mathrm{m}$ realizing that my violence is wrong.

117. The harmful impact of my violent behavior worries me more than it used to.

118. I've been thinking that maybe I need to end the violence, but haven't taken any concrete steps yet. 


\section{Pros and Cons of Ending the Violence}

The following statements represent different opinions about violence in relationships. Some will be true for you, and others won't. Whether or not they're true for you, please rate HOW IMPORTANT each statement would be in your decision about whether or not to end your violent behavior in your relationship.

$$
\begin{aligned}
& A=\text { not at all important } \\
& B=\text { slightly important } \\
& C=\text { moderately important } \\
& D=\text { very important } \\
& E=\text { extremely important }
\end{aligned}
$$

HOW IMPORTANT would each statement be in your decision about whether or not to end your violent behavior in your relationship:

119. By ending the violence I'd be setting an example for other men.

120. I'd feel ashamed talking about the way I treat my partner.

121. I'd have more self-respect if I ended the violence.

122. In a non-violent relationship I wouldn't have to worry about getting arrested.

123. My friends and/or family will admire me for doing what it takes to end the violence.

124. My partner would feel embarrassed if I got help to end the violence.

125. The violence is an effective way of punishing my partner.

126. I like the "making up part" after our fights.

127. If I didn"t get violent my anger would just build and build.

128. If I don't end my violent behavior, I might get into trouble with the law.

129. By ending the violence a man teaches his children that violence is not O.K.

130. I'd lose my macho image if I stopped being violent.

131. I will gain the respect of my partner if I end the violence.

132. If I ended the violence I'd feel better about my relationship.

133. If I ended the violence I'd receive more love and kindness from my partner.

134. If I ended the violence my partner would feel less shame.

135. If I ended the violence, I wouldn't get my own way as often with my partner.

136. My friends and/or family will think I'm weak if my partner gets the upper hand in this relationship.

137. If I don"t change my community will label me as a "batterer."

138. I'll lose my friends if I don't end the violence.

139. If I ended my violent behavior, I'd have to listen to my partner's nagging.

140. I'd feel less guilty in a non-vjolent relationship.

141. If $I$ ended the violence $l ' d$ have no way of letting off steam.

142. My community expects men to act macho.

143. My parner will probably leave me if I don't end the violence.

144. My partner would feel better about herselfhimself if I ended the violence.

145. I wouldn't feel superior anymore if I stopped being violent.

146. My community expects a man to protect his parther, not harm her/him.

147. If I put an end to the violence, I could enjoy my relationship with my children more.

148. The only way to end the violence is to end the relationship.

149. If $I$ end my violent behavior, my partner will take advantage of me.

150. I'd feel better about myseif if I put an end to the violence. 


\section{Pros and Cons of Ending the Violence (continued)}

HOW IMPORTANT wouldeach statement be in your decision about whether or not to end your violent behavior in your relationship:

$$
\begin{aligned}
& A=\text { not at all important } \\
& B=\text { slightly important } \\
& C=\text { moderately important } \\
& D=\text { very important } \\
& E=\text { extremely important }
\end{aligned}
$$

151. I'd feel like a "wimp" if I ended the violence.

152. I'd have less control over my partner if I ended the vioience.

153. If I end the violence my children will have more respect for me.

154. in a violence-free relationship, my partner would trust me more.

155. My partner could feel safer if I ended the violence.

136. If I try to end the violence, people will respect me for "doing what's right."

157. If I end the violence my partner and I will have a better telationship.

158. I'd have more peace of mind in a non-violent relationship.

159. I wouldn't feel like the "man of the house" if I ended the violence.

160. If I didn't use violence with my partner, our fights would go on and on.

161. If I ended the violence I wouldn't have to worry about damaging property (e.g., holes in walls).

162. My partner wouldn't suffer any injuries if I ended the violence.

163. Children are happier in a violence-free home.

164. My violent behavior embarrasses my family.

165. My friends and/or family will respect me more if I gain control of my violent behavior.

166. If I ended the violence, I'd have no way of getting my partner to leave me alone.

167. Getting angry is bad for my health.

168. Ending the violence would mean ending the relationship.

169. I'd be happier in a non-violent relationship.

$170 \quad$ l'd feel embarrassed asking someone for help ending the violence.

171. People would think I'm a wimp if I let my partner push me around.

172. My community disapproves of a man who picks on someone who's smaller than he is.

173. In a violence-free home, children don't need to feel afraid,

174. If I don't end the violence I may lose my children.

175. Children are safer in a violence-free home.

176. If I did something about the violence I'd feel a sense of accomplishment.

177. If I ended the violence, I'd have a hard time getting my point across with my partner.

178. If I ended the violence, I wouldn't know who I am anymore.

179. By ending the violence, I'd be setting an example for my children

180. My friends disapprove of the violence.

181. My violent behavior might put my job/schooling on the line.

182. I'd feel like I have more self-control if I ended the violence.

183. Making the changes necessary to end the violence would be disnuptive to my family.

184. If I ended the violence I'd have to listen to my partner criticize me.

185. Children can depend more on a father who solves his problems without violence. 


\section{Temptations}

Listed below are situations that might tempt some people to use violence against a partner. We would like to know how tempted you would be to use violence in each situation.

$$
\begin{aligned}
& A=\text { not at all tempted } \\
& B=\text { not very tempted } \\
& C=\text { moderately tempted } \\
& D=\text { very tempted } \\
& E=\text { extremely tempted }
\end{aligned}
$$

How tempted would you be to use violence against a partner in the following situations?

186. When I'm having money probiems

187. When I'm high on alcohol or drugs

188. When my partner spends too much

189. When my partner and I argue about children

190. When my partner and I argue about chores around the house

191. When my partner and I argue about my going out with friends

192. When my partner insults me

193. When my partner interrupts me when $l^{1} \mathrm{~m}$ talking

194. When I'm out of work and have nothing to do with my time

195. When I feet life is unfair

196. When I expect something and don't get it

197. When I feel like other people are taking advantage of me

198. When my partner and I argue about my drinking

199. When my partner contradicts me

200. When my partner goes out with friends

201. When I'm feeling pressure at work

202. When I feel like a failure

203. When my partner visits her family

204. When my partner and I argue about my partner's job

205. When things aren't going my way and I'm frustrated

206. When my partner yells at me

207. When my partner gets drunk

208. When my partner and I argue about my partner's drinking

209. When my partner and I argue about my job

210. When I'm tired

211. When I'm feeling angry and stressed

212. When I'm hungry

213. When my partner and I argue about sex

214. When my partner won't give me my space

215. When my partner hits me 
216. Have you ever considered ending your relationship with this partner?
A) yes
B) no

217. Is your relationship with this partner still going on?
A) yes
B) no

If yes, relationship is still going on:

If $\underline{N_{0}}$, relationship is not still going on:
218.

Are you seriously considering ending this relationship?

A) I am not seriously considering ending this relationship

B) yes, but don't know if I'll end it

C) yes, and I plan to end it in the next year

D) yes, and I plan to end it in the next six months

E) yes, and 1 plan to end it in the next 30 days

219. Do you think your partner is seriously considering ending this relationship?
A) yes
B) no
C) don't know

220. If you've ever attempted to break up with or separate from your partner, how recent was your last attempt?

$\begin{array}{ll}\text { A) } 6 \text { months ago or less } & \text { B) 7-11 months ago }\end{array}$

$\begin{array}{lll}\text { C) 1-2 years ago } & \text { D) more than two years ago }\end{array}$

E) I never attempted to break up with or separate from my partner

218. How long ago did this relationship end?
A) less than 6 months ago
B) 7-11 months ago
C) $1-2$ years ago
D) 3-4 years ago
E) 5 or more years ago

219. Who made the decision to end the relationship?
A) self
B) partner
C) both self and partner

220. How long did this relationships last?
A) less than 6 months
B) 7-11 months
C) 1-2 years
D) 3-4 years
E) 5 or more years 
For questions 221-227, think about the dating or marital relationship in which you MOST RECENTLY used violence.

221. Currently, what is your partner's age?
A) 24 or under
B) $25-29$
C) $30-39$
D) $40-49$
E) 50 or older

222. What is your partner's sex?
A) fenale
B) male

223. Did you and your partner ever live together while you were involved?
A) yes
B) no

224. Were you and your partner ever married?
A) yes
B) no

225. Did you and your partner have any children together?
A) yes
B) $n 0$

226. During your relationship, how many drinks of alcohol did you have on a typical weekend night?
A) 0
B) $1-2$
C) $3-5$
D) $6-10$
E) more than 10

227. Are you seriously considering cutting back on the amount of alcohol you drink?
A) Yes, in the next six months
B) Yes, in the next 30 days
C) No, I cut back more than 6 months ago
D) No, I cut back less than 6 months ago
E) No, I don't plan to cut back-or--
E) No, I never had a problem with alcohol 
Please rate how true or false each of the following statements is for you.

$$
\begin{aligned}
& A=\text { completely true } \\
& B=\text { mostly true } \\
& C=\text { partly true, partly false } \\
& D=\text { mostly false } \\
& E=\text { completely false }
\end{aligned}
$$

228. It is sometimes hard for me to go on with my work if I am not encouraged

229. I sometimes feel resentful when I don't get my way

230. On a few occasions, I have given up doing something because I thought too little of my ability

231. There have been times when I felt like rebelling against people in authority even though I knew they were right

232. No matter who I'm talking to I'm always a good listener

233. There have been occasions when I took advantage of someone

234. I'm always willing to admit it when I've made a mistake

235. I sometimes try to get even rather than forgive and forget

236. I am always courteous, even to people who are disagreeable

237. I have never been irked when people expressed ideas very different from my own

238. There have been times when I was quite jealous of the good fortune of others

239. I am sometimes iritated by people who ask favors of me

240. I have deliberately said something that hurt someone's feelings 


\section{Bibliography}

Adams, D., \& McCormick, A. (1982). Men unlearning violence: A group approach based on the collective model. In M. Roy (Ed.), The abusive partner: An analysis of domestic battering (pp. 170-197). New York: Van Nostrand Reinhold.

Aldenderfer, M.S., \& Blashfield, R.K. (1984). Cluster analysis. Newbury Park, CA:

\section{Sage}

Arias, I., \& Beach, S.R.H. (1987). Validity of self-reports of marital violence. Journal of Family Violence, 2, 139-149.

Astin, M.C., Lawrence, K.J., \& Foy, D.W. (1993). Posttraumatic stress disorder among battered women: Risk and resiliency factors. Violence and Victims, $\underline{8}$, 17-28.

Astin, M.C., Ogland-Hand, S.M., Coleman, E.M., \& Foy, D.W. (1995). Posttraumatic stress disorder and childhood abuse in battered women: Comparisons with maritally distressed women. Journal of Clinical and Consulting Psychology, $\underline{63}$, $308-312$

Avis, J.M. (1992). Where are all the family therapists? Abuse and violence in families and the family therapist's response. Journal of Marital and Family Therapy, 18 , $225-232$

Azjen, I. (1988). Attitudes, personality, and behavior. Chicago, IL: Dorsey Press. Azjen, I. (1991). The Theory of Planned Behavior. Organizational Behavior and Human Decision Processes, $\underline{50}, 179-211$.

Bachman, R., \& Saltzman, L.E. (1995). Violence against Women: Estimates from the redesigned survey (Special Report No. NCJ-154348). Washington, DC: Bureau of Justice Statistics, U.S. Department of Justice. 
Baekeland, F., \& Lundwall, L. (1975). Dropping out of treatment: A critical review. Psychological Bulletin, 82, 738-783.

Bandura, A. (1973). Aggression: A social learning analysis. Englewood Cliffs, NJ: Prentice Hall.

Bandura, A. (1977). Self-efficacy: Toward a unifying theory of behavior change. Psychological Review, 84, 191-215

Barrera, M., Palmer, S., Brown, R., \& Kalaher, S. (1994). Characteristics of courtinvolved men and non-court-involved men who abuse their wives. Journal of Family Violence, 9 , 333-345.

Baum, F., Brand, R., Colley, D., \& Cooke, R. (1987). Preventing family violence: The evaluation of a group of men who are violent toward their partners. Australian Journal of Sex, Marriage, \& Family, $\underline{8}, 173-183$.

Beck, A.T., Freeman, A., \& Associates (1990). Cognitive therapy of personality disorders. New York: Guilford Press.

Begun, A., Strodhoff, T., Weinstein, B., Shelley, G., Short, L. (1997, June).

Development of an instrument to assess readiness to change battering behavior: Preliminary results. Paper presented at the 5th International Family Violence Research Conference, Durham, $\mathrm{NH}$.

Beninati, J. (1989). Pilot project for male batterers. Social Work with Groups, 12 , 6374.

Berk, R.A., Campbell, A., Klap, R., \& Western, B. (1992). The deterrent effect of arrest in incidents of violence: A Bayesian analysis of four field experiments. American Sociological Review, 57, 698-708. 
Bidgood, B., Tutty, L.M., \& Rothery, M. (1991). An evaluation of the Coordinated Family Violence Treatment Program in the Waterloo area: A summary report. Waterloo, Ontario, Canada: Centre for Social Welfare Studies.

Blashfield, R.K. (1980). Propositions regarding the use of cluster analysis in clinical research. Journal of Consulting and Clinical Psychology, 48, 456-459.

Blumstein, A., \& Cohen, J., \& Nagin, D. (Eds.). (1978). Deterrence and incapacitation: Estimating the effects of criminal sanctions on crime rates. Washington, DC: National Academy Press.

Bodnarchuk, M., Knopp, P.R., Ogloff, J.R.P., Hart, S.D., \& Dutton, D.G. (1995).

Predicting cessation of intimate assaultiveness after group treatment. Report \#4887-10-91-106 submitted to Family Violence Prevention Division, Health Canada, Ottawa, Canada.

Bograd, M. (1992). Values in conflict: Challenges to family therapists' thinking. Journal of Marital and Family Therapy, 18, 245-256.

Brannen, S.J. (1994). Effectiveness of gender-specific versus couples' groups in a courtmandated spouse abuse treatment program: A comparative study (Doctoral dissertation, University of Texas at Austin, 1994). Dissertation Abstracts International, 56(02), 704B. (University Microfilms No. AAC 9519251)

Brehm, J.W. (1966). A theory of psychological reactance. New York: Academic Press. Brown, J. (1997). Working toward freedom from violence: The process of change in battered women. Violence against women, 3, 5-26.

Browne, A. (1993). Violence against women by male partner: Prevalence, outcomes, and policy implications. American Psychologist, 48, 1077-1087. 
Browne, A., \& Williams, K.R. (1989). Exploring the effect of resource availability and the likelihood of female-perpetrated homicides. Law and Society Review, 23, 7594.

Buss, A.H., \& Durkee, A. (1957). An inventory for assessing different kinds of hostility. Journal of Consulting Psychology, 2, 513-524.

Buzawa, E.S., \& Buzawa, C.G. (1990). Domestic violence:-The criminal justice response. Newbury Park, CA: Sage.

Cadsky, O., \& Crawford, M. (1988). Establishing batterer typologies in a clinical sample of men who assault their female partners. Canadian Journal of Community Mental Health, 7, 119-127.

Cadsky, O., Hanson, R.K., Crawford, M., \& Lalonde, C. (1996). Attrition from a male batterer treatment program: Client-treatment conguence and lifestyle instability. Violence and Victims, 11, 51-64.

Campbell, D.T., \& Stanley, J.C. (1963). Experimental and quasi-experimental designs for research. Chicago: Rand McNally College Publishing Company.

Campbell, J.C., Kub, J., Belknap, R.A., \& Templin, T.S. (1997). Predictors of depression in battered women. Violence Against Women, 3, 271-293.

Chen, H., Bersani, C., Meyers, S.C., \& Denton, R. (1989). Evaluating the effectiveness of a court-sponsored treatment program. Journal of Family Violence, 4, 309-322.

Cohen, J. (1988). Statistical power analysis for the behavioral sciences (2nd ed.). Hillsdale, NJ: Erlbaum.

Comrey, A.L. (1988). Common methodological problems in factor analytic studies. Journal of Consulting and Clinical Psychology, 46, 648-659. 
Comrey, A.L. (1988). Factor-analytic methods of scale development in personality and clinical psychology. Journal of Consulting and Clinical Psychology, 56, 754-761.

Crowne, D.P., \& Marlowe, D. (1960). A new scale of social desirability independent of psychopathology, Journal of Clinical and Consulting Psychology, 349-354.

Daniels, J.W., \& Murphy, C.M. (1997). Stages and processes of change in batterers' treatment. Cognitive and Behavioral Practice, 4, 123-145.

Davis, R.C., \& Taylor, B.G. (1997, June). A randomized experiment of the effects of batterer treatment: Summary of preliminary research findings. Paper presented at the 5th International Family Violence Research Conference, Durham, NH.

DeMaris, A. (1989). Attrition in batterers' counseling: The role of social and demographic factors. Social Service Review, 63, 142-154.

DeMaris, A., \& Jackson, J.K. (1987). Batterers' reports of recidivism after counseling. Social Casework, 68, 458-465..

Deschner, J.P. (1984). How to end the hitting habit: Anger control for battering couples. New York: The Free Press.

Dickersin, K. (1990). The existence of publication bias and risk factors for its occurrence. Journal of the American Medical Association, 263, 1385-1390.

DiClemente, C.C. (1981). Self-efficacy and smoking cessation maintenance: A preliminary report. Cognitive Therapy and Research, $\underline{5}, 175-187$.

DiClemente, C.C., \& Hughes, S.O. (1990). Stages of change profiles in outpatient alcoholism treatment. Journal of Substance Abuse, 2 , 217-235. 
DiClemente, C.C., \& Prochaska, J.O. (1982). Self-change and therapy change of smoking behavior: A comparison of processes of change in cessation and maintenance. Addictive Behaviors, 7, 133-142.

DiClemente, C.C., Prochaska, J.O., Fairhurst, S.K., Velicer, W.F., Velasquez, M.M., \& Rossi, J.S. (1991). The process of smoking cessation: An analysis of precontemplation, contemplation, and preparation stages of change. Journal of Consulting and Clinical Psychology, 59, 295-304.

DiClemente, C.C., Prochaska, J.O., \& Gibertini, M. (1985). Self-efficacy and the stages of self-change of smoking. Cognitive Therapy and Research, $9,181-200$.

Ding, L., Velicer, W.F., \& Harlow, L.L. (1995). Effects of estimation methods, number of indicators per factor, and improper solutions on structural equation modeling fit indices. Structural Equation Modeling, 2, 119-144.

Dobash, R.E., \& Dobash, R.P. (1979). Violence against wives: A case against the patriarchy. New York: Free Press.

Dobash, R.E., \& Dobash, R.P. (1992). Women, violence, and social change. New York: Routledge.

Dobash, R.E., \& Dobash, R.P. (1997). Men's violence and programs focused on change. Current Issues in Criminal Justice, $\underline{8}, 243-262$.

Dooley, D.G., \& Catalano, R. (1984). The epidemiology of economic stress. American Journal of Community Psychology, 12, 387-409.

Dunford, F.W., Huizinga, D., \& Elliott, D.S. (1990). The role of arrest in domestic assault: A quasi-experimental evaluation. Violence and Victims, 1, 163-175. 
Dutton, D.G. (1986). The outcome of court-mandated treatment for wife assault: A quasi-experimental evaluation. Violence and Victims, 1 , 163-176.

Dutton, D.G. (1994). Patriarchy and wife assault: The ecological fallacy. Violence and Victims, 9 , 167-182.

Dutton, D.G. (1995). The domestic assault of women. Vancouver: UBC Press.

Dutton, D.G., Bodnarchuk, M., Kropp, R., Hart, S.D., \& Ogloff, J.R.P (1997). Wife assault treatment and criminal recidivism: An 11-year follow-up. International Journal of Offender Therapy and Comparative Criminology, 41, 9-23

Dutton, D.G., \& Hemphill, K.J. (1992). Patterns of socially desirable responding among perpetrators and victims of wife assault. Violence and Victims, $\underline{7}, 29-39$.

Dutton, D. G., \& Starzomski, A.J. (1994). Psychological differences between courtreferred and self-referred wife assaulters. Criminal Justice and Behavior, 21, 203222.

Dutton, M.A. (1992). Assessment and treatment of post-traumatic stress disorder among battered women. In D.W. Foy (Ed.), Treating PTSD: Cognitive behavioral stategies (pp. 69-97). New York: Guilford Press.

Eaton, C.A., Velicer, W.F., \& Fava, J.L. (1992, October). Determining the number of components: An evaluation of alternative procedures. Paper presented at the annual meeting of the Society of Multivariate Experimental Psychology, Cape Cod, MA.

Eddy, M., \& Myers, T. (1984). Helping men who batter: A profile of programs in the U.S. Texas Department of Human Resources. 
Edelbrook, C. (1979). Mixture models of hierarchical clustering algorithms: The problems of classifying everybody. Multivariate Behavioral Research, 14, 367384.

Edleson, J.L. (1984). Working with men who batter. Social Work, 29, 237-242.

Edleson, J.L., \& Brygger, M.P. (1986). Gender differences in self-reporting of battering incidents. Family Relations, 35 , 377-382,

Edleson, J.L., \& Grusznski, R.J. (1989). Treating men who batter: Four years of outcome data from the Domestic Abuse Project. Joumal of Social Service Research, 12, 3-22.

Edleson, J., Miller, D., \& Stone, G.W., \& Chapman, D.G. (1985). Group treatment for men who batter: A multiple baseline design. Social Work Research and Abstracts, 21(3), 18-21.

Edleson, J.L., \& Syers, M. (1990). The relative effectiveness of group treatment for men who batter. Social Work Research and Abstracts, 26, 10-17.

Eisenhart, C. (1947). Inverse sine transformation of proportions. In C. Eisenhart, M.W. Haysty, \& W.A. Wallis, (Eds.), Selected techniques of statistical analysis for scientific and industrial research production and management engineering (pp. 395-416). New York: McGraw-Hill.

Eisikovitz , Z.C., \& Edleson, J.L. (1989). Intervening with men who batter: A critical review of the literature. Social Service Review, 384-414.

Ellis, A. (1970). The Essence of rational psychotherapy: A comprehensive approach to treatment. New York: Institute for Rational Living. 
Everitt, B. (1980). Cluster analysis ( $2^{\text {nd }}$ ed.) New York: Halsted Press.

Fagan, J. (1989). Cessation of family violence: Deterrence and dissuasion. In L. Ohlin \& M. Tonry (Eds.), Family violence. Chicago: University of Chicago Press.

Fagan, J. (1996). The criminalization of domestic violence: Promises and limits [Online series: NIJ Research Report]. Available: ncjrs.aspensys.com:81/new//crimdon.txt.

Faulkner, K., Stoltenberg, C.D., Cogen, R., Nolder, M., \& Shooter, E. (1992). Cognitive-behavioral group treatment for male spouse abusers. Journal of Family Violence, $7,37-55$

Feazell, C.S., Mayers, R., \& Deschner, J.P. (1984). Services for men who batter: Implications for programs and policies. Family Relations, 33 , 217-223.

Federal Bureau of Investigation. (1997). Crime in the United States 1996. Washington, DC: U.S. Department of Justice.

FeId, S.L., \& Straus, M.A. (1990). Escalation and desistance from wife assault in marriage. In M.A. Straus \& R.J. Gelles (Eds.), Physical violence in American families: Risk factors and adaptations to violence in 8.145 families (pp. 489-505). New Brunswick, NJ: Transaction Publishers.

Feldman, C.M., \& Ridley, C.A. (1995). The etiology and treatment of domestic violence between adult partners. Clinical Psychology: Science and Practice, 2 $2,317-348$.

Ferraro, K.J. (1989). Policing women battering. Social Problems, 36, 61-74.

Flournoy, P.S. (1992). A comparison of groups for men who batter (Doctoral dissertation, Washington State University). Dissertation Abstracts International, 533(11), 5974B. (University Microfilms No. AAC-9309051). 
Flournoy, P.S., \& Wilson, G.L. (1991). Assessment of MMPI profiles of male batterers. Violence and Victims, $\underline{6}, 309-320$.

Ganley, A. (1981). Court mandated counseling for men who batter: A three-day workshop. Washington, D.C.: Center for Women's Policy Studies.

Ganley, A. (1981). Participant and trainer's manual for working with men who batter. Washington, D.C.: Center for Women's Policy Studies.

Ganley, A. (1987). Perpetrators of domestic violence: An overview of counseling the court-mandated client. In D.J. Sonkin (Ed.), Domestic violence on trial: Psychological and legal dimensions of family violence (pp. 155-173). New York: Springer.

Gamer, J., Fagan, J., \& Maxwell, C. (1995). Published findings from the NIJ Spouse Assault Replication Program: A Critical Review. Journal of Quantitative Criminology, 11, 3-28.

Gelles, R.J. (1974). The violent home. Beverly Hills, CA: Sage.

Gelles, R.J. (1983). An exchange/social control theory. In D. Finkelhore, R.J. Gelles, G.T. Hotaling, \& M.A. Straus (Eds.), The dark side of families: Current family violence research (pp. 151-165). Beverly Hills, CA: Sage.

Gelles, R.J., \& Harrop, J.W. (1989). Violence, battering, and psychological distress among women. Journal of Interpersonal Violence, 4, 400-420.

Gelles, R.J., \& Straus, M.A. (1979). Determinants of violence in the family: Toward a theoretical integration. In W.R. Burr, R. Hill, F.I. Nye, \& I.L. Reiss (Eds.), Contemporary theories about the family (Vol. 1, pp. 549-581). New York: Free Press. 
Gibbs, J. (1975). Crime, punishment, and deterrence. New York: Elsevier.

Glaser, D. (1973). Routinizing evaluations: Getting feedback on effectiveness on crime and delinquency programs. Rockville, MD: National Institute of Mental Health, U.S. Department of Health, Education, and Welfare.

Gleason, W.J. (1993). Mental disorders in battered women: An empirical study. Violence and Victims, $\underline{8}, 69-84$

Goldner, V., Penn, P., Sheinberg, M., Walker, G. (1990). Love and violence: Gender paradoxes in volatile attachments. Family Process, 29, 343-364.

Gondolf, E.W. (1987). Changing men who batter: A developmental model for integrated interventions. Journal of Family Violence, 2, 335-349.

Gondolf, E.W. (1988). The effect of batterer counseling on shelter outcome. Journal of Interpersonal Violence, 3 , 275-289.

Gondolf, E.W. (1988). How some men stop their abuse: An exploratory program evaluation. In G.T. Hotaling, D. Finkelhor, J.T. Kirkpatrick, \& M.A. Straus (Eds.), Coping with family violence: Research and policy perspectives. Newbury Park: Sage.

Gondolf, E.W. (1988). The effect of batterer counseling on shelter outcome. Journal of Interpersonal Violence, 3, 275-289.

Gondolf, E.W. (1988). Who are those guys? Towards a behavioral typology of men who batter. Violence and Victims, 3 , 187-203.

Gondolf, E.W. (1990). An exploratory survey of court-mandated batterer programs. Response, 13(3), 7-11. 
Gondolf, E.W. (1997, June). A comparison of four batterer intervention systems: Do court-referral, program length, and services matter? Paper presented at the 5th International Family Violence Research Conference, Durham, NH.

Gondolf, E.W., \& Russell, D. (1986). The case against anger control treatment programs for batterers. Response, 9(3), 2-5.

Gottman, J., Jacobson, N., Rushe, R., Short, J., Babcock, J., LaTaillade, J., \& Waltz, J. (1995). The relationship between heart rate reactivity, emotionally aggressive behavior, and general violence in batterers. Journal of Family Psychology, $\underline{9}$, $227-248$.

Grusznski, R.J. (1985). Court-ordered treatment of men who batter (Doctoral dissertation, University of Minnesota) . Dissertation Abstracts International, 46(10), 3594B. (University Microfilms No. AAC 8526416).

Gruznski, R.J., \& Carillo, R.P. (1988). Who completes batterer treatment groups? An empirical investigation. Journal of Family Violence, $\underline{3}, 141-150$.

Hamberger, L.K., \& Hastings, J.E. (1986). Characteristics of spouse abusers: Predictors of treatment acceptance. Journal of Interpersonal Violence, $1,323-341$.

Hamberger, L.K., \& Hastings, J.E. (1988). Skills training for treatment of spouse abusers: An outcome study. Journal of Family Violence, $\underline{3}, 121-130$.

Hamberger, L.K., \& Hastings, J.E. (1989). Counseling male spouse abusers: Characteristics of treatment completers and dropouts. Violence and Victims, $\underline{4}$, $275-286$. 
Hamberger, L.K., \& Hastings, J.E. (1990). Recidivism following spouse abuse abatement counseling: Treatment program implications. Violence and Victims, $4,275-286$.

Hamberger, L.K., \& Hastings, J.E. (1993). Court-mandated treatment of men who assault their partner: Issues, controversies, and outcomes. In Z. Hilton (Ed.), Legal responses to wife assault (pp. 188-229). Newbury Park, CA: Sage.

Hamberger, L.K., Lohr., Bonge, D., \& Tolin, D.E. (1996). A large sample empirical typology of male spouse abusers and its realtionship to dimensions of abuse.

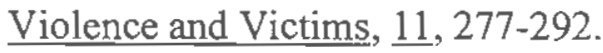

Hanson, R. K., Marques, J. K., Quinsey, V. L., Gordon, A., Murphy, W., Seto, M. C., \& Harris, A. (1997, October). Collaborative data base of sex offender treatment outcome. Presentation at the 16 th Annual Research and Treatment Conference of the Association for the Treatment of Sexual Abusers, Arlington, VA.

Harrell, A.V. (1991). Evaluation of court-ordered treatment for domestic violence offenders. Final report submitted to the State Justice Institute. Washington, D.C: The Urban Institute.

Harris, J. (1986). Counseling violent couples using Walker's model. Psychotherapy, 23, 613-621.

Harris, R., Savage, S., Jones, T., \& Brooke, W. (1988). A comparison of treatments for abusive men and their partners within a family service agency. Canadian Journal of Community Mental Health, I, 147-155.

Hart, B. (1992). Accountability: Program standards for batterer intervention services. Reading, PA: Pennsylvania Coalition Against Domestic Violence. 
Hathaway, S.R., \& McKinley, J.C. (1967). MMPI inventory manual. New York: Psychological Press.

Hawkins, R., \& Beauvais, C. (1986, August). Evaluation of group therapy with abusive men: The police record. Paper presented at the Annual Meeting of the American Psychological Association, Los Angeles, CA.

Hedges, L.V. (1994). Fixed effects models. In H. Cooper \& L.V. Hedges (Eds.), The handbook of research synthesis (pp. 285-299). New York: Russell Sage Foundation.

Herbert, T.B., Silver, R.C., \& Ellard, J.H. (1991). Coping with an abusive relationship: 1. How and why to women stay? Journal of Marriage and the Family, $\underline{53}, 311-$ 325.

Hershorn, M., \& Rosenbaum, A. (1991). Over-vs. Undercontrolled hostility: Application of the construct to the classification of maritally violent men. Violence and Victims, $\underline{6}, 151-158$.

Hilton, N.Z. (Ed.). (1993). Legal responses to wife assault. Current trends and evaluation. Newbury Park, CA: Sage.

Hirschel, J.D., Hutchison, I.W., \& Dean (1992). Female spouse abuse and the police response: The Charlotte, North Carolina experiment. Journal of Criminal Law and Criminology, $\underline{83}, 73-119$.

Holtzworth-Munre, A., \& Ghose, S. (1997, June). The reliability of violent husbands' self-reports: Examining interspousal agreement. Paper presented at the 5th International Family Violence Research Conference, Durham, NH. 
Holtzworth-Munroe, A., \& Stuart, G.L. (1994). Typologies of male batterers: Three subtypes and differences among them. Psychological Bulletin, 116, 476-497. Hong, S-M., \& Page, S. (1989). A psychological reactance scale: Development, factor structure and reliability. Psychological Reports, 64, 1323-1326.

Horn, J.L. (1965). A rationale and test for the number of factors in factor analysis. Psychometrika, 30, 179-185.

Houskamp, B.M., \& Foy, D.W. (1991). The assessment of posttraumatic stress disorder in battered women. Journal of Interpersonal Violence, $\underline{6}, 367-375$.

Jackson, D.N. (1970). A sequential system for personality scale development. In C.D. Spielberger (Ed.), Current topics in clinical and community psychology (vol. 2) (pp.61-96). Orlando, FL: Academic Press.

Jackson, D.N. (1970). A sequential system for personality scale development. Current Topics in Clinical and Community Psychology, 2, 61-96.

Jackson, D.N. (1971). The dynamics of structured personality tests. Psychological Review, $\underline{78}, 229-248$.

Jacobson, N.S., Gottman, J.M., \& Shortt, J.W. (1995). The distinction between type 1 and type 2 batterers--Further considerations: Reply to Ornduff et al. (1995), Margolin et al., (1995), and Walker (1995). Journal of Family Psychology, $\underline{9}$ 272-279.

Jaffe, P., Wolfe, D.A., Wilson, S., \& Zak, L. (1986). Emotional and physical health problems of battered women. Canadian Journal of Psychiatry, 31, 625-629. Janis, I.L., \& Mann, L. (1977). Decision making: A psychological analysis of conflict. choice and commitment. New York: Free Press. 
Jennings, J.L. (1987). History and issues in the treatment of battering men: A case for unstructured group therapy. Journal of Family Violence, 2 , 193-213.

Jennings, J.L. (1990). Preventing relapse versus "stopping" domestic violence: Do we expect too much too soon from battering men? Joumal of Family Violence, $\underline{5}, 43-$ 60.

Johnson, B.T. (1989). DSTAT: Software for the meta-analytic review of research literatures. Hillsdale, NJ: Lawrence Erlbaum Associates.

Johnson, I.M. (1992). Economic, situational, and psychological correlates of the decision-making process of battered women. Families in Society, 57, 168-176.

Johnson, I.M., Crowley, J., \& Sigler, R.T. (1992). Agency reponse to domestic violence: Services provided to battered women. In E.C. Viano (Ed.), Intimate violence: Interdisciplinary perspectives (pp. 191-202). Washington, DC: Hemisphere Publishing Corporation.

Johnson, J.M., \& Kanzer, D.J. (1993). Treating domestic violence: Evaluating the effectiveness of a domestic violence diversion program. Studies in Symbolic Interaction, 15, 271-289.

Johnson, S.S. (1997). Oral contraceptive use: The application of the Transtheoretical Model. Unpublished doctoral dissertation, University of Rhode Island, Kingston, RI.

Joreskog, K.G., Sorbom, D. (1989). LISREL 7: A guide to the program and applications (2nd ed.). Chicago: SPSS, Inc.

Jouriles, E., \& O'Leary, K. (1985). Interspousal reliability of reports of marital violence. Journal of Consulting and Clinical Psychology, 53, 419-421. 
Kaufman, G. (1992). The mysterious disappearance of battered women from family therapists' offices. Male privilege colluding with male violence. Journal of Marital and Family Therapy, 18, 233-243.

Kemp, A., Green, B.L., Hovanitz, C., \& Rawlings, E.T. (1995). Incidence and correlates of posttraumatic stress disorder in battered women: Shelter and community samples. Journal of Interpersonal Violence, 10, 43-55.

Kernp, A., Rawlings, E.T., \& Green, B.L. (1991). Posttraumtic stress disorder (PTSD) in battered women: A shelter sample. Journal of Traumatic Stress, 4, 137-148.

Klein, P.A. (1992). Efficacy of conjoint group treatment in therapy for spouse abuse (Doctoral dissertation, Pacific Graduate School of Psychology). Dissertation Abstracts International, 53(01), 565B. (University Microfilms No: AAC 9216154).

Kohlberg, L. (1981). The philosophy of moral development. San Francisco: Harper \& Row.

Kohlberg, L, \& Kramer, R. (1969). Continuities and discontinuities in childhood and adult development. Human Development, 12, 93-120.

Laforge, R.G., Velicer, W.F., Richmond, R.L., \& Owen, N. (1998). Stage distributions for five health behaviors in the USA and Australia. Manuscript submitted for publication.

Lam, C.S., McMahon, B.T., Priddy, D.A., \& Gehred-Schultz, A. (1988). Deficit awareness and treatment performance among traumatic head injury adults. Brain Injury, 2, 235-242. 
Levesque, D.A. (1995, May). Battering men and battered women: Applying the trantheoretical model to desistance and change. Invited address Brown/Yale/University of Rhode Island Collaborative Research Meeting. Providence, RI.

Levesque, D., \& Gelles, R. (1997, June). Battering men: Applying the transtheoretical model to desistance and change. Paper presented at the 5th International Family Violence Research Conference, Durham, NH.

Levesque, D.A, Gelles, R.J., \& Velicer, W.F. (1997, August). Battering men and courtmandated treatment: Applying the Transtheoretical Model to desistance and change. Paper presented at the $105^{\text {th }}$ annual meeting of the American Psychological Association, Chicago, IL.

Levesque, D.A., Velicer, W.F., Norman, G.J., Prochaska, J.O., \& Fava, J.L. (1998). Development of measures of "negative processes of change" in cigarette smokers. Unpublished data.

Loseke, D.R., \& Berk, S.F. (1982). The work of shelters: Battered women and initial calls for help. Victimology: An International Journal, 7, 35-48.

Maiuro, R.D. (1997, June). Are current standards for the treatment of domestically violent perpetrators adequately informed by research? A question of questions. Paper presented at the 5th International Family Violence Research Conference, Durham, NH.

Marcus, B.H., Rossi, J.S., Selby, V.C., Niaura, R.S., \& Abrams, D.B. (1992). The stages and processes of exercise adoption and maintenance. Health Psychology, $11,386-$ 395. 
Martin, D. (1976). Battered wives. New York: Pocket Books.

Massachusetts Guidelines and Standards for the Certification of Batterers' Treatment

Programs (1994, May). Massachusetts Department of Public Health.

McCauley, J., Kern, D.E., Kolodner, K., Dill, L., Schroeder, A.F., DeChant, H.K., Ryden, J., Bass, E.B., \& Derogatis, L.R. (1995). The "battering syndrome":

Prevalence and clinical characteristics of domestic violence in primary care medicine practices. Annals of Internal Medicine, 123 , 737-746.

McConnaughy, E.A., DiClemente, C.C., Prochaska, J.O., \& Velicer, W.F. (1989).

Stages of change in psychotherapy: A follow-up report. Psychotherapy, 26, 494503.

McConnaughy, E.A., Prochaska, J.O., \& Velicer, W.F. (1983). Stages of change in psychotherapy: Measurement and sample profiles. Psychotherapy: Theory, Research and Practice, 20, 368-375.

Medieros, M., \& Prochaska, J.O. (1992). Predicting premature termination from psychotherapy. Unpublished manuscript.

Mederer, H.J., \& Gelles, R.J. (1989). Compassion or control: Intervention in cases of wife assault. Journal of Interpersonal Violence, 4 , 25-43.

Miller, W.R., \& Rollnick, S. (1991). Motivational interviewing: Preparing people to change addictive behavior. New York: The Guilford Press.

Milligan, G.W., \& Cooper, M.C. (1987). Methodology review: Clustering methods. Applied Psychological Measurement, 11, 329-354.

Millon, T. (1983). Millon Clinical Multiaxial Inventory Manual. Minneapolis, MN: Interpretive Scoring Systems. 
Murphy, C.M., \& Baxter, V.A. (1997). Motivating batterers to change in the treatment context. Joumal of Interpersonal Violence, 12, 07-619.

National Research Council \& Institute of Medicine. (1998). R. Chalk \& P.A. King (Eds.), Violence in families: Assessing prevention and treatment programs. Washington, DC: National Academy Press.

National Research Council. (1996). N.A. Crowell \& W.A. Burgess (Eds.), Understanding violence against women. Washington, DC: National Academy Press.

Newell, R.G. (1994). The effectiveness of court-mandated counseling for domestic violence: an outcome study (Doctoral dissertation, University of Toledo). Dissertation Abstracts International, 55(05), 1193A. (University Microfilms No: ACC 9426446).

Norcross, J.C., Prochaska, J.O., \& DiClemente, C.C. (1998). The stages and processes of behavior change: Two replications with weight control. Manuscript submitted for publication.

Novaco, R.W. (1975). Anger control: The development and evaluation of an experimental treatment. Lexington, MA: Lexington Books.

Okun, L. (1988). Termination or resumption of cohabition in woman battering relationships: A statistical study. In G.T. Hotaling, D. Finkelhor, J.T. Kirkpatrick, \& M. Straus (Eds.), Coping with family violence: Research and public policy perspectives (pp. 107-119). Newbury Park: Sage. 
Palmer, S.E., Brown, R.A., \& Barrera, M.E. (1992). Group treatment program for abusive husbands: Longterm evaluation. American Journal of Orthopsychiatry, 62, 276-283.

Pan, H.S., Neidig, P.H., \& O'Leary, K.D. (1994). Male-female and aggressor-victim differences in the factor structure of the Modified Conflict Tactic Scale. Journal of Interpersonal Violence, 9, 366-382.

Pate, A.M., \& Hamilton, E.E. (1992). Formal and informal deterrents to domestic violence: The Dade County spouse assault experiment. American Sociological Review, 57, 691-697.

Pate, A.M., Hamilton, E.E., \& Annan, S. (1991). Metro-Dade Spouse Abuse Replication Project: Final draft report. National Institute of Justice, Washington, DC. Pence, E. (1983). The Duluth Domestic Abuse Intervention Project. Hamline Law Review, $\underline{6}, 247-275$.

Pence, E. (1985). Response to Peter Neidig's articles: “Women's shelters, men's collectives and other issues in the field of spouse abuse." Victimology: An International Journal, 9 , 477-482.

Pence, E. (1989). Batter programs: Shifting from community collusion to community confrontation. In P.L. Caesar \& L.K. Hamberger (Eds.), Treating men who batter: Theory, Practice, and Programs (pp. 24-50). New York: Springer.

Pence, E., \& Paymar, M. (1993). Education groups for men who batter. New York: Springer. 
Petrik, N.D., Gildersleeve-High, L., McEllistrem, J.E., \& Subotnik, L.S. (1994). The reduction of male abusiveness as a result of treatment. Reality or myth? Journal of Family Violence, 9, 307-316.

Pirog-Good, M., \& Stets, J. (1986). Programs for abusers: Who drops out and what can be done? Response, 2, 17-19.

Pirog-Good, M., \& Stets-Kealey, J. (1985). Male batterers and battering prevention programs: A national survey. Response, $\underline{8}, 8-12$.

Pizzey, E. (1974). Scream quietly or the neighbors will hear. London: Penguin.

Pleck, E. (1989). Criminal approaches to family violence, 1640-1980. In L. Ohlin \& M. Tonry (Eds.), Family violence (pp. 19-57). Chicago: University of Chicago Press.

Poynter, T.L. (1989). An evaluation of a group programme for male perpetrators of domestic violence. Australian Journal of Sex, Marriage \& Family, 13(3), 133142.

Poynter, T.L. (1991). An evaluation of a group programme for male perpetrators of domestic violence: A follow-up study. Australian Journal of Marriage \& Family, $12(2), 64-76$

Prochaska, J.O. (1984). Systems of psychotherapy: A transtheoretical approach. Homewood, Illinois: The Dorsey Press.

Prochaska, J.O., \& DiClemente, C.C. (1983). Stages and processes of self-change of smoking: Toward and integrative model of change. Journal of Consulting and Clinical Psychology, 51, 390-395. 
Prochaska, J.O., \& DiClemente, C.C. (1984). The transtheoretical approach: Crossing traditional boundaries of change. Homewood, IL: Dorsey Press.

Prochaska, J.O. \& DiClemente, C.C. (1985). Common processes of change in smoking, weight control, and psychological distress. In S. Shiffman and T. Wills (Eds.), Coping and substance use: A conceptual framework (pp. 345-363). New York: Academic Press.

Prochaska, J.O., \& DiClemente, C.C. (1986). Toward a comprehensive model of behavior change. In W.R. Miller \& N. Heather (Eds.), $\underline{\text { Treating addictive }}$ behaviors: Processes of change (pp. 3-27). New York: Plenum Press.

Prochaska, J.O., DiClemente, C.C., \& Norcross, J.C. (1992). In search of how people change: Applications to addictive behaviors. American Psychologist, 47, 11021114.

Prochaska, J.O., DiClemente, C.C., Velicer, W.F., Ginpil, S., \& Norcross, J. (1985). Predicting change in smoking status for self-changers. Addictive Behavior, 10 , 395-406.

Prochaska, J.O., DiClemente, C.C., Velicer, W.F., \& Rossi, J.S. (1993). Standardized, individualized, interactive, and personalized self-help programs for smoking cessation. Health Psychology, 12, 399-405.

Prochaska, J.O., Norcross, J.C., Fowler, J.L., Follick, M.J., \& Abrams, D.B. (1992). Attendance and outcome in a work-site weight control program: Processes and stages of change as process and predictor variables. Addictive Behaviors, 17, 3545 . 
Prochaska, J.O., Redding, C.A., \& Evers, K.E. (1997). The transtheoretical model and stages of change. In K. Glanz, F.M. Lewis, \& B.K. Rimer (Eds.), Health behavior and health education: Theory, research, and practice (2nd ed., pp. 60-84). San Francisco: Jossey-Bass.

Prochaska, J.O., Redding, C.A., Harlow, L.L., Rossi, J.S., \& Velicer, W.F. (1994). The transtheoretical model of change and HIV prevention: A review. Health Education Quarterly, 21, 471-486.

Prochaska, J.O., Rossi, J.S., \& Wilcox, N.S. (1991). Change processes and psychotherapy outcomes in integrative case research. Journal of Psychotherapy Integration, 1(2), 103-119.

Prochaska, J.O., Velicer, W.F., DiClemente, C.C., \& Fava, J. (1988). Measuring processes of change: Applications to the cessation of smoking. Journal of Consulting and Clinical Psychology, 56, 520-528.

Prochaska, J.O., Velicer, W.F., Fava, J.L., Rossi, J.S., \& Tsoh, J. (1998). A stagematched expert system intervention for a total population of smokers. Manuscript submitted for publication.

Prochaska, J.O., Velicer, W.F., Rossi, J.S., Goldstein, M.G., Marcus, B.H., Rakowski, W., Fiori, C., Harlow, L.L., Redding, C.A., Rosenbloom, D., \& Rossi, S.R. (1994). Stages of change and decisional balance for twelve problem behaviors. Health Psychology, $13,39-46$.

Purdy, F., \& Nickle, N. (1981). Practice principles for working with groups of men who batter. Social Work with Groups, 4, 111-122. 
Rachor, R.E. (1995). An evaluation of the First Step "Passages" domestic violence program. Journal of Reality Therapy, 14(2), 29-36.

Rakowski, W., Ehrich, B., Dube, C.E., Pearlman, D.N., Goldstein, M.G., Peterson, K.K., Rimer, B.K., \& Woolverton, H. (1996). Screening mammography and constructs from the transtheoretical modal: Associations using two definitions of the stagesof-adoption. Society of Behavioral Medicine, 18,9 91-100.

Rand, M.J. (1997). Violence-related injuries treated in hospital emergency departments (Special Report No. NCJ-156921). Washington, DC: Bureau of Justice Statistics, U.S. Department of Justice.

Rest, J. (1973). The hierarchical nature of moral judgment. Journal of Personality, $\underline{41}$, 86-109.

Reynolds, W.M. (1982). Development of reliable and valid short forms of the MarloweCrowne Social Desirability Scale. Journal of Clinical Psychology, 38, 119-125.

Rice, M.E., \& Harris, G.T. (1995). Violent recidivism: Assessing predictive validity. Journal of Consulting and Clinical Psychology, 63, 737-748.

Riggs, D.S., Kilpatrick, D.G., \& Resnick, H.S. (1992). Long-term psychological distress associated with marital rape and aggravated assault: A comparison to other crime victims. Journal of Family Violence, 7, 283-296.

Ritmeester, T., \& Pence, E. (1992). A cynical twist of fate: How processes of ruling in the criminal justice system and the social sciences impede justice for battered women. Review of Law and Women's Studies, 2, 255-292.

Roberts, A.R. (1981). Sheltering battered women: A national study and service guide. New York: Springer. 
Roberts, A. (1982). A national survey of services for batterers. In M. Roy (Ed.), The abusive partner (pp.230-243). New York: Van Nostrand Reinhold.

Rosenbaum, A. (1986). Group treatment of battering men: Process and outcome.

Psychotherapy, 23, 607-612.

Rosenbaum, A. (1988). Methodological issues in marital violence research. Journal of Family Violence, $\underline{3}, 91-104$.

Rosenbaum, A., Gearan, P.J., \& Ondovic, C. (1997, June). Completion and recidivism among court- and self-referred batterers in a psychoeducational group treatment program: Implications for intervention and public policy. Paper presented at the 5th International Family Violence Research Conference, Durham, NH.

Rosenfeld, B.D. (1992). Court-ordered treatment of spouse abuse. Clinical Psychology Review, 12, 205-226.

Rosenthal, R. (1994). Parametric measures of effect size. In H. Cooper \& L.V. Hedges (Eds.), The handbook of research synthesis (pp. 231-244). New York: Russell Sage Foundation.

Rossi, J.S. (1985). Tables of effect size for $Z$ score tests of differences between proportions and between correlation coefficients. Educational and Psychological Measurement, 4 5, 737-743.

Rossi, J.S. (I992, March). Stages of change for I5 health risk behaviors in an HMO population. Paper presented at the annual meeting of the Society of Behavioral Medicine, New York, NY. 
Rossi, J.S., Blais, L.M., Redding, C.A., \& Weinstock, M.A. (1995). Preventing skin cancer through behavior change: Implications for interventions. Dermatologic Clinics, 13, 613-622.

Rounsaville, B. J. (1978), Theories in marital violence: Evidence from a study of battered women. Victimology: An International Joumal, 3 , 11-31.

SAS Institute, Inc. (1989). SAS/STAT user's guide, version 6 (4th ed., vol. 1). Cary, NC: SAS Institute, Inc.

Satel, S.L. (1997). It's always his fault. The Women's Quarterly, Summer(12), 4-10. Sato, R.A., \& Heiby, E.M. (1992). Correlates of depressive symptoms among battered women. Joumal of Family Violence, $7,229-245$,

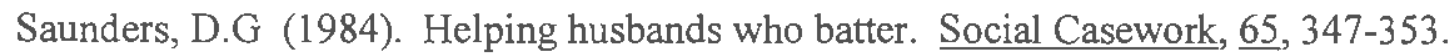

Saunders, D.G. (1988). Issues in conducting treatment research with men who batter. In G.T. Hotaling, D. Finkelhor, J.T. Kirkpatrick, \& M.A. Straus (Eds.), Coping with family violence: Research and policy perspectives. Newbury Park: Sage.

Saunders, D.G. (1989). Cognitive-behavioral interventions with men who batter: Applications and outcome. In P.L. Caesar \& L.K. Hamberger (Eds.), Treating men who batter: Theory, Practice, and Programs (pp. 77-100). New York: Springer.

Saunders, D.G. (1992). A typology of men who batter: Three types derived from cluster analysis. American Journal of Orthopsychiatry, 62, 264-275.

Saunders, D.G. (1993). Husbands who assault: Multiple profiles requiring multiple responses. In Z. Hilton (Ed.), Legal responses to wife assault. Newbury Park, CA: Sage. 
Saunders, D.G. (1994). Posttraumatic stress symptom profiles of battered women: A comparison of survivors in two settings. Violence and Victims, 9, 31-44.

Saunders, D.G. (1996). Feminist-cognitive-behavioral and process-psychodynamic treatments for men who batter: Interaction of abuser traits and treatment models. Violence and Victims, 11, 393-413.

Saunders, D.G., \& Azar, S.T. (1989). Treatment programs for family violence. In L. Ohlin \& M. Tonry (Eds.), Family violence (pp. 481-546). Chicago: University of Chicago Press.

Saunders, D.G., \& Hanusa, D. (1986). Cognitive-behavioral treatment of men who batter: The short-term effects of group therapy. Journal of Family Violence, 1 , $357-372$.

Saunders, D.G., \& Parker, J.C. (1989), Legal sanctions and treatment follow-through among men who batter: A multivariate analysis. Social Work Research and Abstracts, September, 1989, 21-29.

Schechter, S. (1982). Women and male violence: The visions and struggles of the battered women's movement. Boston: South End Press.

Seligman, M.E.P. (1975). Helplessness: On depression, development and death. San Francisco: Freeman.

Shadish, W.R., \& Haddock, C.K. (1994). Combining estimates of effect size. In H. Cooper \& L.V. Hedges (Eds.), The handbook of research synthesis (pp. 261-281). New York: Russell Sage Foundation. 
Shepard, M. (1987, July). Intervention with men who batter: An evaluation of a domestic abuse program. Paper presented at the Third National Conference for Family Violence Researchers, Durham, NH.

Shepard, M. (1992). Predicting batterer recidivism five years after community intervention. Journal of Family Violence, 1, 167-178.

Shepard, M.F., \& Campbell, J.A. (1992). The Abusive Behavior Inventory: A measure of psychological and physical abuse. Journal of Interpersonal Violence, 7,291 305.

Sherman, L., \& Berk, R. (1984). The specific deterrent effects of arrest for domestic assault. American Sociological Review, 49, 261-272.

Sherman, L.W. (1992). Policing domestic violence. New York: Free Press.

Sherman, L.W., Schmidt, J.D., \& Rogan, D.P. (1992). Policing domestic violence: Experiments and Dilemmas. New York: Free Press.

Sherman, L.W., Schmidt, J.D., Rogan, D.P., Gartin, P., Cohen, E.G., Collins, D.J., \& Bacich, A.R. (1991). From initial deterrence to long-term escalation: Short custody arrest for poverty ghetto domestic violence. Criminology, 29, 821-850.

Shupe, A., Stacey, W., \& Hazelwood, L. (1987). Violent men, violent couples: The dynamics of domestic violence. Lexington, MA: Lexington Press.

Simes, R.J. (1986). Publication bias: The case for an international registry of clinical trials. Journal of Clinical Oncology, $\underline{4}, 1529-1541$.

Soler, E. (1987). Domestic violence is a crime: A case study of the San Francisco family violence project. In D.J. Sonkin (Ed.), Domestic violence on trial (pp. 2138). New York: Springer. 
Spanier, G.B. (1976). Measuring dyadic adjustment: New scales for assessing the quality of marriage and similar dyads. Joumal of Marriage and the Family, $\underline{38}$, $15-38$.

Straus, M.A. (1974). Introduction. In R.J. Gelles, The violent home. Beverly Hills, CA: Sage

Straus, M.A. (1979). Measuring intrafamily conflict and violence: The Conflict Tactics (CT) Scales. Journal of Marriage and the Family, 41,75-88.

Straus, M.A. (1990). The Conflict Tactics Scales and its critics: An evaluation and new date on validity and reliability. In M.A. Straus \& R.J. Gelles (Eds.), Physical violence in American families: Risk factors and adaptation to violence in 8,145 families. New Brunswick, NJ: Transaction Publishers.

Straus, M.A., \& Gelles, R.J. (1986). Societal change and changes in family violence from 1975 to 1985 as revealed by two national surveys. Journal of Marriage and the Family, $\underline{48}, 465-479$.

Straus, M.A., \& Gelles, R.J. (1990). How violent are American families? Estimates from the National Family Violence Resurvey and other studies. In M.A. Straus \& R.J. Gelles (Eds.), Physical violence in American families: Risk factors and adaptations to violence in 8,145 families (pp. 95-112). New Brunswick, NJ: Transaction Publishers.

Straus, M.A., \& Kaufman Kantor, G. (1992, July). Change in spouse assault rates from 1975 to 1992: A comparison of three national surveys in the United States. Paper presented at the 13th World Congress of Sociology, Bielefeld, Germany. 
Straus, M.A., \& Smith, C. (1990). Family patterns and primary prevention of family violence. In M.A. Straus \& R.J. Gelles (Eds.), Physical violence in American families: Risk factors and adaptations to violence in 8,145 families (pp. 507-526). New Brunswick, NJ: Transaction Publishers.

Straus, M.A., Gelles, R.J., \& Steinmetz, S.K. (1980). Behind closed doors: Violence in the American family. Garden City, NY: Anchor.

Strube, M.J., \& Barbour, L.S. (1984). Factors associated with the decision to leave an abusive relationship. Journal of Marriage and the Family, 46, 837-844.

Sugarman, D.B., \& Hotaling, G.T. (1989). Dating violence: prevalence, context, and risk markers. In M.A. Pirog-Good \& J.E. Stets (Eds.), Violence in dating relationships: Emerging social issues (pp. 3-32). New York: Praeger.

Sweeney, S., \& Key, L.J. (1982). Psychological issues in counseling batterers. Theology, News, and Notes, June, 12-16.

Szinovacz, M.E. (1983). Using couple data as a methodological tool: The case of marital violence. Journal of Marriage and the Family, 45, 633-644

Tolman, R.M. \& Bennett, L.W. (1990). A review of quantitative research on men who batter. Journal of Interpersonal Violence,, , 87-118.

Tolman, R.M., \& Bhosley, G. (1989). A comparison of two types of pregroup preparation for men who batter. Journal of Social Science Research, 13, 33-43. Tolman, R.M., \& Bhosley, G. (1991). The outcome of participation in a sheltersponsored program for men who batter. In D.D. Krudsen \& J.L. Miller (Eds.), Abused and battered: Social and legal responses to family violence (pp. 113-122). New York: Aldine de Gruyter. 
Tolman, R.M., \& Edleson, J.L. (1995). Effectiveness of batterer intervention. In S.R. Stith \& M.A. Straus (Eds.), Understanding partner violence: Prevalence, causes. consequences, and solutions (pp. 262-273). Minneapolis, MN: National Council on Family Relations.

Tolman, R.M., \& Saunders, D.G. (1988). The case for the cautious use of anger control with men who batter. Response, 11(2), 15-20.

Tolman, R.M., Edleson, J.L., \& Fendrich, M. (1996). The applicability of the Theory of Planned Behavior to abusive men's cessation of violent behavior. Violence and Victims, 11, 341-354.

Tsoh, J.Y. (1995). Stages of change, dropouts, and outcome in substance abuse treatment. Unpublished doctoral dissertation, University of Rhode Island, Kingston, RI.

Tucker, L.R., \& Lewis, C. (1973). A reliability coefficient for maximum likelihood factor analysis. Psychometrika, $\underline{38}, 1-10$.

US Attorney General's Task Force on Family Violence. (1984). Final report. Washington, DC: US Government Printing Office.

US Department of Justice. (1995). Uniform crime reports for the United States, 1994.

Washington, DC: US Department of Justice, Federal Bureau of Investigation.

Velicer, W.F. (1976). Determining the number of components from the matrix of partial correlations. Psychometrika, 41, 321-327.

Velicer, W.F., \& Prochaska, J.O. (in press). An expert system intervention for smoking cessation. Patient Education and Counseling. 
Velicer, W.F., DiClemente, C.C., Prochaska, J.O., \& Brandenburg, N. (1985).

Decisional balance measure for assessing and predicting smoking status. Journal of Personality and Social Psychology, 48, 1279-1289.

Velicer, W.F., DiClemente, C.C., Rossi, J.R., \& Prochaska, J.O. (1990). Relapse situations and self-efficacy: An integrative model. Addictive Behaviors, 15,271 283.

Velicer, W.F., Fava, J.L., Prochaska, J.O., Abrams, D.B., Emmons, K.M., \& Pierce, J.P. (1995). Distribution of smokers by stage in three representative samples. Preventive Medicine, 24, 401-411.

Velicer, W.F., Fava, J.L., Zwick, W.R., \& Harrop, J.W. (1988). Component Analysis Extended [Computer Software]. Kingston, RI: University of Rhode Island. Velicer, W.F., Martin, R.A., \& Collins, L.M. (1996). Latent transition analysis for longitudinal data. Addiction, 91 (Supplement), 197-209.

Vitanza, S., Vogel, L.C.M., \& Marshall, L.L. (1995). Distress and symptoms of Posttraumatic stress disorder in abused women. Violence and Victims, 10, 23-34.

Waldo, M. (1986). Group counseling for military personnel who battered their wives. Journal for Specialists in Group Work, 9, 132-138.

Waldo, M. (1988). Relationship enhancement counseling groups for wife abusers. Journal of Mental Health Counseling, 10, 37-45.

Walker, L. (1979). The battered woman. New York: Harper and Row.

Walker, L.E.A. (1991). Posttraumatic stress disorder in women: Diagnosis and treatment of battered woman syndrome. Psychotherapy, 28(1), 21-29. 
Walker, L.E.A. (1995). Current perspectives on men who batter women--Implications for intervention and treatment to stop violence against women: Comment on Gottman et al. (1995). Journal of Family Psychology, 9, 264-271.

Wampold, B.E., Mondin, G.W., Moody, M., Stich, F., Benson, K., \& Ahn, N. (1997). A meta-analysis of outcome studies comparing bona fide psychotherapies:

Empirically, "All must have prizes." Psychological Bulletin, 122, 203-215.

Ward, J.H. (1963). Hierarchical grouping to optimize an objective function. Journal of the American Statistical Association, 58, 236-244.

West, C.G., Fernandez, A., Hillard, J.R., Schoof, M., \& Parks, J. (1990). Psychiatric disorders of abused women at a shelter. Psychiatric Quarterly, 61, 295-301.

Wierzbicki, M., \& Pekarik, G. (1993). A meta-analysis of psychotherapy dropout. Professional Psychology: Research and Practice, 24, 190-195

Williams, K.R. (1992). Social sources of marital violence and deterrence: Testing an integrated theory of assaults between partners. Journal of Marriage and the Family, 54, 620-629.

Wilson, M., \& Daly, M. (1993). Spousal homicide risk and estrangement. Violence and victims, $\underline{8}, 3-16$.

Yllo, K. (1993). Through a feminist lens: Gender, power, and violence. In R.J. Gelles \& D.R. Loseke (Eds.), Current controversies on family violence. Newbury Park, CA: Sage.

Zamora, E. (December, 1995). State statutes regarding mandatory treatment for batterers and treatment program Standards. Minneapolis, MN: Criminal Justice Center, Battered Women's Justice Project. 
Zwick, W.R., \& Velicer, W.F., (1986). Comparison of five rules for determining the number of components to retain. Psychological Bulletin, 99, 432-442. 